\title{
EFFECTS OF CLOUD-INDUCED PHOTOVOLTAIC POWER TRANSIENTS ON POWER SYSTEM PROTECTION
}

\author{
A Thesis \\ Presented to the \\ Faculty of California Polytechnic State University, \\ San Luis Obispo
}

\author{
In Partial Fulfillment \\ of the Requirements for the Degree \\ Master of Science in Electrical Engineering
}

by

Joel A. Nelson

December 2010 
(C) 2010

Joel Anthony Nelson

ALL RIGHTS RESERVED 


\section{COMMITTEE MEMBERSHIP}

TITLE:

AUTHOR:

DATE SUBMITTED:

COMMITTEE CHAIR:

COMMITTEE MEMBER:

COMMITTEE MEMBER:
Effects of Cloud-Induced Photovoltaic Power Transients on Power System Protection

Joel Anthony Nelson

December 2010

Dr. Ali Shaban, Professor

Dr. Ahmad Nafisi, Professor

Dr. Bill Ahlgren, Professor 


\begin{abstract}
EFFECTS OF CLOUD-INDUCED PHOTOVOLTAIC POWER TRANSIENTS ON POWER SYSTEM PROTECTION
\end{abstract}

\author{
Joel Anthony Nelson
}

December 2010

As the world strives towards finding alternative sources of power generation, photovoltaic generation has become an increasingly prevalent alternative energy source on power systems world-wide. This paper studies the effects that incorporating photovoltaic generation has on the existing power systems and their power system protection schemes. Along with the addition of this emerging alternative energy source comes the volatility of PV power generation as cloud-cover produces erratic variations in solar irradiance and PV power production. Such variations in PV power may lead to unfavorable operating conditions and power system failures. The issues addressed in this paper include a study of inverter harmonic levels for variations in DC voltage and power, and a study of power system protection failures caused by cloud-induced PV power variations. Such issues are addressed so as to provide a better understanding of the effects that cloud-induced PV power generation variability has on power systems and its protection schemes. 


\section{Table of Contents}

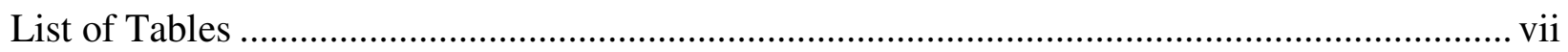

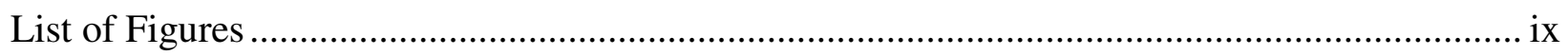

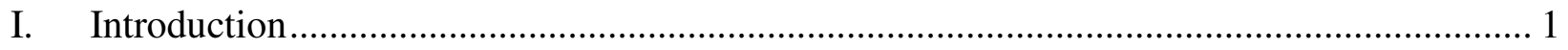

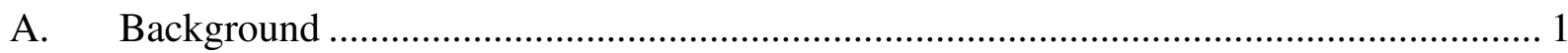

B. Thesis Scope

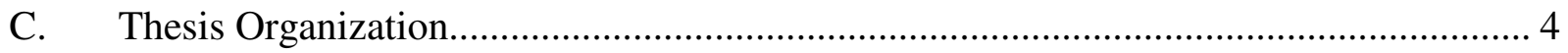

II. Solar Irradiance and PV Power Transients .................................................................. 5

A. PV Equivalent Circuit Model ........................................................................... 5

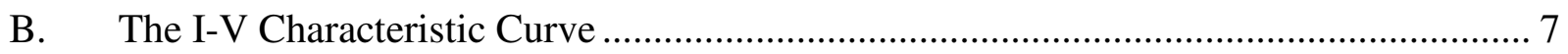

i. Factors that Shift the King's Model Points ................................................................... 7

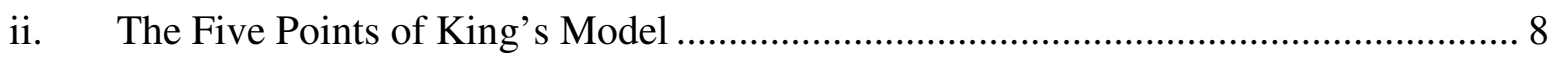

iii. The King's Model Points at Standard Reference Conditions (SRC)............................ 8

iv. Generating a Curve-Fitted I-V Curve …………................................................ 10

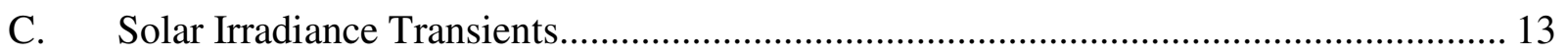

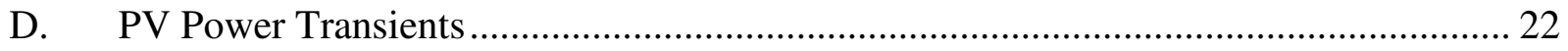

i. Determining the PV Module's Power-Responsiveness ................................................. 22

ii. Effect of Load Resistance on PV Power Drop ……………………….................. 29

iii. Measuring Power Drops for Various Loads and Transmittance Levels..................... 33

E. Effect of Solar Irradiance Transients on a Grid-Connected PV System's Max Power

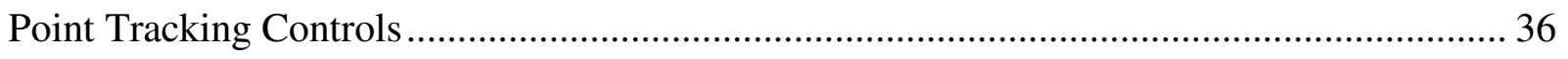

F. Effects of Varying Solar Irradiance on Large Scale PV Generation ................................. 45 


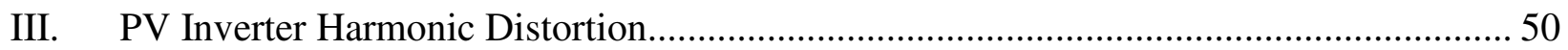

A. Harmonic Effects on the Power System.................................................................... 54

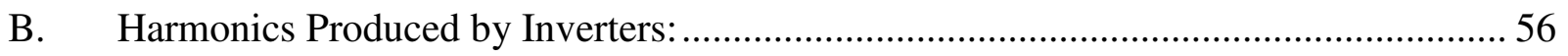

C. Inverter Harmonic and THD Testing ………………............................................... 57

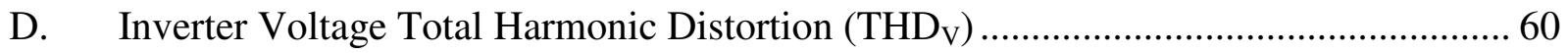

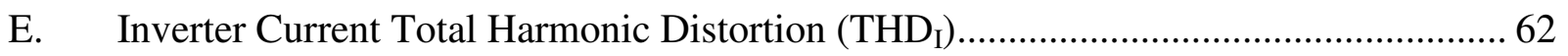

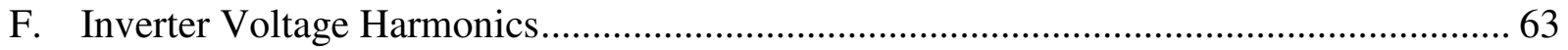

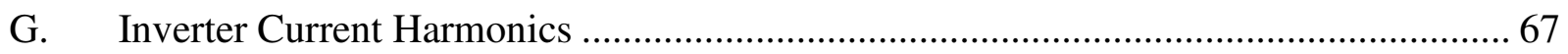

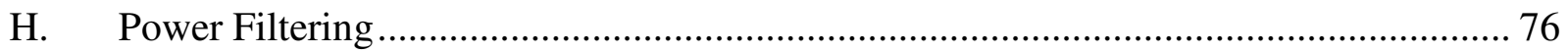

I. Implications for Inverter Harmonic Generation ………….......................................... 78

IV. Effects of Photovoltaic Power Transients on Power Systems …………………............... 80

A. Inverter Fault Contribution and Anti-Islanding Protection ............................................. 80

B. PV Effects on Distribution Power System Protection...................................................... 82

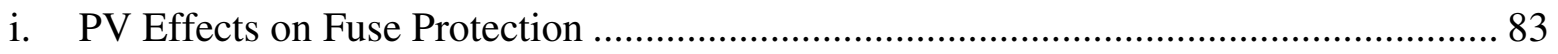

ii. PV Effects on Circuit Breakers and Overcurrent Relay Protection............................. 93

C. Effects of Large-Scale PV Solar Irradiation-induced Power Transients....................... 105

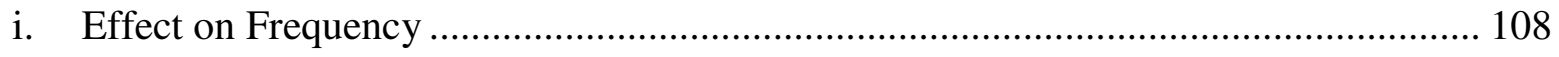

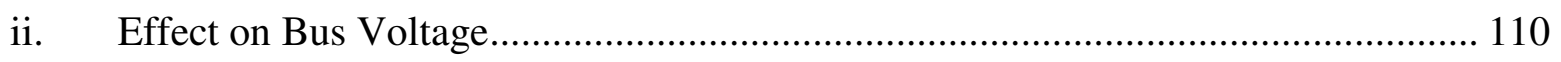

iii. Effect of Generators.......................................................................................... 115

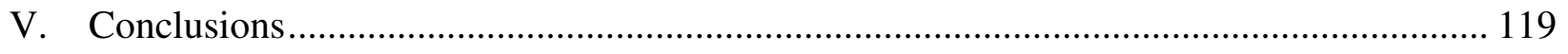

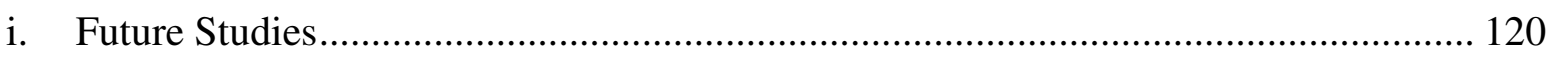

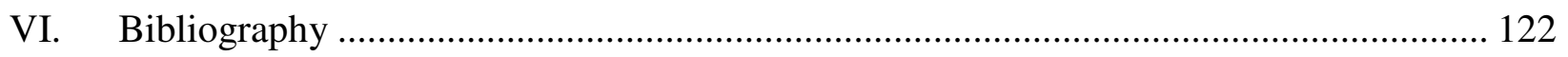




\section{List of Tables}

Table II.1: Summary of the Most Maximum Solar Irradiance Transients - magnitude in solar irradiance change for a given time intervals $(0.1 \mathrm{~s}, 1 \mathrm{~s}, 5 \mathrm{~s}$, and $10 \mathrm{~s})$.

Table II.2: Summary of Maximum Solar Irradiance Changes for a Given Time Duration from

Table II.1 21

Table II.3: Percent Solar Irradiance Drop Associated with the Number of Window-shade

Shade-Layers 34

Table II.4: Simulated Results for a MPPT-controlled PV System’s Percentage Power Drop

for an Associated Drop in Solar Irradiance.......................................................................... 43

Table III.1: IEEE 519 Current Distortion Limits [1] ..................................................... 53

Table III.2: Voltage Distortion Limits [1] ................................................................. 54

Table III.3: Summary of Loads Connected to AC Output of Inverter........................................ 60

Table III.4: Voltage Harmonic Limits Exceeded - DC Offset ........................................... 66

Table III.5: IEEE 519-1992 Odd and Even Harmonic Limits ............................................... 67

Table III.6: Current Harmonic Limits Exceeded for $\mathrm{h}<11$.................................................. 71

Table III.7: Current Harmonic Limits for $11 \leq \mathrm{h}<17$ and $17 \leq \mathrm{h}<23$...................................... 73

Table III.8: Current Harmonic Limits Exceeded for $23 \leq \mathrm{h}<35$......................................... 74

Table III.9: Current Harmonic Limits Exceeded for $35 \leq \mathrm{h}$................................................. 75

Table IV.1: Summary of Relay Tripping Times for Fault at Bus 3 ..................................... 99

Table IV.2: Relay and Fuse Primary Currents and Tripping Times for Fault at Bus 1 ............. 102

Table IV.3: Tripping Times for PV2 Shaded................................................................ 104

Table IV.4: IEEE 1547 Frequency Relay Recommended Trip Times [18].......................... 110

Table IV.5: Alternative Energy Source Clearing Times for Abnormal Voltage Conditions 
Table IV.6: Summary of Undervoltage Relay Trip Times

Table C.0.1: Experimental PV Power Drop Data for 4-Shade-Layers . 128

Table C.0.2: Experimental PV Power Drop Data for 3-Shade-Layers

Table C.0.3: Experimental PV Power Drop Data for 2-Shade-Layers

Table C.0.4: Experimental PV Power Drop Data for 1-Shade-Layer. 130

Table C.0.5: Experimental Summary of Solar Irradiance Changes for Various Shade-Layers

Over a Range of Load Resistances

Table C.0.6: Experimental Summary of PV Power Changes for Various Shade-Layers Over

a Range of Load Resistances 


\section{List of Figures}

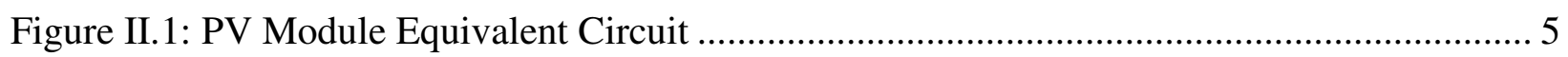

Figure II.2: I-V Characteristic Curve with the King's 5-Point Model [5] ...................................... 7

Figure II.3: Effects of Temperature and Solar Irradiance on the I-V Curve [6] ........................... 10

Figure II.4: MATLAB Generated I-V Curve Given the 5 King's Model Points........................... 11

Figure II.5: I-V Curves for 2 Parallel-Connected PV Devices [7] ………………...................... 12

Figure II.6: I-V Curves for 2 Series-Connected PV Devices [7] ............................................. 12

Figure II.7: NREL Solar Irradiance Plot over the Span of One Day sampled at $1 / 10^{\text {th }}$ of a

second from months of NREL solar irradiance data [8] ............................................................ 14

Figure II.8: Three Types of Unwanted Maximum Solar Irradiance Slopes Taken from

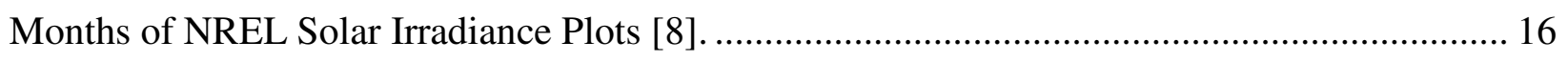

Figure II.9: Example of a Maximum Increasing Solar Irradiance Transient ................................. 18

Figure II.10: Example of a Maximum Decreasing Solar Irradiance Transient............................. 19

Figure II.11: Pictures of the Step Response Guillotine and Kyocera KC50T PV Modules ......... 23

Figure II.12: Picture of Solar Irradiance Shading Guillotine and KC50T PV Modules............... 23

Figure II.13: Percent Transmittance of Solar Irradiance for Various Layers of Shading

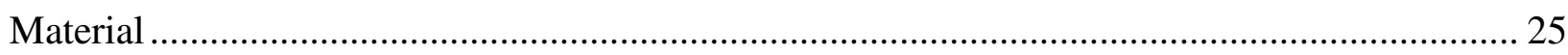

Figure II.14: Simulated I-V Load-Determined Operating Points on Two Solar Irradiance-

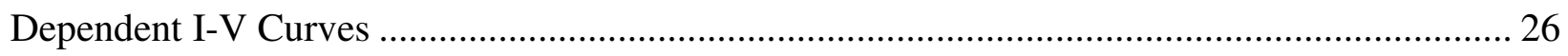

Figure II.15: Step Response of KC50T Module for 90\% Drop in Solar Irradiance over

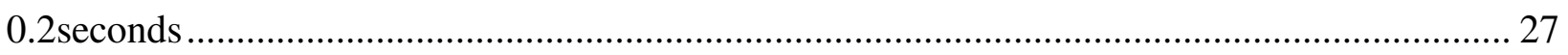

Figure II.16: Simulated Power Transients (Right Column) and Current Transients

(Left Column) for a Given Variation in Solar Irradiance and a Fixed Load Resistance. 
Graphs illustrate operating conditions for: $[\mathrm{a}]-$ Connected Load $=1 \Omega,[\mathrm{b}]-$ Connected

Load $=10 \Omega$, and $[\mathrm{c}]-$ Connected Load $=100 \Omega$.

Figure II.17: Experimentally Measured Percent PV Power Drop Associated with the Number of Shade-Layers Used Over a Range of Load Resistance. Experimental data associated with this Figure is located in Appendix C

Figure II.18: PV Module Characteristics for 3 Solar Irradiance levels and 2 different panels' operating temperatures: (a) output power vs. voltage and (b) current vs. voltage [10] 37

Figure II.19: P\&O and INC MPPT Operating Point Paths in Response to a Solar Irradiance Transient of $200 \mathrm{~W} / \mathrm{m}^{2}$ to $800 \mathrm{~W} / \mathrm{m}^{2}$. The $*$ represents MPP points for different solar irradiance levels: (a) slow solar irradiance transient and (b) rapid solar irradiance transient $[10]$ 39

Figure II.20: Simulated Change in PV Output Power from the Max Power Point of the Starting Solar Irradiance Curve to the Max Power Point of the Ending Solar Irradiance Curve. 42

Figure II.21: Simulated Percentage of MPPT-controlled PV Power Drop for a Given Percentage Drop in Solar Irradiance. 44

Figure II.22: Cumulative Distributions of Irradiance and PV power changes over various time increments from a $30 \mathrm{~kW}$ PV system (Left) and a multi-MW PV system (Right) [2] ........ 47 Figure III.1: Ideal Non-distorted Sinusoidal Waveform ................................................ 51

Figure III.2 Distorted Waveform and its Harmonic Sinusoidal Components .......................... 52

Figure III.3: Diagram of a Grid-Connected PV System [15] .............................................. 58

Figure III.4: Xantrex VFX3524 Inverter. (Left) - Xantrex Inverter, (Right) - AC load involving a fixed inductor of $39 \mathrm{mH}$ connected in series with a variable resistance. 59 
Figure III.5: THD $\mathrm{V}$ vs. Inverter Input Voltage for Various Loads

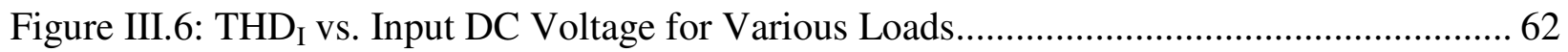

Figure III.7: Voltage Harmonics for $\mathrm{ZL}=\mathrm{R}+\mathrm{jX}, \mathrm{S}=165 \mathrm{VA}, \mathrm{PF}=0.98$ Lagging................ 63

Figure III.8: Voltage Harmonics for $\mathrm{ZL}=\mathrm{R} / 2+\mathrm{jX}, \mathrm{S}=311 \mathrm{VA}, \mathrm{PF}=0.92$ Lagging .............. 64

Figure III.9: Voltage Harmonics for ZL = R/5 + jX, S = 577 VA, PF = 0.70 Lagging............. 64

Figure III.10: Voltage Harmonics for $\mathrm{ZL}=\mathrm{R} / 10+\mathrm{jX}, \mathrm{S}=731 \mathrm{VA}, \mathrm{PF}=0.42$ Lagging.......... 65

Figure III.11: Voltage Harmonics for ZL $=$ R/15 + jX, S = 767 VA, PF $=0.30$ Lagging.......... 65

Figure III.12: Current Harmonics for ZL $=\mathrm{R}+\mathrm{jX}, \mathrm{S}=165 \mathrm{VA}, \mathrm{PF}=0.98$ Lagging ............... 68

Figure III.13: Current Harmonics for $\mathrm{ZL}=\mathrm{R} / 2+\mathrm{jX}, \mathrm{S}=311 \mathrm{VA}, \mathrm{PF}=0.92$ Lagging ............ 68

Figure III.14: Current Harmonics for ZL = R/5 + jX, S = 577 VA, PF = 0.70 Lagging ............ 69

Figure III.15: Current Harmonics for $\mathrm{ZL}=\mathrm{R} / 10+\mathrm{jX}, \mathrm{S}=731 \mathrm{VA}, \mathrm{PF}=0.42$ Lagging ........... 69

Figure III.16: Current Harmonics for $\mathrm{ZL}=\mathrm{R} / 15+\mathrm{jX}, \mathrm{S}=767 \mathrm{VA}, \mathrm{PF}=0.30$ Lagging .......... 70

Figure III.17: APF Harmonic Conditioning............................................................... 78

Figure IV.1: Fuse Protected Radial Distribution System with PV Generation........................... 84

Figure IV.2: Current Flow for Radial Distribution System with PV Generation, [a] -

Unshaded PV Conditions, Ppv = 900kW, [b] Shaded PV Conditions, Ppv = 450kW .............. 85

Figure IV.3: Fuse Characteristic Curves.......................................................................... 86

Figure IV.4: Simulated Fault Analysis for a Fault at Bus 2. [a] - Unshaded PV fault operating conditions, represented by a 360kW generator, [b] - Shaded PV fault operating conditions,

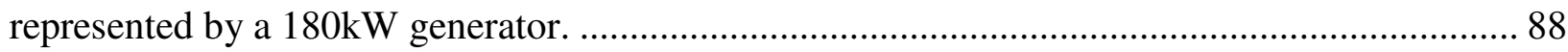

Figure IV.5: Fuse Protection Problems for a Fault at Load 1. [a] - Unshaded PV fault operating conditions, represented by a $360 \mathrm{~kW}$ generator, [b] - Shaded PV fault operating conditions, represented by a $180 \mathrm{~kW}$ generator 90 
Figure IV.6: Fuse Protection Problems for a Fault at Node C. [a] - Unshaded PV fault operating conditions, represented by a 360kW generator, [b] - Shaded PV fault operating

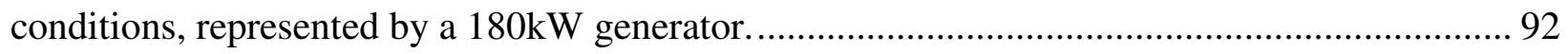

Figure IV.7: Radial Distribution System with Overcurrent Relay Protection ........................... 94

Figure IV.8: Relay Coordination for Radial Distribution System of Figure IV.7 .................... 96

Figure IV.9: Radial Distribution System Current Flow Diagram with No PV Connected.......... 96

Figure IV.10: Fault Currents Flowing for Fault at Bus 3 with No PV Connected ..................... 97

Figure IV.11: Current Flow of the Radial Distribution System with PV Generation................ 100

Figure IV.12: Fault Current Contributions for a Fault at Bus 1........................................ 101

Figure IV.13: Single Line-Ground Fault at Bus 2 with PV2 Shaded and PV1 Unshaded ........ 103

Figure IV.14: Fault at Bus 2 with PV2 Shaded and No PV1 Connected................................. 103

Figure IV.15: Power System with a 60 MW PV Power Plant ............................................. 106

Figure IV.16: Simulation of a PV Power Drop Caused by a Cloud's Shade Passing Over the 60 MW PV Array 107

Figure IV.17: Frequency Oscillations caused by 10s PV Power Ramp ................................ 108

Figure IV.18: Zoomed in Version of Figure IV.17 - Frequency Oscillations......................... 109

Figure IV.19: Power System Bus Voltages for a 10 second 40\% PV Power Drop.................. 112

Figure IV.20: Undervoltage Relay Time-Voltage Characteristics [23]................................. 113

Figure IV.21: Generators' Field Currents during a 10s PV Power Ramp .............................. 116

Figure IV.22: Generator Field Short-time Thermal Capability .......................................... 116 


\section{Introduction}

\section{A. Background}

The recent goal of the $21^{\text {st }}$ century can be described with one word: "sustainability." Such a word has so many connotations and meanings; most of which, however, pertain to environmental pursuits. Sustainability has not only transformed the consumer world, but also has greatly influenced the energy market as well. No longer is energy only procured via rotating mechanical machines. Such "green" endeavors have evolved the energy production market leading to the emergence of new alternative energies. While photovoltaic generation has been around since the 70's, applying them in mass quantities to power grids has become a trend only recently. With the growing emergence of PV generation in power systems, the effect of their introduction to traditional grid designs and power protection schemes, and the variability in their power production can lead to unfavorable operating conditions and power system failures.

The traditional power grid comprised of a system of large-scale, high voltage, powerprocuring, mechanically-rotating generators. The power produced by these generators was delivered long distances over high voltage transmission lines at which point substations stepped down the voltage and dispersed the power among distribution networks. Such a system employed high voltage generation and low voltage distribution networks, where power was solely delivered from the high voltage generation source to the low voltage load. Additionally, the power system protection systems were designed with the assumption that the power system adhered to this traditional system framework. However, modern technologies have allowed for new sources of generation, such as PV arrays, to connect to power grids, which invalidate traditional power system assumptions and their interdependent protection systems. 
When analyzing the effects of incorporating PV generation into a system, one must note that there are two different categories that PV generation usually falls into. The first category is known as distributed generation, which describes small- to medium-scale PV arrays connected at the distribution level. Such PV arrays are privately owned, produce less than a MW of power, and are often connected to a power system for economic and environmental reasons. Such reasons include a reduction in a facility's reliance on the utility grid for power. These privatelyowned PV implementations are less worried about how their PV generation affects power system reliability and stability and more concerned about how reducing their reliance on utility reduces their economic expenditures in the long run. With the addition of distribution level PV arrays, the current electric grid and its power protection schemes must be re-engineered so as to incorporate these new changes without compromising reliable and safe delivery of power.

The second category of PV generation is known as large-scale generation. PV plants within this category generate in the 10 's to 100 's of MW of power [1]. With the recent technological advances in photovoltaic energy-conversion efficiencies, large-scale PV generation plants have become more of an economically feasible option. However, the larger a generation source is, the more that deviations in power generation affect the surrounding power system and its protection.

\section{B. Thesis Scope}

Both large-scale and small-scale PV arrays are affected by the variability of solar insolation, which is the amount of solar radiation experienced by a surface over a given period of time. Solar insolation and solar irradiance are often used interchangeably to describe the amount of solar radiation power received by a photovoltaic array. While smaller PV generation's power tends to follow the fluctuations in solar insolation more closely, larger PV arrays tend to have more of an inherent time delay and a smooth, more gradual power ramp for a given change in 
solar irradiance [2]. However, research is still being done on the effects that cloud shading has on large-scale PV arrays and their cloud-induced power ramps. References [2] and [3] investigate the distribution of solar irradiance and PV power changes over a fixed time interval (i.e. 1 second, 10 seconds, 1 minutes, 10 minute, etc.). However, the duration and magnitude of solar irradiance and PV power changes have not been used to study their effects on power systems and their protective schemes. While research proves that a change in solar irradiance leads to a change in a PV array's operating voltage and power output, an investigation as to the effect that variations in DC voltage and supplied DC power have on an inverter's harmonic generation would prove a very insightful study.

Research is still being done to better understand the variability and uncertainty of PV power generation. System operators and planners need to know what sort of variability and uncertainty are associated with PV plants. Such knowledge would allow them to better manage a PVconnected power grid. Moreover, the effects of such PV variations and uncertainties on power system performance must also be studied so as to develop solutions for remediating unfavorable situations. Understanding PV power fluctuations will allow for the creation of enforceable reliability standards. Conversely, while standards provide recommended limits for reliable operating conditions, they do not, however, dictate how to meet such requirements [2].

The focus of this paper is to investigate the effect that cloud shading has on PV power output response. It will also shed light on the outcomes that cloud-induced PV power drops have on power system operation and protection. This paper will also investigate whether a cloud-shaded PV array's operating conditions influence an inverter's harmonic generation and total harmonic distortion. Such issues must be examined so as to provide insight on how to incorporate PV systems in the most advantageous, reliable, cost-effective way. 


\section{Thesis Organization}

Chapter I of this thesis begins by providing a background on PV power generation and explains the importance of understanding PV uncertainty and variability and their impact on power system operation.

Chapter II provides more background on the operational characteristics of PV arrays and explains how such characteristics are altered by solar irradiance fluctuations. This section also investigates cloud-induced PV power transients, shedding light on recent discoveries about the duration and magnitude of such solar irradiance variations and their associated PV power transients.

Chapter III studies how cloud-shaded PV operating conditions influence inverter harmonic generation and total harmonic distortion. When a cloud's shadow envelopes a PV array, the operating voltage and output power of the PV array will drop. Therefore, variations of DC voltage and supplied DC power on inverter harmonic generation will be investigated in this section.

Chapter IV examines the effect that introducing PV arrays, with irregular power generation capabilities, to power systems has on existing power system protection schemes. Through simulation, this paper explores the problems caused by PV power drops and a power system's ability to maintain stability while delivering reliable and safe power under dynamic PV power generation conditions.

Finally, the paper is wrapped up in Chapter V with conclusions about the study, solutions to investigated problems, and future studies, related to PV uncertainty and variability, that can be performed. 


\section{Solar Irradiance and PV Power Transients}

"PV variability and uncertainty" refers to fluctuations in PV-generated power caused by variations in solar irradiance over time. Such PV power fluctuations are synonymous to phrases such as "PV Power Transients" and "PV Power Ramps." To understand why and how changes in solar irradiance lead to changes in PV generated power, one must first understand the basic operating characteristics of photovoltaics.

\section{A. PV Equivalent Circuit Model}

In order to understand the operating characteristics of a PV panel, one must know the fundamental electrical circuit components of the PV equivalent circuit model, which dictate how a PV panel operates. Figure II.1 below shows the equivalent circuit model.

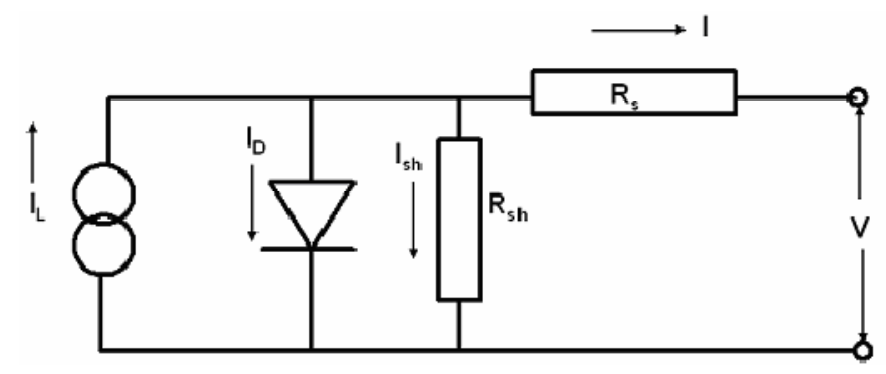

\section{Figure II.1: PV Module Equivalent Circuit}

Above is the equivalent circuit model for a photovoltaic module, which includes a series resistance $\left(\mathrm{R}_{\mathrm{s}}\right)$ and a solar-irradiance-controlled current source $\left(\mathrm{I}_{\mathrm{L}}\right)$ in parallel with a shunt resistance $\left(R_{\text {sh }}\right)$ and a diode (D) [4]. The amount of current synced by $I_{L}$ is dependent on the amount of solar irradiance received by the panel. Solar irradiance is measured in $\mathrm{W} / \mathrm{m}^{2}$ and is the amount of solar radiation power over a given surface area in square meters. NOTE: $\mathrm{I}_{\mathrm{D}}$ is the diode current, $\mathrm{I}_{\mathrm{sh}}$ is the current traveling through the shunt resistor $\left(\mathrm{R}_{\mathrm{sh}}\right)$, I is the current leaving the solar panel module positive terminal and V is the voltage across the PV module terminals. 
This equivalent circuit produces the following equation to describe the PV module current, I, for a given voltage, V. The PV current equation is listed below:

$$
I=I_{L}-I_{o}\left(e^{\frac{V+I \cdot R_{s}}{a_{c}}}-1\right)-\frac{V+I \cdot R_{s}}{R_{s h}}
$$

Where the equation for $\mathrm{a}_{\mathrm{C}}$ is defined as:

$$
a_{c}=\frac{N_{s} \cdot n \cdot k \cdot T_{c}}{q}=N_{s} \cdot n \cdot V_{T}
$$

For equation II.1, IL is the solar irradiance dependent current-source current, $\mathrm{I}_{\mathrm{o}}$ is the diode reverse saturation current in amps, $\mathrm{a}_{\mathrm{c}}$ represents the temperature-dependent diode non-ideality factor, $\mathrm{N}_{\mathrm{s}}$ represents the number of solar cells connected in series which make up the PV module, $\mathrm{n}$ represents the diode ideality factor or emission coefficient, k represents Boltzmann's constant $\left(\mathrm{k}=1.38066 \times 10^{-23} \mathrm{~J} /{ }^{\circ} \mathrm{K}\right), \mathrm{T}_{\mathrm{c}}$ is the operating temperature of the PV module in degrees Kelvin, $\mathrm{q}$ represents the charge of an electron $\left(q=1.60218 \times 10^{-19}\right.$ Coulombs $), V_{T}$ represents the diode thermal voltage, and V represents the operating terminal voltage of the PV module. Thus, Equation II.1 derives the PV operating current as a function of PV operating voltage for a given operating temperature and solar irradiance level delivered to the PV module.

NOTE: For definitions and units for any symbol used in this section, refer to Appendix A. Also, for equation 1 , there are 4 unknowns: $I_{L}, I_{o}, R_{s}$, and $R_{\text {sh. }}$. These 4 unknowns are the components of the PV equivalent circuit model of Figure II.1. Furthermore, the PV current equation II.1 produces a current-voltage characteristic curve (I-V Curve) that describes the operating point of a panel for any given load connected to the PV terminals. Refer to subsection B (The I-V Characteristic Curve) for an explanation of the PV I-V Characteristic curve. 


\section{B. The I-V Characteristic Curve}

The PV current equation, Equation II.1, produces a current vs. voltage characteristic curve as the one shown in Figure II.2. Figure II.2 also shows the King's 5 point model, which provides 5 points on the I-V characteristic curve for over 400 different solar panels. Although Figure II.2 shows a solid curve-fit for the King's 5 Point Model, the Sandia database only provides the 5 points that describe the I-V characteristic curve. Thus, a best-fit curve must be derived so as to produce a complete I-V characteristic curve.

\section{i. Factors that Shift the King's Model Points}

There are many factors that shift the 5 points of the King's model. However, for this paper, the King's model has been simplified so as to apply only the effects of solar irradiance and temperature on the I-V Characteristic Curve.

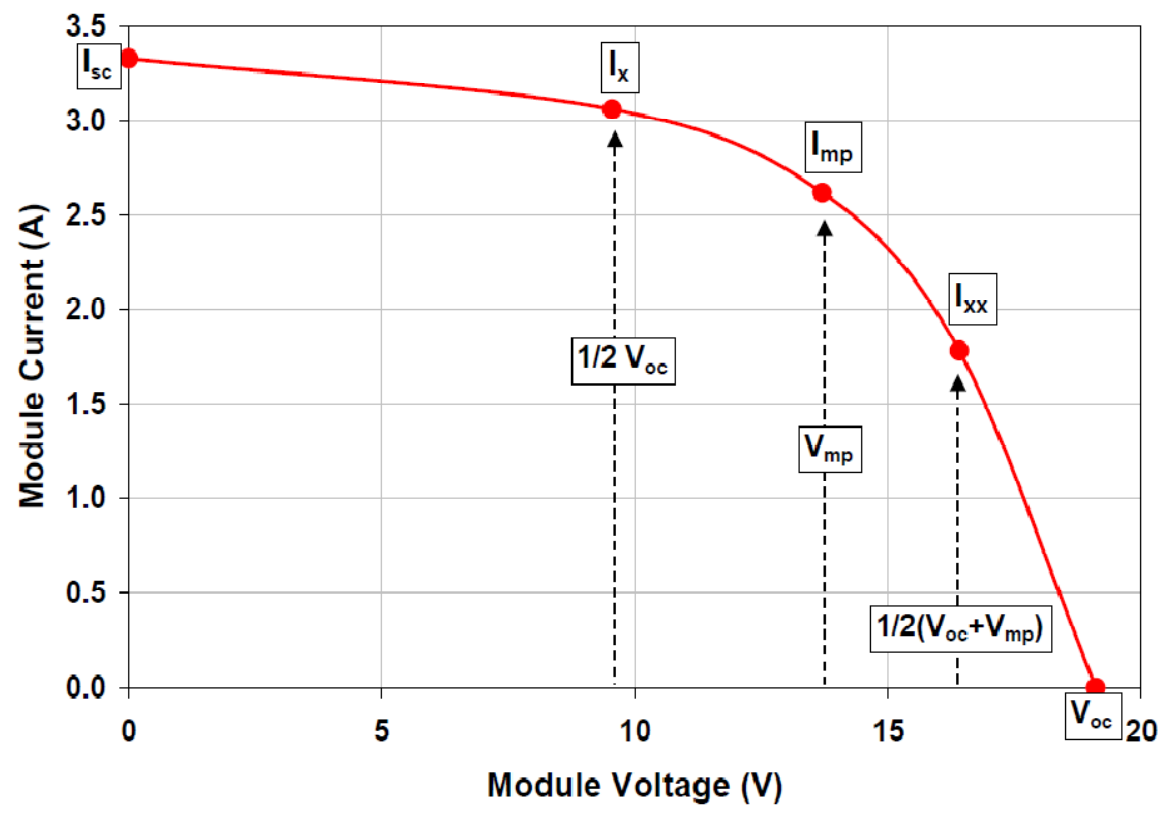

Figure III.2: I-V Characteristic Curve with the King's 5-Point Model [5]

Figure II. 2 shows the I-V Characteristic Curve with the King's 5 Point Model. The King's model was developed by the Sandia National Laboratories as a way of characterizing a 
wide range of solar panels on the market. Sandia decided to use five points for their I-V model so as to best model a PV module's I-V curve and how temperature and solar irradiance alter the curve. Sandia, however, does not provide a curve to fit the points. Therefore, a best fit-curve was derived so as to better characterize the PV operating conditions for any point the I-V curve for a given solar irradiance and operating temperature. See Figure II.4 for an illustration of the generated best-fit curve for a Kyocera KC50T PV module.

\section{ii. The Five Points of King's Model}

The 5 King's Model points shown in Figure II.2 are defined as follows:

- $\mathrm{I}_{\mathrm{SC}}$ is the short circuit current

- $\mathrm{I}_{\mathrm{X}}$ is the current at a voltage $\mathrm{V}_{\mathrm{X}}=1 / 2 \mathrm{~V}_{\mathrm{OC}}$

- $\left[\mathrm{V}_{\mathrm{mp}}, \mathrm{I}_{\mathrm{mp}}\right]$ is the point where the solar module supplies maximum power, where $P_{m p}=V_{m p} I_{m p}$.

- $\mathrm{I}_{\mathrm{XX}}$ is the current at a voltage $\mathrm{V}_{\mathrm{XX}}=1 / 2\left(\mathrm{~V}_{\mathrm{OC}}+\mathrm{V}_{\mathrm{mp}}\right)$.

- $\mathrm{V}_{\mathrm{OC}}$ is the open circuit voltage

The five points of the King's model are

\section{iii. The King's Model Points at Standard Reference Conditions (SRC)}

When each of the five King's points' subscripts end with 'o' (as in $\mathrm{I}_{\mathrm{sc}}$ becomes $\mathrm{I}_{\mathrm{sco}}$ ), the King's model point occurs at the "Standard Reference Condition" (SRC) [5]. SRC is the condition where $\mathrm{T}_{\mathrm{c}}=\mathrm{T}_{\mathrm{o}}=25^{\circ} \mathrm{C}$ and $\mathrm{E}_{\mathrm{e}}=1$ [4]. Note: $\mathrm{T}_{\mathrm{o}}$ is the $\mathrm{SRC}$ temperature constant of $25^{\circ} \mathrm{C}, \mathrm{T}_{\mathrm{c}}$ is the operating temperature of the $\mathrm{PV}$ module in degrees Celsius and $\mathrm{E}_{\mathrm{e}}$ is the effective irradiance of the sun [5]. $\mathrm{E}_{\mathrm{e}}$ can be calculated by dividing the solar irradiance, $\mathrm{E}_{\mathrm{x}}\left(\mathrm{W} / \mathrm{m}^{2}\right)$, by the reference solar irradiance, $E_{0}=1000 \mathrm{~W} / \mathrm{m}^{2}$ [5]. The equation for calculating the effective irradiance is shown below: 


$$
E_{e}=\frac{E_{x}}{E_{o}}=\frac{E_{x}}{1000 \mathrm{~W} / \mathrm{m}^{2}}
$$

Therefore, at $\mathrm{SRC}\left(\mathrm{T}_{\mathrm{c}}=\mathrm{T}_{\mathrm{o}}=25^{\circ} \mathrm{C}, \mathrm{E}_{\mathrm{e}}=1.0\right)$ the five King's Model points become:

- $\mathrm{I}_{\mathrm{sc}} \rightarrow \mathrm{I}_{\mathrm{sco}}$

- $\left[\mathrm{V}_{\mathrm{x}}, \mathrm{I}_{\mathrm{x}}\right] \rightarrow\left[\mathrm{V}_{\mathrm{xo}}, \mathrm{I}_{\mathrm{xo}}\right]$

- $\left[\mathrm{V}_{\mathrm{mp}}, \mathrm{I}_{\mathrm{mp}}\right] \rightarrow\left[\mathrm{V}_{\mathrm{mpo}}, \mathrm{I}_{\mathrm{mpo}}\right]$

- $\left[\mathrm{V}_{\mathrm{xx}}, \mathrm{I}_{\mathrm{xx}}\right] \rightarrow\left[\mathrm{V}_{\mathrm{xxo}}, \mathrm{I}_{\mathrm{xxo}}\right]$

- $\mathrm{V}_{\mathrm{oc}} \rightarrow \mathrm{V}_{\mathrm{oco}}$

Sandia's database provides the five King's model points at SRC as well as the equations for calculating the King's model points for temperatures and solar irradiances other than $T_{0}$ and $E_{0}$. For temperatures $\left(T_{c}\right)$ and effective irradiances $\left(E_{e}\right)$ other than $25 \square C$ and 1.0 respectively, the five points of the King's Model can be derived using the following equations [5]:

$$
\begin{aligned}
& I_{s c}=I_{s c o} \cdot E_{e} \cdot\left\{1+\alpha I_{s c} \cdot\left(T_{c}-T_{o}\right)\right\}, \text { where } T_{o}=25^{o} C \\
& V_{o c}=V_{o c o}+M_{s} \cdot N_{s} \cdot \delta\left(T_{c}\right) \cdot \ln \left(E_{e}\right)+M_{s} \cdot \beta V_{o c} \cdot\left(T_{c}-T_{o}\right) \\
& I_{m p}=I_{m p o} \cdot\left(C_{0} \cdot E_{e}+C_{1} \cdot E_{e}{ }^{2}\right) \cdot\left\{1+\alpha I_{m p} \cdot\left(T_{c}-T_{o}\right)\right\} \\
& V_{m p}=V_{m p o}+M_{s} \cdot N_{s} \cdot C_{2} \cdot \delta\left(T_{c}\right) \cdot \ln \left(E_{e}\right)+M_{s} \cdot N_{s} \cdot C_{2} \cdot\left\{\delta\left(T_{c}\right) \cdot \ln \left(E_{e}\right)\right\}^{2}+M_{s} \cdot \beta V_{o c} \cdot\left(T_{c}-T_{o}\right) \\
& I_{x}=I_{x o} \cdot\left(C_{4} \cdot E_{e}+C_{5} \cdot E_{e}{ }^{2}\right) \cdot\left\{1+\alpha I_{s c} \cdot\left(T_{c}-T_{o}\right)\right\} \\
& V_{x}=1 / 2 \cdot V_{o c} \\
& I_{x x}=I_{x x o} \cdot\left(C_{6} \cdot E_{e}+C_{7} \cdot E_{e}{ }^{2}\right) \cdot\left\{1+\alpha I_{s c} \cdot\left(T_{c}-T_{o}\right)\right\} \\
& V_{x x}=1 / 2 \cdot\left(V_{o c}+V_{m p}\right)
\end{aligned}
$$

The above equations provide the effects that temperature and effective solar irradiance have on shifting the I-V Characteristic curve. Figure II.3 shows the effects that temperature and solar irradiance have on shifting the I-V characteristic curve. 


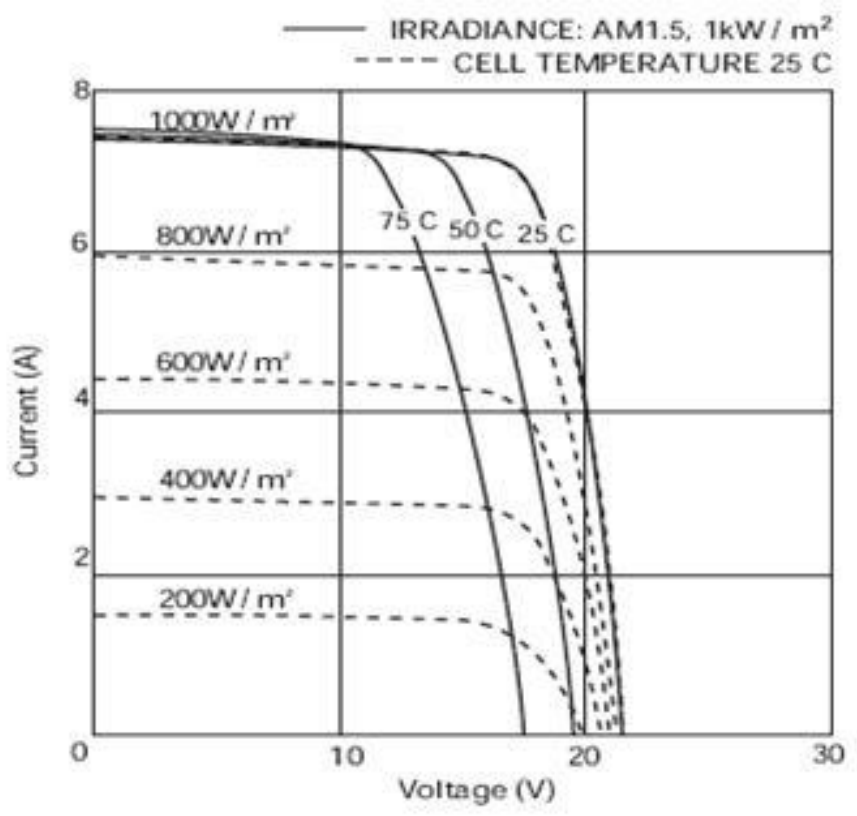

Figure II.3: Effects of Temperature and Solar Irradiance on the I-V Curve [6]

The above figure shows the effects that solar irradiance and temperature have on a PV module's I-V Curve. The short circuit current varies proportionally with effective solar irradiance $\left(\mathrm{E}_{\mathrm{e}}\right)$, while the open circuit voltage varies logarithmically with $\mathrm{E}_{\mathrm{e}}$. As the temperature of the PV module increases for a fixed solar irradiance, the open circuit voltage decreases drastically while the short circuit current increases very minimally.

\section{iv. Generating a Curve-Fitted I-V Curve}

Using the five King's Model points and plugging them into Equation 1, the 4 unknowns $\left(I_{L}, I_{o}, R_{s}\right.$, and $R_{s h}$ ) can be calculated. As the voltage, $V$, varies from 0 to Voc, the current value, for a given voltage, can be calculated and thus, the I-V curve can be generated. Figure II.4 below shows an example of a generated I-V curve for a Kyocera KC50T Panel. 


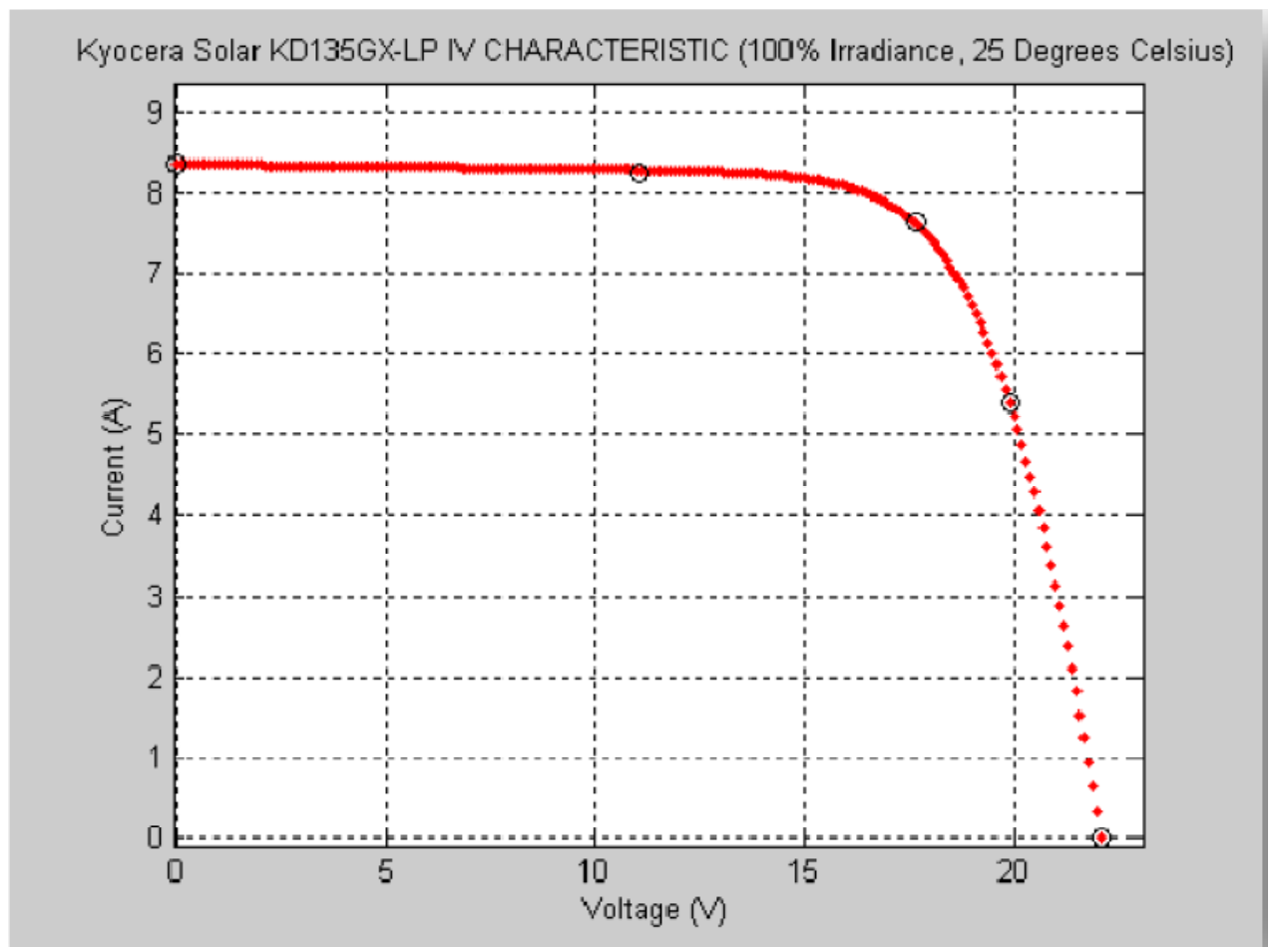

Figure II.4: MATLAB Generated I-V Curve Given the 5 King's Model Points

Figure II.4 shows the generated best-fitted I-V curve created using the five King's Model points after they have been adjusted for solar irradiance and temperature. This curve represents the I-V characteristic curve for a Kyocera KC50T panel operating at an effective irradiance of $100 \%$ and a temperature of $25 \square \mathrm{C}$.

PV arrays are often constructed of series and parallel combinations of PV modules. Figures II.5 and II.6 illustrate the equivalent I-V curves for PV modules connected in parallel and series respectively. 


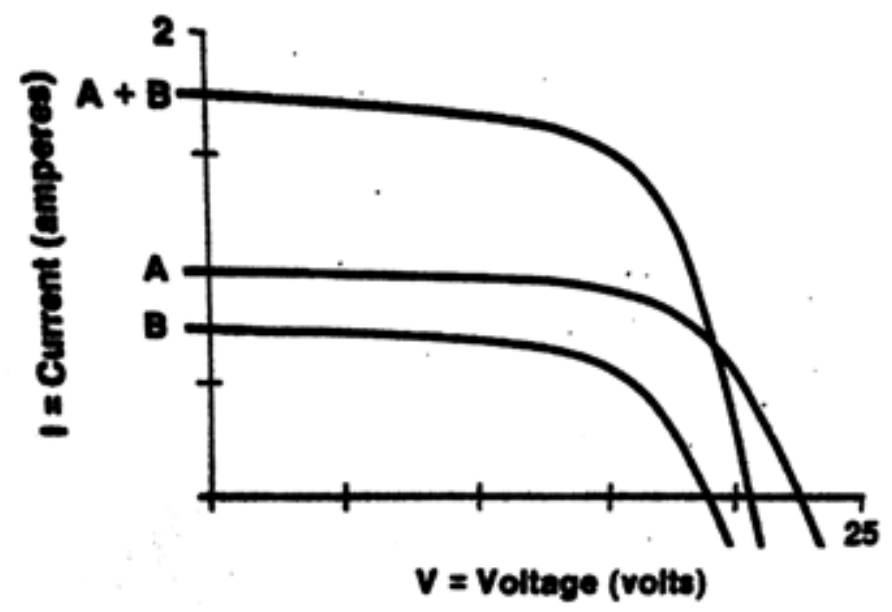

Figure II.5: I-V Curves for 2 Parallel-Connected PV Devices [7]

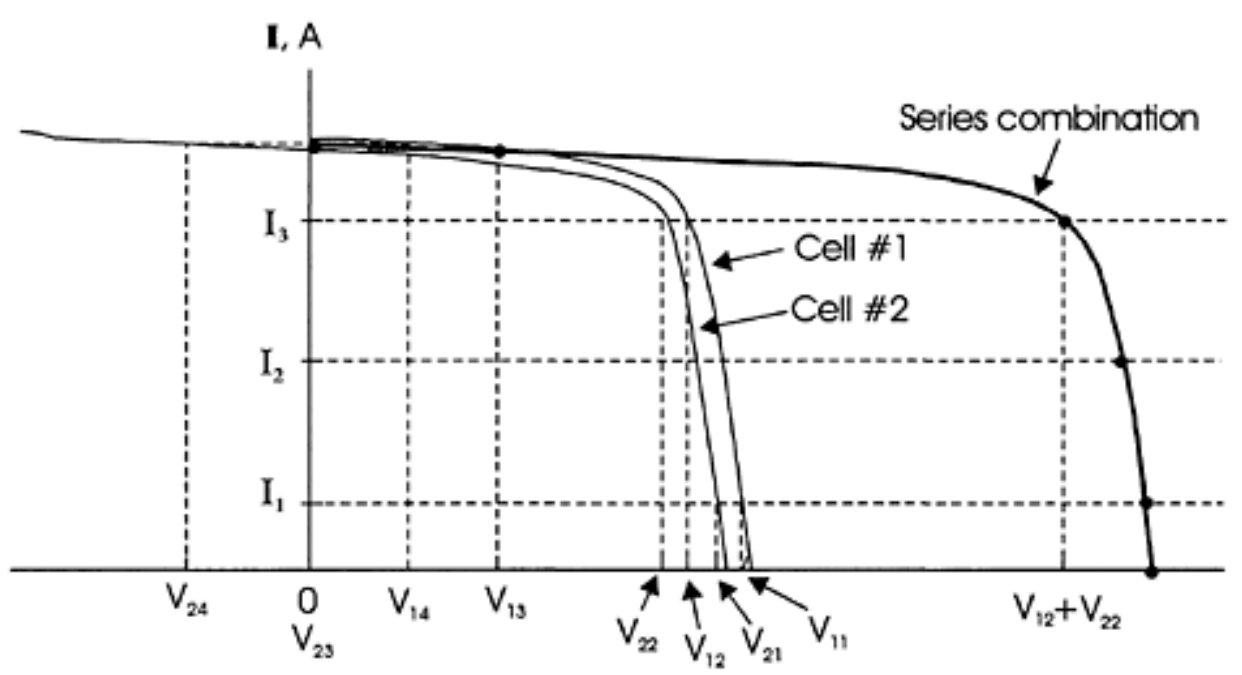

Figure II.6: I-V Curves for 2 Series-Connected PV Devices [7]

Figures II.5 and II.6 show I-V curves for 2 parallel-connected and 2 series-connected PV modules. When PV modules are placed in parallel, the new equivalent I-V curve has a new short circuit current that is the sum of the parallel-connected PV arrays' short circuit currents. The new equivalent parallel-connected I-V curve also has an open circuit voltage equal to the average of the parallel-connected PV arrays' open circuit voltages.

On the other hand, for series-connected PV combinations, the new equivalent I-V curve has a short circuit current determined by the PV module with the most limited short-circuit current. 
Moreover, the new series-connected PV I-V curve's equivalent voltage is the sum of all the series PV modules' voltages. Thus, the equivalent series-connected I-V curve has an open circuit equal to the sum of all of the series-connected PV modules' open circuits. Connecting PV arrays together in series forms strings, which are often used to produce a voltage that resides within the operating DC range of a PV array's inverter. Strings will then be connected in parallel so as to increase the current output of the array.

By incorporating the properties of parallel-connected and series-connected equivalent I-V characteristics curves, the equivalent PV array $\mathrm{I}-\mathrm{V}$ characteristic curve can then be generated for any solar irradiance and PV array temperature. However, before calculating a PV array Power transient, one must understand solar irradiance transients and how variations in solar irradiance affects the output power of a PV array. The next section classifies solar irradiance transients so as to better understand the nature of PV current, voltage, and power transients.

\section{Solar Irradiance Transients}

Weather often brings much variation and uncertainty. Solar irradiance is very much affected by changes in weather. A warm, sunny day produces large solar irradiance values, while cold, cloudy days limit the available solar irradiance. Hence, clouds have a large impact on the solar irradiance received by a solar panel array. Figure II.7 shows a typical day's solar irradiance plot taken from NREL solar irradiance data [8]. NREL, the National Renewable Energy Laboratory, collects solar irradiance plots over the span of a day for months on end sampling the solar irradiance every tenth of a second. The months of NREL solar irradiance data were analyzed so as to determine the most maximum increasing and decreasing solar irradiance slopes over various time increments. Such maximum increasing and decreasing slopes represent only a small change of larger, longer-duration solar irradiance transients. Additionally, some solar irradiance 
slopes must be filtered out because they represent corrupt data or represent the same larger, complete solar irradiance transient. This section will explain how solar irradiance slopes are determined and explain what unwanted slopes must be filtered out in the pursuit of the most maximum increasing and decreasing solar irradiance transients.

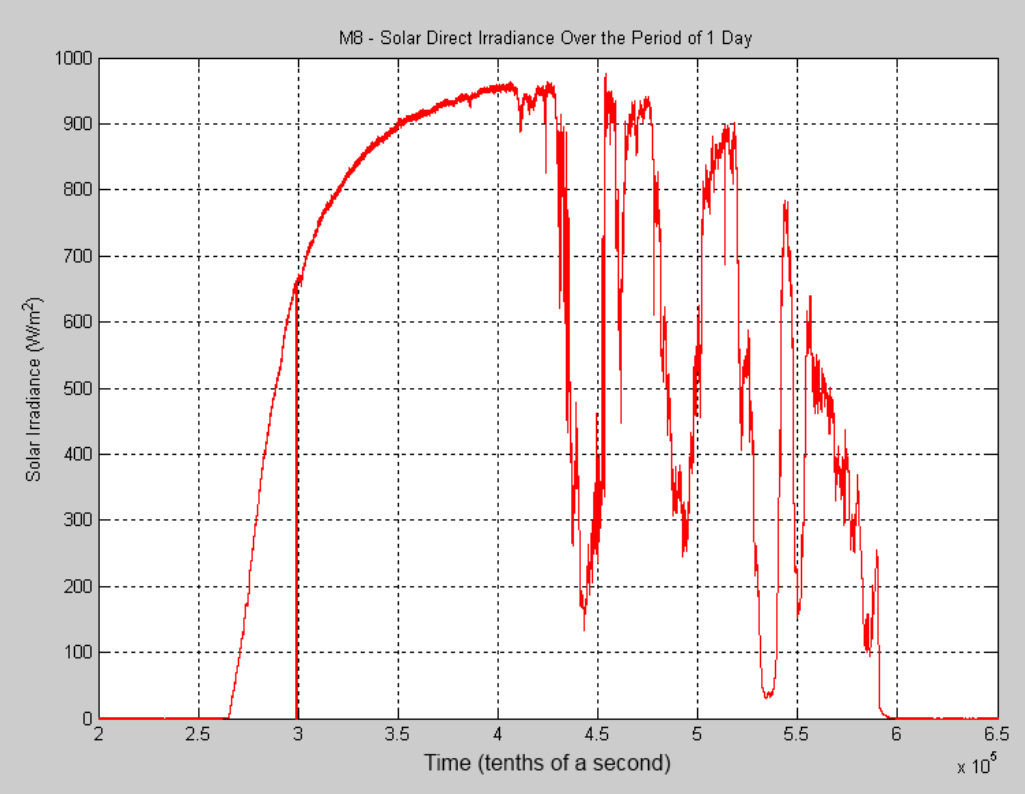

Figure II.7: NREL Solar Irradiance Plot over the Span of One Day sampled at $1 / 10^{\text {th }}$ of a second from months of NREL solar irradiance data [8].

Figure II.7 portrays a solar irradiance plot over the span of one day. The solar irradiance data was taken from months of NREL solar irradiance data, which is sampled at $10 \mathrm{~Hz}$. Note, for Figure II.7, time $\mathrm{t}=0$ correlates to $12: 00 \mathrm{AM}$ and there are 86,400 seconds or 864,000 tenths of a second in the span of one day. For a clear, sunny day, the solar irradiance plot would appear parabolic. The parabola would intersect the horizontal axis (the time-axis) at sunrise and sunset and would peak around solar noon. The solar irradiance plot of Figure II.7, however, contains distortions that have altered it from its ideal, parabolic shape. These distortions, or variations, are known as solar irradiance transients and are caused by over-passing clouds that shade the surrounding area when traveling in front of the sun. Such solar irradiance transients represent 
random irradiance increases and drops throughout the day. Determining the speed at which solar irradiance changes over time provides useful information for better comprehending how quickly PV power would drop if exposed to such solar irradiance changes.

The process of determining maximum positive and negative solar irradiance variations isn't as simple as finding the most maximum solar irradiance slopes for a given time increment. Faulty data and noise within NREL solar irradiance data produce large, unwanted solar irradiance transients that do not truly represent a cloud-induced solar irradiance increase or decrease. Therefore, the legitimate solar irradiance slopes must be filtered out from the corrupt, faulty solar irradiance slopes so as to determine the true maximum solar irradiance transients. Figure I-V.8 shows three examples of unwanted solar irradiance slopes that must be filtered out of the selection process so as to determine only the top, most-maximum solar irradiance transients. 


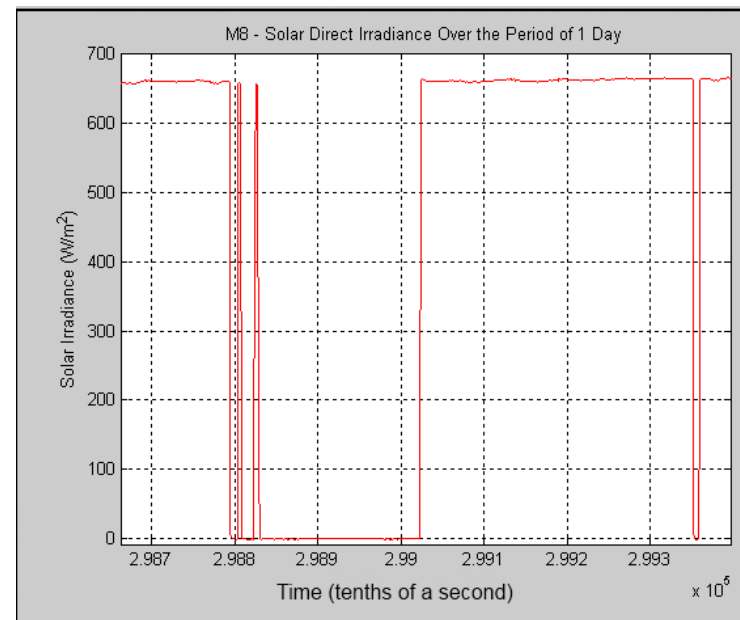

(a)

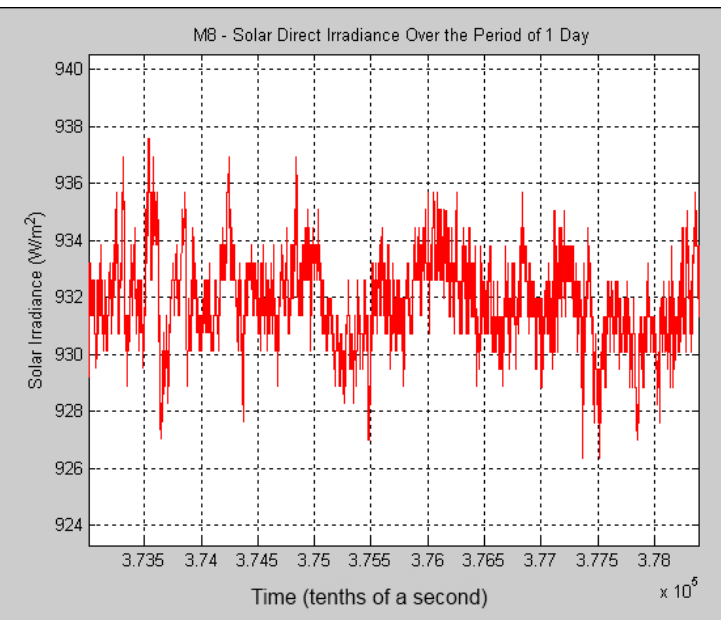

(b)

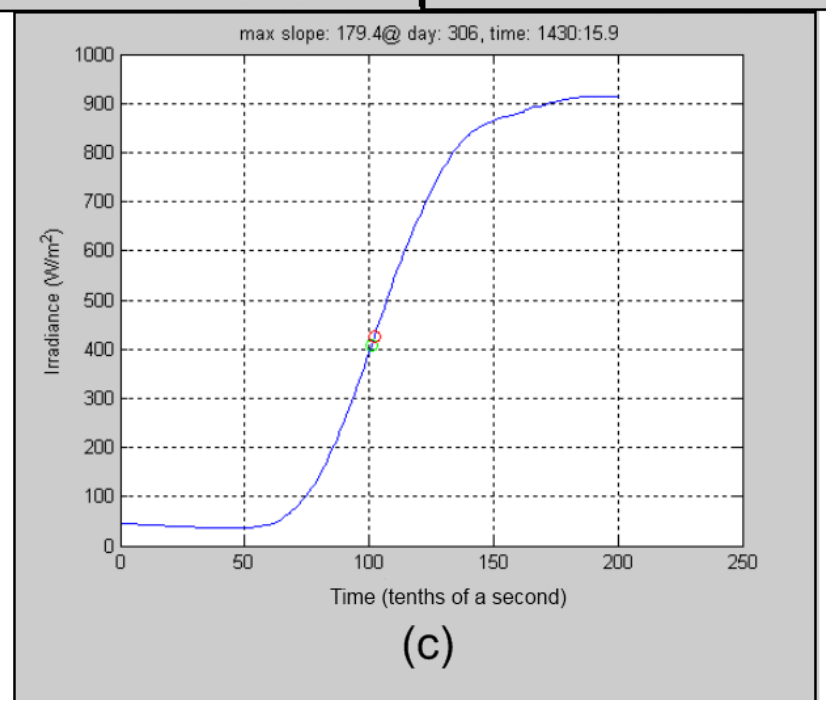

Figure II.8: Three Types of Unwanted Maximum Solar Irradiance Slopes Taken from Months of NREL Solar Irradiance Plots [8].

Unwanted solar irradiance slopes must be filtered out to find the top 20 most maximum, unique increasing and decreasing solar irradiance transients. Unwanted solar irradiance slopes fall into one of these three categories:

1. Solar irradiance slopes that represent a transition from a large solar irradiance value to zero solar irradiance (or vice versa) within $10^{\text {th }}$ s of a second (Figure II.8a)

2. Slopes caused by sensor noise in insolation meter solar irradiance readings (Figure II.8b) 
3. Slopes that represent the same larger solar irradiance transient (Figure II.8c). Duplicate larger solar irradiance transients illustrated as the blue curve of Figure II.8c must be filtered out.

Solar Irradiances transients that involve a "to" or "from" zero solar irradiance value change from a large irradiance value to zero solar irradiance or vice versa within 0.1 to 0.3 seconds. These transients are often caused by someone, or something, walking in front of the sensor and covering all direct sunlight to the device.

Next, transients caused by sensor noise include transients, which take the form of noise fluctuations. The accuracy of NREL's solar irradiance sensor is only about $10 \mathrm{~W} / \mathrm{m}^{2}$. Thus when the actual solar irradiance remains rather constant over a given period of time, the solar irradiance sensor will read solar irradiance values, which randomly oscillate between $\pm 10 \mathrm{~W} / \mathrm{m}^{2}$ of the actual solar irradiance value. Plus, every noise-related oscillation has its own associated solar irradiance slope and noise-related solar irradiance slopes are unwanted transients and therefore should be filtered out.

Lastly, if a slope is an ideal, maximum slope that occurs within 10s of another ideal, maximum slope, both slopes do not need to both be included in the most maximum solar irradiance transient list. By removing duplicate transients, the most maximum transient list becomes more diverse. If multiple slopes are identical in magnitude and both represent the same, ideal, positive or negative, multiple 10ths of a second change in solar irradiance, only one of the two slopes needs to be included in the maximum slopes list. Both slopes represent parts of the same, entire, ideal transient and therefore it is redundant to choose both slopes for the maximum slope list. (The two open-circled points on Figure II.8 show two slopes of equal magnitude, representing the same, larger, ideal transient which is represented by the blue curve). 
After unwanted slopes have been filtered out, the batch of solar irradiance transients should represent the most ideal solar irradiance transients. Figure II.9 shows an example of an ideal maximum solar irradiance transient.

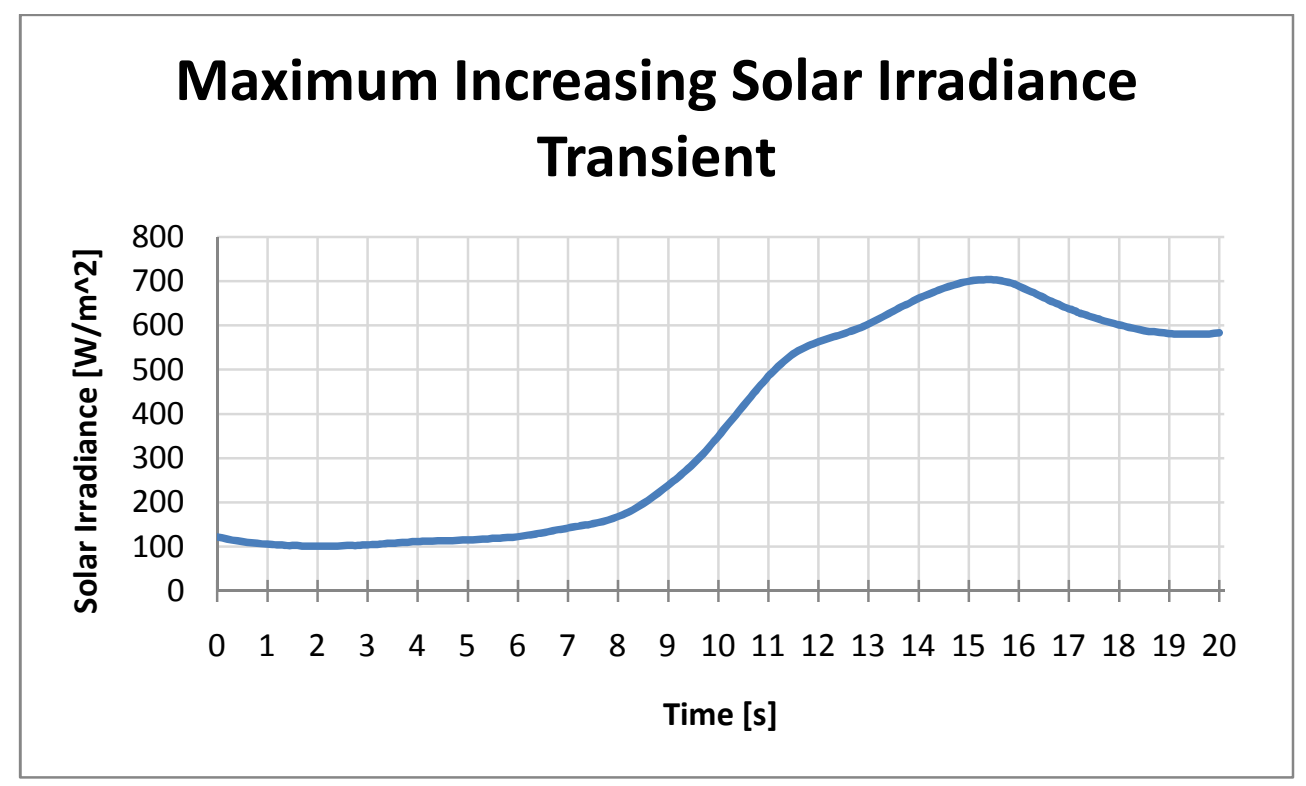

Figure II.9: Example of a Maximum Increasing Solar Irradiance Transient

Figure II.9 shows a good example of an increasing, cloud-induced solar irradiance transient. Such a transient would be produced when the sun, hiding behind a cloud, emerges from the cloud that is passing by. Similarly, Figure II.10 shows an example of a decreasing cloud-induced solar irradiance transient. 


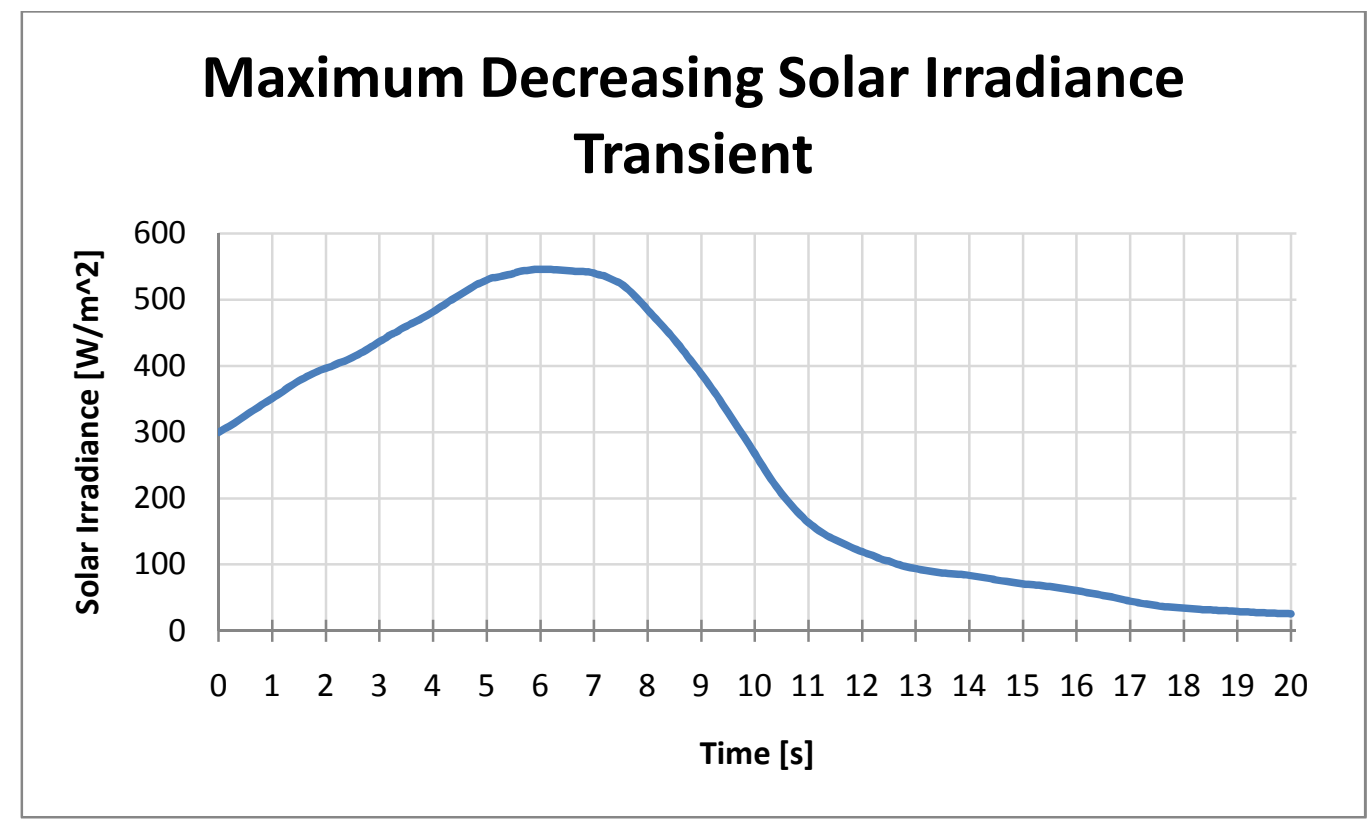

Figure II.10: Example of a Maximum Decreasing Solar Irradiance Transient

Figure II.10 shows an example of a maximum decreasing solar irradiance transient that has been selected after the unwanted solar irradiance slopes and transients have been filtered out. This scenario would be caused by a cloud traveling in front of the sun, thus casting a shadow, which would shade a PV panel and drop its power output capabilities. From the maximum solar irradiance transients gathered, Table II.1 summarizes the most maximum increasing and decreasing solar irradiances transients over different time intervals $(0.1 \mathrm{~s}, 1 \mathrm{~s}, 5 \mathrm{~s}$, and $10 \mathrm{~s})$. 
Table II.1: Summary of the Most Maximum Solar Irradiance Transients - magnitude in solar irradiance change for a given time intervals $(0.1 \mathrm{~s}, 1 \mathrm{~s}, 5 \mathrm{~s}$, and $10 \mathrm{~s})$.

\begin{tabular}{|c|c|c|c|c|c|}
\hline & & \multicolumn{4}{|c|}{ Solar Irradiance Increase } \\
\hline & \multirow[b]{2}{*}{ Transient \# } & \multicolumn{4}{|c|}{ Time Interval } \\
\hline & & $0.1 \mathrm{~s}$ & 1s & $5 s$ & 10s \\
\hline $\mathrm{W} / \mathrm{m}^{\wedge} 2$ & \multirow{2}{*}{1} & 14.24 & 136.76 & 437.5 & \begin{tabular}{|l}
587.85 \\
\end{tabular} \\
\hline$\%$ & & $2.02 \%$ & $19.42 \%$ & $62.13 \%$ & $83.48 \%$ \\
\hline $\mathrm{W} / \mathrm{m}^{\wedge} 2$ & \multirow{2}{*}{2} & 10.52 & 98.39 & 365.71 & 408.41 \\
\hline$\%$ & & $1.31 \%$ & $12.26 \%$ & $45.57 \%$ & $50.89 \%$ \\
\hline $\mathrm{W} / \mathrm{m}^{\wedge} 2$ & \multirow{2}{*}{3} & 9.9 & 89.71 & 233.88 & 240.69 \\
\hline$\%$ & & $2.29 \%$ & $20.74 \%$ & $54.08 \%$ & $55.65 \%$ \\
\hline $\mathrm{W} / \mathrm{m}^{\wedge} 2$ & \multirow{2}{*}{4} & 11.76 & 104.57 & 288.37 & 181.93 \\
\hline$\%$ & & $1.74 \%$ & $15.45 \%$ & $42.60 \%$ & $26.87 \%$ \\
\hline $\mathrm{W} / \mathrm{m}^{\wedge} 2$ & \multirow{2}{*}{5} & 8.67 & 80.45 & 258.04 & 320.54 \\
\hline$\%$ & & $1.79 \%$ & $16.58 \%$ & $53.19 \%$ & $66.07 \%$ \\
\hline $\mathrm{W} / \mathrm{m}^{\wedge} 2$ & \multirow{2}{*}{6} & 8.67 & 82.91 & 169.536 & 134.267 \\
\hline$\%$ & & $3.62 \%$ & $34.63 \%$ & $70.80 \%$ & $56.07 \%$ \\
\hline $\mathrm{W} / \mathrm{m}^{\wedge} 2$ & \multirow{2}{*}{7} & 8.04 & 47.03 & 206.68 & 353.95 \\
\hline$\%$ & & $0.90 \%$ & $5.28 \%$ & $23.21 \%$ & $39.75 \%$ \\
\hline $\mathrm{W} / \mathrm{m}^{\wedge} 2$ & \multirow{2}{*}{8} & 7.43 & 68.06 & 180.66 & 197.37 \\
\hline$\%$ & & $2.05 \%$ & $18.74 \%$ & $49.74 \%$ & $54.34 \%$ \\
\hline $\mathrm{W} / \mathrm{m}^{\wedge} 2$ & \multirow{2}{*}{9} & 7.43 & 64.35 & 250.57 & 334.1 \\
\hline$\%$ & & $1.12 \%$ & $9.68 \%$ & $37.71 \%$ & $50.28 \%$ \\
\hline$W / m^{\wedge} 2$ & \multirow{2}{*}{10} & 7.42 & 61.87 & 261.091 & 232.011 \\
\hline$\%$ & & $1.93 \%$ & $16.05 \%$ & $67.74 \%$ & $60.19 \%$ \\
\hline $\mathrm{W} / \mathrm{m}^{\wedge} 2$ & \multirow{2}{*}{ Average } & 9.41 & 83.41 & 265.20 & 299.11 \\
\hline$\%$ & & $1.88 \%$ & $16.88 \%$ & $50.68 \%$ & $54.36 \%$ \\
\hline $\mathrm{W} / \mathrm{m}^{\wedge} 2$ & \multirow{2}{*}{$\operatorname{Max}$} & 14.24 & 136.76 & 437.50 & 587.85 \\
\hline$\%$ & & $2.02 \%$ & $19.42 \%$ & $62.13 \%$ & $83.48 \%$ \\
\hline
\end{tabular}

\begin{tabular}{|c|c|c|c|c|c|}
\hline & & \multicolumn{4}{|c|}{ Solar Irradiance Decrease } \\
\hline & \multirow[b]{2}{*}{ Transient } & \multicolumn{4}{|c|}{ Time Interval } \\
\hline & & $0.1 \mathrm{~s}$ & $1 \mathrm{~s}$ & $5 s$ & $10 \mathrm{~s}$ \\
\hline $\mathrm{W} / \mathrm{m}^{\wedge} 2$ & & \begin{tabular}{|l|}
13.61 \\
\end{tabular} & 125 & \begin{tabular}{|l|}
422.02 \\
\end{tabular} & 495.66 \\
\hline$\%$ & & $2.49 \%$ & $22.90 \%$ & $77.32 \%$ & $90.82 \%$ \\
\hline $\mathrm{W} / \mathrm{m}^{\wedge} 2$ & \multirow{2}{*}{2} & 11.76 & 104.57 & 288.37 & 417.07 \\
\hline$\%$ & & $2.01 \%$ & $17.90 \%$ & $49.37 \%$ & $71.40 \%$ \\
\hline $\mathrm{W} / \mathrm{m}^{\wedge} 2$ & \multirow{2}{*}{3} & 11.14 & 106.42 & 249.96 & 262.34 \\
\hline$\%$ & & $2.65 \%$ & $25.33 \%$ & $59.50 \%$ & $62.45 \%$ \\
\hline $\mathrm{W} / \mathrm{m}^{\wedge} 2$ & & 11.14 & 98.39 & 273.51 & 435.02 \\
\hline$\%$ & & $1.38 \%$ & $12.20 \%$ & $33.92 \%$ & $53.95 \%$ \\
\hline $\mathrm{W} / \mathrm{m}^{\wedge} 2$ & \multirow{2}{*}{5} & 8.67 & 84.14 & 233.255 & 254.291 \\
\hline$\%$ & & $2.67 \%$ & $25.95 \%$ & $71.95 \%$ & $78.43 \%$ \\
\hline $\mathrm{W} / \mathrm{m}^{\wedge} 2$ & & 9.9 & 89.71 & 233.88 & 133.02 \\
\hline$\%$ & & $2.29 \%$ & $20.74 \%$ & $54.08 \%$ & $30.76 \%$ \\
\hline $\mathrm{W} / \mathrm{m}^{\wedge} 2$ & \multirow[t]{2}{*}{7} & 8.67 & 80.45 & 258.04 & 241.95 \\
\hline$\%$ & & $1.79 \%$ & $16.58 \%$ & $53.19 \%$ & $49.87 \%$ \\
\hline $\mathrm{W} / \mathrm{m}^{\wedge} 2$ & & 7.43 & 65.59 & 155.91 & 209.126 \\
\hline$\%$ & & $2.42 \%$ & $21.33 \%$ & $50.70 \%$ & $68.01 \%$ \\
\hline $\mathrm{W} / \mathrm{m}^{\wedge} 2$ & & 7.42 & 65.58 & 287.08 & 398.44 \\
\hline$\%$ & & $1.06 \%$ & $9.35 \%$ & $40.92 \%$ & $56.79 \%$ \\
\hline $\mathrm{W} / \mathrm{m}^{\wedge} 2$ & \multirow{2}{*}{10} & 7.425 & 65.587 & 202.944 & 205.418 \\
\hline$\%$ & & $2.96 \%$ & $26.17 \%$ & $80.99 \%$ & $81.98 \%$ \\
\hline $\mathrm{W} / \mathrm{m}^{\wedge} 2$ & \multirow{2}{*}{ Average } & 9.72 & 88.54 & 260.50 & 305.23 \\
\hline$\%$ & & $2.17 \%$ & $19.85 \%$ & $57.19 \%$ & $64.45 \%$ \\
\hline $\mathrm{W} / \mathrm{m}^{\wedge} 2$ & \multirow{2}{*}{ Max } & 13.61 & 125.00 & 422.02 & 495.66 \\
\hline$\%$ & & $2.49 \%$ & $22.90 \%$ & $77.32 \%$ & $90.82 \%$ \\
\hline
\end{tabular}

Table II.1 shows the most maximum increasing (Left) and decreasing (Right) solar

irradiance transients from months of NREL solar irradiance data [8]. The solar irradiance data of the maximum transients were analyzed over different time intervals to determine the maximum change in solar irradiance for a given time interval. Percentage changes in solar irradiance were calculated using the following equations:

Decreasing Change in Solar Irradiance:

$\Delta E_{\text {decrease }}=\frac{\left|E_{\text {start }}-E_{\text {end }}\right|}{E_{\text {start }}} \cdot 100 \%$

Increasing Change in Solar Irradiance:

$\Delta E_{\text {increase }}=\frac{\left|E_{\text {end }}-E_{\text {start }}\right|}{E_{\text {end }}} \cdot 100 \%$ 
Where $\Delta \mathrm{E}_{\text {increase }}$ and $\Delta \mathrm{E}_{\text {decrease }}$ represent the increasing and decreasing percent change in solar irradiance, $E_{\text {start }}$ represents the starting solar irradiance value in $\mathrm{W} / \mathrm{m}^{2}$ and $\mathrm{E}_{\text {end }}$ represents the ending solar irradiance value in $\mathrm{W} / \mathrm{m}^{2}$.

Table II.2 summarizes results of Table II.1 by providing the maximum amount of solar irradiance changes per given change in time.

Table II.2: Summary of Maximum Solar Irradiance Changes for a Given Time Duration from Table II.1.

\begin{tabular}{|c|r|r|r|r|r|}
\hline \multirow{2}{*}{\begin{tabular}{c} 
Maximum Change \\
in Solar Irradiance \\
\cline { 2 - 6 } for Increasing
\end{tabular}} & $\mathbf{0 . 1 s}$ & $\mathbf{1 s}$ & $\mathbf{5 s}$ & Units \\
\cline { 2 - 6 } Transients & $7.4-14.2$ & $47.0-136.8$ & $169.5-437.5$ & $134.3-587.9$ & $\mathbf{W} / \mathbf{m}^{\wedge} \mathbf{2}$ \\
\cline { 2 - 6 } & $1.9 \%-2.0 \%$ & $5.28 \%-19.42 \%$ & $70.8 \%-62.1 \%$ & $56.1 \%-83.5 \%$ & $\mathbf{1 0 s}$ \\
\hline
\end{tabular}

\begin{tabular}{|c|r|r|r|r|r|}
\hline Maximum Change & \multicolumn{4}{|c|}{ Time Interval [s] } & \multirow{2}{*}{ Units } \\
\cline { 2 - 5 } in Solar Irradiance & $\mathbf{0 . 1 s}$ & $\mathbf{1 s}$ & $\mathbf{5 s}$ & $\mathbf{1 0 s}$ & \\
\cline { 2 - 6 } for Decreasing & $7.4-13.6$ & $65.6-125.0$ & $155.9-422.0$ & $133.0-495.7$ & $\mathbf{W} / \mathbf{m}^{\wedge} \mathbf{2}$ \\
\cline { 2 - 6 } Transients & $1.1 \%-2.5 \%$ & $9.35 \%-23.0 \%$ & $50.7 \%-77.3 \%$ & $30.76 \%-90.82 \%$ & $\mathbf{\%}$ \\
\hline
\end{tabular}

Table II.2 summarizes the data shown in Table II.1. The top table in Table II.1 portrays maximum changes solar irradiance for increasing solar irradiance transients, while the bottom table of Table II. 2 portrays maximum changes in solar irradiance for decreasing solar irradiance transients. For a duration of 0.1 seconds, the solar irradiance can change a maximum of 13.6 to 14.2 W/m ${ }^{2}$, a duration of 1 second could produce a solar irradiance change of 125 to 136.8 $\mathrm{W} / \mathrm{m}^{2}$, a maximum of 422 to $437.5 \mathrm{~W} / \mathrm{m}^{2}$ of solar irradiance could change in 5 seconds, and a duration of 10 seconds could lead to a maximum irradiance change of 495.7 to $587.9 \mathrm{~W} / \mathrm{m}^{2}$. In order to apply this knowledge of solar irradiance transients to PV power transients, the step response of a photovoltaic module must be determined. Knowing a PV module's step response time for varying solar irradiance changes, would allow one to estimate the amount of time required for a PV module's power to change for a given fluctuation in solar irradiance. That 
being said, a PV module's slew rate determines a PV power transient's duration and magnitude for a given change in solar irradiance.

\section{PV Power Transients}

In order to characterize PV power transients, two important details must be known. These details include a PV module's time-delayed output response and magnitude of power variation for a given change in input solar irradiance.

\section{i. Determining the PV Module's Power-Responsiveness}

Usually an electrical device's output, time-delayed response is determined by a step response. A step response is the measurement of the duration of time and magnitude of output change that occurs for a given rapidly stepped input. In regards to PV modules, a change in output corresponds to a change in output power, while a stepped-change in input corresponds to a rapid change in solar irradiance.

In order to test the step response of the solar panels, a screen-guillotine-device was designed to rapidly change the solar irradiance delivered to a PV module. This was done by dropping a window-screen in front of the PV panel so as to change its solar irradiance levels rather quickly. Figures II.11 and II.12 portray the screen-guillotine-device, which was used to determine the output power response of a Kyocera KC50T PV module. 

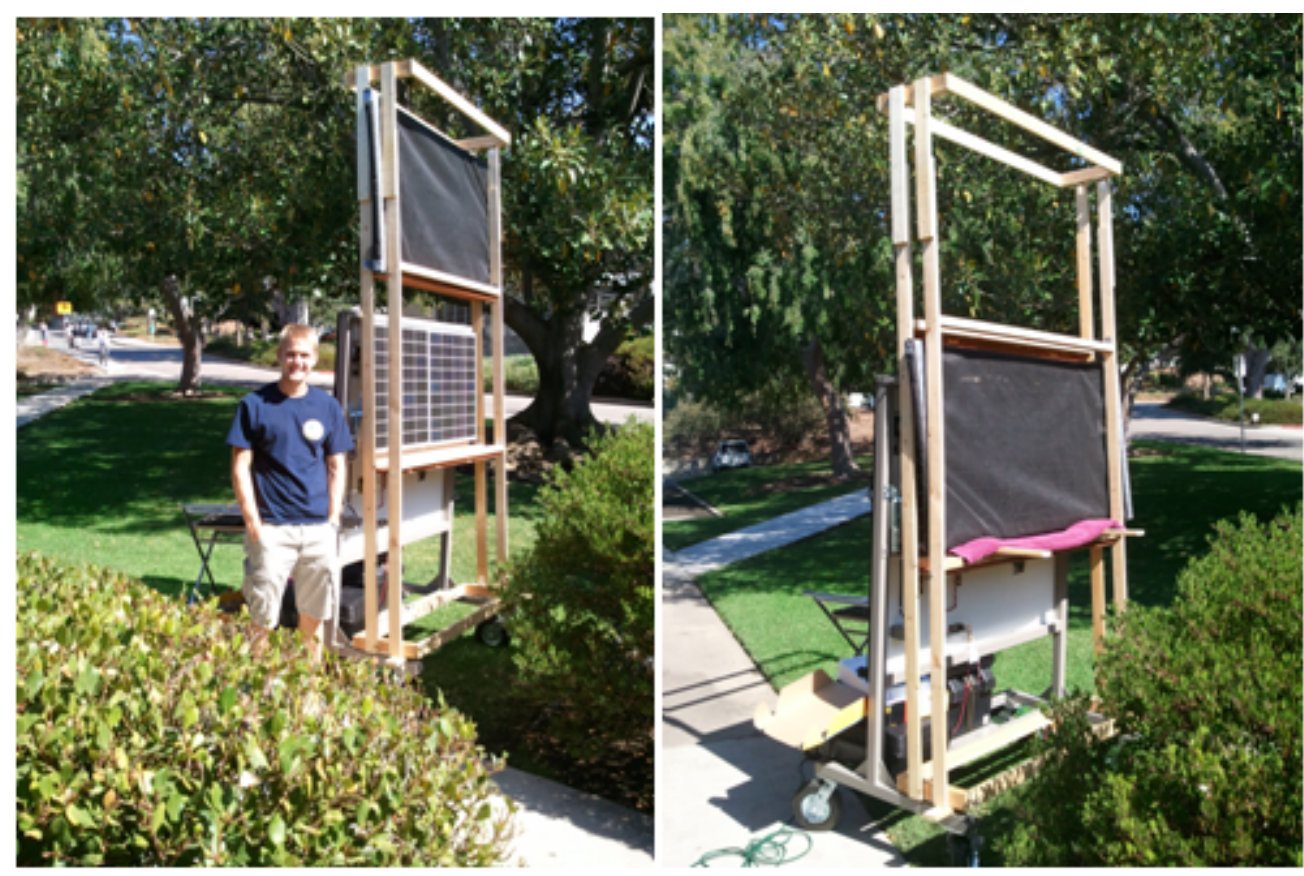

Figure II.11: Pictures of the Step Response Guillotine and Kyocera KC50T PV Modules

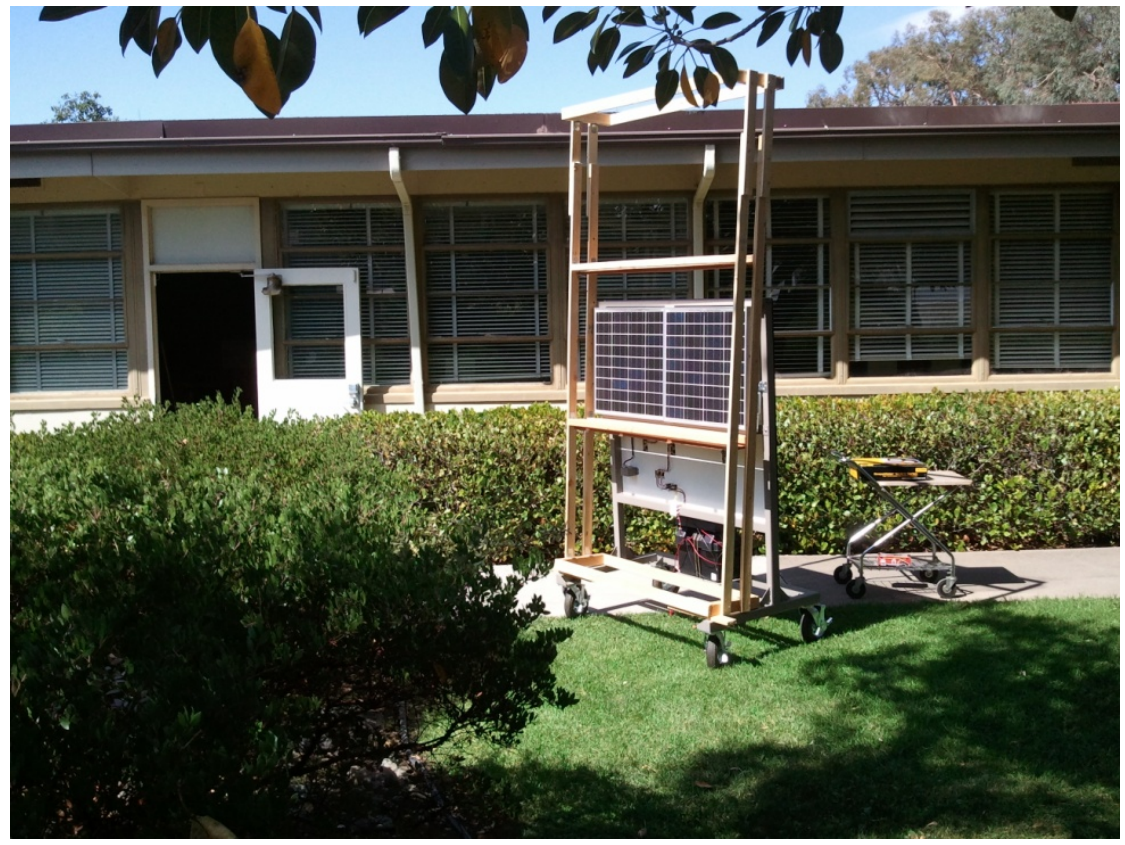

Figure II.12: Picture of Solar Irradiance Shading Guillotine and KC50T PV Modules

Figure II.11 and II.12 show the screen guillotine designed for testing the KC50T solar panels at different solar irradiance levels. This device was also used for determining the power response time for the KC50T panels. Figure II.11 shows two pictures: one where the window-shade is 
above the PV module (Left) and the other where the window-shade is in front of the PV module (Right). The left and right pictures of Figure II.11 show the two steady-state solar irradiance levels at which the PV module is tested: shaded and unshaded.

A step response for the PV module was conducted by dropping the window-shade from the position above the PV module (Figure II.11 - Left) and letting the window-shade free-fall until it reaches the position where it covers the entire PV module (Figure II.11 - Right). Gravity pulls on the window-shade at $9.81 \mathrm{~m} / \mathrm{s}^{2}$. Therefore, the window falls this entire distance in an average of 0.2 seconds. The change in solar irradiance is very quick; much quicker than any large cloudinduced solar irradiance transient could ever be. Therefore, such a change in solar irradiance can be assumed rapid-enough that it represents a stepped change in solar irradiance.

Moreover, the size of the solar irradiance change can be varied by adding or removing shading-material to and from the window-shade. More shading-layers lead to a smaller amount of solar irradiance received by the PV module. On the other hand, less shading-layers allow for more solar irradiance to be delivered to the PV module. The relationship between transmittance of solar irradiance versus the number of shade-layers is portrayed in Figure II.13. 


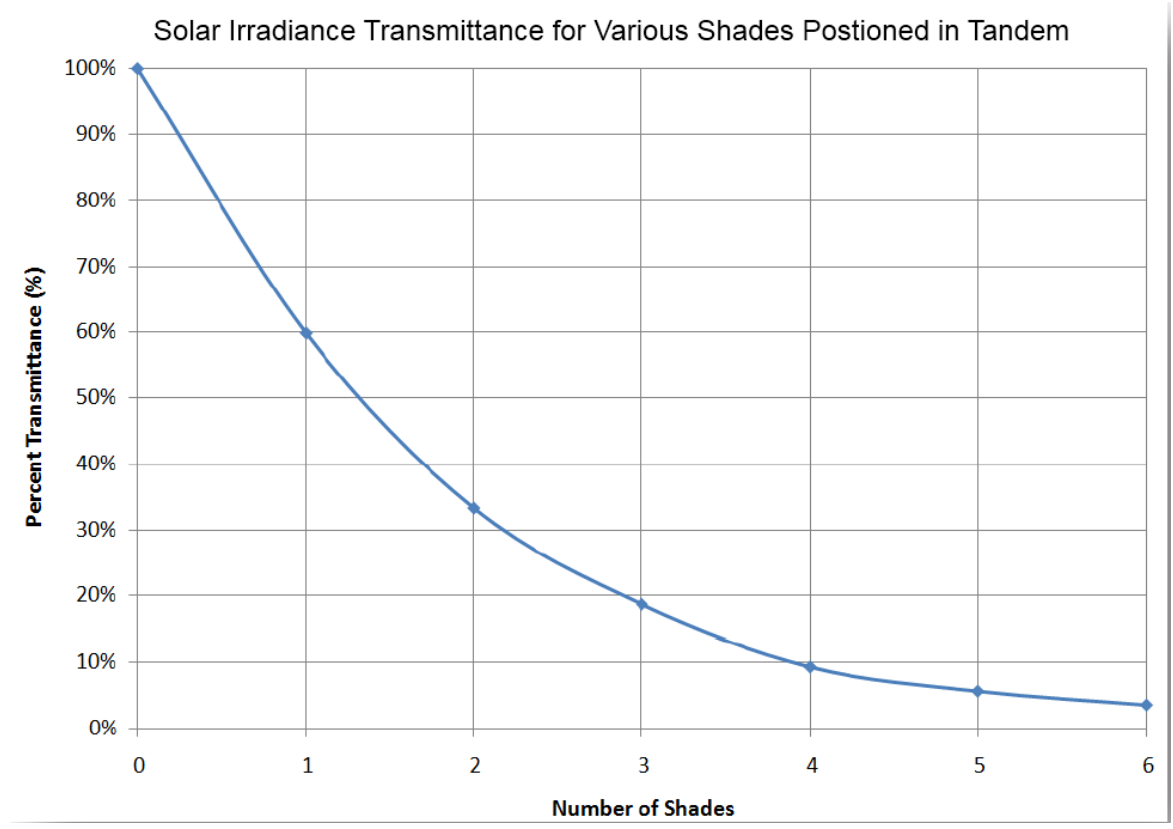

Figure II.13: Percent Transmittance of Solar Irradiance for Various Layers of Shading Material

Figure II.13 illustrates the amount of solar irradiance transmitted through the windowshade as a function of the number of shade-layers used. A window-shade with 3 layers, for example, would only allow $18 \%$ of the sun's solar irradiance through the shade. Thus if a 3 layered window-shade falls from above the panel to the position covering the PV panel, the solar irradiance would drop $82 \%$. Similarly, a 4-layered window shade would drop $90 \%$ from an unshaded solar irradiance value. While the graph in Figure II.13 shows the percent transmittance for window-shades up to 6 layers, experimentation for this paper tested no more than 4 layers. This choice was made because the difference in transmittance between 4, 5 and 6 layers is very minimal and the amount of material available limited the maximum number of window-shade layers.

When experimentally determining the power-slew rate of the PV module, the maximum number of shade-layers should be used so as to evoke the largest, most rapid change over the 0.2 seconds. Recall that a window-shade with 4 shade-layers drops the solar irradiance level from 
$100 \%$ to $10 \%$ within 0.2 seconds. The solar irradiance stepped-input is conducted using a KC50T Panel (See Appendix B for Kyocera KC50T Specs) for various load resistances. With a constant load resistance, the operating current-voltage point and I-V curve will both change for a given variation in solar irradiance and temperature. For a fixed load and given change in solar irradiance, a solar panel will move from the operating point of one I-V curve to the operating point of another curve. Figure II.14 illustrates that a variation in solar irradiance changes the PV module's I-V curve as well as the operating point (a voltage and corresponding current) from one $\mathrm{I}-\mathrm{V}$ curve to the next. This figure also shows an example of a load line that determines the PV operating points for two different I-V curves.

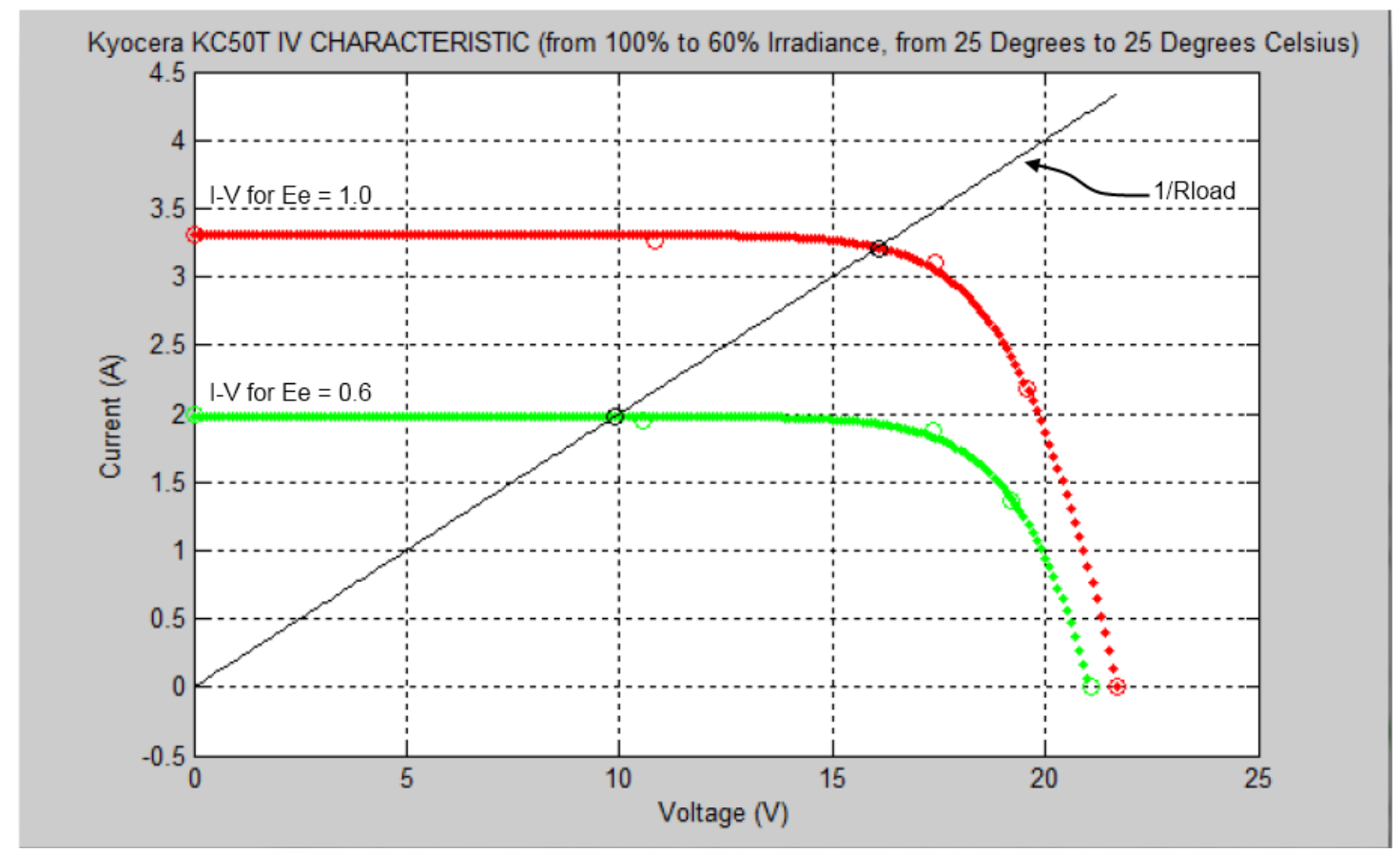

Figure II.14: Simulated I-V Load-Determined Operating Points on Two Solar IrradianceDependent I-V Curves

Figure II.14 describes the two current-voltage points that the KC50T PV module operates at for two different solar irradiance levels and a fixed resistive load. Such a set up was implemented to determine the step response time for a PV module. 


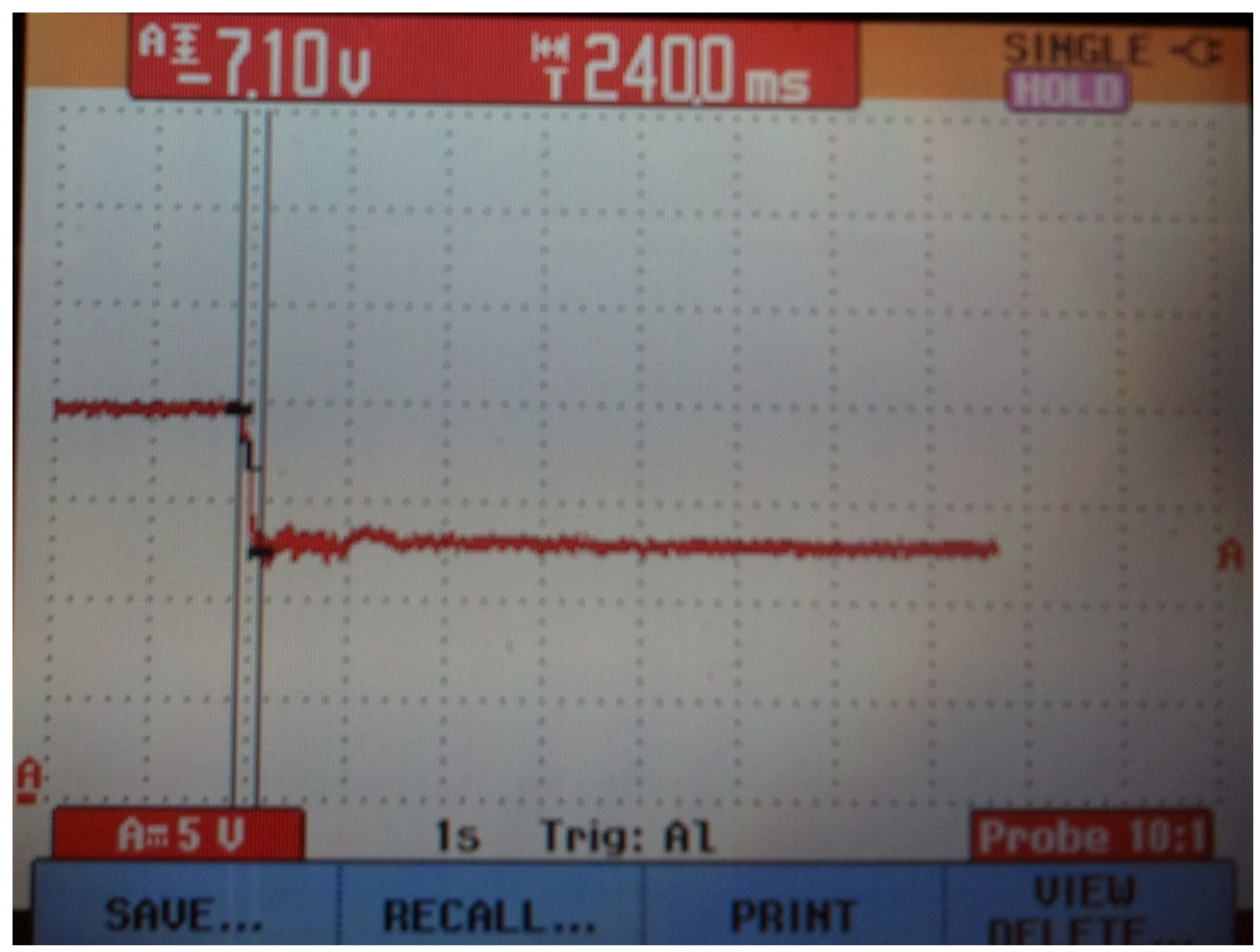

Figure II.15: Step Response of KC50T Module for 90\% Drop in Solar Irradiance over 0.2 seconds

Figure II.15 shows the step response of the Kyocera KC50T PV module for a solar irradiance drop from an unshaded value of $720 \mathrm{~W} / \mathrm{m}^{2}$ to a shaded value of $59 \mathrm{~W} / \mathrm{m}^{2}$. A $100 \Omega$ resistor was connected to the output terminals of the PV module, and the voltage was recorded over time, while the window-shade free-fell from the position above the PV module to the position covering the PV module. The step response resulted in a $92 \%$ solar irradiance drop over a 0.2 second duration. Additionally, the unshaded PV module voltage was $19.86 \mathrm{~V}$, which corresponds to 3.94 $\mathrm{W}$ of output power, while the shaded PV module voltage was $12.76 \mathrm{~V}$, which corresponds to 1.63 $\mathrm{W}$ of output power. Therefore, dropping the solar irradiance $91.8 \%$ in 0.2 seconds produced a $58.6 \%$ power drop in 0.24 seconds. While the window-shade may not experience complete freefall because of random collisions with the guidance rails as the window-shade falls, it can be assumed that the window-shade falls very close to 0.2 seconds almost every time. Assuming that the window-shade fell in 0.2 seconds, and Figure II. 15 shows a power drop in 0.24 seconds, then 
$40 \mathrm{~ms}$ can be assumed to be the inherent delay of the PV module for a given step change in solar irradiance. Thus, for a load of $100 \Omega$ and a rapid solar irradiance change of $450 \%$ per second, the PV module's output power changed with a slew rate of $58.6 \%$ per 0.24 seconds or $244.2 \%$ per second. Hence, a PV module's responsively to change at $100 \mathrm{ohms}$ can be assumed to be $54.3 \%$ less than a solar irradiance change in solar irradiance.

Note, however, that the amount of power drop that a PV produces for a variation in solar irradiance will change with the magnitude of solar irradiance variation, as well as the load connected to the solar panel. That being said, over the range of PV power drops, the intent of this paper was to study the power response time of a Kyocera KC50T solar panel. Hence, this study was more interested in the inherent time delay of a PV array, rather than the amount of power drop for a given amount of time. Nevertheless, the next section will investigate the magnitude of power drop associated with a variation in solar irradiance for a variety of resistive loads.

All in all, the inherent delay between a quick change in solar irradiance and the PV's ability to change its output power averaged between 30 and $40 \mathrm{~ms}$ over the wide-range of connected loads. Whether or not this inherent PV time delay was a result of the free-falling window-shade's random collisions with the guide rails or if the inherent PV time delay was caused by the PV module's the intrinsic electrical components, one can conclude that for a quick change in solar irradiance, a PV module's power will also change very rapidly.

Moreover, recent research has concluded that for a given large, rapid drop in solar irradiance, a PV system, with a grid-connected inverter, tends to exhibit a drop in output power in an average of 200ms [9]. The majority of the PV power drop time delay can be attributed to the DC link capacitance, which connects the PV array to the DC input terminal of the inverter. Such a study was conducted via simulation on a 10kWp PV array for an immediate solar irradiance drop 
from $1000 \mathrm{~W} / \mathrm{m}^{2}$ to $200 \mathrm{~W} / \mathrm{m}^{2}$. While $200 \mathrm{~ms}$ is much larger than the response time of an individual PV module, such a drop in PV power occurs in only 12 cycles, which still incredibly quick.

The experiment from reference [9] is similar to the responsiveness study that this paper conducted; however, this paper was limited with materials and therefore, was only able to test the responsiveness of a PV module. Nevertheless, knowledge of the responsiveness of gridconnected systems is important because this paper will later test the effects that grid-connected PV systems' power drops have on power systems and their implemented protection schemes.

\section{ii. Effect of Load Resistance on PV Power Drop}

While the power responsiveness of a PV module was determined to be between very swift for an alteration in solar irradiance, the magnitude of a PV power change for a variation in solar irradiance must also be studied so as to better characterize PV power transients. Figure II.16 shows the operating points on both $\mathrm{I}-\mathrm{V}$ and P-V characteristic curves for 3 different loads so as to show the effect of load resistance on power or current drops for a given change in solar irradiance. 

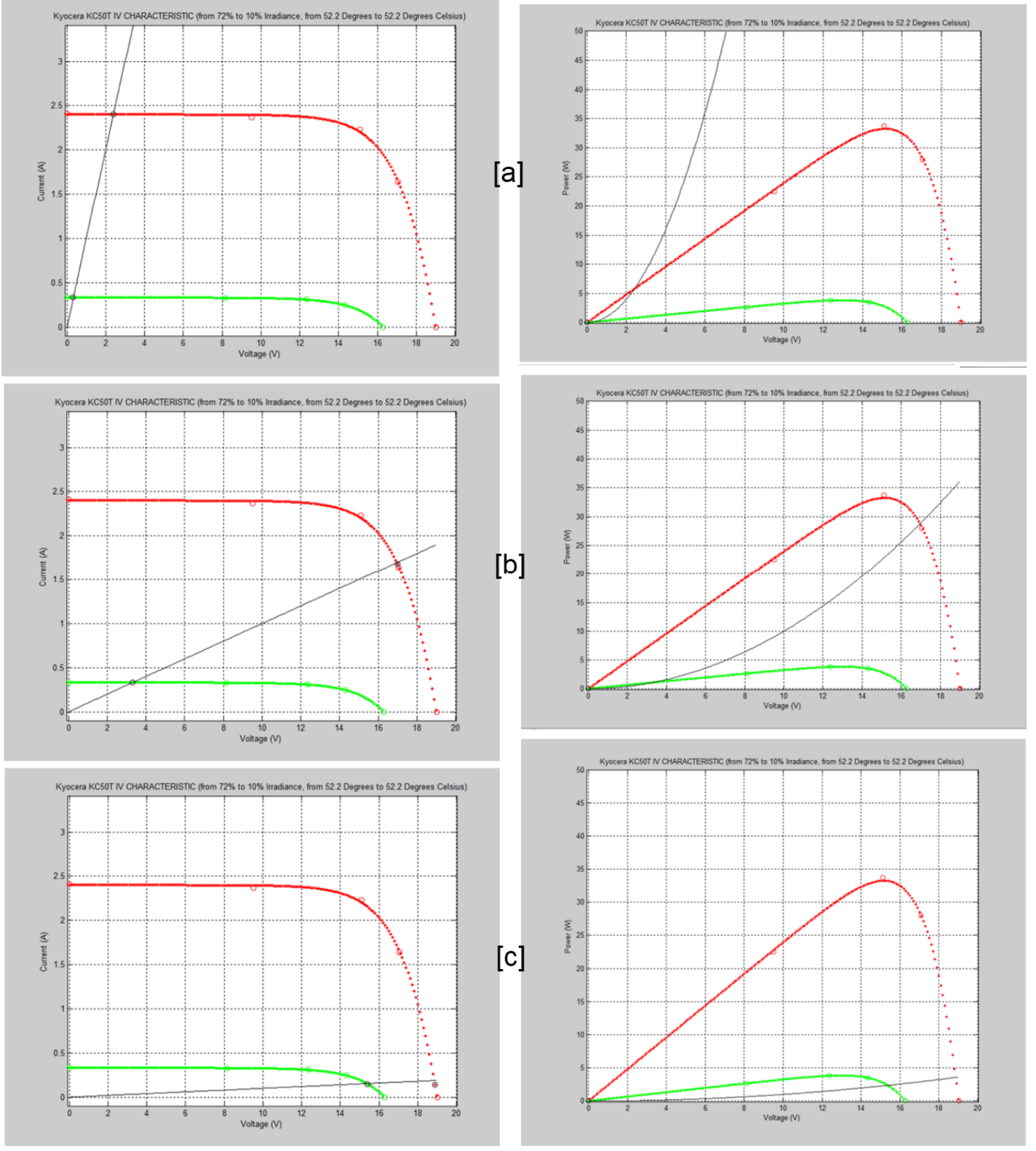

Figure II.16: Simulated Power Transients (Right Column) and Current Transients (Left Column) for a Given Variation in Solar Irradiance and a Fixed Load Resistance. Graphs illustrate operating conditions for: $[\mathrm{a}]$ - Connected Load $=1 \Omega,[\mathrm{b}]-$ Connected Load $=$ $10 \Omega$, and $[\mathrm{c}]-$ Connected Load $=100 \Omega$.

Figure II.16 shows current and power changes for three different loads $(1,10$, and $100 \Omega)$ corresponding to Figure II.16a, Figure II.16b, and Figure II.16c respectively. The left column shows the current vs. voltage changes, while the right column shows the corresponding power vs. voltage changes for a given variation in solar irradiance. The red curve represents the curve 
procured by the initial, unshaded, full-sun solar irradiance value of $720 \mathrm{~W} / \mathrm{m}^{2}$. The green curve represents the curve produced by the final, shaded solar irradiance value of $100 \mathrm{~W} / \mathrm{m}^{2}$. Lastly, the black line represents the current or power curve associated with a given resistive load. The resistance current curve employs the function: $I_{R}=V / R$, while the resistance power curve utilizes the function $P_{R}=V^{2} / R$. The intersection of the black resistance curve with the red and green curves represents the PV operating point on each solar irradiance dependent curve for the given resistive load.

When calculating the percentage solar irradiance drop and the percentage PV power drop, the following equations are utilized:

The Percentage Solar Irradiance Drop:

$\% E_{\text {drop }}=\frac{\left|E_{\text {unshaded }}-E_{\text {shaded }}\right|}{E_{\text {unshaded }}} \cdot 100 \%$

The Percentage PV Power Drop:

$\% P_{\text {drop }}=\frac{\left|P_{\text {unshaded }}-P_{\text {shaded }}\right|}{P_{\text {unshaded }}} \cdot 100 \%$

Therefore, the percentage solar irradiance drop and percentage PV power drop are calculated with respect to the unshaded, full-sun solar irradiance value and its corresponding PV output power. Understanding the above two equations will allow one to better comprehend how a change in solar irradiance affects the percentage PV power drop over a range of resistive loads.

Small loads, such as the $1 \Omega$ load in Figure II.16a, operate near the I-V curve's short circuit current points for both curves. Therefore, the corresponding percentage drop in power for a drop in solar irradiance is rather large because the final operating power point is rather small when compared to the starting operating power point. Recall that the short-circuit current varies almost 
proportionally with solar irradiance, while the voltage varies logarithmically. A PV power drop for a very small load procures a large change in current and a very small change in voltage. Because the output power is DC, the operating power of a PV panel is Pout $=I^{*} \mathrm{~V}$. Therefore, for a very minimal change in voltage, but a large change in current, the drop in power will be rather significant.

On the other hand, for large loads, like the $100 \Omega$ load of Figure II.16c, the operating currentvoltage points are very close to open-circuit voltages of both I-V curves. Recall that open-circuit voltages vary logarithmically for a given change in solar irradiance. Additionally, notice that the current magnitudes between both operating points do not change substantially. Thus, for a large resistive load, the change in power for a change in solar irradiance is rather small.

Equally important, as the load varies between $1 \Omega$ and $100 \Omega$, the power drop percentage peaks when the load resistance operates its initial operating point near the curve's maximum power point, while the ending operating point resides at a current rather close to the short circuit current. After the load increases past the resistance that produces the most maximum power drop, the initial operating power point reduces as the ending power point gradually increases. This leads to a decrease in the amount of power drop that occurs until the operating current magnitudes of both the initial and final solar irradiance values are equal. If the load resistance continues to increase, the power drop remains constant because the only change in power is not caused by a variation in current, but instead is caused by the change in voltage. Such voltage changes remains constant for a change in resistance because the operating points on the two curves reside close to the open circuit voltage points. 


\section{iii. Measuring Power Drops for Various Loads and Transmittance Levels}

In addition to understanding the effect that load variation has on a given percentage power drop, the effect of solar irradiance variation on a given percentage power drop must also be studied. Therefore, the shade-guillotine device, which was used to determine PV power responsiveness, was utilized to study the steady-state output power conditions for a given solar irradiance transient. Solar irradiance transients of varying magnitudes were tested for their effect on corresponding PV power transients; specifically the magnitude of the power drop they procured. Such measurements were done for 4 different solar irradiance transmittance conditions: 4 shades (10\% transmittance), 3 shades (20\% transmittance), 2 shades (40\% transmittance), and 1 shade (60\% transmittance).

For a fixed number of shade layers, the percentage solar irradiance drop remained rather constant for over the vast range of resistive loads. Any minimal variations in the percentage solar irradiance drop associated with the number of shade layers can be attributed to measurement error. The angle and position of the solar insolation meter, used to measure solar irradiance, can affect the $\mathrm{W} / \mathrm{m}^{2}$ reading. Plus, when the shade-layers overlap, the overlap pattern is not universally distributed across the whole area of shading. This causes some parts of the shade to block more solar irradiance than others. However, such discrepancies did not affect the percentage of solar irradiance drop because it remained rather constant over the entire range of resistive loads. Additionally, as the number of shade-layers decreased, the percentage solar irradiance drop decreased as well. Table II.3 summarizes the average solar irradiance percentage drop associated with the number of shade-layers implemented. 
Table II.3: Percent Solar Irradiance Drop Associated with the Number of Window-shade Shade-Layers.

\begin{tabular}{|l|r|r|r|r|r|}
\hline \# Shade Layers: & 4 & 3 & 2 & 1 & 0 \\
\hline \% Solar Irradiance Drop: & $90 \%$ & $80 \%$ & $67 \%$ & $38 \%$ & $0 \%$ \\
\hline
\end{tabular}

Equally important, Figure II.17 illustrates the associated PV power drop percentages for a given number of shades over a range of resistive load impedances.

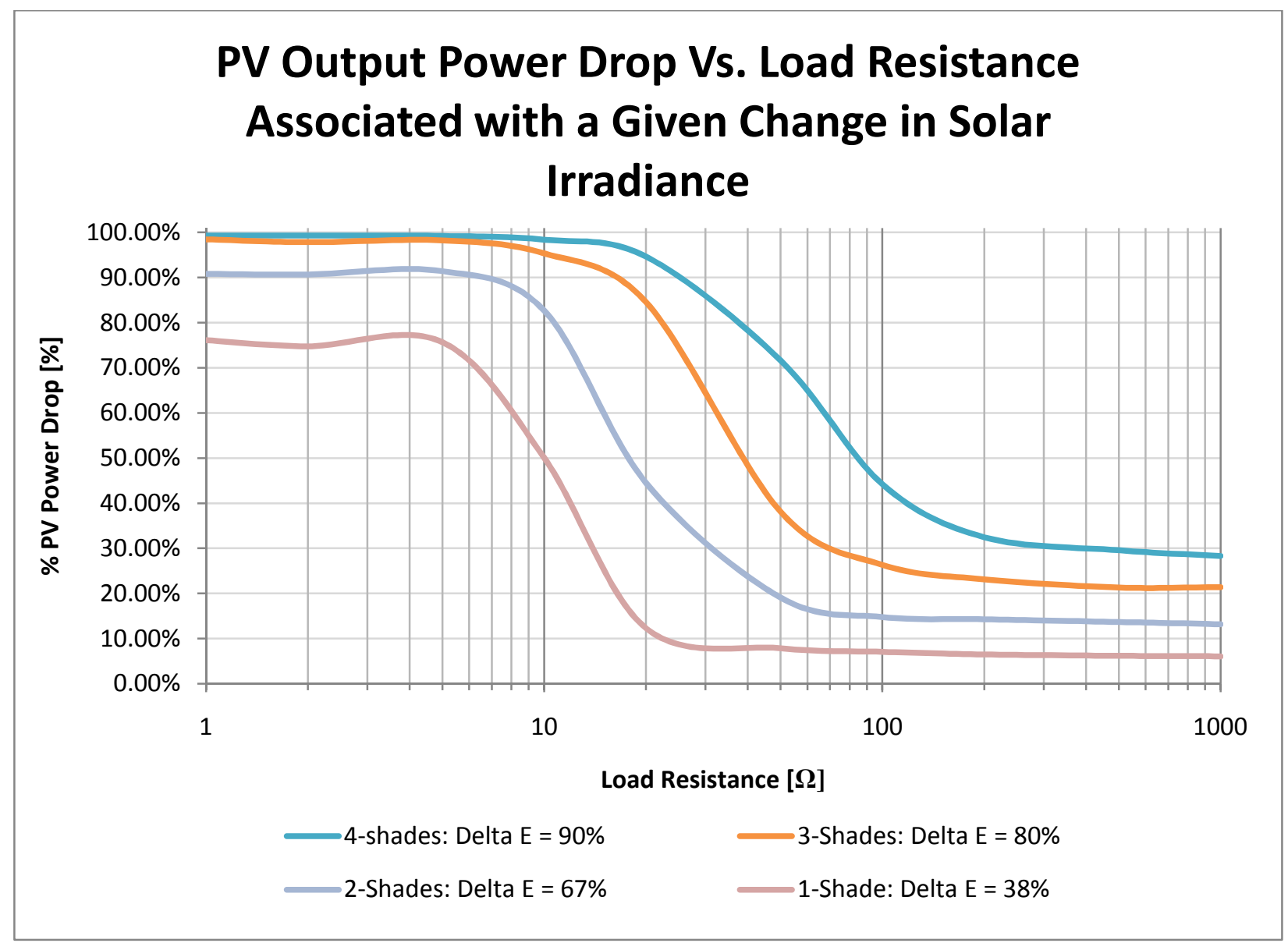

Figure II.17: Experimentally Measured Percent PV Power Drop Associated with the Number of Shade-Layers Used Over a Range of Load Resistance. Experimental data associated with this Figure is located in Appendix C.

Figure II.17 portrays the affect that the number of shade-layers and the load resistance have on a percentage of PV power dropped. Delta E refers to the percentage drop in solar irradiance associated with the number of shade-layers implemented for each test. (i.e. The 4-shade-layers test produces a drop in solar irradiance of 90\%). Experimental Data associated with Figure II.17 
is located in Appendix C. For a fixed number of shade-layers, the PV power drop curves follow a rather identical pattern over the entire range of resistive loads with only minor deviations. As the number of shades decrease, the maximum PV power drop and the PV power drop corresponding to large-resistance loads decrease as well. The linear portion of the PV power drop curve is also shifted right as the number of shades is increased.

The power drop curves follow the outcomes described in the previous subsection. The power drop percentage is maximum for the load resistance (between $1 \Omega$ and $11 \Omega$ ) that operates on the initial I-V curve at the maximum power point, while the ending I-V curve operating point resides at a current close to the short circuit current. As the resistance increases, the PV power drop decreases until the load resistance reaches between $12 \Omega$ and $200 \Omega$, at which point the PV power drop percentage levels out. Such loads produce operating points on both starting and ending I-V curves near the open circuit voltages. These same loads also produce very little variance in current and a difference in voltage close to the difference in open-circuit voltages of both I-V curves. For this reason, the percentage of power drop does not change as the resistance increase above the $12 \Omega$ and $200 \Omega$ resistance.

\section{Overlapping Shades - PV Power vs. Solar Irradiance Drops}

For the case of 4 overlapping shades, the shaded amount of solar irradiance received by the PV module is only $10 \%$ of the nominal unshaded solar irradiance value. Therefore, such a scenario creates a 90\% solar irradiance drop between the unshaded and shaded solar irradiance conditions. For the 4 shade-layers test, the PV power drop percentages vary between $99.8 \%$ at low resistance loads and $28 \%$ at high resistance loads. 


\section{Overlapping Shades - PV Power vs. Solar Irradiance Drops}

With 3 overlapping shades, the shaded amount of solar irradiance received by the PV module is only $20 \%$ of the nominal unshaded solar irradiance value. Therefore, these conditions create a $80 \%$ solar irradiance drop between the shaded and unshaded conditions. For the 3 -shade-layers test, the PV power drop percentages vary between $99.78 \%$ at low resistance loads and $21 \%$ at high resistance loads.

\section{Overlapping Shades - PV Power vs. Solar Irradiance Drops}

For the case of 2 overlapping shades, the shaded amount of solar irradiance received by the PV module is only $33 \%$ of the nominal unshaded solar irradiance value. Therefore, such a scenario creates a $67 \%$ solar irradiance drop between the unshaded and shaded solar irradiance values. For the 2 shade-layers test, the PV power drop percentages vary between $91 \%$ for low resistance loads and $13 \%$ for high resistance loads.

\section{Shade - PV Power vs. Solar Irradiance Drops}

Lastly, with 1 shade, the shaded amount of solar irradiance received by the PV module is $62 \%$ of the nominal unshaded solar irradiance value. Therefore, these conditions create a $38 \%$ solar irradiance drop between the shaded and unshaded conditions. For the 1-shade-layer test, the PV power drop percentages vary between $76 \%$ at low resistance loads and $6 \%$ at high resistance loads.

E. Effect of Solar Irradiance Transients on a Grid-Connected PV System's Max Power Point Tracking Controls

While the scope of this paper was limited to characterizing PV-module power transients, such knowledge can also be applied to small- and medium-scale PV arrays, because the same 
principles apply. A drop in solar irradiance will not only affect the output power of a PV module, or PV array, but also the power supplied by the PV array's grid-connected inverter. While studying the effects of solar irradiance transients on grid-connected inverters would suffice for a thesis itself, this paper will briefly address how grid-connected PV systems are affected by solar irradiance variations.

Most grid-connected PV systems employ maximum power point tracking control systems (MPPT) to ensure that the PV panel operates at a point that produces maximum power generation. This operation point is known as the maximum power point (MPP). Nonetheless, maintaining a PV array near its MPP is a difficult feat when atmospheric conditions lead to variations in temperature and solar irradiance. Figure II.18 show the effect that solar irradiance and temperature have on a PV array's power, current, MPP operating points.

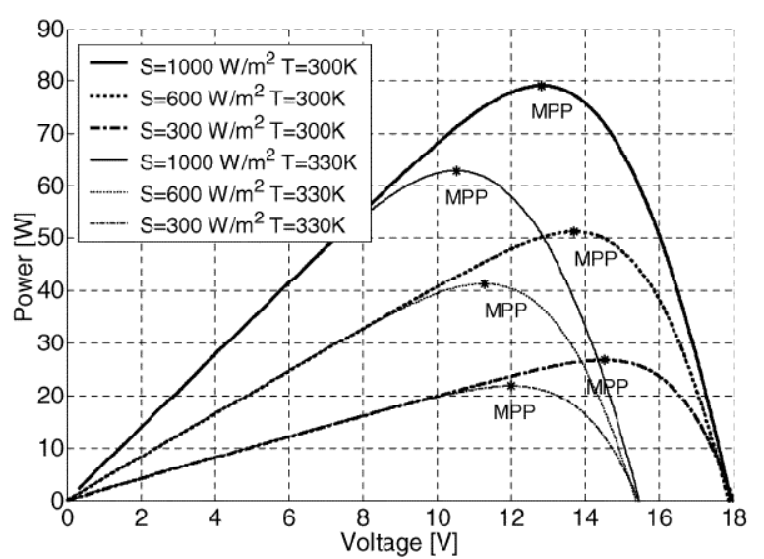

(a)

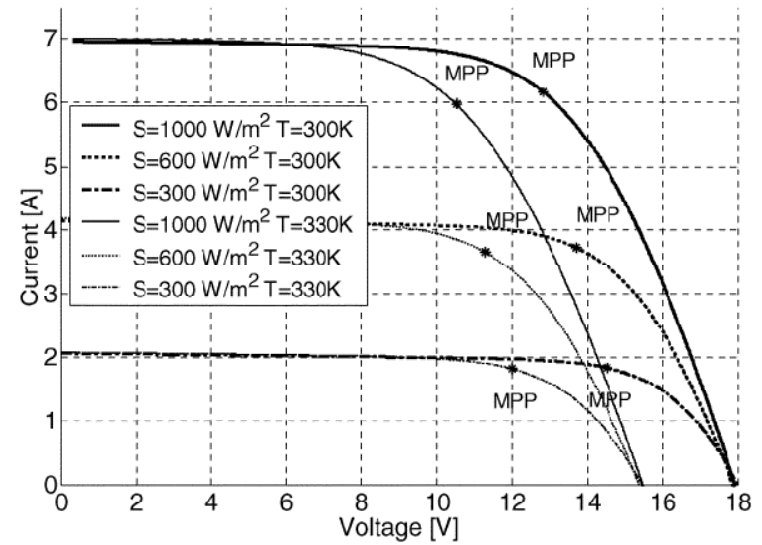

(b)

Figure II.18: PV Module Characteristics for 3 Solar Irradiance levels and 2 different panels' operating temperatures: (a) output power vs. voltage and (b) current vs. voltage [10]

Figure II.18 portrays that as the solar irradiance increases, the magnitude of maximum power increases, and the operating MPP voltage slightly decreases. Additionally, temperature affects the maximum power point of a given solar irradiance-driven power curve by decreasing the magnitude of power and reducing the voltage at which MPP occurs. 
MPPT controllers come in many varieties. Most MPPT controllers however implement either Perturb and Observe (P\&O) or Incremental Conductance (INC) techniques to control a PV array to operate around its MPP [10]. P\&O control techniques are most-widely used for PV systems for its ease in implementation [10]. This MPPT technique steps the PV operating voltage in a direction and measures a change in power. If the power increases, the controller continues to step the voltage in the same direction until the power decreases. When the change in power from one step to the next becomes negative, the $\mathrm{P} \& \mathrm{O}$ controller steps the voltage in the opposite direction. While such a control technique is simple in its approach, its disadvantage is that, at steady state conditions, the operating point of the PV array oscillates around the MPP. Such actions waste energy because the PV array never actually operates exactly at MPP, but instead jumps to operating points on either side of the MPP.

As an attempt to improve an MPPT control system's ability to operate at the MPP, INC control techniques where developed. Such techniques adjust the operating point of a PV array based on the fact that the derivative of the power vs. voltage curve equals zero at MPP. While such a control technique allows the PV array to more closely operate at MPP than P\&O techniques, the disadvantage of INC is its increase in hardware requirements, software complexity, and computational control system response time (slower sampling rate) [10].

Even so, both INC and P\&O methods are affected by solar irradiance transients because, a PV array's operating point can move away from the MPP instead of remaining close to it [10]. Figure II.19 shows how MPPT control systems respond to solar irradiance transients. 


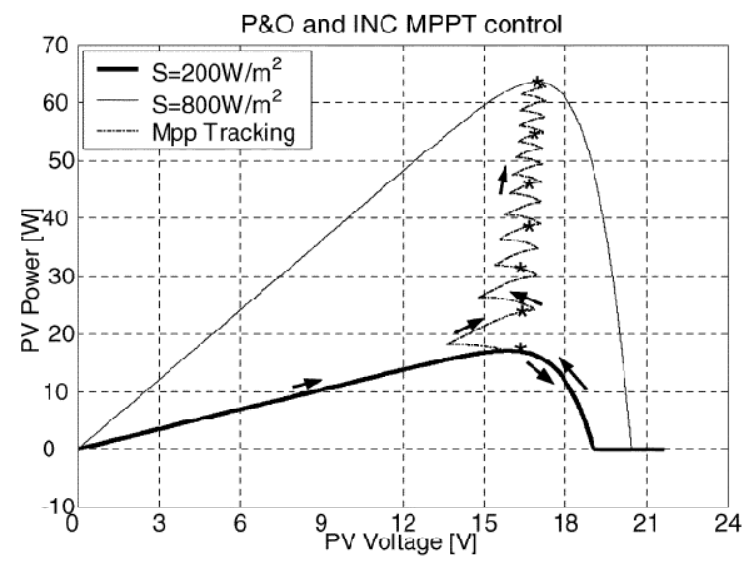

(a)

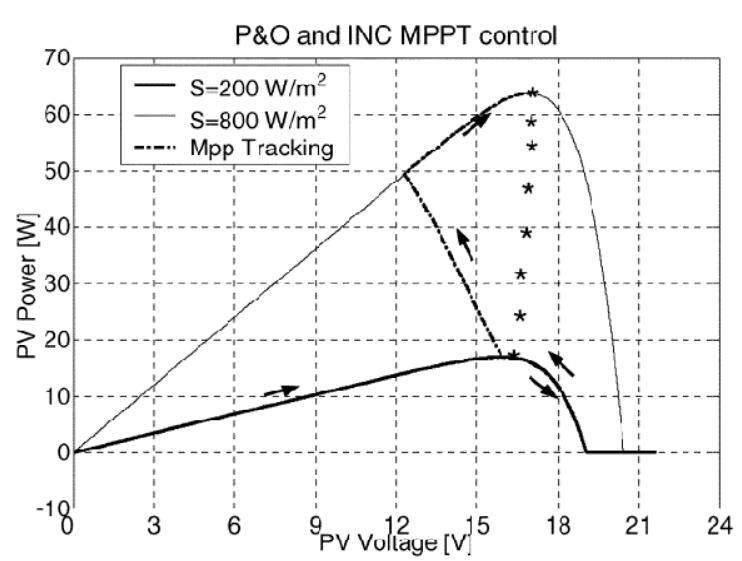

(b)

Figure II.19: P\&O and INC MPPT Operating Point Paths in Response to a Solar Irradiance Transient of $200 \mathrm{~W} / \mathrm{m}^{2}$ to $800 \mathrm{~W} / \mathrm{m}^{2}$. The * represents MPP points for different solar irradiance levels: (a) slow solar irradiance transient and (b) rapid solar irradiance transient [10].

Figure II.19 illustrates two scenarios where solar irradiance variation speeds affect the power response of a MPPT-controlled PV array. Figure II.19a shows a MPPT controlled PVarray's power output for a slow change in solar irradiance. If the change in solar irradiance is slow enough, the MPPT will increase the PV array's output power in jigsaw pattern as shown in Figure II.19a. This jigsaw pattern illustrates that the PV operating points oscillate around the max power points of various solar irradiance levels even as the solar irradiance slowly increases. Therefore, slow variations in solar irradiance do not cause the MPPT control system to venture out of reasonable distance from MPP points as the solar irradiance changes.

On the other hand, rapid changes in solar irradiance can cause a MPPT-controlled PV array's operating points to venture way outside the vicinity of the solar-irradiance-dependent maximum power points. (Note that MPP points of Figure II.19 are signified by the * symbols) When the MPPT control system steps the voltage of the PV array back toward the initial curve's MPP point, a rapid increase in solar irradiance occurs. With a quick increase in solar irradiance, the power outputted by the array will increase. Therefore, the controller is fooled into believing that 
it is traveling in a path leading to the maximum power point of its curve. However, while decreasing the voltage still increases the power output of the PV array, the MPPT controller moves the PV array's operating point further and further from the maximum power point. It is not until the solar irradiance levels reach steady-state that the MPPT can follow the steady-state power curve back to MPP.

Quick solar irradiance changes not only can confuse MPPT trackers, they can also possibly lead a PV array to operate at voltages outside the inverter's DC operating ranges. As was the case with Figure II.19b, when the solar irradiance rapidly increased, the MPPT control system continued to decrease the operating voltage of the PV array. As the increasing solar irradiance ramp continued to increase, the PV output power also increased. In some cases, MPPT controllers can drop PV operating voltages outside the inverter's operating DC voltage range. This scenario, in turn, would force the inverter to shutdown and discontinue supplying power to the power system [11].

As a result of such a scenario, large step changes in PV output power can take place from simultaneous inverter tripping. Such inverter-tripping-induced PV power changes often exceed the size and severity of any cloud-induced PV power fluctuations [2]. Investigating the effect of such a scenario would provide a thesis topic in itself. While such knowledge would be very important, the scope of this thesis limits its focus to the effects that cloud-induced solar irradiance variations' have on PV power output, and power system protection reliability.

The change in MPPT-controlled PV power operating conditions for a change in solar irradiance was simulated with the assumption that a MPPT controller follows the maximum power points rather closely from one solar irradiance power curve to the next for a given change in solar irradiance (See Figure II.20). In Figure II.20, the red curve represents the power vs. 
voltage curve for the initial solar irradiance value of $1000 \mathrm{~W} / \mathrm{m}^{2}$, the green curve represents the power vs. voltage curve for the final solar irradiance value and the five dashed curves show five, incremental power vs. voltage curves between the starting power curve (red) and the ending power curve (green). Recall that the percentage PV power drop is calculated using the following equation:

$\% P_{\text {drop }}=\frac{\left|P_{\text {unshaded }}-P_{\text {shaded }}\right|}{P_{\text {unshaded }}} \cdot 100 \%$

This equation was used to determine the percentage PV power drop for a MPPT-controlled PV system for a given drop in solar irradiance. The magnitude of solar irradiance drop was varied and the corresponding percentage of PV power drop was simulated. Table II.4 and Figure II.21 illustrate the simulated results. 


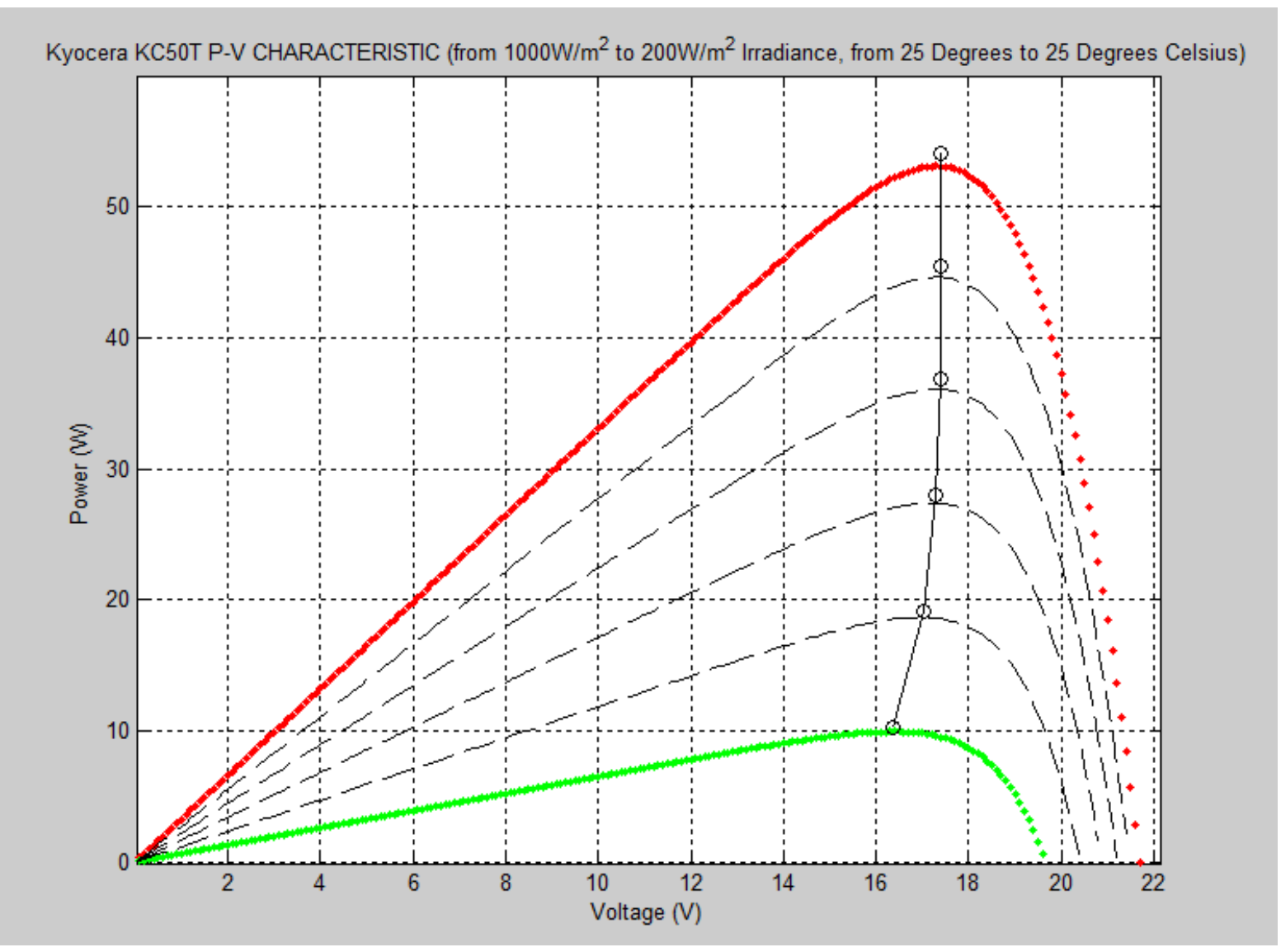

Figure II.20: Simulated Change in PV Output Power from the Max Power Point of the Starting Solar Irradiance Curve to the Max Power Point of the Ending Solar Irradiance Curve.

Figure II.20 shows a simulation of a MPPT-controlled PV module and its operating power vs. voltage path as the solar irradiance changes from an unshaded, full-sun value of 1000 $\mathrm{W} / \mathrm{m}^{2}$ to a shaded solar irradiance level of $200 \mathrm{~W} / \mathrm{m}^{2}$. This simulation portrays several incremental power vs. voltage curves for the Kyocera KC50T PV module: The red curve denotes the P-V characteristic curve for the starting solar irradiance value of $1000 \mathrm{~W} / \mathrm{m}^{2}$. Similarly, the green curve represents the $\mathrm{P}-\mathrm{V}$ characteristic curve for the ending solar irradiance value of 200 $\mathrm{W} / \mathrm{m}^{2}$. The dashed black curves represent incremental power vs. voltage curves to show the transition from the starting curve to the ending curve. Black circles symbolize max power points for each power vs. voltage curve. Additionally, the solid black curve illustrates the average PV 
operating-point path of the MPPT-controlled PV module for a drop in solar irradiance from 1000 $\mathrm{W} / \mathrm{m}^{2}$ to $200 \mathrm{~W} / \mathrm{m}^{2}$. The PV system starts at the red curve's max power point and travels down the black line to the green curve's max power point as the solar irradiance drop from its unshaded solar irradiance value to its shaded solar irradiance value. This simulation assumed that the change in solar irradiance was not drastic enough to cause the operating point of the PV module to stray far from the maximum power points as the solar irradiance changed the power vs. voltage curve from one curve to the next.

In addition to the simulation of Figure II.20, the change in PV module power from one max power point to the next max power point was simulated for various changes in solar irradiance. Table II.4 and Figure II.21 show the relationship between a MPPT-controlled PV power change and its associated solar irradiance change. Such simulation results assumed that the change in solar irradiance occurred uniformly across the entire PV system.

Table II.4: Simulated Results for a MPPT-controlled PV System's Percentage Power Drop for an Associated Drop in Solar Irradiance.

\begin{tabular}{|r|r|r|r|r|r|r|r|}
\hline Estart [W/m^2] & Eend [W/m^2] & Edrop [W/m^2] & Edrop [\%] & Pmpp-start [W] & Pmpp-stop [W] & Pdrop [W] & Pdrop [\%] \\
\hline 1000 & 1000 & 0 & $0.0 \%$ & 54.114 & 54.114 & 0.00 & $0.0 \%$ \\
\hline 1000 & 900 & 100 & $10.0 \%$ & 54.114 & 48.76020235 & 5.35 & $9.9 \%$ \\
\hline 1000 & 800 & 200 & $20.0 \%$ & 54.114 & 43.36424975 & 10.75 & $19.9 \%$ \\
\hline 1000 & 700 & 300 & $30.0 \%$ & 54.114 & 37.92616982 & 16.19 & $29.9 \%$ \\
\hline 1000 & 600 & 400 & $40.0 \%$ & 54.114 & 32.44672606 & 21.67 & $40.0 \%$ \\
\hline 1000 & 500 & 500 & $50.0 \%$ & 54.114 & 26.92805526 & 27.19 & $50.2 \%$ \\
\hline 1000 & 400 & 600 & $60.0 \%$ & 54.114 & 21.37500769 & 32.74 & $60.5 \%$ \\
\hline 1000 & 300 & 700 & $70.0 \%$ & 54.114 & 15.79832139 & 38.32 & $70.8 \%$ \\
\hline 1000 & 200 & 800 & $80.0 \%$ & 54.114 & 10.22367484 & 43.89 & $81.1 \%$ \\
\hline 1000 & 100 & 900 & $90.0 \%$ & 54.114 & 4.727931249 & 49.39 & $91.3 \%$ \\
\hline
\end{tabular}




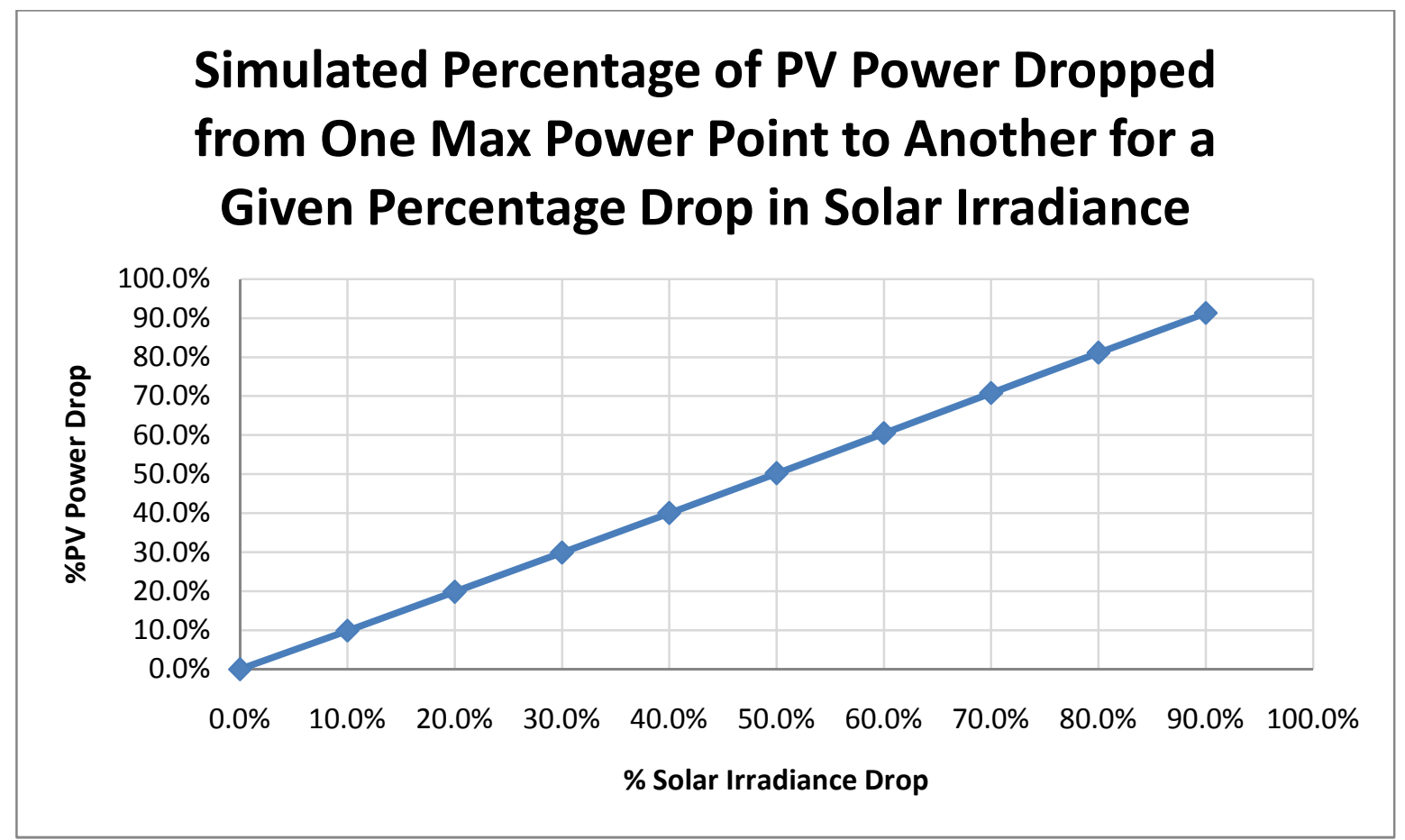

Figure II.21: Simulated Percentage of MPPT-controlled PV Power Drop for a Given Percentage Drop in Solar Irradiance.

Table II.4 and Figure II.21 illustrate the simulated PV power drop associated with a given drop in solar irradiance. The starting, unshaded, full-sun solar irradiance value was $1000 \mathrm{~W} / \mathrm{m} 2$ and the amount of solar irradiance drop was varied from $0 \%$ to $90 \%$. The associated change in PV drop was calculated as the difference between the unshaded max power point power value and the shaded max power point power value. Recall that a MPPT-control system strives to maintain its PV system's operating point at its maximum power point. A change in solar irradiance will not only change the power-voltage curve that the PV system operates on, but also the max power point that the MPPT-controller searches for. Therefore, the change in PV power will be the change power from one solar irradiance determined max power point to another solar irradiance dependent max power point. With the assumption that a drop in solar irradiance occurs uniformly across an entire PV system, the simulated results of Table II.4 and Figure II.21 
portray a 1 to 1.004 linear relationship between the amount of solar irradiance drop and the magnitude of power drop from one MPP to the other.

While such an assumption that a change in solar irradiance occurs uniformly across the entire PV system has been used to simulate a PV system's associated power drop for a change in solar irradiance in this paper as well as references [3], [4], [9], [10], [11], and [16], new research proves that such assumptions do not apply to larger PV systems. The next section will explain that larger PV systems exhibit a smaller PV power drop than the associated drop in solar irradiance. Factors such as the size of a PV system's surface-area, and the size, speed and height of a cloud affect the amount of PV power variation. Therefore, the relationship between solar irradiance drop and PV power drop is not 1:1.004 for large-scale PV systems as was the simulated case for this section.

\section{F. Effects of Varying Solar Irradiance on Large Scale PV Generation}

With the many random fluctuations in atmospheric conditions that occur frequently from day to day, there are innumerable uncertainties and variations involved in the operating conditions of PV generation. Variations in atmospheric conditions can not only lead to large changes in solar irradiance, but can also significantly vary PV power output. Recent research sheds light on the effects that solar irradiance variation has on large-scale PV output.

However, before addressing such effects, one must understand how clouds produce variations in solar irradiance over a given surface area. When a cloud travels in front of the sun, it produces a shaded region on the surface of the earth. Depending on the size of the PV array, and the speed, height, and density of the passing cloud, the effect that a cloud's shadow has on a PV array can vary. Therefore, especially with large-scale PV plants, which are spread over large surface areas, there are many unknowns about the effects that a cloud's shade has on a PV 
array's received solar irradiance and output power response. The larger the array, the larger the cloud's shade must become to have a significant effect on the PV array's power generation levels. For PV systems in the 100's of MW, for example, the time it takes to shade the entire system is on the order of minutes, rather than seconds [2].

In addition, references [2], [3], and [11] note that the tendency of clouds to modulate solar irradiance is not well documented and understood. Reference [11] denotes that studies of the dynamic behavior of PV systems should be conducted for time increments of seconds and minutes. Such investigations, however, have not been given much study. Reference [2], on the other hand, exhibits that times scales of seconds to hours should be used to best understand the dynamic variations in large-scale PV plant power generation.

However, no matter what time base is implemented, not much research has been done on large-scale PV power plants. As this paper has previously mentioned, while solar irradiance variations produce large fluctuations rather quickly, there is an inherent time delay and reduction in PV output power variation. Reference [2] refers to a PV array's ability to dampen and prolong such variations as a PV array's "ramp smoothing" property. Thus, the results of this thesis have been confirmed with recent Moreover, a PV plant is often more diverse and spread out over a larger surface area, while a solar insolation meter is often relatively confined to a single-point measurement. Thus, the diversity and spacious quality of PV arrays tends to smooth the PV output power ramp when compared to a solar irradiance ramp [2]. Additionally, this paper earlier found that the electrical properties of a PV module tend to produce an inherent time delay. Still, while some research within this field of study has been conducted for small-scale PV plants, large-scale PV plants have not yet received much study. Figure II.22 shows recently discovered 
knowledge about the smoothing effect of PV arrays. This figure compares solar irradiance ramps to PV plant power ramps over various time increments.
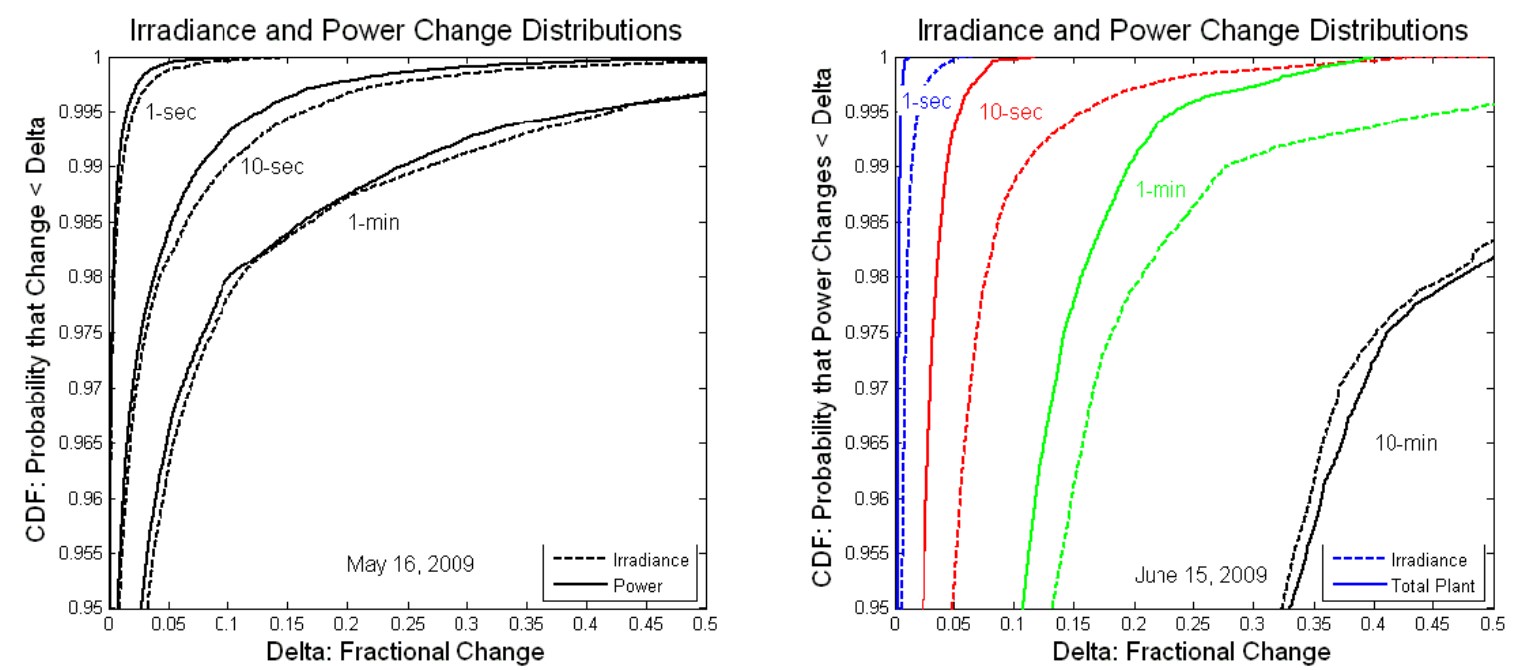

Source: Joshua Stein, Sandia National Laboratories, adapted from presentation at the PV Variability Workshop

Figure II.22: Cumulative Distributions of Irradiance and PV power changes over various time increments from a $30 \mathrm{~kW}$ PV system (Left) and a multi-MW PV system (Right) [2]

Comparison of the variability of a 30kW PV power plant and an insolation meter (Figure II.22 - Left) show that the 1 second and 10 second PV power ramps are less drastic than irradiance ramps. However, for 1 minute ramps, the insolation meter's solar irradiance ramps and the 30kW PV array's power ramps are almost identical.

On the other hand, comparison of a multi-MW PV plant's power ramps with an insolation meter's ramps (Figure II.22 - Right) shows an even greater smoothing effect between the PV array and the insolation meter than was the case for the 30kW PV plant. Thus, larger PV arrays introduce less variability in output power than smaller PV arrays and insolation meters. This is true because of comparatively wide-spread surface area required for large-scale PV plants. Moreover, as the measured time increment increases, the smoothing factor between the insolation meter and the PV array decreases. Thus, for long, gradual, large variations in solar irradiance, the PV array's power ramp will closely follow the measured solar irradiance ramp. 
All in all, while there are many unknowns and uncertainties about the dynamic variability of PV generation, research is characterizing fluctuations in solar irradiance and PV power response one small step at a time. Rapid, large changes in solar irradiance lead to more prolonged, reduced changes in PV output power. Even though the magnitude and speed of PV power variation does not compare to the degree of cloud-induced solar irradiance changes, such fluctuations in solar irradiance alter the operating characteristics of a PV system. Operating conditions affected by solar irradiance changes include output voltage, supplied current, and output power. The effects that PV output variations have on inverter harmonic generation and the reliable operation of power systems and power protection will be investigated in the next two chapters of this paper.

Nonetheless, this section helped to better characterize the solar irradiance transients as well as PV power transients. From months of NREL solar irradiance data, the maximum change in solar irradiance for different time increments were determined. Additionally, the time-delayed output power response of a PV module to a stepped-change in solar irradiance was experimentally resolved so as to better characterize a PV module's output power response time for a change in solar irradiance. The degree of PV power variation for various magnitudes of solar irradiance changes and a wide-range of load resistances were simulated and experimentally determined. Such studies shed light on how a PV module's load affects the amount of power variation for a given change in solar irradiance. Additionally, solar irradiance changes were evaluated for their effect on MPPT-controlled PV systems to determine the relationship between changes in PV power from one maximum power point to another to fluctuations in solar irradiance. Lastly, this section illustrated recent experimental finding about the relationship between solar irradiance transients and associated PV power ramps. With the introduction of larger PV systems on the power grid, new experimental discoveries are now revealing that the 
magnitude of PV power variation is slightly less than the measured change in solar irradiance for solar irradiance transients in the 1 to 10 second range. Such knowledge is useful because the majority of past research assumed that a change in solar irradiance, led to a comparable change in PV power. While this paper could not confirm such new research finding due to a limitation of resources, such knowledge is important to understand and therefore, was included in this paper. 


\section{PV Inverter Harmonic Distortion}

In an ideal world, the electric grid would possess unadulterated voltage and current sinusoidal waveforms. These ideal waveforms would oscillate at the designed fundamental frequency, which in the United States is $60 \mathrm{~Hz}$. In reality, however, the electric grid's voltage and current waveforms are distorted due to harmonics. Harmonics are sinusoidal voltages and currents which oscillate at multiples of the fundamental frequency. Harmonics coincide with the fundamental waveform to produce a distorted waveform. Power Electronics, non-linear loads, and even generators contribute to the harmonic content within a power system.

No matter how distorted a waveform may be, it can always be represented as a sum of the fundamental sine wave in addition to all of the other harmonic sinusoidal waveforms. An ideal wave is only comprised of a single sinusoidal waveform that oscillates at the fundamental frequency. On the other hand, distorted waveforms contain a fundamental sinusoid but also contain sinusoidal waveforms that oscillate at multiples of the fundamental frequency.

For example, an ideal waveform would take on the form of:

$i(t)=\sqrt{2} V_{1} \sin (2 \pi t) \quad A$

An ideal current waveform is represented in the example equation below and plotted in Figure III-1:

$i_{\text {ideal }}(t)=1.0 \sin (377 t) \quad A$ 


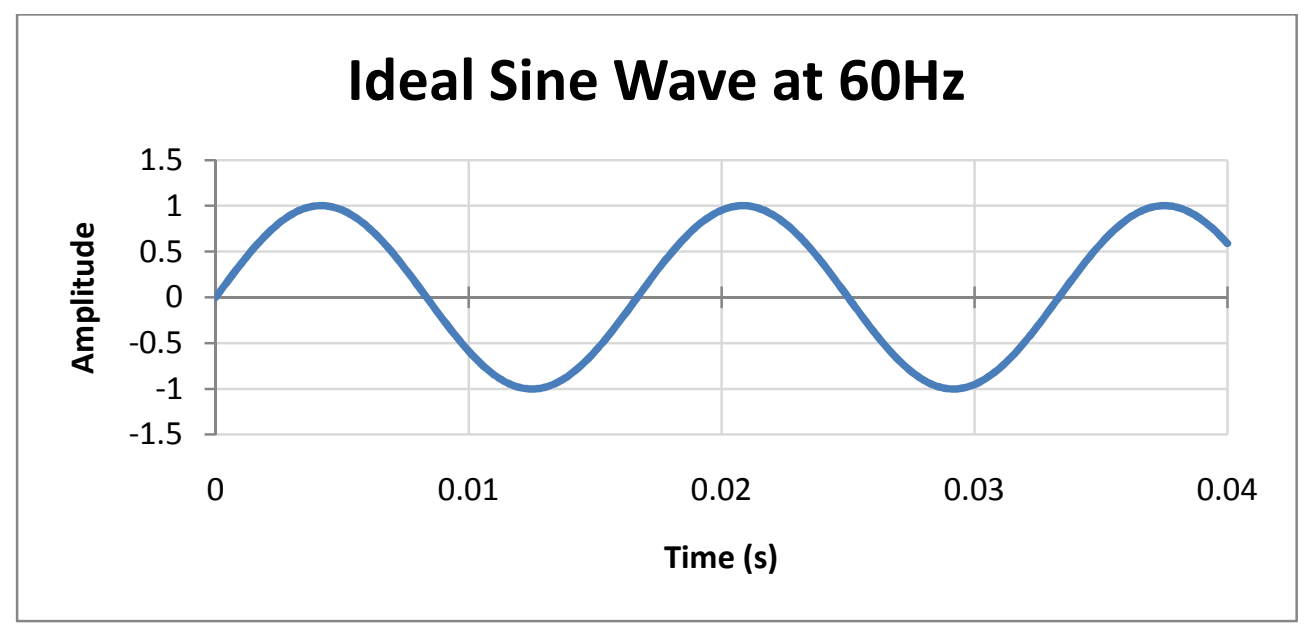

Figure III.1: Ideal Non-distorted Sinusoidal Waveform

However, research shows that voltage and current waveforms are comprised of their fundamental sine wave as well as several harmonic sinusoids.

A distorted waveform would take the form:

$$
i(t)=\sum_{h=1}^{\infty} \sqrt{2} V_{h} \sin \left(h\left[2 \pi f_{o} t\right]\right) \quad A
$$

NOTE: $h$ represents the harmonic number, $f_{o}$ represents the fundamental frequency $(60 \mathrm{~Hz})$, and $\sqrt{2} V_{h}=$ the amplitude of the harmonic sinusoid. Also make note that $\mathrm{h}=1$ represents the fundamental sinusoid because it oscillates at the fundamental frequency. An example of a distorted waveform is shown below:

$$
i(t)=0.55 \sin (377 t)+0.3 \sin (1131 t)+0.1 \sin (1885 t)+0.05 \sin (2639 t) \quad A
$$

This waveform, $\mathrm{i}(\mathrm{t})$, and each of its harmonic components are represented in the following figure: 


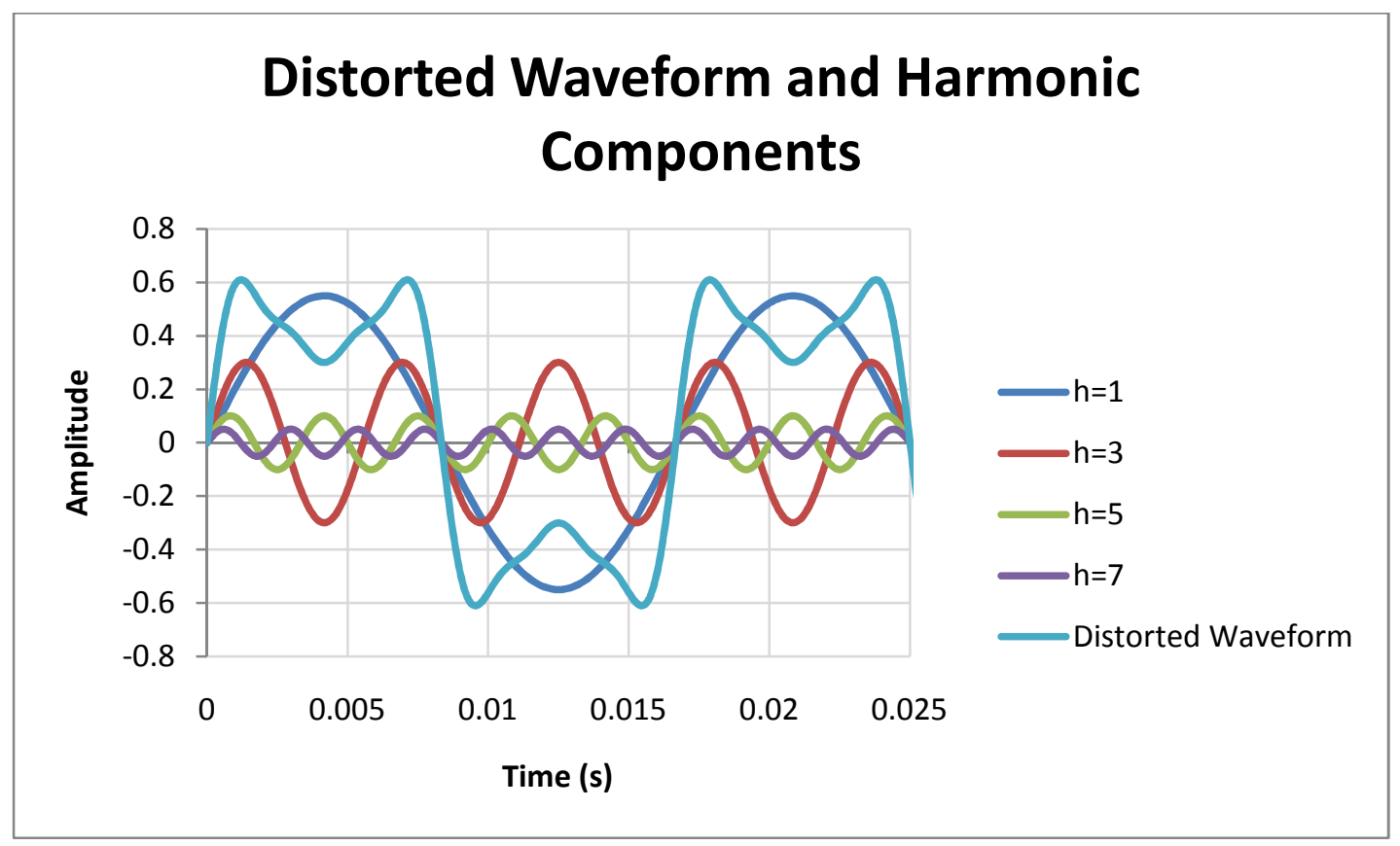

Figure III.2 Distorted Waveform and its Harmonic Sinusoidal Components

It is, however, important to note how frequency changes as the harmonic sinusoid

number changes. The distorted waveform, as a sum of all of its harmonic components, no longer takes on the ideal shape of a sine-wave but instead is more m-like. This distorted waveform, like any other waveform distorted by harmonics, can be harmful to components on the electric grid system, as this paper will further discuss.

One method of quantifying waveform distortion is known as total harmonic distortion, or THD. THD is commonly used to describe the amount of distortion a waveform may have, however, it lacks the description as to the origin from which harmonics originate.

THD is calculated using the following equation:

$$
T H D=\frac{\sqrt{\sum_{h=2}^{\infty} I_{h R M S}^{2}}}{I_{1 R M S}}
$$

Recall our distorted waveform:

$$
i(t)=0.55 \sin (377 t)+0.3 \sin (1131 t)+0.1 \sin (1885 t)+0.05 \sin (2639 t)
$$


The THD for $\mathrm{i}(\mathrm{t})$ will be:

$$
T H D=\frac{\sqrt{(0.3 / \sqrt{2})^{2}+(0.1 / \sqrt{2})^{2}+(.05 / \sqrt{2})^{2}}}{(0.55 / \sqrt{2})}=0.582=58.2 \%
$$

The amount of distortion is clearly represented by a percentage, however this percentage by itself does not tell us which harmonics contribute to the waveform's distortion and the magnitude each harmonic contributes to a waveform's distortion. For instance, a current waveform may have a THD of 7\%, however it is unclear whether the $7 \%$ distortion comes only from a $3^{\text {rd }}$ harmonic or if that distortion is derived from a vast spectrum of harmonic sinusoids. Thus, because THD does not describe the distortion contributions from harmonic components, IEEE standard 519-1992 has determined harmonic and THD standards to ensure that a power system operates within acceptable ranges. These standards are listed in Tables III.1 and III.2.

Table III.1: IEEE 519 Current Distortion Limits [1]

Table 10.3

\section{Current Distortion Limits for General Distribution Systems $(120 \mathrm{~V}$ Through $69000 \mathrm{~V}$ )}

\begin{tabular}{|c|c|c|c|c|c|c|}
\hline \multicolumn{7}{|c|}{$\begin{array}{l}\text { Maximum Harmonic Current Distortion } \\
\text { in Percent of } I_{\mathrm{L}}\end{array}$} \\
\hline \multicolumn{7}{|c|}{ Individual Harmonic Order (Odd Harmonics) } \\
\hline$I_{\mathrm{sc}} / I_{\mathrm{L}}$ & $<11$ & $11 \leq h<17$ & $17 \leq h<23$ & $23 \leq h<35$ & $35 \leq h$ & TDD \\
\hline$<20^{*}$ & 4.0 & 2.0 & 1.5 & 0.6 & 0.3 & 5.0 \\
\hline $20<50$ & 7.0 & 3.5 & 2.5 & 1.0 & 0.5 & 8.0 \\
\hline $50<100$ & 10.0 & 4.5 & 4.0 & 1.5 & 0.7 & 12.0 \\
\hline $100<1000$ & 12.0 & 5.5 & 5.0 & 2.0 & 1.0 & 15.0 \\
\hline$>1000$ & 15.0 & 7.0 & 6.0 & 2.5 & 1.4 & 20.0 \\
\hline \multicolumn{7}{|c|}{ Even harmonics are limited to $25 \%$ of the odd harmonic limits above. } \\
\hline \multicolumn{7}{|c|}{$\begin{array}{l}\text { Current distortions that result in a dc offset, e.g., half-wave converters, are not } \\
\text { allowed. }\end{array}$} \\
\hline \multicolumn{7}{|c|}{$\begin{array}{l}\text { *All power generation equipment is limited to these values of current distortion, } \\
\text { regardless of actual } I_{\mathrm{sc}} / I_{\mathrm{L}} \text {. }\end{array}$} \\
\hline \multicolumn{7}{|c|}{ where } \\
\hline \multicolumn{7}{|c|}{$\begin{array}{l}I_{\mathrm{sc}}=\text { maximum short-circuit current at PCC. } \\
I_{\mathrm{L}}=\text { maximum demand load current (fundamental frequency component) at } \\
\text { PCC. }\end{array}$} \\
\hline
\end{tabular}


Table III.2: Voltage Distortion Limits [1]

\begin{tabular}{ccc}
\hline \hline Bus Voltage at PCC & $\begin{array}{c}\text { Individual Voltage } \\
\text { Distortion (\%) }\end{array}$ & $\begin{array}{c}\text { Total Voltage } \\
\text { Distortion THD (\%) }\end{array}$ \\
\hline $69 \mathrm{kV}$ and below & 3.0 & 5.0 \\
$69.001 \mathrm{kV}$ through $161 \mathrm{kV}$ & 1.5 & 2.5 \\
$161.001 \mathrm{kV}$ and above & 1.0 & 1.5 \\
\hline \hline
\end{tabular}

Tables III.1 and III.2 demonstrate the distortion limits for both voltage and current waveforms. Notice how IEEE not only provided THD limits but also distortion limits for individual components so as to address THD's vagueness in describing harmonic contribution toward waveform distortion.

\section{A. Harmonic Effects on the Power System}

Harmonics of different frequencies can have ranging adverse effects on a power system. Harmonics can affect many components of the power system including transformers, conductors, circuit breakers, etc...

Triplen Harmonics, which are harmonics, whose harmonic numbers are multiples of 3 (i.e. $\mathrm{h}=3^{\text {rd }}, 6^{\text {th }}, 9^{\text {th }}, 15^{\text {th }}$, etc...), are specifically harmful harmonics to the power system, because they produce zero sequence current [12]. Current with triplen harmonic content causes many problems with power system grounding, because it causes current to flow through the neutral wire. The zero-sequence currents for a three-phase power system are all in phase, while positivesequence and negative-sequence currents are $120^{\square}$ or 240 apart from phase to phase. When all three phases' positive-sequence currents combine, the combined positive-sequence current's magnitude is less than that of the positive-sequence current from each phase. Likewise, negative sequence currents share the same property. On the other hand, when all three phases' zerosequence currents combine, they can produce a combined zero-sequence current, whose magnitude is larger than a zero-sequence current flowing through just one phase. It is in the 
neutral wire of a grounded three-phase power system that these zero sequence currents combine. The more triplen harmonic content supplied to a power system, the more zero-sequence current that will travel through the neutral wires. Enough triplen harmonic generation could exceed some neutral conductor ratings. Additionally, unlike phase conductors, ground conductors do not usually contain circuit breaker protection. Therefore, for excessive current flowing through a neutral conductor, a breaker cannot open to protect the neutral conductor from damage. To prevent exceeding neutral conductor current ratings, the neutral conductor should possess ampacity capabilities of twice that the phase conductor [13]. While sizing the neutral conductor correctly may solve exceeding current ratings, triplen harmonics may also lead to nuisance grounding relay tripping. In many cases, neutral wires are often examined by grounding relays in search of ground faults within a power system. Excessive triplen harmonics within a power system could produce enough zero sequence current to influence a grounding relay to trip the phase circuit breakers even though a ground fault may not have occurred [14].

Neutral conductors are not the only conductors affected by harmonics within a power system. Any conductor that carries current with harmonic content will experience additional heating because high frequency harmonic currents can lead to additional power losses than lower frequency currents of equivalent magnitudes. This is true because conductor impedance increases with frequency due to the skin effect [12]. Additionally, if a line conductor is carrying rated current at the fundamental frequency and that current also contains harmonic content, then the total current traveling through the line conductor will exceed the current rating. This additional current can lead to larger voltage drops as the current travels down the line, which may lead to voltage regulation problems within the power system. 
Harmonics also affect capacitors and transformers within a power system. Capacitors are often used to improve power factor and voltage by supplying reactive power to the power system. They do not produce harmonics, but they do produce resonance with other inductances present in the power system. If a harmonic frequency occurs near the resonant frequency, the capacitors may amplify that harmonic current or voltage created by nonlinear loads [12]. Additionally, a capacitor's reactance decreases as frequency increases. Therefore, at higher frequencies, a capacitor's reactance becomes very small. For this reason, larger high-frequency harmonic currents tend to sync into capacitor banks and cause overheating and higher dielectric stress [13].

Similar to capacitors, transformers can also contribute to resonant frequency harmonic current amplification. Transformers have an inherent inductance that interacts with the capacitance of surrounding capacitor banks to produce a resonant frequency. As stated before, harmonics that oscillate at a frequency near this resonant frequency will be amplified and can cause large voltage drops, power losses, and overheating to equipment within the surrounding area. Additionally, similar to conductors, harmonics affect transformers by increasing their electrical and magnetic losses. Harmonic also affect transformers by producing additional hysteresis losses, proportional to frequency, eddy current losses, proportional to frequency squared, and additional copper and steel losses [12].

\section{B. Harmonics Produced by Inverters:}

According to IEEE standard 519, single-phase inverters used for distributed generation are usually rated less than $10 \mathrm{~kW}$ and usually do not cause harmonic problems in small numbers. However, if large numbers of inverters are tied to the same feeder and their harmonic content is excessive enough, then problems may begin to arise [1]. On the other hand, 3-phase inverters 
used for distributed generation, usually run in the size of $10 \mathrm{~kW}$ to $1 \mathrm{MW}$. Inverters of this type are much more likely to introduce unacceptable waveforms within a power system if their harmonics are large enough [1]. Additionally, unbalanced line voltages, unbalanced phase separation, harmonics produced by the surrounding electric utilities, and line impedances all tend to affect the harmonics that an inverter contributes to a power system.

While it is critical to evaluate whether these unfavorable characteristics of a power system would influence an inverter to produce unacceptable harmonic levels within a power system, this paper focuses on whether cloud cover would affect a photovoltaic array's inverter to produce harmonics and THD levels that would exceed IEEE 519-1992 standards.

\section{Inverter Harmonic and THD Testing}

As previously mentioned in this paper, the amount of solar irradiance that hits a photovoltaic array affects the amount of power that the photovoltaic array can produce and supply to the electric grid system. However, most large scale photovoltaic array systems have an intermediate voltage regulation stage that connects between the DC output of the PV array and the DC input of the inverter. This voltage regulation stage can take on many different variations and topologies, but the main purpose of this intermediate stage is to regulate the voltage and operate the PV array around its max power point voltage so as to extract the maximum power from the PV array for any solar irradiance level. A diagram of a grid-connected PV system with intermediate voltage regulation is shown in Figure III.3. 


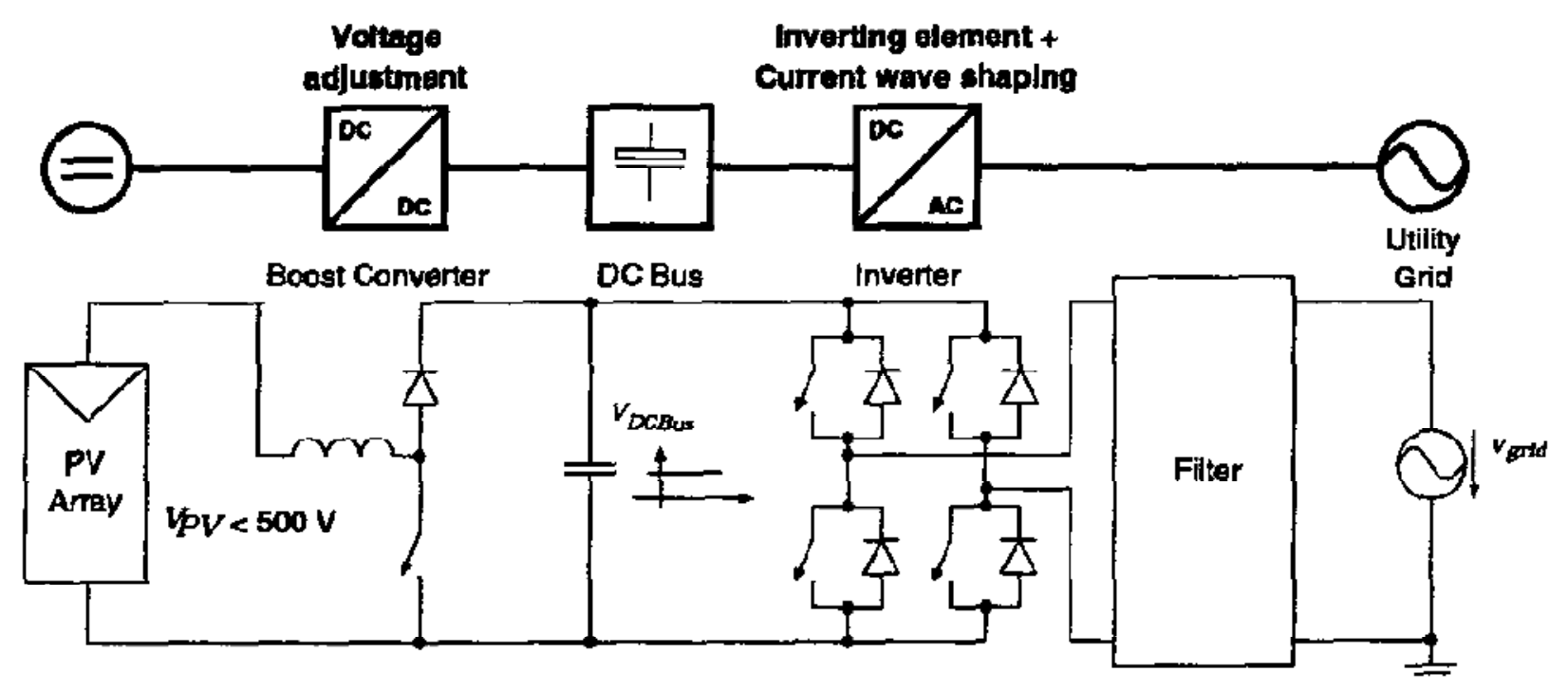

Figure III.3: Diagram of a Grid-Connected PV System [15]

For a system like that in Figure III.3, the inverter input DC voltage will remain rather constant even if the PV voltage and power, which are supplied to the input of the boost converter, may vary due to variations in solar irradiance. Other grid connected PV systems, such as residential PV systems on the other hand, do not have an intermediate voltage regulation stage, but instead the PV array connects directly to the input of the inverter. This type of system, however, will only operate if the PV supplied voltage lies within the input DC voltage range specified by each inverter. A change in solar irradiance, for example, might not only drop the output power of a PV array, but might also drop the operating voltage that the PV array supplies to the inverter.

All in all, this section will study the effect that input DC voltage and power supplied to PWM true-sine-wave inverter has on the inverter's production of harmonic content and total harmonic distortion.

According to [16], although a PV array is a constant current source and a DC generator is a constant voltage source, a DC generator can be used to simulate a PV array and its solar irradiance fluctuation-driven power changes by variation of the field of a DC generator. [16] ran 
an experiment to compare the power factor $(\mathrm{PF})$ of inverter output power connected to a PV array to the inverter output power factor of an inverter connected to a DC generator at different supplied power levels. His results concluded that both generation systems were very similar over the vast range of their power generation capabilities. For this reason, a DC generator was used to measure the effects of input voltage and power supplied to an inverter on its production of THD and Harmonic Magnitudes for its voltage and current waveforms.

Limited by resources, rather than testing a grid-connected inverter, this paper studied the harmonic content and THD of a non-grid connected inverter, whose specifications and operating characteristics are very similar to its grid-connectable counterpart. The inverter tested was a 3600VA Outback VFX3524 Inverter with a DC input voltage range of 21-34V and an AC output RMS voltage of $120 \mathrm{~V}$. The device tested is shown in figure below.

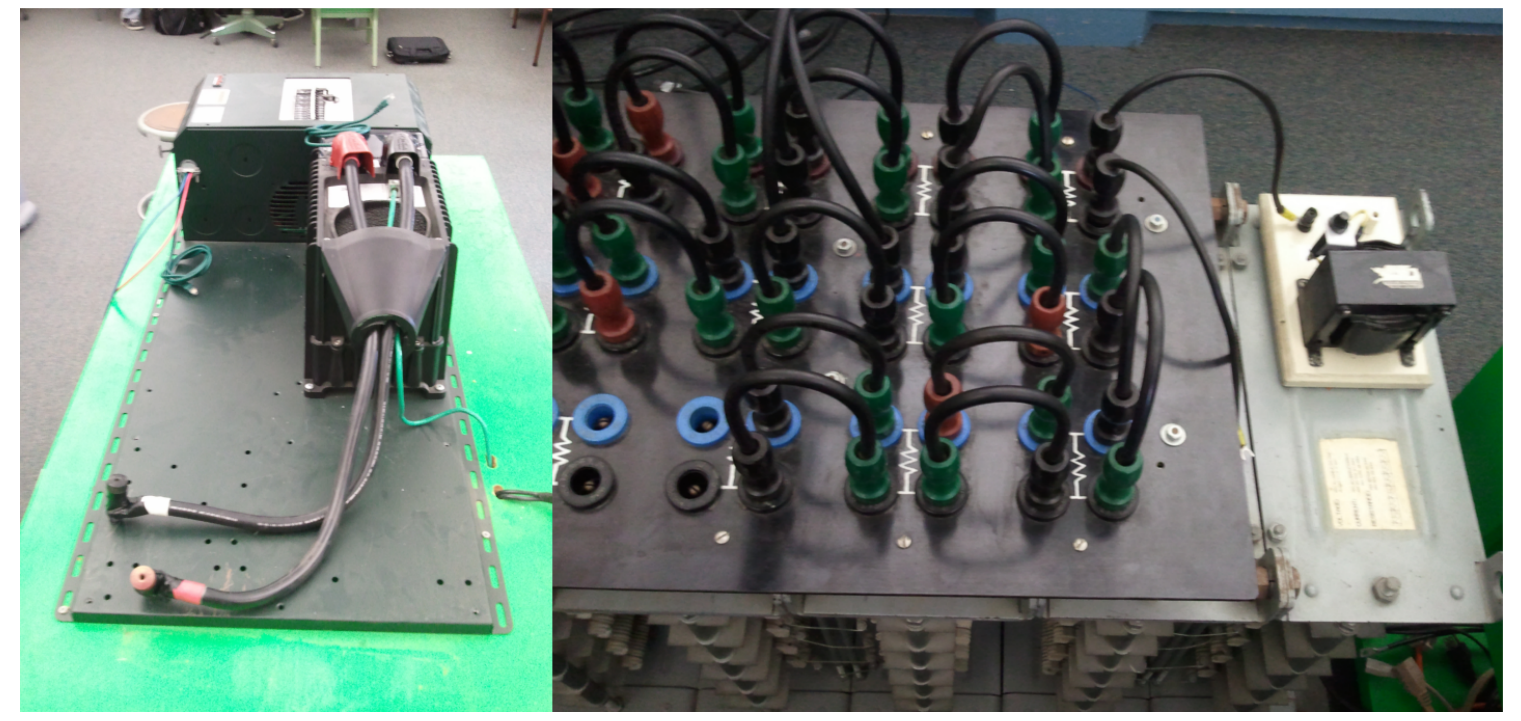

Figure III.4: Xantrex VFX3524 Inverter. (Left) - Xantrex Inverter, (Right) - AC load involving a fixed inductor of $39 \mathrm{mH}$ connected in series with a variable resistance.

The inverter's load consisted of a $39.94 \mathrm{mH}$ inductor in series with a resistor that took on 5 different values: $\mathrm{R}, \mathrm{R} / 2, \mathrm{R} / 5, \mathrm{R} / 10$, and $\mathrm{R} / 15$, where $\mathrm{R}$ was measured to be $72 \Omega$. A summary 
of the resistance, inductance and total impedance values for the 5 resistance values is located in a table below.

Table III.3: Summary of Loads Connected to AC Output of Inverter

\begin{tabular}{|l|r|r|r|r|r|r|r|r|r|}
\hline & $\mathrm{R}[\Omega]$ & $\mathrm{X}[\Omega]$ & Zload [ $\Omega$ ] & IZloadl $[\Omega]$ & $\theta$ load [] & $\mathrm{P}[\mathrm{W}]$ & $\mathrm{Q}[\mathrm{VAR}]$ & $\mathrm{S}[\mathrm{VA}]$ & PF Lagging \\
\hline $\mathrm{R}$ & 72 & 15.06 & $72+\mathrm{j} 15.06$ & 73.56 & 11.81 & 161.01 & 33.67 & 164.5 & 0.98 \\
\hline $\mathrm{R} / 2$ & 35.9 & 15.06 & $35.9+\mathrm{j} 15.06$ & 38.93 & 22.75 & 286.62 & 120.22 & 310.82 & 0.92 \\
\hline $\mathrm{R} / 5$ & 14.6 & 15.06 & $14.6+\mathrm{j} 15.06$ & 20.97 & 45.88 & 401.61 & 414.19 & 576.92 & 0.7 \\
\hline $\mathrm{R} / 10$ & 6.9 & 15.06 & $6.9+\mathrm{j} 15.06$ & 16.56 & 65.38 & 304.34 & 664.13 & 730.54 & 0.42 \\
\hline $\mathrm{R} / 15$ & 4.7 & 15.06 & $4.7+\mathrm{j} 15.06$ & 15.77 & 72.66 & 228.56 & 732.25 & 767.09 & 0.3 \\
\hline
\end{tabular}

Note that for Table III.3 that the P, Q, and S values for each load were calculated assuming that the output voltage was $\mathrm{V}_{\mathrm{RMS}}=120 \mathrm{~V}$.

With the 5 loads listed in Table III.3, the inverter was tested with the following input DC voltages applied: $22 \mathrm{~V}, 25 \mathrm{~V}, 28 \mathrm{~V}, 31 \mathrm{~V}$, and $34 \mathrm{~V}$. For each test, the inverter's voltage and current harmonic magnitudes, as well as THD values, were measured. Such experimentation was conducted using a Fluke 43B Power Quality Analyzer to confirm that an inverter's harmonic generation, over its range of input voltages and AC loads, adhered to IEEE 519 harmonic distortion standards. Such study relates to PV Power fluctuations because a change in solar irradiance leads to a change in PV operating characteristics: current, voltage, and power output.

\section{Inverter Voltage Total Harmonic Distortion (THDV)}

With the set up described above, the voltage total harmonic distortion, or $\mathrm{THD}_{\mathrm{V}}$, was studied at various DC input voltages and various impedances. The test results are listed below. 


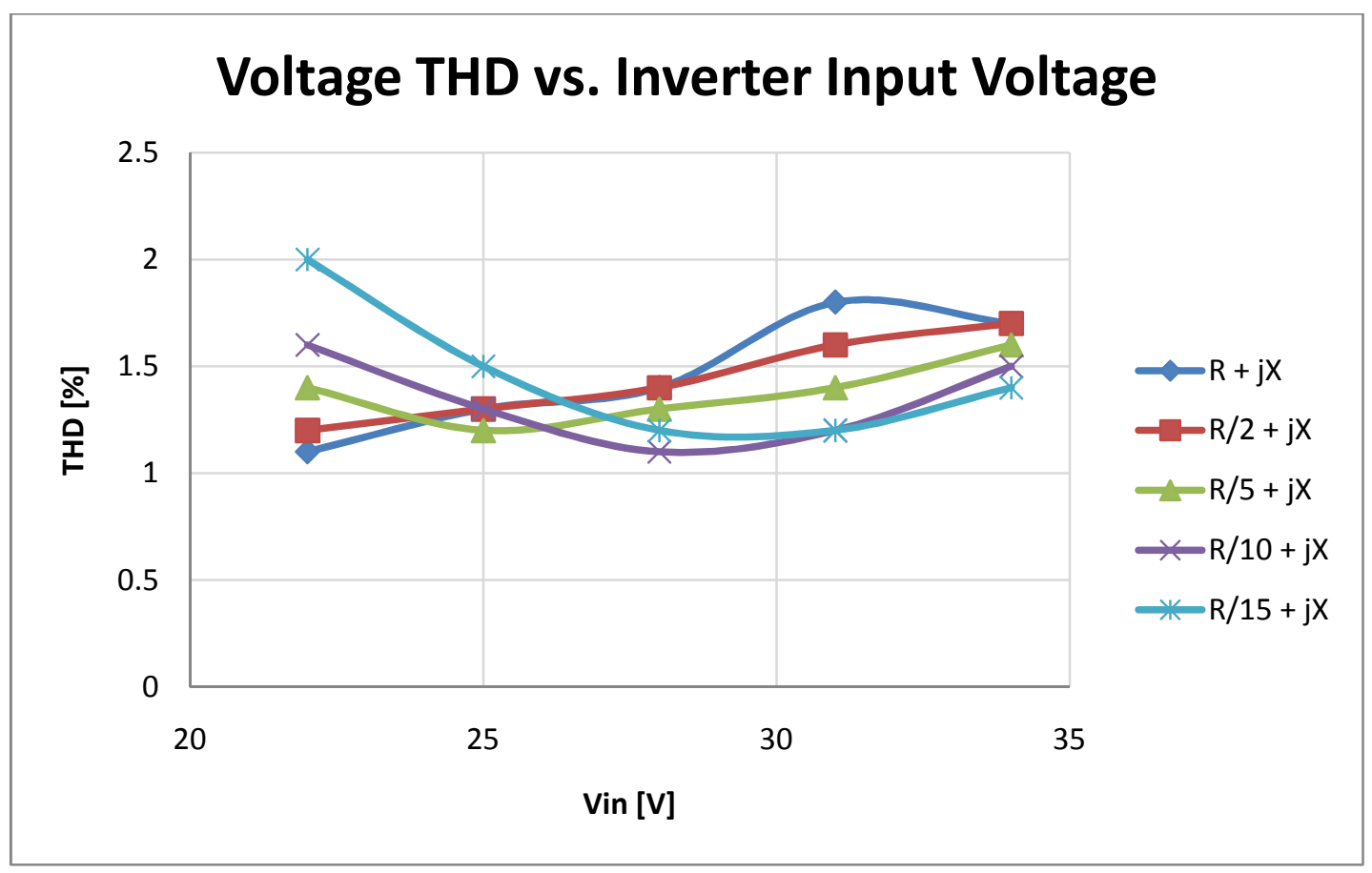

Figure III.5: THDV vs. Inverter Input Voltage for Various Loads

Figure III.5 shows the Voltage THD measured for a range of input voltages and various loads. Notice that the THD for any voltage or load applied did not exceed the IEEE 519 standard of 5\%, as listed in Table III.2. Therefore, when a PV panel is not supplying much power, due to low solar irradiance exposure, the voltage THD values are much within the IEEE 519 limit.

This thesis was limited with equipment, whose ratings restrict the maximum amount of current that can be supplied to the load. Therefore, although the inverter is rated at $3600 \mathrm{VA}$, this experiment was only able to test up to $767 \mathrm{VA}$, which is only $21 \%$ of the inverter's maximum potential. Additionally, the inverter is designed to shut-off when the supplied DC voltage travels outside the inverter's operating voltage range. Thus, harmonic distortion tests were limited to inverter operating ranges. 


\section{E. Inverter Current Total Harmonic Distortion (THD $)$}

Like the Voltage THD measurements, the current THD, or $\mathrm{THD}_{\mathrm{I}}$, was measured for various DC voltages supplied to the inverter for a range of impedances. The results are shown in Figure III.6.

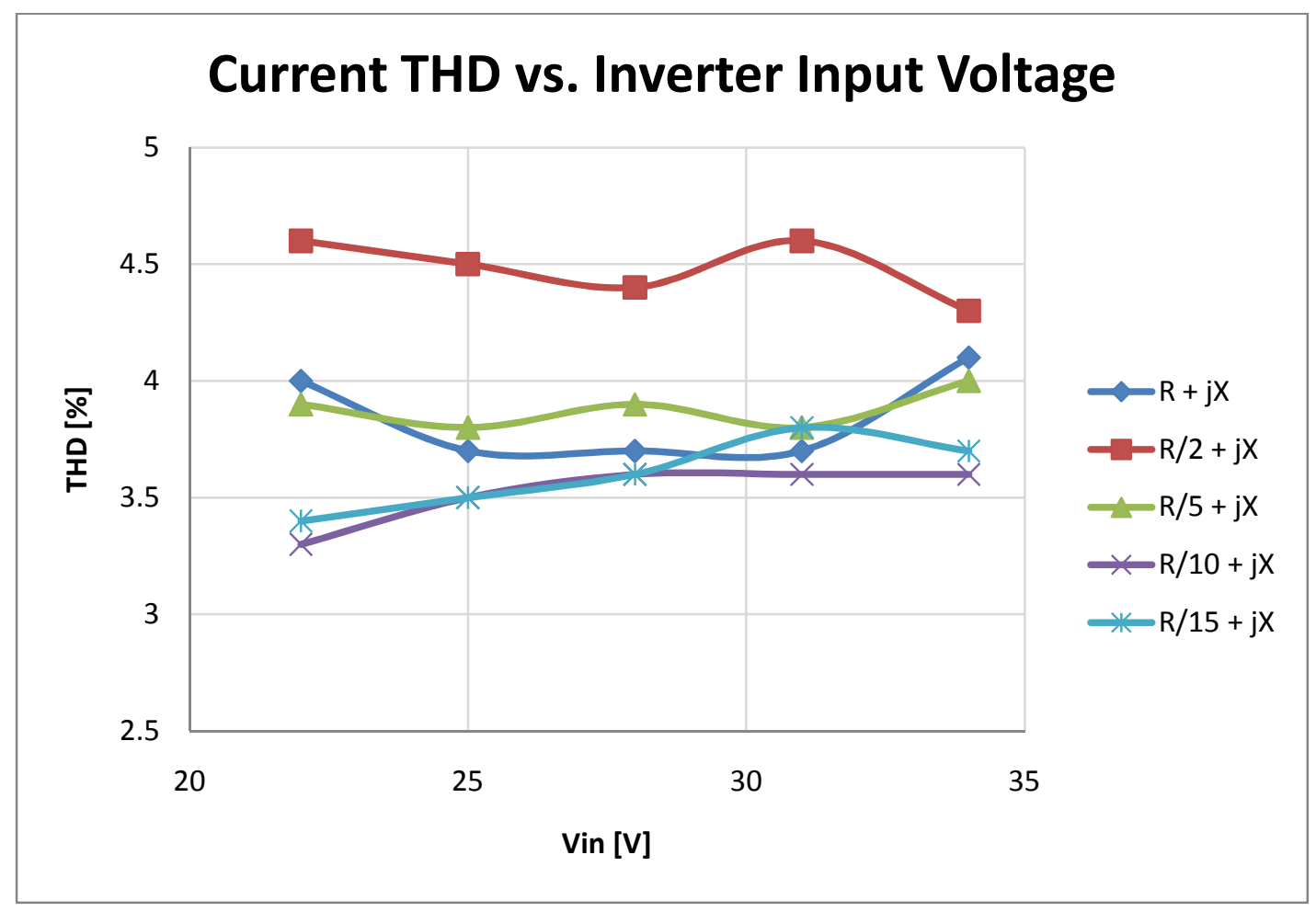

Figure IIII.6: THDI vs. Input DC Voltage for Various Loads

Figure III.6 shows the $\mathrm{THD}_{\mathrm{I}}$ over a range of input DC voltages for various loads. Notice how all of the THD values remain within the IEEE 519-1992 limit of 5.0\%. This being said, however, the load impedance R/2 + JX has THD values that exist rather close to 5\% limit with a maximum measured $\mathrm{THD}_{\mathrm{I}}$ of $4.6 \%$. Yet, $4.6 \%$ is still an acceptable $\mathrm{THD}_{\mathrm{I}}$ value. Yet, such results can possibly be attributed to harmonic resonance. Notice that the $\mathrm{THD}_{\mathrm{I}}$ seem to remain rather constant over the range of input $\mathrm{DC}$ voltage for a fixed load. For each load, the $\mathrm{THD}_{\mathrm{I}}$ values only deviate around $\pm 0.15 \%$ from each load's average $\mathrm{THD}_{\mathrm{I}}$ value. Therefore, it is safe to say that the 
current total harmonic distortion remains rather constant for a given load over the range of its operating input DC voltages.

\section{F. Inverter Voltage Harmonics}

In addition to voltage and current THD measurements, normalized harmonic magnitudes from $h=0(D C)$ to $h=51(3060 \mathrm{~Hz})$ were measured for each load for the tested range of DC input voltages. The results are shown in Figures III.7 through III.11.

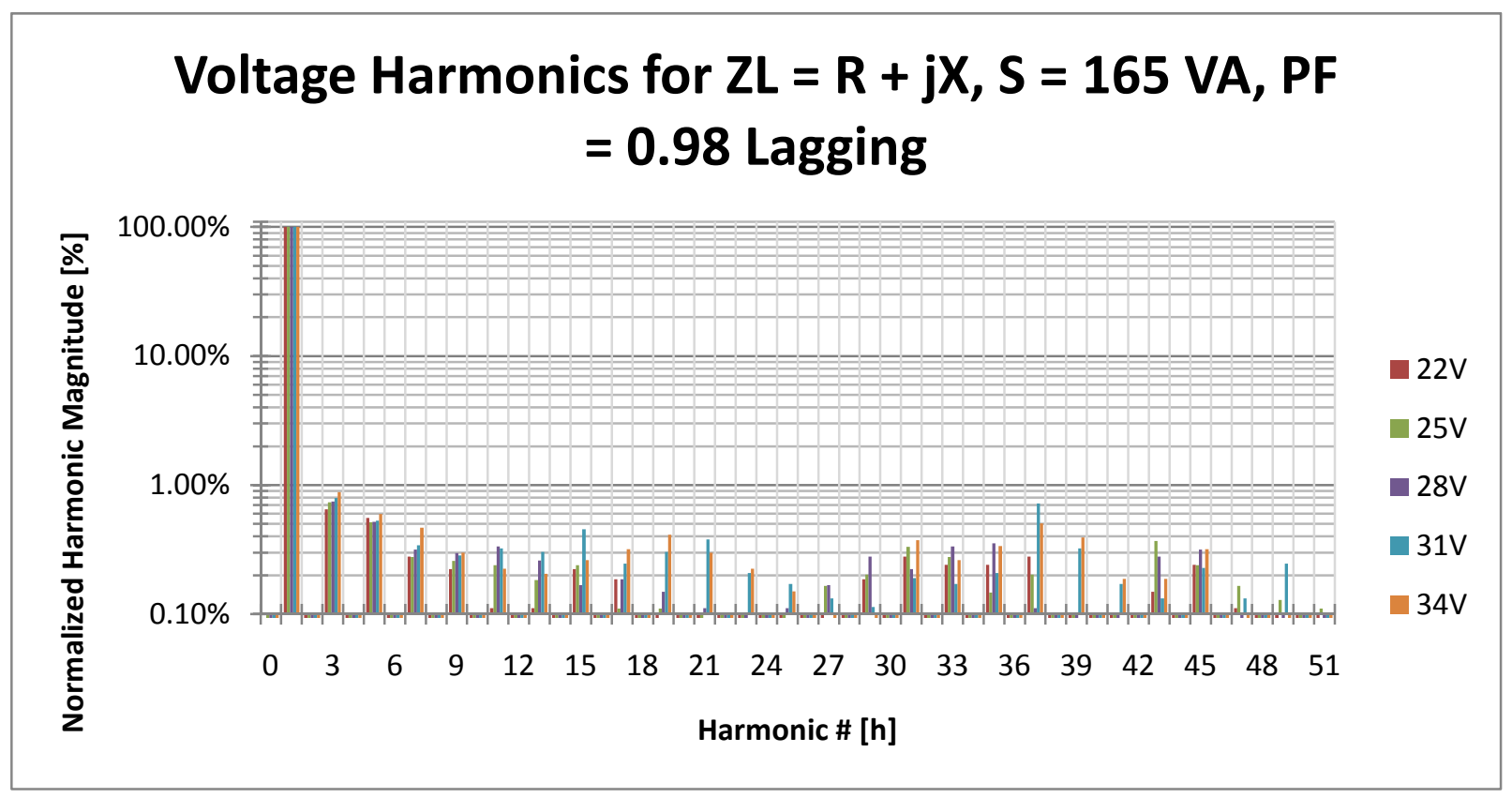

Figure III.7: Voltage Harmonics for $\mathrm{ZL}=\mathrm{R}+\mathrm{jX}, \mathrm{S}=165 \mathrm{VA}, \mathrm{PF}=0.98$ Lagging 


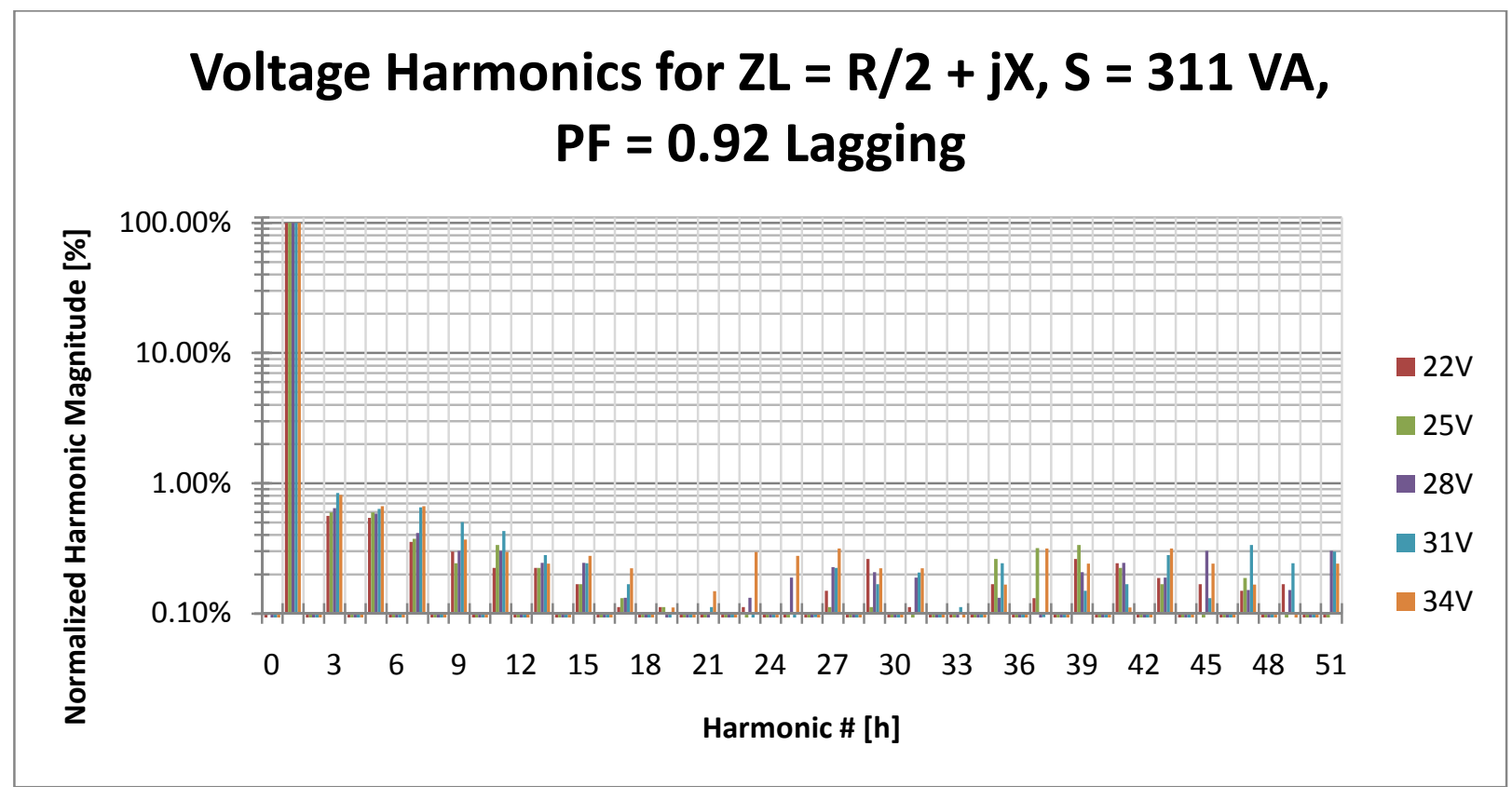

Figure III.8: Voltage Harmonics for $\mathrm{ZL}=\mathrm{R} / 2+\mathrm{jX}, \mathrm{S}=311 \mathrm{VA}, \mathrm{PF}=0.92$ Lagging

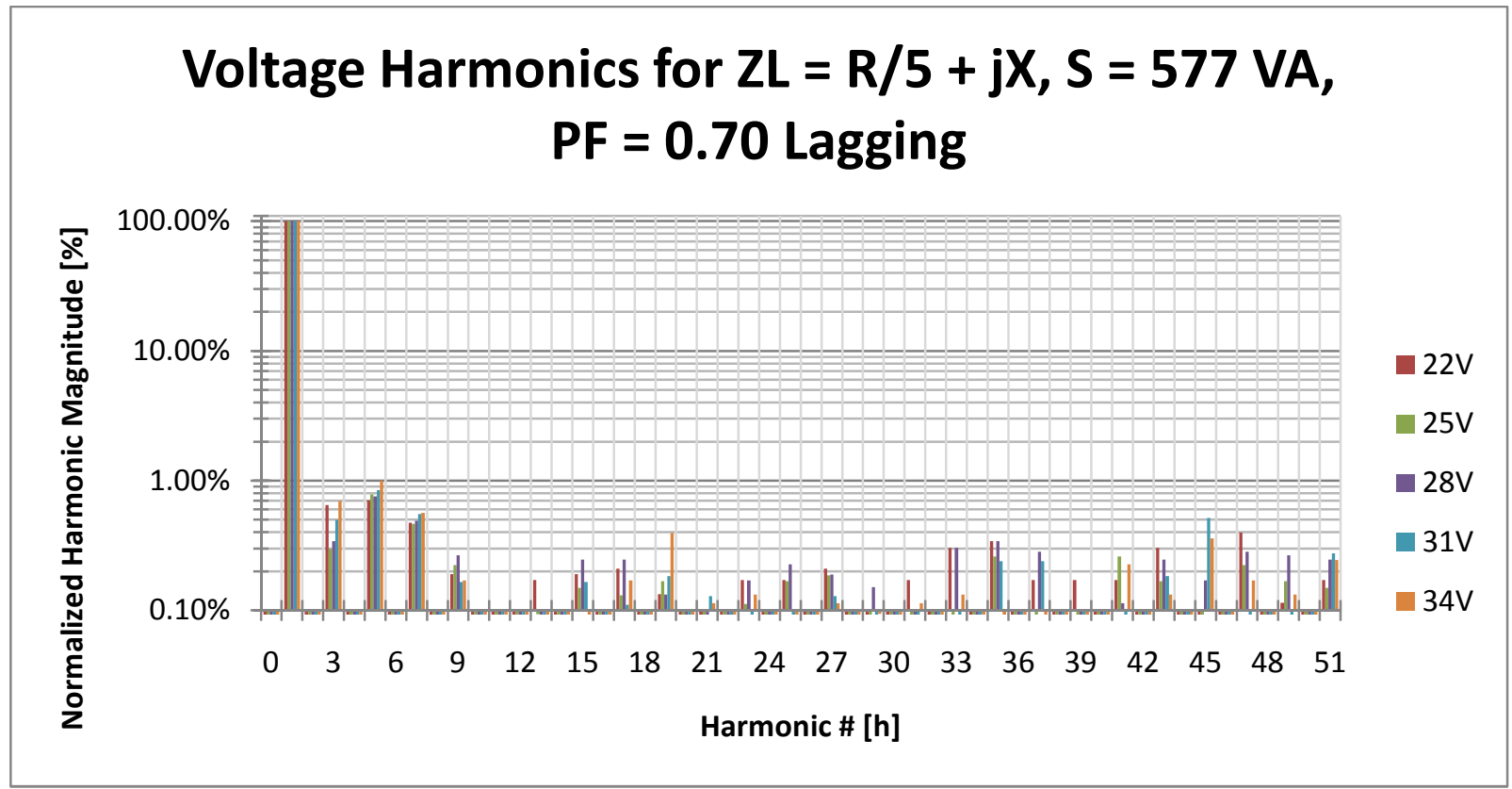

Figure III.9: Voltage Harmonics for $\mathrm{ZL}=\mathrm{R} / 5+\mathrm{jX}, \mathrm{S}=577 \mathrm{VA}, \mathrm{PF}=0.70$ Lagging 


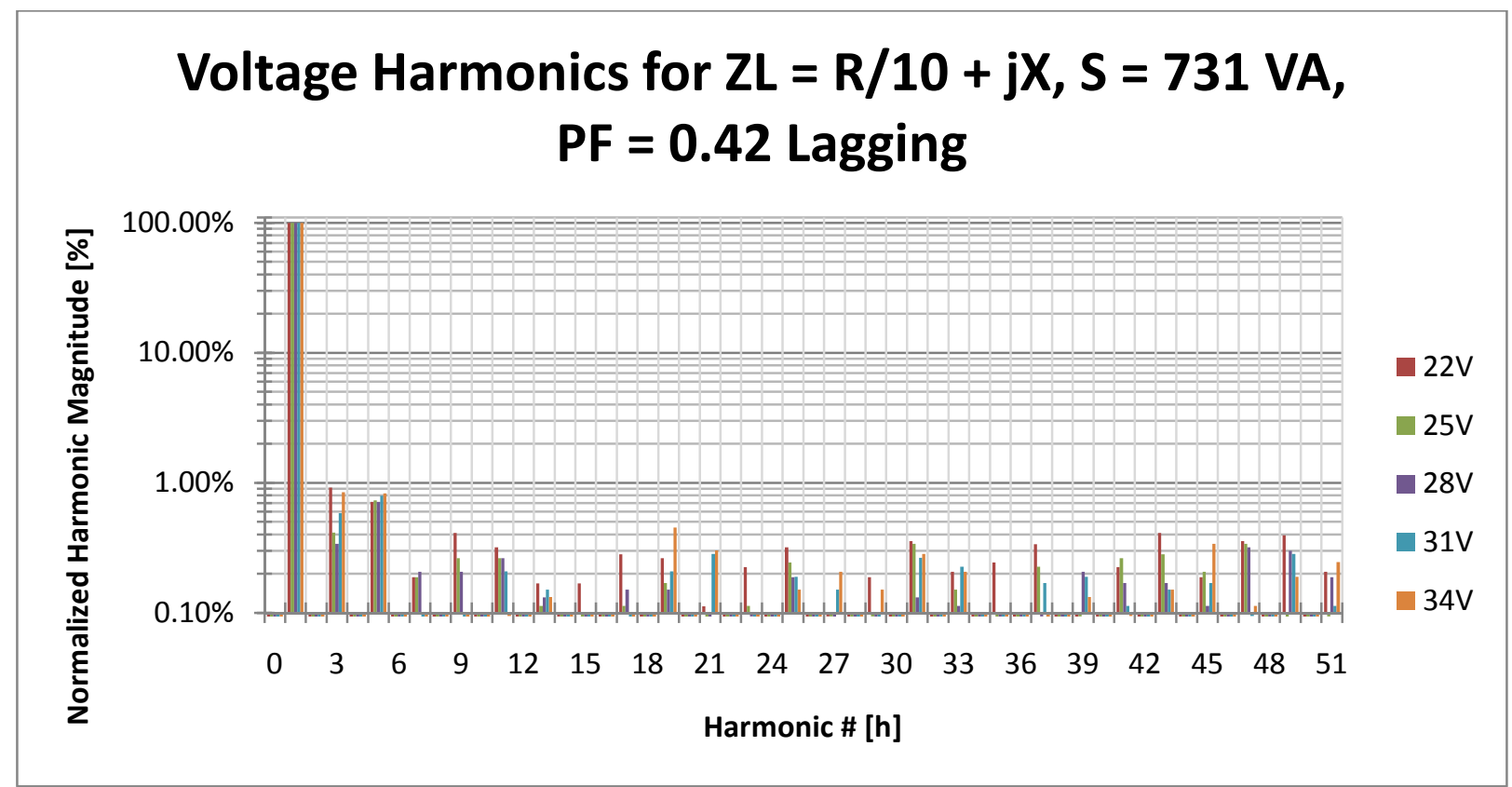

Figure III.10: Voltage Harmonics for $\mathrm{ZL}=\mathrm{R} / 10+\mathrm{jX}, \mathrm{S}=731 \mathrm{VA}, \mathrm{PF}=\mathbf{0 . 4 2}$ Lagging

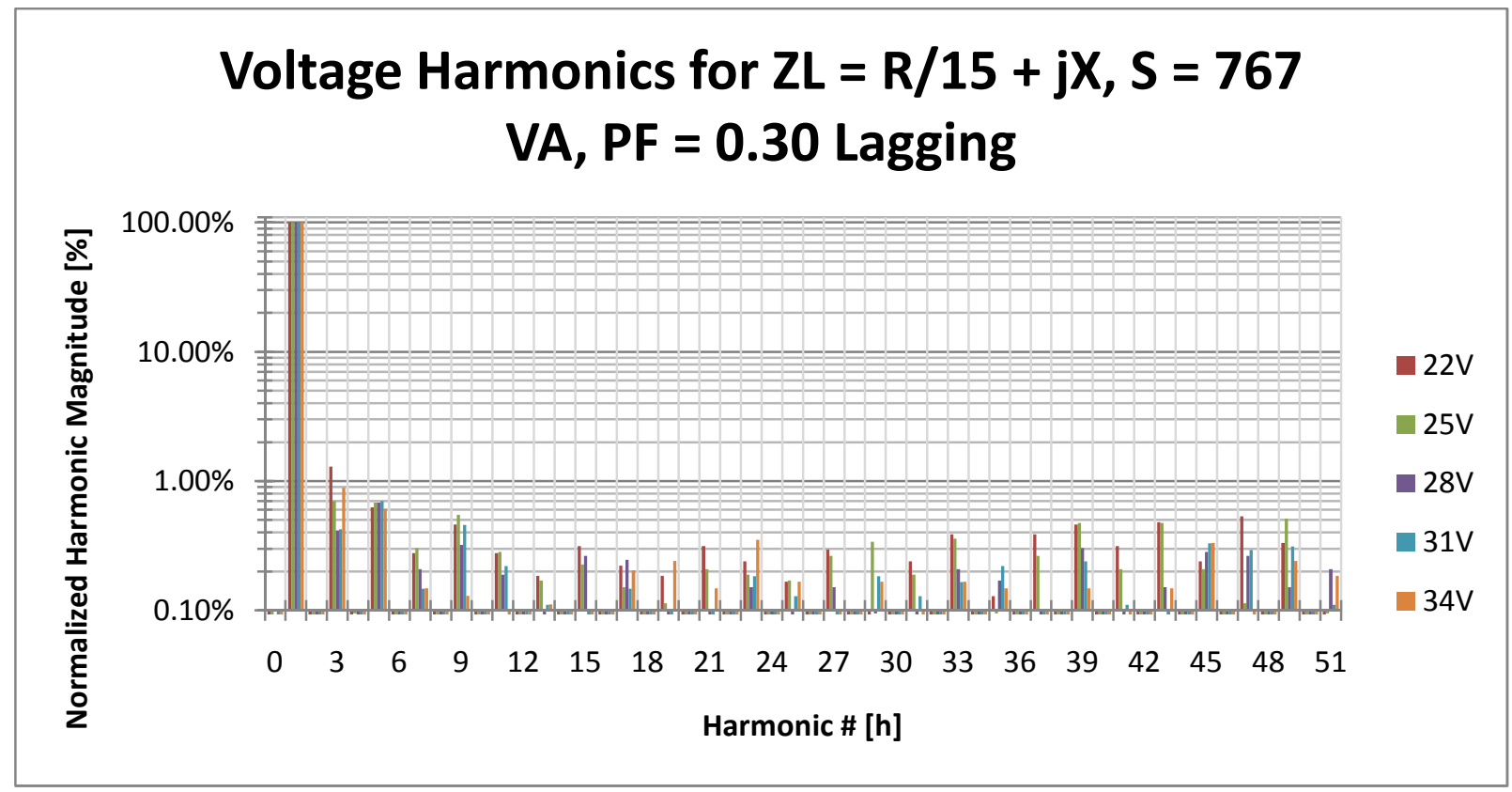

Figure III.11: Voltage Harmonics for ZL = R/15 + jX, S = 767 VA, PF = 0.30 Lagging

Figures III.7 through III.11 show the voltage harmonic magnitudes for 5 different load impedances tested at various input voltages between $22 \mathrm{~V}_{\mathrm{DC}}$ and $34 \mathrm{~V}_{\mathrm{DC}}$. According to Table III.2, the IEEE Standard 519-1992 limits harmonic magnitudes to $3.0 \%$ for bus voltages of $69 \mathrm{kV}$ and 
below. The voltage harmonic magnitudes fall much under that limit with a maximum harmonic magnitude of $1.29 \%$ for $\mathrm{h}=3$ when $22 \mathrm{~V}_{\mathrm{DC}}$ is supplied to the generator with a load of $\mathrm{R} / 15+\mathrm{jX}$.

Table III.4: Voltage Harmonic Limits Exceeded - DC Offset

\begin{tabular}{|l|r|r|r|r|r|r|r|r|r|r|}
\hline Voltage & \multicolumn{5}{|c|}{$22 \mathrm{~V}$} & \multicolumn{5}{|c|}{$25 \mathrm{~V}$} \\
\hline $\mathrm{h}$ & $\mathrm{R}$ & $\mathrm{R} / 2$ & $\mathrm{R} / 5$ & $\mathrm{R} / 10$ & $\mathrm{R} / 15$ & $\mathrm{R}$ & $\mathrm{R} / 2$ & $\mathrm{R} / 5$ & $\mathrm{R} / 10$ & $\mathrm{R} / 15$ \\
\hline $\mathrm{0}$ & $0.00 \%$ & $0.05 \%$ & $0.05 \%$ & $0.08 \%$ & $0.08 \%$ & $0.03 \%$ & $0.00 \%$ & $0.03 \%$ & $0.03 \%$ & $0.05 \%$ \\
\hline
\end{tabular}

\begin{tabular}{|l|r|r|r|r|r|r|r|r|r|r|}
\hline Voltage & \multicolumn{5}{|c|}{$28 \mathrm{~V}$} & \multicolumn{5}{|c|}{$31 \mathrm{~V}$} \\
\hline $\mathrm{h}$ & $\mathrm{R}$ & $\mathrm{R} / 2$ & $\mathrm{R} / 5$ & $\mathrm{R} / 10$ & $\mathrm{R} / 15$ & $\mathrm{R}$ & $\mathrm{R} / 2$ & $\mathrm{R} / 5$ & $\mathrm{R} / 10$ & $\mathrm{R} / 15$ \\
\hline $\mathrm{0}$ & $0.05 \%$ & $0.03 \%$ & $0.05 \%$ & $0.05 \%$ & $0.00 \%$ & $0.03 \%$ & $0.05 \%$ & $0.03 \%$ & $0.03 \%$ & $0.03 \%$ \\
\hline
\end{tabular}

\begin{tabular}{|l|r|r|r|r|r|}
\hline Voltage & \multicolumn{5}{|c|}{$34 \mathrm{~V}$} \\
\hline $\mathrm{h}$ & $\mathrm{R}$ & $\mathrm{R} / 2$ & $\mathrm{R} / 5$ & $\mathrm{R} / 10$ & $\mathrm{R} / 15$ \\
\hline $\mathrm{0}$ & $0.05 \%$ & $0.03 \%$ & $0.05 \%$ & $0.05 \%$ & $0.03 \%$ \\
\hline
\end{tabular}

Although all voltage harmonic magnitudes measured exist within the acceptable IEEE 519 limits, the voltage waveforms possessed a slight DC offset, as shown in Table III.4. The redshaded portions highlight the tests that produced waveforms with DC offsets. Power Systems tend to avoid waveforms with any DC offsets because of their detrimental effects. Although, it is not stated in the IEEE standard 519-1992 that voltage waveform DC offsets are not allowed, indirectly the issue of waveform DC offsets is addressed. Table III.1 states IEEE 519's standard for DC offset within waveforms: "Current distortions that result in a dc offset... ... are not allowed" [1]. Although IEEE does not refer to DC offsets within voltage waveforms directly, it can be assumed from ohms law (V=IR) that a voltage waveform with DC offset will lead to current waveform with DC offset. For this reason, any voltage distortions that lead to a DC offset should not be allowed as well. Nevertheless, Table III.4 shows that the maximum DC offset over the vast range of tests was $0.05 \%$ of the fundamental component magnitude. This DC offset is small enough that it is pretty much rather negligible. Regardless of the size of a DC offset, it is important to note that the voltage distortion did contain an offset. 


\section{G. Inverter Current Harmonics}

While the inverter may have provided allowable voltage waveforms over the range of loads and DC input voltages, the current waveforms were much more susceptible to harmonic distortion and surpassed harmonic limits.

Table IIII.5: IEEE 519-1992 Odd and Even Harmonic Limits

\begin{tabular}{|l|r|r|r|r|r|}
\hline \multirow{2}{*}{ Odd Harmonics } & $\mathrm{h}<11$ & $11 \leq \mathrm{h}<17$ & $17 \leq \mathrm{h}<23$ & $23 \leq \mathrm{h}<35$ & $35 \leq \mathrm{h}$ \\
\cline { 2 - 6 } & $4 \%$ & $2 \%$ & $1.5 \%$ & $0.6 \%$ & $0.3 \%$ \\
\hline \multirow{2}{*}{ Even Harmonics } & $\mathrm{h}<12$ & $12 \leq \mathrm{h}<18$ & $18 \leq \mathrm{h}<24$ & $24 \leq \mathrm{h}<36$ & $36 \leq \mathrm{h}$ \\
\cline { 2 - 6 } & $1 \%$ & $0.5 \%$ & $0.375 \%$ & $0.15 \%$ & $0.075 \%$ \\
\hline
\end{tabular}

Table III.5 re-emphasizes the IEEE 519-1992 current waveform harmonic magnitude limits as listed in Table III.1 and also provides both the odd and even harmonic limits. Even harmonics are limited to $25 \%$ of the odd harmonics because they should be less prevalent within a power system. Even harmonic magnitude limits are stricter than odd harmonic limits, because even harmonics often occur in current waveforms with DC offsets; current waveforms with DC offsets are prohibited from the grid $[1,9]$. Current waveforms with DC offsets are prohibited in the power systems because they shift a transformer's operating location on its B-H curve closer towards saturation. Transformers operating in saturation generate a large change in current for a small change in voltage. This, in turn, could lead to exceeded transformer current ratings, overheating, and subjecting the transformer to formidable damage. For these reasons, current waveforms with DC offsets are prohibited for their destructive repercussions.

Figures III.12 through III.16 illustrate the harmonic distortion associated with an assortment of tests of different impedances and various input DC voltages. 


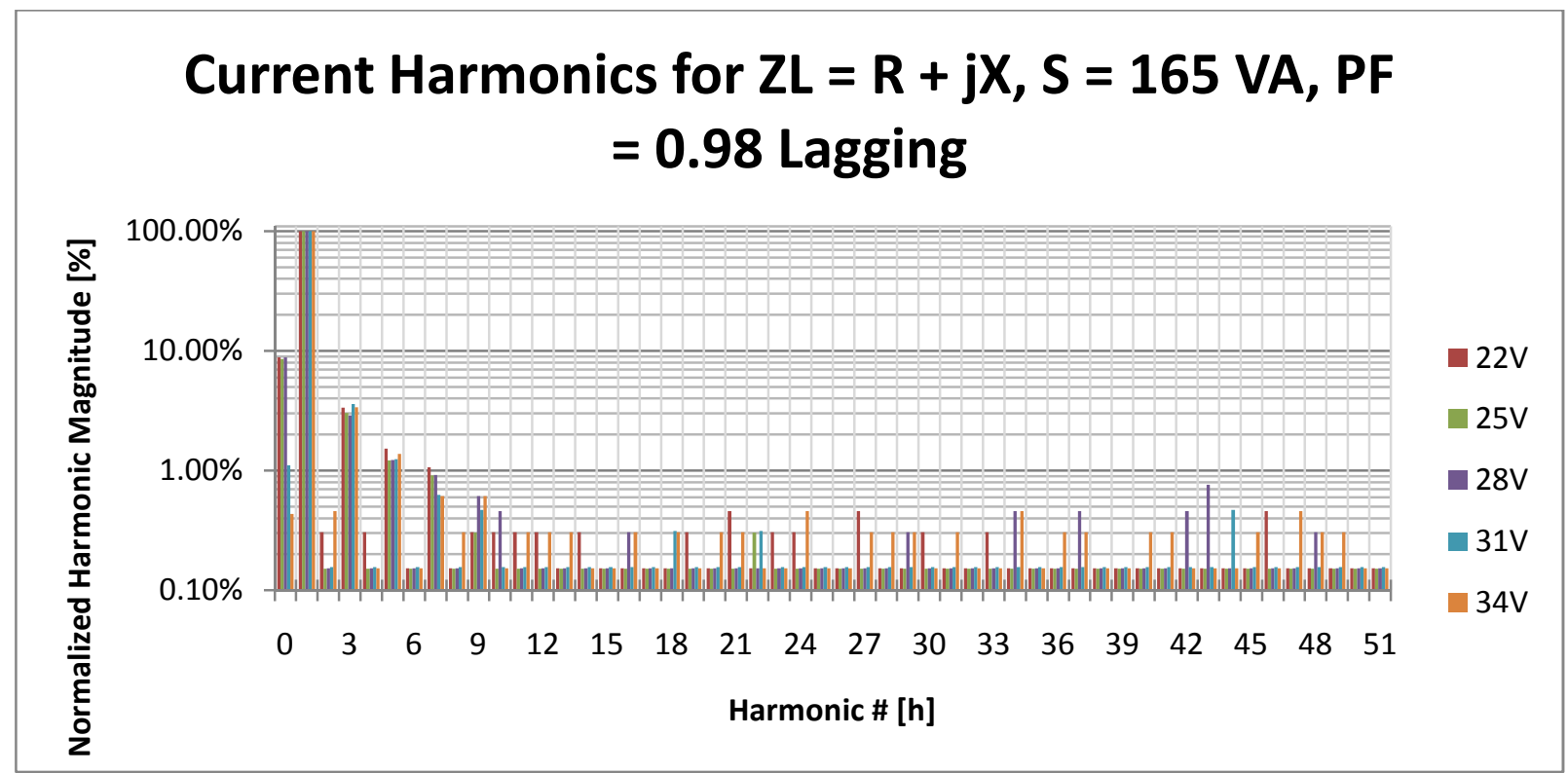

Figure III.12: Current Harmonics for $\mathrm{ZL}=\mathrm{R}+\mathrm{jX}, \mathrm{S}=165 \mathrm{VA}, \mathrm{PF}=0.98$ Lagging

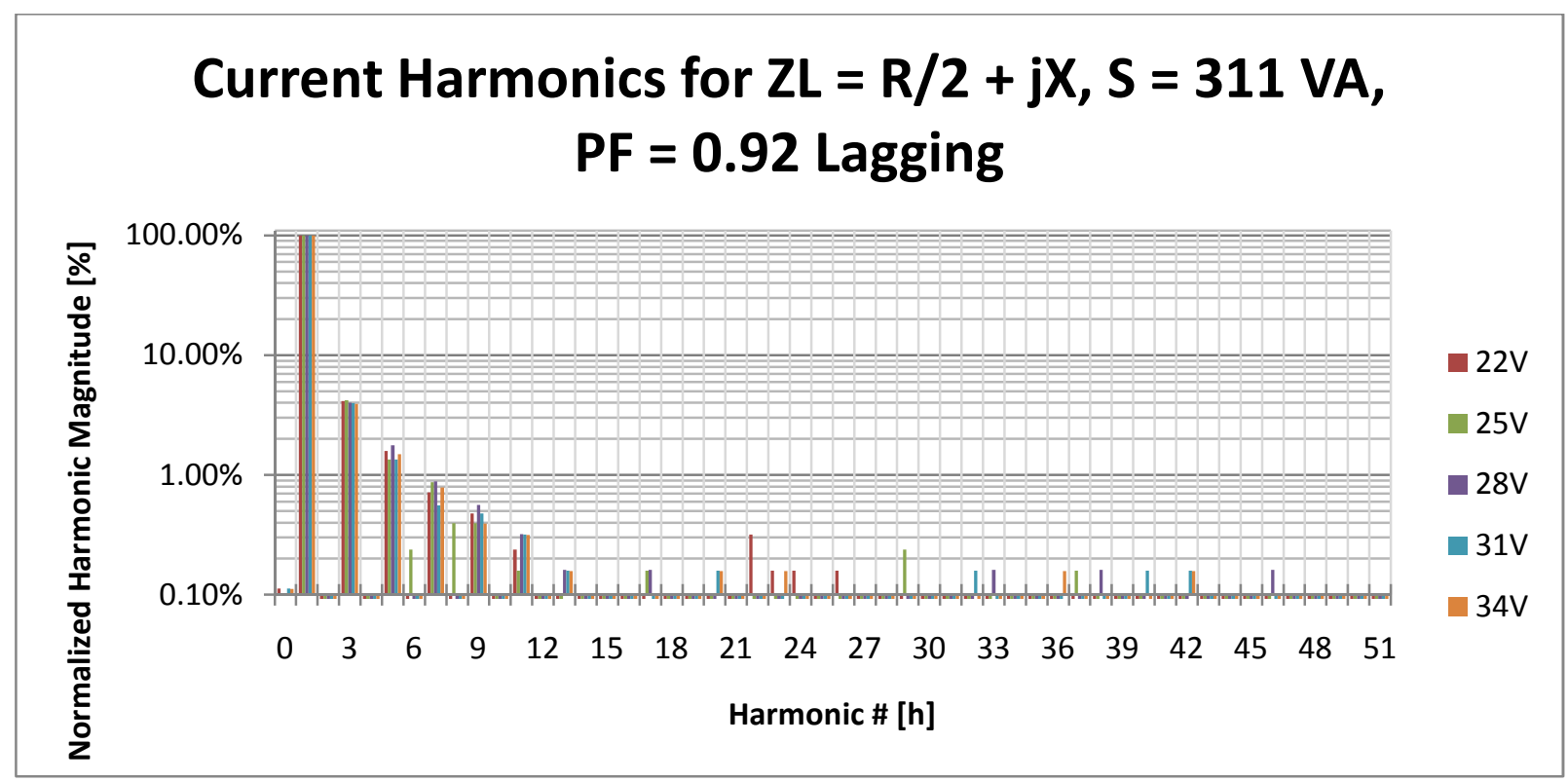

Figure III.13: Current Harmonics for $\mathrm{ZL}=\mathrm{R} / 2+\mathrm{jX}, \mathrm{S}=311 \mathrm{VA}, \mathrm{PF}=0.92$ Lagging 


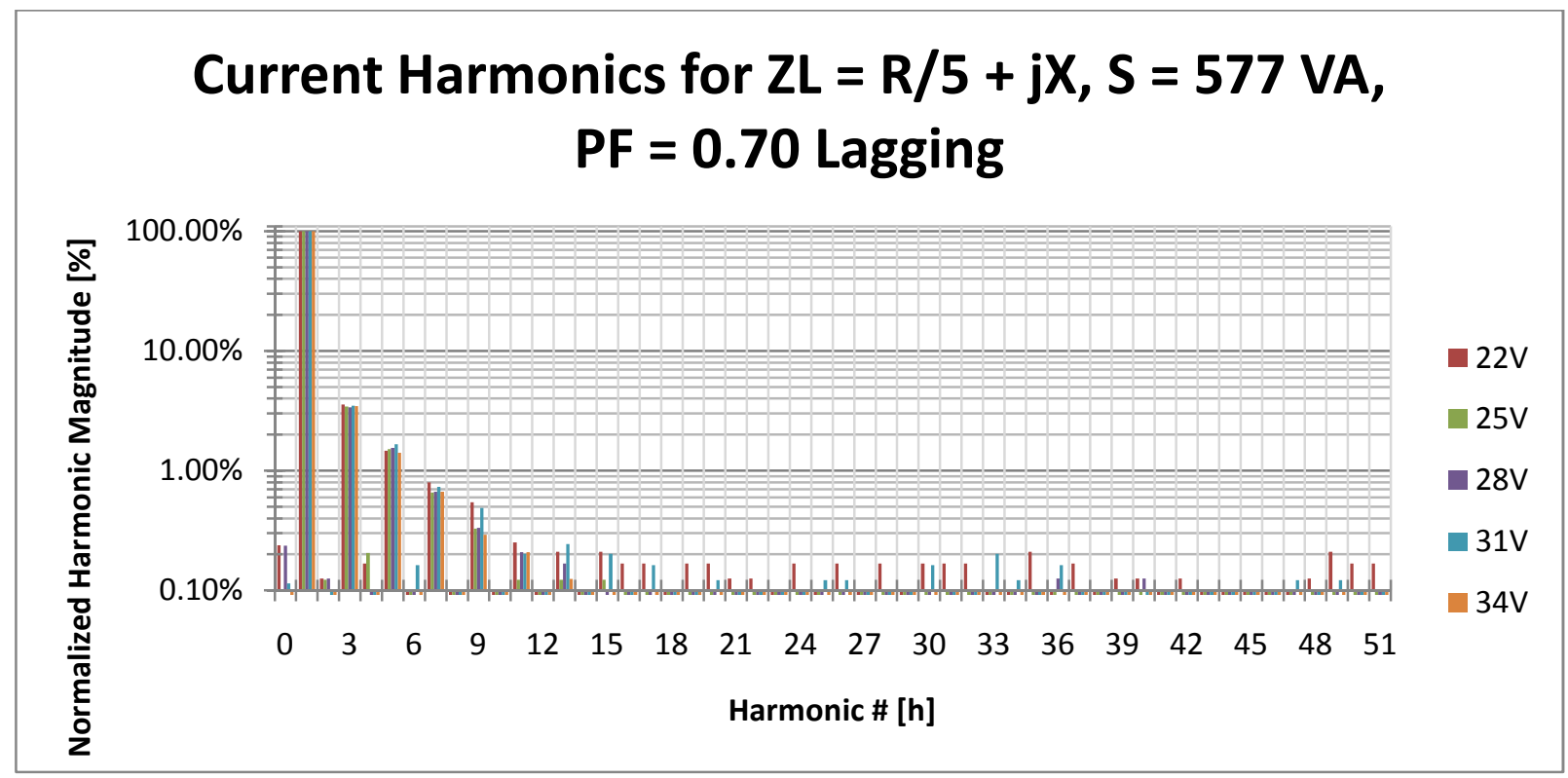

Figure III.14: Current Harmonics for $\mathrm{ZL}=\mathrm{R} / 5$ + jX, S = 577 VA, PF = 0.70 Lagging

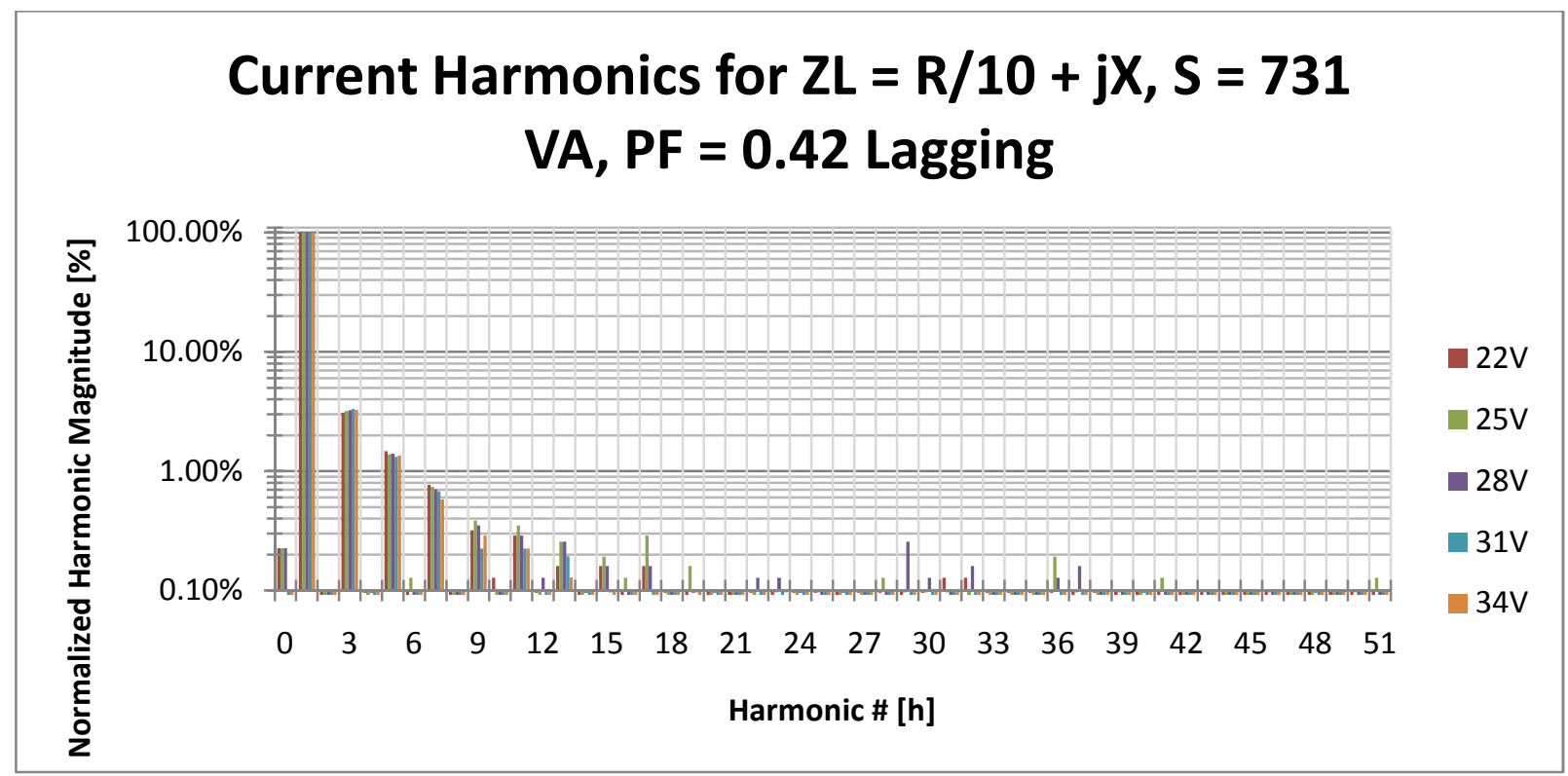

Figure III.15: Current Harmonics for $\mathrm{ZL}=\mathrm{R} / 10+\mathrm{jX}, \mathrm{S}=731 \mathrm{VA}, \mathrm{PF}=0.42$ Lagging 


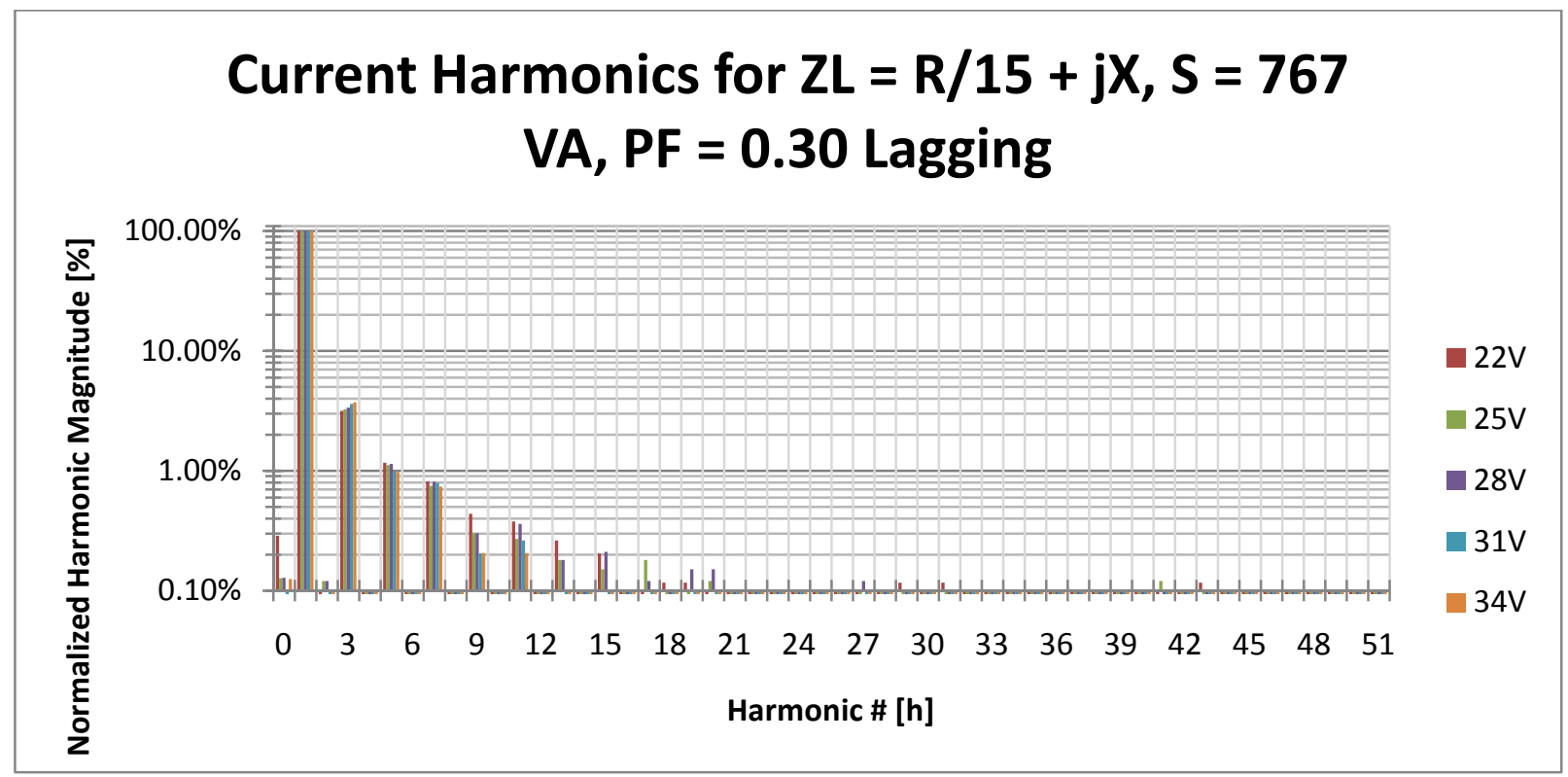

Figure III.16: Current Harmonics for $\mathrm{ZL}=\mathrm{R} / 15+\mathrm{jX}, \mathrm{S}=767 \mathrm{VA}, \mathrm{PF}=0.30$ Lagging

Figures III.12 through III.16 illustrate the current harmonic magnitudes of the five different impedance loads at various input DC voltages. A summary of the results for these harmonic figures are listed in Tables III.6 through III.9. The red-highlighted cells within each table illustrate harmonic magnitudes that exceed IEEE 519 allowable limits. 
Table III.6: Current Harmonic Limits Exceeded for $\mathrm{h}<11$

\begin{tabular}{|r|r|r|r|r|r|r|r|r|r|r|r|}
\hline \multicolumn{2}{|c|}{ Current } & \multicolumn{6}{|c|}{$22 \mathrm{~V}$} & \multicolumn{5}{|c|}{$25 \mathrm{~V}$} \\
\hline $\mathrm{h}$ & LIMITS & $\mathrm{R}$ & $\mathrm{R} / 2$ & $\mathrm{R} / 5$ & $\mathrm{R} / 10$ & $\mathrm{R} / 15$ & $\mathrm{R}$ & $\mathrm{R} / 2$ & $\mathrm{R} / 5$ & $\mathrm{R} / 10$ & $\mathrm{R} / 15$ \\
\hline $\mathrm{0}$ & $0 \%$ & $8.85 \%$ & $0.11 \%$ & $0.24 \%$ & $0.23 \%$ & $0.29 \%$ & $8.57 \%$ & $0.00 \%$ & $0.00 \%$ & $0.23 \%$ & $0.13 \%$ \\
\hline 1 & $100 \%$ & $100.00 \%$ & $100.00 \%$ & $100.00 \%$ & $100.00 \%$ & $100.00 \%$ & $100.00 \%$ & $100.00 \%$ & $100.00 \%$ & $100.00 \%$ & $100.00 \%$ \\
\hline 2 & $1 \%$ & $0.31 \%$ & $0.08 \%$ & $0.13 \%$ & $0.06 \%$ & $0.06 \%$ & $0.15 \%$ & $0.08 \%$ & $0.12 \%$ & $0.06 \%$ & $0.12 \%$ \\
\hline 3 & $4 \%$ & $3.36 \%$ & $4.14 \%$ & $3.57 \%$ & $3.10 \%$ & $3.15 \%$ & $3.03 \%$ & $4.20 \%$ & $3.44 \%$ & $3.20 \%$ & $3.25 \%$ \\
\hline 4 & $1 \%$ & $0.31 \%$ & $0.08 \%$ & $0.17 \%$ & $0.10 \%$ & $0.06 \%$ & $0.15 \%$ & $0.08 \%$ & $0.20 \%$ & $0.06 \%$ & $0.09 \%$ \\
\hline 5 & $4 \%$ & $1.53 \%$ & $1.59 \%$ & $1.47 \%$ & $1.47 \%$ & $1.17 \%$ & $1.21 \%$ & $1.35 \%$ & $1.52 \%$ & $1.38 \%$ & $1.11 \%$ \\
\hline 6 & $1 \%$ & $0.15 \%$ & $0.08 \%$ & $0.04 \%$ & $0.06 \%$ & $0.03 \%$ & $0.15 \%$ & $0.24 \%$ & $0.08 \%$ & $0.13 \%$ & $0.09 \%$ \\
\hline 7 & $4 \%$ & $1.07 \%$ & $0.72 \%$ & $0.80 \%$ & $0.77 \%$ & $0.82 \%$ & $0.91 \%$ & $0.87 \%$ & $0.66 \%$ & $0.74 \%$ & $0.75 \%$ \\
\hline 8 & $1 \%$ & $0.15 \%$ & $0.08 \%$ & $0.04 \%$ & $0.03 \%$ & $0.06 \%$ & $0.15 \%$ & $0.40 \%$ & $0.04 \%$ & $0.06 \%$ & $0.09 \%$ \\
\hline 9 & $4 \%$ & $0.31 \%$ & $0.48 \%$ & $0.55 \%$ & $0.32 \%$ & $0.44 \%$ & $0.30 \%$ & $0.40 \%$ & $0.33 \%$ & $0.38 \%$ & $0.30 \%$ \\
\hline 10 & $1 \%$ & $0.31 \%$ & $0.08 \%$ & $0.08 \%$ & $0.13 \%$ & $0.06 \%$ & $0.15 \%$ & $0.08 \%$ & $0.04 \%$ & $0.06 \%$ & $0.06 \%$ \\
\hline
\end{tabular}

\begin{tabular}{|r|r|r|r|r|r|r|r|r|r|r|r|}
\hline \multicolumn{2}{|c|}{ Current } & \multicolumn{6}{|c|}{$28 \mathrm{~V}$} & \multicolumn{4}{|c|}{$31 \mathrm{~V}$} \\
\hline $\mathrm{h}$ & LIMITS & $\mathrm{R}$ & $\mathrm{R} / 2$ & $\mathrm{R} / 5$ & $\mathrm{R} / 10$ & $\mathrm{R} / 15$ & $\mathrm{R}$ & $\mathrm{R} / 2$ & $\mathrm{R} / 5$ & $\mathrm{R} / 10$ & $\mathrm{R} / 15$ \\
\hline $\mathrm{0}$ & $0 \%$ & $8.85 \%$ & $0.00 \%$ & $0.24 \%$ & $0.23 \%$ & $0.13 \%$ & $1.10 \%$ & $0.11 \%$ & $0.11 \%$ & $0.05 \%$ & $0.04 \%$ \\
\hline 1 & $100 \%$ & $100.00 \%$ & $100.00 \%$ & $100.00 \%$ & $100.00 \%$ & $100.00 \%$ & $100.00 \%$ & $100.00 \%$ & $100.00 \%$ & $100.00 \%$ & $100.00 \%$ \\
\hline 2 & $1 \%$ & $0.15 \%$ & $0.08 \%$ & $0.13 \%$ & $0.06 \%$ & $0.12 \%$ & $0.16 \%$ & $0.08 \%$ & $0.04 \%$ & $0.03 \%$ & $0.06 \%$ \\
\hline 3 & $4 \%$ & $2.90 \%$ & $4.02 \%$ & $3.38 \%$ & $3.23 \%$ & $3.37 \%$ & $3.59 \%$ & $3.97 \%$ & $3.49 \%$ & $3.31 \%$ & $3.60 \%$ \\
\hline 4 & $1 \%$ & $0.15 \%$ & $0.08 \%$ & $0.04 \%$ & $0.10 \%$ & $0.06 \%$ & $0.16 \%$ & $0.08 \%$ & $0.08 \%$ & $0.03 \%$ & $0.06 \%$ \\
\hline 5 & $4 \%$ & $1.22 \%$ & $1.77 \%$ & $1.54 \%$ & $1.41 \%$ & $1.14 \%$ & $1.25 \%$ & $1.35 \%$ & $1.66 \%$ & $1.32 \%$ & $0.99 \%$ \\
\hline 6 & $1 \%$ & $0.15 \%$ & $0.08 \%$ & $0.04 \%$ & $0.06 \%$ & $0.06 \%$ & $0.16 \%$ & $0.08 \%$ & $0.16 \%$ & $0.06 \%$ & $0.03 \%$ \\
\hline 7 & $4 \%$ & $0.92 \%$ & $0.88 \%$ & $0.67 \%$ & $0.70 \%$ & $0.81 \%$ & $0.63 \%$ & $0.56 \%$ & $0.73 \%$ & $0.67 \%$ & $0.79 \%$ \\
\hline 8 & $1 \%$ & $0.15 \%$ & $0.08 \%$ & $0.04 \%$ & $0.06 \%$ & $0.06 \%$ & $0.16 \%$ & $0.08 \%$ & $0.04 \%$ & $0.03 \%$ & $0.03 \%$ \\
\hline 9 & $4 \%$ & $0.61 \%$ & $0.56 \%$ & $0.33 \%$ & $0.35 \%$ & $0.30 \%$ & $0.47 \%$ & $0.48 \%$ & $0.49 \%$ & $0.22 \%$ & $0.20 \%$ \\
\hline 10 & $1 \%$ & $0.46 \%$ & $0.08 \%$ & $0.04 \%$ & $0.06 \%$ & $0.06 \%$ & $0.16 \%$ & $0.08 \%$ & $0.04 \%$ & $0.03 \%$ & $0.03 \%$ \\
\hline
\end{tabular}

\begin{tabular}{|r|r|r|r|r|r|r|}
\hline \multicolumn{2}{|c|}{ Current } & \multicolumn{5}{|c|}{$34 \mathrm{~V}$} \\
\hline $\mathrm{h}$ & LIMITS & $\mathrm{R}$ & $\mathrm{R} / 2$ & $\mathrm{R} / 5$ & $\mathrm{R} / 10$ & $\mathrm{R} / 15$ \\
\hline $\mathrm{0}$ & $0 \%$ & $0.43 \%$ & $0.11 \%$ & $0.06 \%$ & $0.05 \%$ & $0.13 \%$ \\
\hline 1 & $100 \%$ & $100.00 \%$ & $100.00 \%$ & $100.00 \%$ & $100.00 \%$ & $100.00 \%$ \\
\hline 2 & $1 \%$ & $0.46 \%$ & $0.08 \%$ & $0.04 \%$ & $0.03 \%$ & $0.03 \%$ \\
\hline 3 & $4 \%$ & $3.37 \%$ & $3.93 \%$ & $3.45 \%$ & $3.28 \%$ & $3.71 \%$ \\
\hline 4 & $1 \%$ & $0.15 \%$ & $0.08 \%$ & $0.08 \%$ & $0.03 \%$ & $0.03 \%$ \\
\hline 5 & $4 \%$ & $1.38 \%$ & $1.49 \%$ & $1.41 \%$ & $1.35 \%$ & $0.97 \%$ \\
\hline 6 & $1 \%$ & $0.15 \%$ & $0.08 \%$ & $0.04 \%$ & $0.03 \%$ & $0.03 \%$ \\
\hline 7 & $4 \%$ & $0.61 \%$ & $0.79 \%$ & $0.67 \%$ & $0.58 \%$ & $0.74 \%$ \\
\hline 8 & $1 \%$ & $0.31 \%$ & $0.08 \%$ & $0.04 \%$ & $0.03 \%$ & $0.03 \%$ \\
\hline 9 & $4 \%$ & $0.61 \%$ & $0.39 \%$ & $0.29 \%$ & $0.29 \%$ & $0.21 \%$ \\
\hline 10 & $1 \%$ & $0.15 \%$ & $0.08 \%$ & $0.04 \%$ & $0.03 \%$ & $0.03 \%$ \\
\hline
\end{tabular}

Table III.6 provides a list of harmonic magnitudes for harmonics numbers $h=0$ (DC offset)

through $h=10(600 \mathrm{~Hz})$. According to Table III.1, all current waveforms with harmonic

distortions that incite DC offsets are prohibited. Except for a few exceptions, almost all of the

current waveforms, across all input voltages and for all the loads, contained DC offset

components. The inverter, operating with these harmonic conditions would exceed IEEE 519

standards and is forbidden. The maximum DC offset component magnitude created was $8.85 \%$, 
which appeared for lagging power factors of 0.9 and 0.98 under conditions where the supplied real power was much less than the rated power of the inverter. Operating the inverter at such conditions puts added stress on the inverter's control system to regulate its waveform distortion procured DC-offsets. Power systems often strive toward improving power factor close to unity power factor for better voltage regulation and overall improved power system performance.

When a PV array is shaded by a cloud, its generated power would be rather limited. Additionally, the power factor on the output of most grid connected converters is often close to unity. If a drop in PV-generated power leads to a distorted current waveform with a DC offset, then such a grid-connected PV system should not be connected to the power system. As previously mentioned, current DC offsets saturate and damage transformers within the power system and therefore, such a grid-connected system should be disconnected from the electric grid.

Additionally, the high power factor, low power-consuming loads produce rather large $3^{\text {rd }}$ harmonic $(\mathrm{h}=3)$ magnitudes; several of which exceeded the IEEE 519 limit of 4\%. Operating the inverter at such conditions, as is the case for a cloud-shaded, grid-connected PV system, often produces large $3^{\text {rd }}$ harmonics. Consequently, PV-arrays, under such conditions, should not be allowed to supply power to the electric grid.

Recall that the $3^{\text {rd }}$ harmonic is a member of the triplen harmonic family, which are responsible for the production of zero-sequence neutral current. These triplen harmonics can be very detrimental and cause many problems for a power system. Moreover, the $3^{\text {rd }}$ harmonic is very hard to filter out because its frequency of $180 \mathrm{~Hz}$ is very close to the fundamental frequency of $60 \mathrm{~Hz}$. Therefore, a very expensive, precise low-pass filter must be utilized to remove the $3^{\text {rd }}$ 
harmonic without filtering out the essential fundamental frequency component of $60 \mathrm{~Hz}$. A more in-depth discussion of harmonic filtering will be in the next subsection.

Table III.7: Current Harmonic Limits for $11 \leq \mathrm{h}<17$ and $17 \leq \mathrm{h}<23$

\begin{tabular}{|c|c|c|c|c|c|c|c|c|c|c|c|}
\hline \multicolumn{2}{|c|}{ Current } & \multicolumn{5}{|c|}{$22 \mathrm{~V}$} & \multicolumn{5}{|c|}{$25 \mathrm{~V}$} \\
\hline $\mathrm{h}$ & LIMITS & $\mathrm{R}$ & $R / 2$ & $R / 5$ & $R / 10$ & $R / 15$ & R & $R / 2$ & $\mathrm{R} / 5$ & $R / 10$ & $R / 15$ \\
\hline 11 & $2 \%$ & $0.31 \%$ & $0.24 \%$ & $0.25 \%$ & $0.29 \%$ & $0.38 \%$ & $0.15 \%$ & $0.16 \%$ & $0.12 \%$ & $0.35 \%$ & $0.27 \%$ \\
\hline 12 & $0.5 \%$ & $0.31 \%$ & $0.08 \%$ & $0.08 \%$ & $0.10 \%$ & $0.03 \%$ & $0.15 \%$ & $0.08 \%$ & $0.04 \%$ & $0.03 \%$ & $0.06 \%$ \\
\hline 13 & $2 \%$ & $0.15 \%$ & $0.08 \%$ & $0.21 \%$ & $0.16 \%$ & $0.26 \%$ & $0.15 \%$ & $0.08 \%$ & $0.12 \%$ & $0.26 \%$ & $0.18 \%$ \\
\hline 14 & $0.5 \%$ & $0.31 \%$ & $0.08 \%$ & $0.04 \%$ & $0.06 \%$ & $0.03 \%$ & $0.15 \%$ & $0.08 \%$ & $0.04 \%$ & $0.06 \%$ & $0.06 \%$ \\
\hline 15 & $2 \%$ & $0.15 \%$ & $0.08 \%$ & $0.21 \%$ & $0.16 \%$ & $0.20 \%$ & $0.15 \%$ & $0.08 \%$ & $0.12 \%$ & $0.19 \%$ & $0.15 \%$ \\
\hline 16 & $0.5 \%$ & $0.15 \%$ & $0.08 \%$ & $0.17 \%$ & $0.03 \%$ & $0.06 \%$ & $0.15 \%$ & $0.08 \%$ & $0.04 \%$ & $0.13 \%$ & $0.06 \%$ \\
\hline 17 & $1.5 \%$ & $0.15 \%$ & $0.08 \%$ & $0.17 \%$ & $0.16 \%$ & $0.09 \%$ & $0.15 \%$ & $0.16 \%$ & $0.04 \%$ & $0.29 \%$ & $0.18 \%$ \\
\hline 18 & $0.375 \%$ & $0.15 \%$ & $0.08 \%$ & $0.08 \%$ & $0.10 \%$ & $0.12 \%$ & $0.15 \%$ & $0.08 \%$ & $0.04 \%$ & $0.06 \%$ & $0.06 \%$ \\
\hline 19 & $1.5 \%$ & $0.31 \%$ & $0.08 \%$ & $0.17 \%$ & $0.06 \%$ & $0.12 \%$ & $0.15 \%$ & $0.08 \%$ & $0.04 \%$ & $0.16 \%$ & $0.09 \%$ \\
\hline 20 & $0.375 \%$ & $0.15 \%$ & $0.08 \%$ & $0.17 \%$ & $0.06 \%$ & $0.06 \%$ & $0.15 \%$ & $0.08 \%$ & $0.04 \%$ & $0.06 \%$ & $0.12 \%$ \\
\hline 21 & $1.5 \%$ & $0.46 \%$ & $0.08 \%$ & $0.13 \%$ & $0.06 \%$ & $0.09 \%$ & $0.15 \%$ & $0.08 \%$ & $0.04 \%$ & $0.06 \%$ & $0.09 \%$ \\
\hline 22 & $0.375 \%$ & $0.15 \%$ & $0.32 \%$ & $0.13 \%$ & $0.10 \%$ & $0.09 \%$ & $0.30 \%$ & $0.08 \%$ & $0.08 \%$ & $0.03 \%$ & $0.03 \%$ \\
\hline \multicolumn{2}{|c|}{ Current } & \multicolumn{5}{|c|}{$28 \mathrm{~V}$} & \multicolumn{5}{|c|}{$31 \mathrm{~V}$} \\
\hline h & LIMITS & $R$ & $R / 2$ & $\mathrm{R} / 5$ & $R / 10$ & $R / 15$ & $R$ & $R / 2$ & $\mathrm{R} / 5$ & $R / 10$ & $R / 15$ \\
\hline 11 & $2 \%$ & $0.15 \%$ & $0.32 \%$ & $0.21 \%$ & $0.29 \%$ & $0.36 \%$ & $0.16 \%$ & $0.32 \%$ & $0.20 \%$ & $0.22 \%$ & $0.26 \%$ \\
\hline 12 & $0.5 \%$ & $0.15 \%$ & $0.08 \%$ & $0.04 \%$ & $0.13 \%$ & $0.03 \%$ & $0.16 \%$ & $0.08 \%$ & $0.04 \%$ & $0.03 \%$ & $0.03 \%$ \\
\hline 13 & $2 \%$ & $0.15 \%$ & $0.16 \%$ & $0.17 \%$ & $0.26 \%$ & $0.18 \%$ & $0.16 \%$ & $0.16 \%$ & $0.24 \%$ & $0.19 \%$ & $0.06 \%$ \\
\hline 14 & $0.5 \%$ & $0.15 \%$ & $0.08 \%$ & $0.04 \%$ & $0.10 \%$ & $0.09 \%$ & $0.16 \%$ & $0.08 \%$ & $0.04 \%$ & $0.03 \%$ & $0.03 \%$ \\
\hline 15 & $2 \%$ & $0.15 \%$ & $0.08 \%$ & $0.08 \%$ & $0.16 \%$ & $0.21 \%$ & $0.16 \%$ & $0.08 \%$ & $0.20 \%$ & $0.10 \%$ & $0.09 \%$ \\
\hline 16 & $0.5 \%$ & $0.31 \%$ & $0.08 \%$ & $0.04 \%$ & $0.06 \%$ & $0.09 \%$ & $0.16 \%$ & $0.08 \%$ & $0.04 \%$ & $0.03 \%$ & $0.03 \%$ \\
\hline 17 & $1.5 \%$ & $0.15 \%$ & $0.16 \%$ & $0.04 \%$ & $0.16 \%$ & $0.12 \%$ & $0.16 \%$ & $0.08 \%$ & $0.16 \%$ & $0.06 \%$ & $0.09 \%$ \\
\hline 18 & $0.375 \%$ & $0.15 \%$ & $0.08 \%$ & $0.04 \%$ & $0.06 \%$ & $0.06 \%$ & $0.31 \%$ & $0.08 \%$ & $0.04 \%$ & $0.03 \%$ & $0.03 \%$ \\
\hline 19 & $1.5 \%$ & $0.15 \%$ & $0.08 \%$ & $0.04 \%$ & $0.10 \%$ & $0.15 \%$ & $0.16 \%$ & $0.08 \%$ & $0.04 \%$ & $0.10 \%$ & $0.03 \%$ \\
\hline 20 & $0.375 \%$ & $0.15 \%$ & $0.08 \%$ & $0.04 \%$ & $0.10 \%$ & $0.15 \%$ & $0.16 \%$ & $0.16 \%$ & $0.12 \%$ & $0.03 \%$ & $0.03 \%$ \\
\hline 21 & $1.5 \%$ & $0.15 \%$ & $0.08 \%$ & $0.04 \%$ & $0.06 \%$ & $0.09 \%$ & $0.16 \%$ & $0.08 \%$ & $0.04 \%$ & $0.06 \%$ & $0.03 \%$ \\
\hline 22 & $0.375 \%$ & $0.15 \%$ & $0.08 \%$ & $0.04 \%$ & $0.13 \%$ & $0.09 \%$ & $0.31 \%$ & $0.08 \%$ & $0.04 \%$ & $0.03 \%$ & $0.03 \%$ \\
\hline
\end{tabular}

\begin{tabular}{|r|r|r|r|r|r|r|}
\hline \multicolumn{2}{|c|}{ Current } & \multicolumn{5}{|c|}{$34 \mathrm{~V}$} \\
\hline $\mathrm{h}$ & LIMITS & $\mathrm{R}$ & $\mathrm{R} / 2$ & $\mathrm{R} / 5$ & $\mathrm{R} / 10$ & $\mathrm{R} / 15$ \\
\hline 11 & $2 \%$ & $0.31 \%$ & $0.31 \%$ & $0.21 \%$ & $0.22 \%$ & $0.21 \%$ \\
\hline 12 & $0.5 \%$ & $0.31 \%$ & $0.08 \%$ & $0.04 \%$ & $0.03 \%$ & $0.03 \%$ \\
\hline 13 & $2 \%$ & $0.31 \%$ & $0.16 \%$ & $0.12 \%$ & $0.13 \%$ & $0.06 \%$ \\
\hline 14 & $0.5 \%$ & $0.15 \%$ & $0.08 \%$ & $0.04 \%$ & $0.03 \%$ & $0.03 \%$ \\
\hline 15 & $2 \%$ & $0.15 \%$ & $0.08 \%$ & $0.08 \%$ & $0.03 \%$ & $0.09 \%$ \\
\hline 16 & $0.5 \%$ & $0.31 \%$ & $0.08 \%$ & $0.04 \%$ & $0.03 \%$ & $0.09 \%$ \\
\hline 17 & $1.5 \%$ & $0.15 \%$ & $0.08 \%$ & $0.04 \%$ & $0.03 \%$ & $0.06 \%$ \\
\hline 18 & $0.375 \%$ & $0.31 \%$ & $0.08 \%$ & $0.04 \%$ & $0.06 \%$ & $0.03 \%$ \\
\hline 19 & $1.5 \%$ & $0.15 \%$ & $0.08 \%$ & $0.04 \%$ & $0.06 \%$ & $0.03 \%$ \\
\hline 20 & $0.375 \%$ & $0.31 \%$ & $0.16 \%$ & $0.04 \%$ & $0.03 \%$ & $0.03 \%$ \\
\hline 21 & $1.5 \%$ & $0.31 \%$ & $0.08 \%$ & $0.04 \%$ & $0.03 \%$ & $0.03 \%$ \\
\hline 22 & $0.375 \%$ & $0.15 \%$ & $0.08 \%$ & $0.04 \%$ & $0.03 \%$ & $0.03 \%$ \\
\hline
\end{tabular}

Table III.7 shows the current harmonic magnitudes for harmonic numbers 11 through 22 .

Notice for this range of harmonics that no harmonics exceed IEEE 519 standards. Therefore, 
neither the amount of power supplied to the inverter, nor the PV operating DC voltage would

cause any harmonics, within the range of $11 \leq \mathrm{h} \leq 22$, to exceed IEEE harmonic standards.

Table III.8: Current Harmonic Limits Exceeded for $23 \leq \mathrm{h}<35$

\begin{tabular}{|c|c|c|c|c|c|c|c|c|c|c|c|}
\hline \multicolumn{2}{|c|}{ Current } & \multicolumn{5}{|c|}{$22 \mathrm{~V}$} & \multicolumn{5}{|c|}{$25 \mathrm{~V}$} \\
\hline h & LIMITS & $R$ & $R / 2$ & $\mathrm{R} / 5$ & $R / 10$ & $R / 15$ & $R$ & $R / 2$ & $\mathrm{R} / 5$ & $R / 10$ & $R / 15$ \\
\hline 23 & $0.6 \%$ & $0.31 \%$ & $0.16 \%$ & $0.08 \%$ & $0.03 \%$ & $0.09 \%$ & $0.15 \%$ & $0.08 \%$ & $0.04 \%$ & $0.10 \%$ & \begin{tabular}{|l|l}
6 & $0.06 \%$ \\
\end{tabular} \\
\hline 24 & $0.15 \%$ & $0.31 \%$ & $0.16 \%$ & $0.17 \%$ & $0.10 \%$ & $0.03 \%$ & $0.15 \%$ & $0.08 \%$ & $0.04 \%$ & $0.06 \%$ & $0.03 \%$ \\
\hline 25 & $0.6 \%$ & $0.15 \%$ & $0.08 \%$ & $0.04 \%$ & $0.10 \%$ & $0.03 \%$ & $0.15 \%$ & $0.08 \%$ & $0.04 \%$ & $0.10 \%$ & $0.06 \%$ \\
\hline 26 & $0.15 \%$ & $0.15 \%$ & $0.16 \%$ & $0.17 \%$ & $0.06 \%$ & $0.09 \%$ & $0.15 \%$ & $0.08 \%$ & $0.04 \%$ & $0.03 \%$ & $0.06 \%$ \\
\hline 27 & $0.6 \%$ & $0.46 \%$ & $0.08 \%$ & $0.04 \%$ & $0.10 \%$ & $0.06 \%$ & $0.15 \%$ & $0.08 \%$ & $0.04 \%$ & $0.03 \%$ & $0.06 \%$ \\
\hline 28 & $0.15 \%$ & $0.15 \%$ & $0.08 \%$ & $0.17 \%$ & $0.10 \%$ & $0.06 \%$ & $0.15 \%$ & $0.08 \%$ & $0.04 \%$ & $0.13 \%$ & $0.06 \%$ \\
\hline 29 & $0.6 \%$ & $0.15 \%$ & $0.08 \%$ & $0.08 \%$ & $0.06 \%$ & $0.12 \%$ & $0.15 \%$ & $0.24 \%$ & $0.04 \%$ & $0.10 \%$ & $0.09 \%$ \\
\hline 30 & $0.15 \%$ & $0.31 \%$ & $0.08 \%$ & $0.17 \%$ & $0.10 \%$ & $0.09 \%$ & $0.15 \%$ & $0.08 \%$ & $0.04 \%$ & $0.10 \%$ & $0.09 \%$ \\
\hline 31 & $0.6 \%$ & $0.15 \%$ & $0.08 \%$ & $0.17 \%$ & $0.13 \%$ & $0.12 \%$ & $0.15 \%$ & $0.08 \%$ & $0.04 \%$ & $0.10 \%$ & $0.06 \%$ \\
\hline 32 & $0.15 \%$ & $0.15 \%$ & $0.08 \%$ & $0.17 \%$ & $0.13 \%$ & $0.03 \%$ & $0.15 \%$ & $0.08 \%$ & $0.04 \%$ & $0.06 \%$ & $0.03 \%$ \\
\hline 33 & $0.6 \%$ & $0.31 \%$ & $0.08 \%$ & $0.08 \%$ & $0.10 \%$ & $0.09 \%$ & $0.15 \%$ & $0.08 \%$ & $0.04 \%$ & $0.06 \%$ & $0.03 \%$ \\
\hline 34 & $0.15 \%$ & $0.15 \%$ & $0.08 \%$ & $0.08 \%$ & $0.10 \%$ & $0.06 \%$ & $0.15 \%$ & $0.08 \%$ & $0.04 \%$ & $0.06 \%$ & $0.09 \%$ \\
\hline \multicolumn{2}{|c|}{ Current } & \multicolumn{5}{|c|}{$28 \mathrm{~V}$} & \multicolumn{5}{|c|}{$31 \mathrm{~V}$} \\
\hline h & LIMITS & $R$ & $R / 2$ & $\mathrm{R} / 5$ & $R / 10$ & $R / 15$ & $R$ & $R / 2$ & $\mathrm{R} / 5$ & $R / 10$ & $R / 15$ \\
\hline 23 & \begin{tabular}{l|l}
3 & $0.6 \%$ \\
\end{tabular} & $0.15 \%$ & $0.08 \%$ & \begin{tabular}{|l|l}
6 & $0.04 \%$ \\
\end{tabular} & $0.13 \%$ & $0.03 \%$ & $0.16 \%$ & $0.08 \%$ & $0.04 \%$ & $0.03 \%$ & \begin{tabular}{|l|l}
6 & $0.06 \%$ \\
\end{tabular} \\
\hline 24 & $0.15 \%$ & $0.15 \%$ & $0.08 \%$ & $0.04 \%$ & $0.10 \%$ & $0.06 \%$ & $0.16 \%$ & $0.08 \%$ & $0.04 \%$ & $0.03 \%$ & $0.03 \%$ \\
\hline 25 & $0.6 \%$ & $0.15 \%$ & $0.08 \%$ & $0.04 \%$ & $0.06 \%$ & $0.06 \%$ & $0.16 \%$ & $0.08 \%$ & $0.12 \%$ & $0.03 \%$ & $0.03 \%$ \\
\hline 26 & $0.15 \%$ & $0.15 \%$ & $0.08 \%$ & $0.04 \%$ & $0.10 \%$ & $0.06 \%$ & $0.16 \%$ & $0.08 \%$ & $0.12 \%$ & $0.03 \%$ & $0.03 \%$ \\
\hline 27 & $0.6 \%$ & $0.15 \%$ & $0.08 \%$ & $0.04 \%$ & $0.03 \%$ & $0.12 \%$ & $0.16 \%$ & $0.08 \%$ & $0.04 \%$ & $0.03 \%$ & $0.03 \%$ \\
\hline 28 & $0.15 \%$ & $0.15 \%$ & $0.08 \%$ & $0.08 \%$ & $0.03 \%$ & $0.03 \%$ & $0.16 \%$ & $0.08 \%$ & $0.08 \%$ & $0.03 \%$ & $0.03 \%$ \\
\hline 29 & $0.6 \%$ & $0.31 \%$ & $0.08 \%$ & $0.04 \%$ & $0.26 \%$ & $0.06 \%$ & $0.16 \%$ & $0.08 \%$ & $0.04 \%$ & $0.03 \%$ & $0.03 \%$ \\
\hline 30 & $0.15 \%$ & $0.15 \%$ & $0.08 \%$ & $0.04 \%$ & $0.13 \%$ & $0.09 \%$ & $0.16 \%$ & $0.08 \%$ & $0.16 \%$ & $0.03 \%$ & $0.03 \%$ \\
\hline 31 & $0.6 \%$ & $0.15 \%$ & $0.08 \%$ & $0.04 \%$ & $0.06 \%$ & $0.03 \%$ & $0.16 \%$ & $0.08 \%$ & $0.04 \%$ & $0.03 \%$ & $0.03 \%$ \\
\hline 32 & $0.15 \%$ & $0.15 \%$ & $0.08 \%$ & $0.04 \%$ & $0.16 \%$ & $0.09 \%$ & $0.16 \%$ & $0.16 \%$ & $0.04 \%$ & $0.03 \%$ & $0.03 \%$ \\
\hline 33 & $0.6 \%$ & $0.15 \%$ & $0.16 \%$ & $0.04 \%$ & $0.06 \%$ & $0.06 \%$ & $0.16 \%$ & $0.08 \%$ & $0.20 \%$ & $0.06 \%$ & $0.03 \%$ \\
\hline 34 & $0.15 \%$ & $0.46 \%$ & $0.08 \%$ & $0.04 \%$ & $0.03 \%$ & $0.06 \%$ & $0.16 \%$ & $0.08 \%$ & $0.12 \%$ & $0.03 \%$ & $0.03 \%$ \\
\hline \multicolumn{2}{|c|}{ Current } & \multicolumn{5}{|c|}{$34 \mathrm{~V}$} & & & & & \\
\hline h & LIMITS & $\mathrm{R}$ & $R / 2$ & $R / 5$ & $R / 10$ & $R / 15$ & & & & & \\
\hline 23 & $0.6 \%$ & $0.15 \%$ & $0.16 \%$ & $0.08 \%$ & $0.10 \%$ & $0.09 \%$ & & & & & \\
\hline 24 & $0.15 \%$ & $0.46 \%$ & $0.08 \%$ & $0.08 \%$ & $0.03 \%$ & $0.03 \%$ & & & & & \\
\hline 25 & $0.6 \%$ & $0.15 \%$ & $0.08 \%$ & $0.04 \%$ & $0.03 \%$ & $0.03 \%$ & & & & & \\
\hline 26 & $0.15 \%$ & $0.15 \%$ & $0.08 \%$ & $0.04 \%$ & $0.03 \%$ & $0.03 \%$ & & & & & \\
\hline 27 & $0.6 \%$ & $0.31 \%$ & $0.08 \%$ & $0.04 \%$ & $0.03 \%$ & $0.03 \%$ & & & & & \\
\hline 28 & $0.15 \%$ & $0.31 \%$ & $0.08 \%$ & $0.04 \%$ & $0.03 \%$ & $0.03 \%$ & & & & & \\
\hline 29 & $0.6 \%$ & $0.31 \%$ & $0.08 \%$ & $0.04 \%$ & $0.03 \%$ & $0.03 \%$ & & & & & \\
\hline 30 & $0.15 \%$ & $0.15 \%$ & $0.08 \%$ & $0.04 \%$ & $0.03 \%$ & $0.03 \%$ & & & & & \\
\hline 31 & $0.6 \%$ & $0.31 \%$ & $0.08 \%$ & $0.04 \%$ & $0.03 \%$ & $0.03 \%$ & & & & & \\
\hline 32 & $0.15 \%$ & $0.15 \%$ & $0.08 \%$ & $0.04 \%$ & $0.03 \%$ & $0.03 \%$ & & & & & \\
\hline 33 & $0.6 \%$ & $0.15 \%$ & $0.08 \%$ & $0.04 \%$ & $0.03 \%$ & $0.03 \%$ & & & & & \\
\hline 34 & $0.15 \%$ & $0.46 \%$ & $0.08 \%$ & $0.04 \%$ & $0.03 \%$ & $0.06 \%$ & & & & & \\
\hline
\end{tabular}


Table III.9: Current Harmonic Limits Exceeded for $35 \leq$ h

\begin{tabular}{|c|c|c|c|c|c|c|c|c|c|c|c|}
\hline \multicolumn{2}{|c|}{ Current } & \multicolumn{5}{|c|}{$22 \mathrm{~V}$} & \multicolumn{5}{|c|}{$25 \mathrm{~V}$} \\
\hline h & LIMITS & $\mathrm{R}$ & $R / 2$ & $\mathrm{R} / 5$ & $R / 10$ & $R / 15$ & $R$ & $R / 2$ & $R / 5$ & $R / 10$ & $\mathrm{R} / 15$ \\
\hline 35 & $0.3 \%$ & $0.15 \%$ & \begin{tabular}{|l|}
$0.08 \%$ \\
\end{tabular} & $0.21 \%$ & $0.10 \%$ & \begin{tabular}{|l}
$0.06 \%$ \\
\end{tabular} & $0.15 \%$ & $0.08 \%$ & $0.08 \%$ & \begin{tabular}{|l|}
$0.06 \%$ \\
\end{tabular} & $0.06 \%$ \\
\hline 36 & $0.075 \%$ & $0.15 \%$ & $0.08 \%$ & $0.08 \%$ & $0.10 \%$ & $0.03 \%$ & $0.15 \%$ & $0.08 \%$ & $0.04 \%$ & $0.19 \%$ & $0.06 \%$ \\
\hline 37 & $0.3 \%$ & $0.15 \%$ & $0.08 \%$ & $0.17 \%$ & $0.03 \%$ & $0.06 \%$ & $0.15 \%$ & $0.16 \%$ & $0.04 \%$ & $0.10 \%$ & $0.03 \%$ \\
\hline 38 & $0.075 \%$ & $0.15 \%$ & $0.08 \%$ & $0.08 \%$ & $0.10 \%$ & $0.09 \%$ & $0.15 \%$ & $0.08 \%$ & $0.04 \%$ & $0.06 \%$ & $0.03 \%$ \\
\hline 39 & $0.3 \%$ & $0.15 \%$ & $0.08 \%$ & $0.13 \%$ & $0.06 \%$ & $0.09 \%$ & $0.15 \%$ & $0.08 \%$ & $0.04 \%$ & $0.10 \%$ & $0.09 \%$ \\
\hline 40 & $0.075 \%$ & $0.15 \%$ & $0.08 \%$ & $0.13 \%$ & $0.06 \%$ & $0.03 \%$ & $0.15 \%$ & $0.08 \%$ & $0.04 \%$ & $0.06 \%$ & $0.06 \%$ \\
\hline 41 & $0.3 \%$ & $0.15 \%$ & $0.08 \%$ & $0.08 \%$ & $0.03 \%$ & $0.03 \%$ & $0.15 \%$ & $0.08 \%$ & $0.04 \%$ & $0.13 \%$ & $0.12 \%$ \\
\hline 42 & $0.075 \%$ & $0.15 \%$ & $0.08 \%$ & $0.13 \%$ & $0.06 \%$ & $0.09 \%$ & $0.15 \%$ & $0.08 \%$ & $0.04 \%$ & $0.06 \%$ & $0.09 \%$ \\
\hline 43 & $0.3 \%$ & $0.15 \%$ & $0.08 \%$ & $0.08 \%$ & $0.03 \%$ & $0.12 \%$ & $0.15 \%$ & $0.08 \%$ & $0.04 \%$ & $0.10 \%$ & $0.06 \%$ \\
\hline 44 & $0.075 \%$ & $0.15 \%$ & $0.08 \%$ & $0.08 \%$ & $0.06 \%$ & $0.03 \%$ & $0.15 \%$ & $0.08 \%$ & $0.04 \%$ & $0.03 \%$ & $0.09 \%$ \\
\hline 45 & $0.3 \%$ & $0.15 \%$ & $0.08 \%$ & $0.04 \%$ & $0.06 \%$ & $0.03 \%$ & $0.15 \%$ & $0.08 \%$ & $0.04 \%$ & $0.06 \%$ & $0.06 \%$ \\
\hline 46 & $0.075 \%$ & $0.46 \%$ & $0.08 \%$ & $0.04 \%$ & $0.06 \%$ & $0.06 \%$ & $0.15 \%$ & $0.08 \%$ & $0.04 \%$ & $0.10 \%$ & $0.03 \%$ \\
\hline 47 & $0.3 \%$ & $0.15 \%$ & $0.08 \%$ & $0.08 \%$ & $0.06 \%$ & $0.06 \%$ & $0.15 \%$ & $0.08 \%$ & $0.04 \%$ & $0.06 \%$ & $0.03 \%$ \\
\hline 48 & $0.075 \%$ & $0.15 \%$ & $0.08 \%$ & $0.13 \%$ & $0.06 \%$ & $0.03 \%$ & $0.15 \%$ & $0.08 \%$ & $0.04 \%$ & $0.06 \%$ & $0.03 \%$ \\
\hline 49 & $0.3 \%$ & $0.15 \%$ & $0.08 \%$ & $0.21 \%$ & $0.06 \%$ & $0.06 \%$ & $0.15 \%$ & $0.08 \%$ & $0.04 \%$ & $0.03 \%$ & $0.06 \%$ \\
\hline 50 & $0.075 \%$ & $0.15 \%$ & $0.08 \%$ & $0.17 \%$ & $0.06 \%$ & $0.03 \%$ & $0.15 \%$ & $0.08 \%$ & $0.04 \%$ & $0.10 \%$ & $0.06 \%$ \\
\hline 51 & $0.3 \%$ & $0.15 \%$ & $0.08 \%$ & $0.17 \%$ & $0.06 \%$ & $0.06 \%$ & $0.15 \%$ & $0.08 \%$ & $0.04 \%$ & $0.13 \%$ & $0.06 \%$ \\
\hline
\end{tabular}

\begin{tabular}{|c|c|c|c|c|c|c|c|c|c|c|c|}
\hline \multicolumn{2}{|c|}{ Current } & \multicolumn{5}{|c|}{$28 \mathrm{~V}$} & \multicolumn{5}{|c|}{$31 \mathrm{~V}$} \\
\hline h & LIMITS & $\mathrm{R}$ & $R / 2$ & $R / 5$ & $R / 10$ & $R / 15$ & $R$ & $R / 2$ & $R / 5$ & $R / 10$ & $\mathrm{R} / 15$ \\
\hline 35 & $0.3 \%$ & $0.15 \%$ & $0.08 \%$ & $0.08 \%$ & $0.06 \%$ & $0.09 \%$ & $0.16 \%$ & $0.08 \%$ & $0.08 \%$ & $0.06 \%$ & $0.03 \%$ \\
\hline 36 & $0.075 \%$ & $0.15 \%$ & $0.08 \%$ & $0.13 \%$ & $0.13 \%$ & $0.06 \%$ & $0.16 \%$ & $0.08 \%$ & $0.16 \%$ & $0.03 \%$ & $0.03 \%$ \\
\hline 37 & $0.3 \%$ & $0.46 \%$ & $0.08 \%$ & $0.04 \%$ & $0.16 \%$ & $0.06 \%$ & $0.16 \%$ & $0.08 \%$ & $0.08 \%$ & $0.03 \%$ & $0.03 \%$ \\
\hline 38 & $0.075 \%$ & $0.15 \%$ & $0.16 \%$ & $0.04 \%$ & $0.06 \%$ & $0.03 \%$ & $0.16 \%$ & $0.08 \%$ & $0.08 \%$ & $0.03 \%$ & $0.03 \%$ \\
\hline 39 & $0.3 \%$ & $0.15 \%$ & $0.08 \%$ & $0.04 \%$ & $0.06 \%$ & $0.06 \%$ & $0.16 \%$ & $0.08 \%$ & $0.04 \%$ & $0.03 \%$ & $0.03 \%$ \\
\hline 40 & $0.075 \%$ & $0.15 \%$ & $0.08 \%$ & $0.13 \%$ & $0.10 \%$ & $0.06 \%$ & $0.16 \%$ & $0.16 \%$ & $0.04 \%$ & $0.03 \%$ & $0.03 \%$ \\
\hline 41 & $0.3 \%$ & $0.15 \%$ & $0.08 \%$ & $0.04 \%$ & $0.03 \%$ & $0.03 \%$ & $0.16 \%$ & $0.08 \%$ & $0.04 \%$ & $0.03 \%$ & $0.03 \%$ \\
\hline 42 & $0.075 \%$ & $0.46 \%$ & $0.08 \%$ & $0.04 \%$ & $0.06 \%$ & $0.06 \%$ & $0.16 \%$ & $0.16 \%$ & $0.04 \%$ & $0.03 \%$ & $0.06 \%$ \\
\hline 43 & $0.3 \%$ & $0.76 \%$ & $0.08 \%$ & $0.04 \%$ & $0.06 \%$ & $0.09 \%$ & $0.16 \%$ & $0.08 \%$ & $0.04 \%$ & $0.03 \%$ & $0.06 \%$ \\
\hline 44 & $0.075 \%$ & $0.15 \%$ & $0.08 \%$ & $0.04 \%$ & $0.03 \%$ & $0.09 \%$ & $0.47 \%$ & $0.08 \%$ & $0.04 \%$ & $0.03 \%$ & $0.03 \%$ \\
\hline 45 & $0.3 \%$ & $0.15 \%$ & $0.08 \%$ & $0.04 \%$ & $0.06 \%$ & $0.03 \%$ & $0.16 \%$ & $0.08 \%$ & $0.04 \%$ & $0.03 \%$ & $0.03 \%$ \\
\hline 46 & $0.075 \%$ & $0.15 \%$ & $0.16 \%$ & $0.04 \%$ & $0.06 \%$ & $0.06 \%$ & $0.16 \%$ & $0.08 \%$ & $0.08 \%$ & $0.03 \%$ & $0.03 \%$ \\
\hline 47 & $0.3 \%$ & $0.15 \%$ & $0.08 \%$ & $0.04 \%$ & $0.03 \%$ & $0.06 \%$ & $0.16 \%$ & $0.08 \%$ & $0.12 \%$ & $0.03 \%$ & $0.03 \%$ \\
\hline 48 & $0.075 \%$ & $0.31 \%$ & $0.08 \%$ & $0.04 \%$ & $0.10 \%$ & $0.06 \%$ & $0.16 \%$ & $0.08 \%$ & $0.04 \%$ & $0.03 \%$ & $0.03 \%$ \\
\hline 49 & $0.3 \%$ & $0.15 \%$ & $0.08 \%$ & $0.04 \%$ & $0.03 \%$ & $0.03 \%$ & $0.16 \%$ & $0.08 \%$ & $0.12 \%$ & $0.03 \%$ & $0.03 \%$ \\
\hline 50 & $0.075 \%$ & $0.15 \%$ & $0.08 \%$ & $0.04 \%$ & $0.06 \%$ & $0.06 \%$ & $0.16 \%$ & $0.08 \%$ & $0.04 \%$ & $0.03 \%$ & $0.03 \%$ \\
\hline 51 & $0.3 \%$ & $0.15 \%$ & $0.08 \%$ & $0.04 \%$ & $0.03 \%$ & $0.06 \%$ & $0.16 \%$ & $0.08 \%$ & $0.04 \%$ & $0.03 \%$ & $0.03 \%$ \\
\hline
\end{tabular}

\begin{tabular}{|r|r|r|r|r|r|r|}
\hline \multicolumn{2}{|c|}{ Current } & \multicolumn{5}{|c|}{$34 \mathrm{~V}$} \\
\hline h & LIMITS & $\mathrm{R}$ & $\mathrm{R} / 2$ & $\mathrm{R} / 5$ & $\mathrm{R} / 10$ & $\mathrm{R} / 15$ \\
\hline 35 & $0.3 \%$ & $0.15 \%$ & $0.08 \%$ & $0.04 \%$ & $0.03 \%$ & $0.06 \%$ \\
\hline 36 & $0.075 \%$ & $0.31 \%$ & $0.16 \%$ & $0.04 \%$ & $0.03 \%$ & $0.03 \%$ \\
\hline 37 & $0.3 \%$ & $0.31 \%$ & $0.08 \%$ & $0.04 \%$ & $0.03 \%$ & $0.03 \%$ \\
\hline 38 & $0.075 \%$ & $0.15 \%$ & $0.08 \%$ & $0.04 \%$ & $0.03 \%$ & $0.03 \%$ \\
\hline 39 & $0.3 \%$ & $0.15 \%$ & $0.08 \%$ & $0.04 \%$ & $0.03 \%$ & $0.03 \%$ \\
\hline 40 & $0.075 \%$ & $0.31 \%$ & $0.08 \%$ & $0.04 \%$ & $0.03 \%$ & $0.03 \%$ \\
\hline 41 & $0.3 \%$ & $0.31 \%$ & $0.08 \%$ & $0.04 \%$ & $0.06 \%$ & $0.03 \%$ \\
\hline 42 & $0.075 \%$ & $0.15 \%$ & $0.16 \%$ & $0.04 \%$ & $0.03 \%$ & $0.03 \%$ \\
\hline 43 & $0.3 \%$ & $0.15 \%$ & $0.08 \%$ & $0.04 \%$ & $0.03 \%$ & $0.03 \%$ \\
\hline 44 & $0.075 \%$ & $0.15 \%$ & $0.08 \%$ & $0.04 \%$ & $0.03 \%$ & $0.06 \%$ \\
\hline 45 & $0.3 \%$ & $0.31 \%$ & $0.08 \%$ & $0.04 \%$ & $0.03 \%$ & $0.03 \%$ \\
\hline 46 & $0.075 \%$ & $0.15 \%$ & $0.08 \%$ & $0.04 \%$ & $0.03 \%$ & $0.03 \%$ \\
\hline 47 & $0.3 \%$ & $0.46 \%$ & $0.08 \%$ & $0.04 \%$ & $0.03 \%$ & $0.03 \%$ \\
\hline 48 & $0.075 \%$ & $0.31 \%$ & $0.08 \%$ & $0.04 \%$ & $0.03 \%$ & $0.03 \%$ \\
\hline 49 & $0.3 \%$ & $0.31 \%$ & $0.08 \%$ & $0.04 \%$ & $0.03 \%$ & $0.03 \%$ \\
\hline 50 & $0.075 \%$ & $0.15 \%$ & $0.08 \%$ & $0.04 \%$ & $0.03 \%$ & $0.03 \%$ \\
\hline 51 & $0.3 \%$ & $0.15 \%$ & $0.08 \%$ & $0.04 \%$ & $0.03 \%$ & $0.03 \%$ \\
\hline
\end{tabular}


Lastly, Tables III.8 and III.9 list the harmonics, which falls within the range of $23 \leq \mathrm{h}<35$ and $35 \leq \mathrm{h}$. While harmonic component magnitudes may be small, these tables contain a vast number of harmonic magnitudes, which exceed IEEE 519 constraints. Most of the exceeded harmonic magnitudes exist when the PV inverter supplies a small amount of power to loads with power factors of 0.98 to 0.7 . These are the conditions that a grid-connected PV system inverter would operate with when shaded by cloud-cover, because a shaded PV array often operates at lower voltages and a limited amount of its rated output power. Thus, such operating conditions produce unfavorable and unacceptable generation, and operating PV-array inverters under such conditions is frowned upon.

Nevertheless, unlike the undesired $3^{\text {rd }}$ harmonics, whose frequencies occur near the fundamental frequency ( $h=1$ ), harmonics where $h \geq 23$ are more easily filtered using passive lowpass filtering. This is true because $h \geq 23$ harmonics take place further away from the fundamental frequency. Hence, the required harmonic filter for $h \geq 23$ harmonics need not be such a highorder, precise low-pass filter.

\section{H. Power Filtering}

After explaining harmonic distortion, illustrating its detrimental repercussions, and determining inverter operating modes that produce unfavorable harmonic distortion, this section will introduce methods for remediating harmonic content. The two most common harmonic suppression methods are Passive Power Filtering (PPF) and Active Power Filtering (APF). Both types of power filtering methods reduce the detrimental effects that harmonics have on the grid by removing or reducing a waveform's harmonic content. These filters also utilize RLC circuits' advantageous characteristics to filter out unwanted frequencies from the power system. 
On one hand, PPF power filtering is the most common power filtering method employed because of its circuit simplicity and economic advantages. This type of filter employs a RLC circuit connected in shunt with a harmonic generating source. PPF's resistive, capacitive, and inductive components are designed based on normal operating conditions, and the value of R, L, and $\mathrm{C}$ components determine the harmonic frequencies that are filtered out. Nevertheless, PPF is not short of faults. This type of filter can be rather bulky, its performance degrades over time, and frequency variations affect its operating performance [17]. Under special conditions, PPF filters can also procure resonance at certain frequencies based on the surrounding power system's R, L, and C components. Recall that resonance within a power system can be rather detrimental to a power system and its operating conditions.

On the other hand, APF power filters condition waveform harmonic distortion by actively observing the harmonic content on power system waveforms and then generating a signal with harmonic components rather close in magnitude to those of harmonics within a system.

However, the APF generated signal's harmonic sinusoids are $180 \square$ out of phase from the power system's harmonic components. As illustrated below, when two sine waves operate at the same frequency, but with $180 \square$ phase-difference between them, the sine waves cancel out.

$$
\begin{aligned}
& i_{1}(t)=A \sin (\omega t) \\
& i_{2}(t)=B \sin \left(\omega t-180^{\circ}\right) \\
& i_{\Sigma}(t)=i_{1}(t)+i_{2}(t)=A \sin (\omega t)+B \sin \left(\omega t-180^{\circ}\right) \\
& i_{\Sigma}(t)=(A-B) \sin (\omega t)
\end{aligned}
$$

According to the relationship above, by generating a sine wave with amplitude $\mathrm{B}$, which oscillates at the same frequency, but is phase shifted by $180 \square$ from the other sinusoid with amplitude A, then the result is a new sinusoid that operates at the same frequency as initial two 
waves and has an amplitude of the difference of A and B. Hence, if the amplitude B is rather close in magnitude to that of $\mathrm{A}$, then, when both sinusoids are added together, the two sinusoids practically cancel each other out. It is this sinusoid cancelation method of phase-shifted harmonic generation that APF power filters employ to remove harmonic content from a power system.

Figure III.17 shows an example of how APF can reduce harmonics from a distorted waveform. The distorted waveform can be represented by the combination of a fundamental sinusoid and additional harmonic sinusoids. The larger the harmonic sinusoids become, the less the waveform holds its original sinusoidal shape and the more the waveform becomes distorted. An APF power filter monitors the distorted waveform and determines the distorted waveform's harmonic components. Then, the APF generates a waveform, whose harmonic sinusoidal components are $180 \square$ phase-shifted from the distorted waveform's harmonic components. When the distorted waveform comes in contact

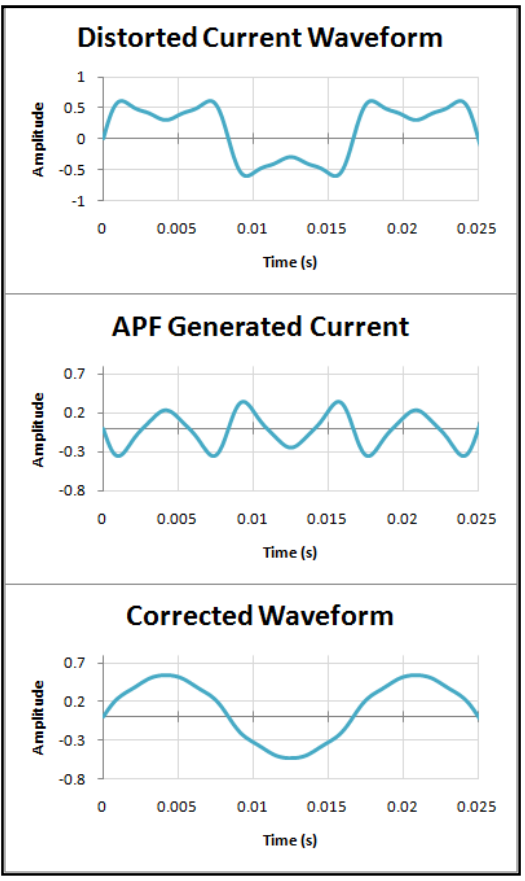

Figure III.17: APF Harmonic Conditioning with the APF-generated waveform, the result is a new waveform, whose harmonic components have been greatly reduced. This newly corrected waveform, still has harmonic content, yet the harmonic content is so reduced, that the corrected waveform shape closely models its fundamental sinusoid component's shape.

\section{Implications for Inverter Harmonic Generation}

While operating inverters at low power levels for various power factor loads produces harmonic content that exceeds IEEE 519 standards, harmonic content violations can be remedied 
with power filtering. Therefore, while cloud-shaded PV arrays may cause harmonic problems, such problems can be remedied with a power filter such as the PPF or APF filters mentioned above.

Still, many distributed generation sources, nonlinear loads, and electronics supply harmonics to the power system without any harmonic filtering. Furthermore, no regulations restricting harmonic generation exist. IEEE 519 standards are only recommendations for acceptable harmonic levels, and it is not until a neighbor or local facility complains about harmonic-induced power quality issues, that actions must be taken to remedy the situation. Unless harmonic filtering is required, many harmonic producing sources will not implement harmonic filters. While APF methods may be very responsive and highly controllable, such methods are inefficient and expensive. On the other hand, while passive filters may be bulky and their performance varies with frequency, passive filters are less expensive, easy to maintain, and often reliable. For this reason, passive filters tend to be the more widely-used harmonic filtering option. Nevertheless, with the ever growing numbers of new PV implementations on the power grid, inverter-generated harmonics will become an issue in the near future. For this reason, harmonic filters will need to be more widely applied in the future so as to maintain power quality throughout the electric grid. 


\section{Effects of Photovoltaic Power Transients on Power Systems}

Reliable and safe power delivery is a very important ideal for utility power grids. Therefore, many power systems creatively employ very extensive power system protection schemes to ensure that power is delivered to the customer safely and reliably. Faults within a power system occur often and are unpreventable. Therefore, power system protection is employed so as to minimize the detrimental effects that a fault may have on power system components. Such protection schemes also strive to maintain grid operation and power flow to non-faulted areas before, during and after the clearing of a fault from a power system. For this reason, power system protection is an art, because a fault must be removed from the power system while still delivering power to the maximum number of customers.

PV arrays, both large and small, provide challenges to the current power system protection schemes. Because photovoltaic-generated power is dependent on the amount of solar irradiance, the PV power delivered to a power system may vary erratically if the solar irradiance undergoes changes. Such is the case when a cloud goes over the sun; the solar irradiance drops drastically and rapidly. Variations in power generation can affect the reliability of power system protection. Therefore, protection schemes must be re-engineered so as to maintain reliability and safety even with the incorporation of new alternative energies.

\section{A. Inverter Fault Contribution and Anti-Islanding Protection}

While a drop in solar irradiance may cause variations in PV power generation and in turn affect power system protection, there are other problems created by the presence of a powerproducing PV array at the load-end of a distribution system. Because a PV array is a generation source, it contributes current when a fault is within close proximity. PV arrays can only connect to the power grid via a grid-connectable inverter. Furthermore, most utility companies require 
that all grid-connectable inverters have anti-islanding protection. Anti-islanding protection discontinues any grid-connected inverter system from energizing a power system after a fault has been cleared and the system should be de-energized. Moreover, inverters with anti-islanding protection may respond similarly to a fault as they would to an islanding condition even without the presence of an island. Inverters' anti-islanding protection often incorporates frequency relay-, overcurrent relay-, and undervoltage relay protection in addition to an inverter's control system to determine if an islanding condition has occurred [18]. Once an islanding event has been detected, most modern inverters will cease energizing a power system between $50 \mathrm{~ms}$ and $100 \mathrm{~ms}$ (3 to 6 cycles) $[19,20]$. IEEE standard 1547 specifies that a grid-connected inverter's antiislanding protection must detect islanding and discontinue inverter power contribution to a power system within 2s $[18,21]$. Clearly, an inverter that can detect an islanding condition and halt energization of a power system within $2 \mathrm{~s}$ has contributed fault current a substantial amount of the time since the moment the fault occurred. In addition, the typical minimum operation time for distribution circuit breakers is 3, 5, or 8 cycles [19]. Therefore, a grid-connected inverter system, such as that of a grid-connected PV array, can contribute fault current from the time of a fault until the time a distribution circuit breaker clears a fault from the power system.

Furthermore, many would assume that a utility line-fault would cause enough of a disturbance to trip the anti-islanding protection of a PV array's inverter. The reason for this misconception is that there will always be a voltage disturbance for a fault condition, which many believe would trip an inverter's anti-islanding undervoltage relay. While this is usually the case for three-phase inverters, single-phase inverters do not always trip due to the voltage disturbance from a fault [22]. In distribution system, the majority of roof-top PV systems are only connected to a single phase of the utility's three phase system. Additionally, most utilities 
use three-phase devices to clear faults. This combination of single phase inverters and threephase fault interrupters can lead to a situation where three-phase breakers open to clear a line fault without creating enough voltage disturbance to trip single-phase inverter anti-islanding protection [22]. An example of such an event would be a single-line-to-ground fault on phase A in a system with a single-phase inverter connected to phase $\mathrm{C}$. With such a case, the circuit breakers could open without creating enough of a voltage disturbance on phase $\mathrm{C}$ to trip the antiislanding protection of the single-phase inverter [22]. Thus phase $\mathrm{C}$ has created an island which the single-phase inverter continues to energize.

Equally important, due to the low thermal inertia of the inverter semiconductor switches, inverters employ active current limiting schemes which limit inverter fault current contributions to $100-200 \%$ of their nominal currents [20]. Convention generators, on the other hand, can supply up to 500-1000\% of their nominal currents [20]. Even though inverter-based distributed generation may not contribute as much fault current as conventional generators, large-scale PV systems or a large number of distributed PV systems within an area can significantly increase the amount of PV contributed fault current within a power system; so much so that it alters the performance of power system protection.

\section{B. PV Effects on Distribution Power System Protection}

Until recently, distribution systems were protected assuming that power flows from the source to the load. However, with the introduction of new alternative energies, the direction of power flow is no longer so simple and distinct. The load and source now coalesce making power flow and distribution protection schemes a much more complex issue. Traditional power protection schemes must be re-engineered to incorporate the change from the old system of purely load feeders to a new system of load and alternative energy source combinations. 
Redesigning a distribution system's components and power system protection for the new emergence of alternative energies on the grid can be costly and difficult. Distribution systems often implement fuses because they are a cost-effective protection system. Fuses, however, are designed based on a unidirectional power flow system. Nevertheless, fuses can operate for bidirectional power flow, but their ratings were designed for reliable operation in a unidirectional power flow system. Overcurrent relays within a radial distribution system are often unidirectional protection schemes, because power tends to flow from the source to the load. However, with the introduction of alternative energies such as PV arrays, power may not always flow in one direction. Therefore, the introduction of new alternative energy sources and their power variations may affect the present overcurrent protection infrastructure. Problems that arise with the introduction of PV array to a distribution system will be further addressed within this section of the paper.

\section{i. PV Effects on Fuse Protection}

Fuses are often used within a distribution system because they are less expensive than other devices such as relays and circuit breakers. There are two properties that characterize fuses: minimum melting time (MM) and total clearing time (TC). Both of these properties describe operation times for an amount of current passing through a fuse. A fuse's MM time describes the amount of time that a fuse can endure a specific amount of current before it is damaged yet not completely tripped. On the other hand, a fuse's TC time describes the amount of time that a fuse can endure a specific amount of current before the fuse fully blows, clearing a fault from the power system. These two properties produce the limiting boundaries for a fuse's characteristic curve. See Figure IV.3 for an example of a fuse characteristic curve. An example of a distribution system with fuse protection is portrayed in Figure IV.1 below. Figure IV.1 will be 
used to show possible protection problems that arise with the addition of a PV array with varying power generation.

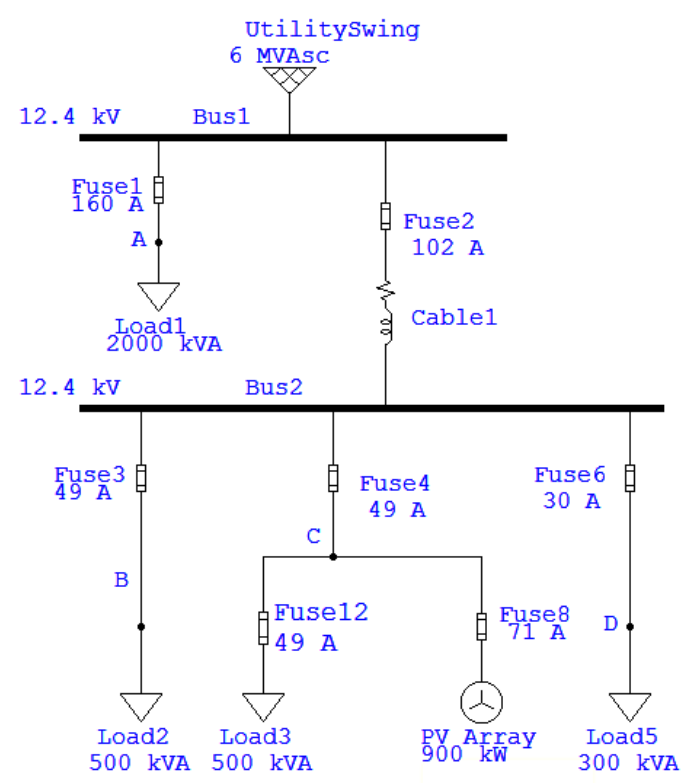

Figure IV.1: Fuse Protected Radial Distribution System with PV Generation.

Figure IV.1 shows a radial distribution system with fuse protection. A PV array of $900 \mathrm{~kW}$ is connected to Node C, and its output capacity can supply enough power to support loads 2 and 3. The utility needs to not supply as much power through Fuse 2 to loads 2,3 and 5 , because the PV array reduces the utility's load by the $900 \mathrm{~kW}$ that it generates.

Additionally, Figure IV.2 portrays the power flow analysis of the radial distribution system of Figure IV.1 for both an unshaded, full sun condition (Figure IV.2[a]) and a shaded condition with 50\% PV output power capability (Figure IV.2[b]). 


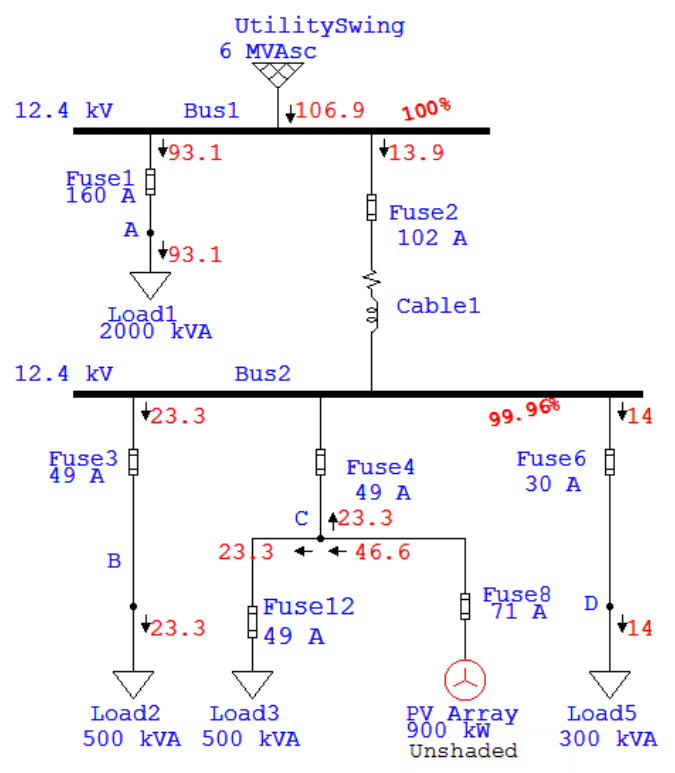

[a]

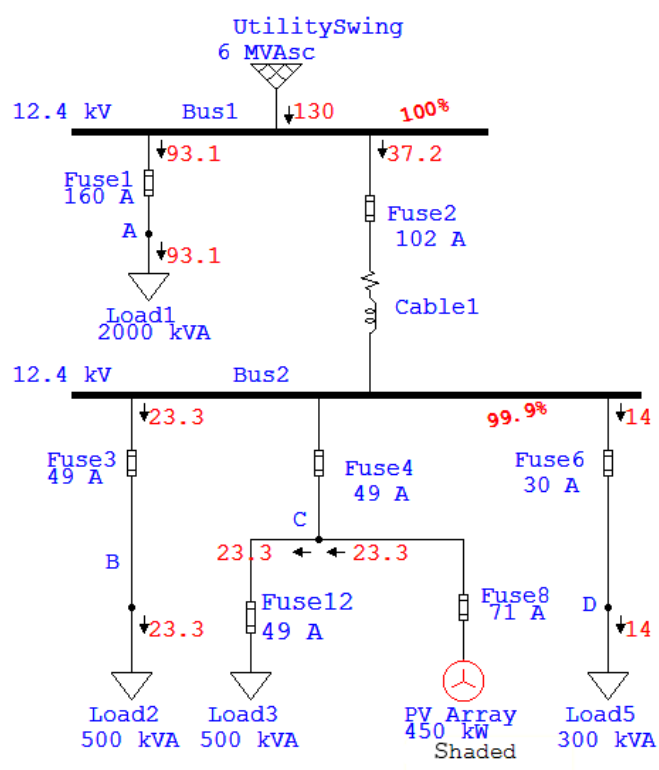

[b]

Figure IV.2: Current Flow for Radial Distribution System with PV Generation, [a] Unshaded PV Conditions, Ppv $=900 \mathrm{~kW}$, [b] Shaded PV Conditions, Ppv $=450 \mathrm{~kW}$

When a new generation source is connected to the power system, the effects of the addition of such source to system are often studied with the generation source supplying its rated output power. Figure IV.2[a] represents the unshaded PV array operating at $100 \%$ rated output power. Now, let's say that a cloud shades the PV array; limiting the power of the array to $50 \%$ $(450 \mathrm{~kW})$ of its rated generation abilities as in Figure IV.2[b]. In other words, the shaded PV array can now only output up to $450 \mathrm{~kW}$, which is less power than the 500kVA load (Load 3) pulls. Consequently, the utility must supply the excess power through cable 1 to make up for the power lost due to shading. It is important to note that PV output power varies with atmospheric conditions. Thus, it is imperative that the effect of both shaded and non-shaded PV operating conditions be investigated when introducing PV systems to distribution systems.

Additionally, recall that the fault contribution of a PV system is limited by the gridconnected inverter, which can supply a fault contribution of no more than twice its nominal operating current. The shaded PV array nominally supplies only 23.3A to the system. Therefore, 
a $180 \mathrm{~kW}$ generator will be used to simulate shaded PV array fault contributions, because it contributes 49A of fault current to the system. Similarly, an unshaded PV array operating at $100 \%$ power output supplies up to $47 \mathrm{~A}$ to the distribution system. Thus, a $360 \mathrm{~kW}$ generator which contributes a fault current of 98A will represent the unshaded PV array for fault simulations.

However, before such fault analysis can be carried out, the distribution system's fuse protection scheme must be understood. That being said, the power flow analysis of Figure IV.2 was used to design the ratings of the radial distribution system's fuses. Fuses are often sized to $\geq 150 \%$ of a normal load operation. Load2, rated at 500kVA, for example, has a normal operating current of $23.3 \mathrm{~A} .150 \%$ of 23.3A is around $35 \mathrm{~A}$. The closest fuse rating available, which

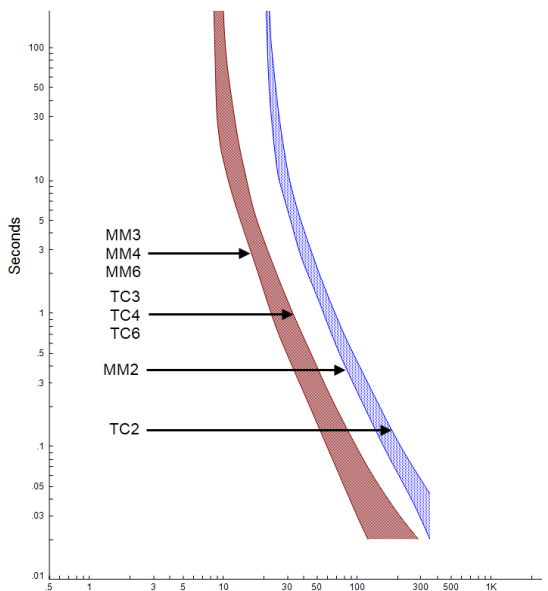

Figure IV.3: Fuse Characteristic Curves is $\geq 150 \%$, is a $49 \mathrm{~A}$ fuse. Additionally, Load 5 only pulls $14 \mathrm{~A}$ so a 30A fuse will be used for Load 5. Fuse 4, which connects to the PV array and Load 3, and Fuse 12, which connects Load 3 to node C, should both be rated for conditions where the PV array is disconnected. With the PV array disconnected, Load 3 pulls 23.3A and therefore, 49A fuses will be used for Fuses 4 and 12 to protect Load 3. Even with 100\% PV generation, the current that flows from the PV array to bus 2 is no more than 23.3A. This current is much less than 49A and therefore a PV array generating $100 \%$ of its rated power will not blow Fuse 4 . Fuse 2, which connects Buses 1 and 2, must also be rated for conditions where the PV array is not connected to the system. By removing the PV array from the system, the total current flowing through Fuse 2 is approximately 60A. Hence, a 100A fuse will be used for Fuse 2. Note that for a 
fault at any of the loads connected to Bus 2, the fuse connecting the specific faulted load to Bus 2 should trip before Fuse 2 trips. This removes a faulted load without disconnecting the other loads on Bus 2 from the utility. To ensure this outcome, for example, the TC values of Fuses 3, 4, and 6 should be set to values less than the MM value of Fuse 2. Refer to Figure IV.3 for a Fuse Characteristic Plot illustrating this point. Therefore, TC3, TC4, and TC6 fuse limits should be set to values less than the MM2 limit. This ensures that faults at Loads 2, 3, or 5 will be cleared without ceasing power flow to the other loads connected to Bus 2.

The next few pages will discuss several different PV-impacted radial distribution examples where fuses within a radial distribution system trip when they are not supposed to. The three cases addressed, where fuses operate incorrectly, are for a fault at Bus 2, a fault at Load 3 and for a fault at Load 1. The following examples cause fuses to operate incorrectly due to the fault contribution of the grid-connected PV array altering the traditional design model which held that power only flowed from the high-voltage generation sources to the distributed system's low-voltage loads. With the addition of a PV array to the distribution network, power now also flows from the load back upstream.

\section{CASE 1 - Fault at Bus 2}

Figure IV.4 shows PV fault contributions to a fault at Bus 2 for unshaded and shaded operating conditions. 

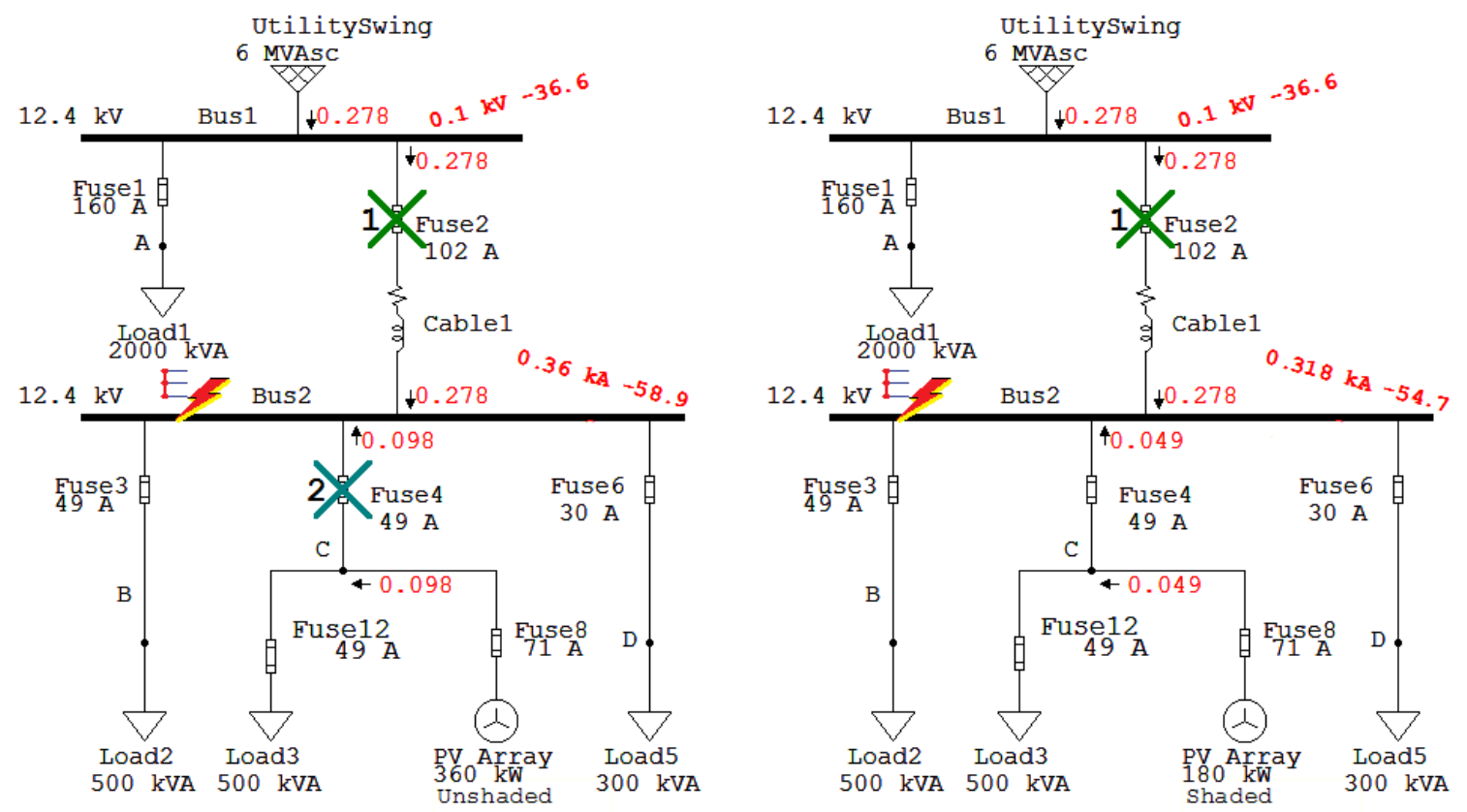

[a]

\begin{tabular}{lllll}
\hline Time $(\mathrm{ms})$ & ID & If $(\mathrm{kA})$ & $\mathrm{T} 1(\mathrm{~ms})$ & $\mathrm{T} 2(\mathrm{~ms})$ \\
\hline 20418 & Fuse2 & 0.278 & 8185 & 20418 \\
566488 & Fuse4 & 0.098 & 15861 & $>566488$
\end{tabular}

\begin{tabular}{|lllll|}
\hline Time $(\mathrm{ms})$ & ID & If $(\mathrm{kA})$ & T1 $(\mathrm{ms})$ & T2 $(\mathrm{ms})$ \\
\hline 20418 & Fuse2 & 0.278 & 8185 & 20418 \\
\hline
\end{tabular}

Figure IV.4: Simulated Fault Analysis for a Fault at Bus 2. [a] - Unshaded PV fault operating conditions, represented by a $360 \mathrm{~kW}$ generator, [b] - Shaded PV fault operating conditions, represented by a $180 \mathrm{~kW}$ generator.

Figure IV.4 shows both the shaded and unshaded PV array fault contributions of the $900 \mathrm{~kW}$ PV array connected to the distribution system. Note that fuse trip times are listed in the tables below each diagram. Additionally, all fault currents are shown in kA and T1 represents the MM time, while T2 represents the TC time for each fuse.

For the unshaded condition in Figure IV.4[a], Fuse 2 trips first and then Fuse 4 trips. For this condition, both fault-contributing sources are disconnected from the faulted bus, which is the expected outcome. When a fault occurs within the power system, the goal of the protection system is to isolate the fault from all fault contributions while maintaining power flow to the largest number of loads. A fault at Bus 2 should always discontinue power flow to Bus 2, which in turn will cease power flow to all Bus 2 connected loads. 
However, for the shaded PV condition of Figure IV.4[b], the fuse protection system fails to disconnect Bus 2 from all fault contributors. Under shaded conditions, the PV array's output is limited due to the reduction in solar irradiance. Therefore, the amount of fault current that the PV array can supply to the fault at Bus 2 will decrease as the solar irradiance decreases. For the case of Figure IV.4[b], the fault current contribution of the PV array is only 49A, which is not sufficient to blow Fuse 4 or Fuse 8 and does not disconnect the PV array fault contribution from the fault at bus 2. Nonetheless, Fuse 2 blows, as was the case with Figure IV.4[a], so as to discontinue the utility bus module's fault contribution. If the PV system's inverter's antiislanding protection does not detect that a fault and or island has occurred after Fuse 2 blows, then the PV array will continue to supply a constant 49A of fault current to the fault at bus 2 . Such a situation is dangerous, especially if utility workers decide to work on Bus 2 with the assumption that the faulted bus has been de-energized. Utility workers are thus at risk of electrocution because the PV array continues to energize the faulted bus. For this reason, backup undervoltage protection should be implemented in the radial distribution system of Figure IV.4 so as to make sure that the PV array ceases to contribute fault current to a fault at Bus 2 .

\section{CASE 2 - Fault at Load 1}

Case 2 investigates the scenario where a fault at Load 1 causes incorrect fuse operation. The scenario is tested for 2 conditions: the shaded PV array $(450 \mathrm{~kW})$ and the unshaded PV array $(900 \mathrm{~kW})$. The results for this case scenario are shown in Figure IV.5 below. 


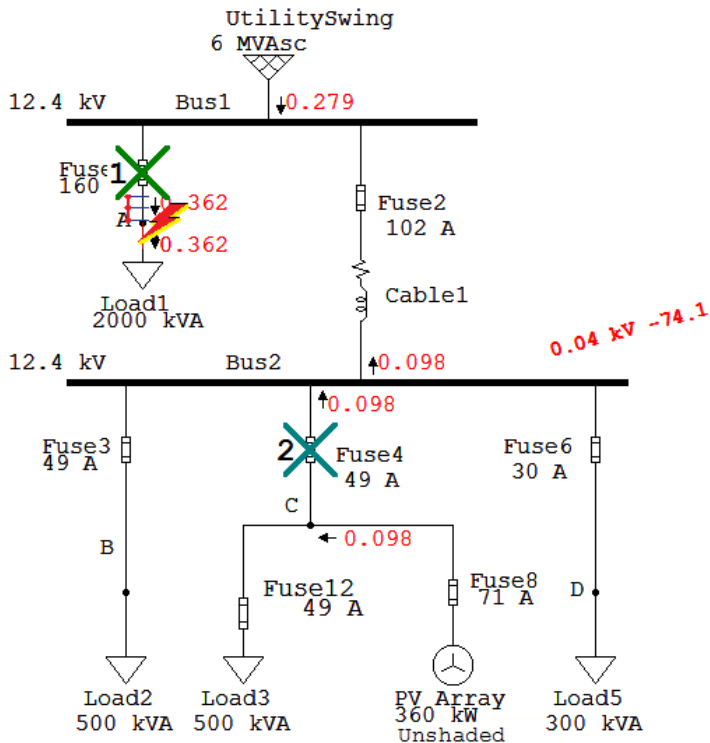

[a]

\begin{tabular}{|lllll}
\hline Time $(\mathrm{ms})$ & ID & If $(\mathrm{kA})$ & $\mathrm{T} 1(\mathrm{~ms})$ & $\mathrm{T} 2(\mathrm{~ms})$ \\
\hline 91841 & Fuse1 & 0.362 & 24239 & 91841 \\
566488 & Fuse4 & 0.098 & 15918 & $>566488$
\end{tabular}

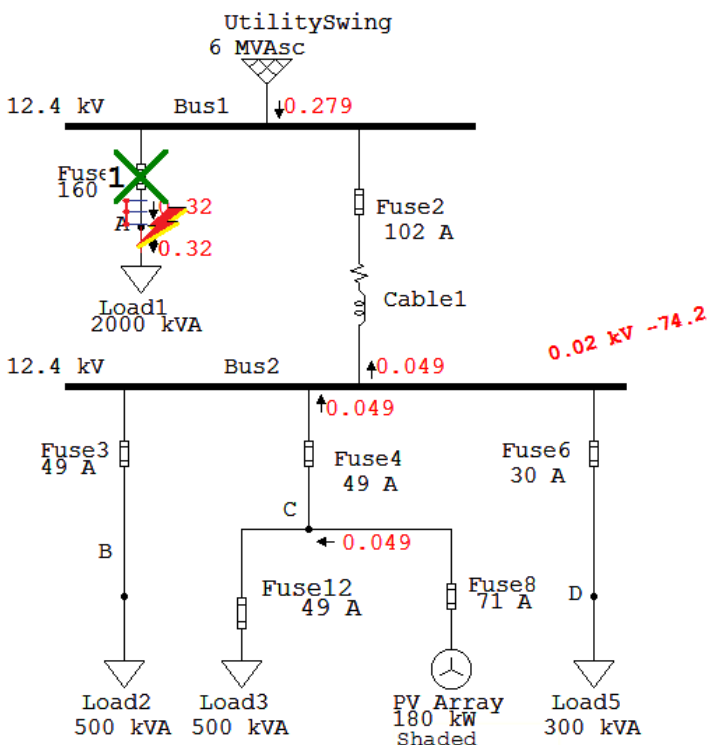

[b]

\begin{tabular}{|lllll|}
\hline Time $(\mathrm{ms})$ & ID & If $(\mathrm{kA})$ & $\mathrm{T} 1(\mathrm{~ms})$ & $\mathrm{T} 2(\mathrm{~ms})$ \\
\hline 601383 & Fuse1 & 0.32 & 340371 & $>601383$ \\
\hline
\end{tabular}

Figure IV.5: Fuse Protection Problems for a Fault at Load 1. [a] - Unshaded PV fault operating conditions, represented by a $360 \mathrm{~kW}$ generator, [b] - Shaded PV fault operating conditions, represented by a $180 \mathrm{~kW}$ generator.

Figure IV.5 shows two scenarios for a fault at Load 1. Scenario 1, represented by Figure IV.5[a], is the condition where the PV is unshaded and outputting $100 \%$ power for a fault at Load 1. On the other hand, scenario 2, represented by Figure IV.5[b], is the condition in which the PV is shaded and can only output $50 \%$ of its power. For Figure IV.5, recall that fuse trip times are listed in the tables below each diagram. Furthermore, all fault currents are shown in kA and $\mathrm{T} 1$ represents the MM time, while T2 represents the TC time for each fuse.

Ideally, for a fault at Load 1, only the fuse connecting Load 1 to Bus 1 (Fuse 1) would trip. This would remove the fault and allow the rest of the power system to operate after the fault has been cleared. Such is the case for the shaded PV operating condition shown in Figure IV.5[b]. 
However, for the unshaded PV condition, while Fuse 1 trips as it should, Fuse 4's MM time occurs before Fuse 1's MM time. This means that for a fault at Load 1, Fuse 4 starts its melting cycle before Fuse 1 does. Although Fuse 1 clears the fault before Fuse 4 has reached its TC time (T2), Fuse 4 has experienced a significant amount of damage from the time its MM time (T1) triggers until the time the fault is cleared. Thus, although Fuse 4 does not fully blow because Fuse 1 reaches its TC time (T2) first, both fuses might need to be replaced for a fault at Load 1 so as to ensure reliable fuse operation for any future faults.

This example shows that the addition of the PV array can lead to extra repair costs for faults at Load 1. Additionally, this problem cannot be resolved by arbitrarily increasing the size of Fuse 4. Notice that Fuse 8, which is rated at 71A, does not trip for a PV-supplied fault current of 98A. Fuse 4 must be designed with a current rating less than 71A that can still trip for 98A. Otherwise, Fuse 4 would not discontinue PV fault contribution for a fault at Bus 2. Therefore, this problem requires other protection schemes such as overcurrent relays to back up the implemented fuse protection schemes when it fails. Nevertheless, the introduction of PV generation also affects overcurrent relay coordination times which could lead to failures in reliable overcurrent relay operation. The next subsection will explain the effects that PV generation has on overcurrent relays. However, one more example, where PV generation affects reliable fuse operation must first be addressed.

\section{Case 3 - Fault at Node C}

Lastly, Figure IV.6 illustrates another example where fuse protection fails to de-energize a fault within the power system. Like the previous two cases, a fault at Node $\mathrm{C}$ is studied for both shaded and unshaded PV operating conditions. 


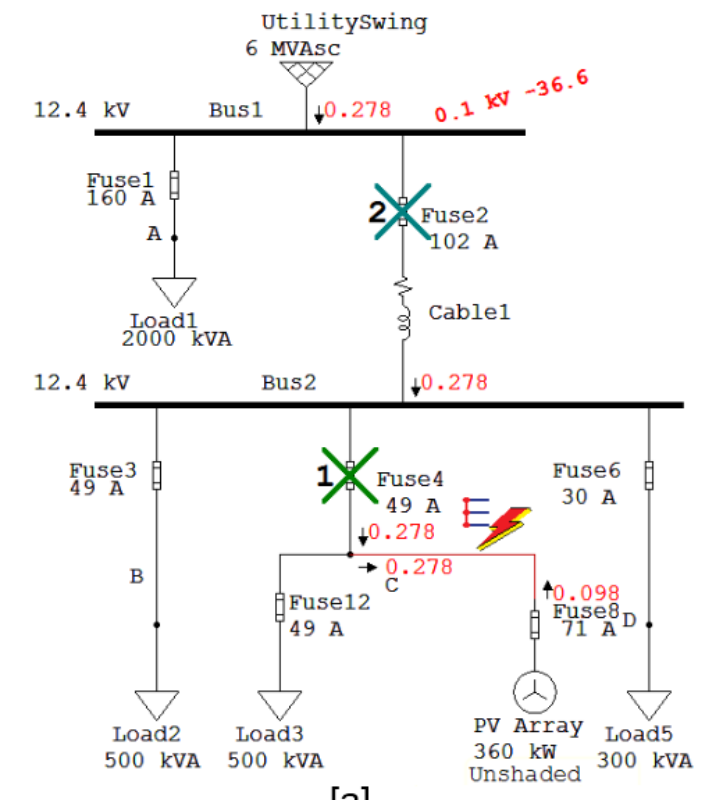

[a]

\begin{tabular}{|lllll|}
\hline Time (ms) & ID & If $(\mathrm{kA})$ & T1 (ms) & T2 (ms) \\
\hline 1542 & Fuse4 & 0.278 & 592 & 1542 \\
20418 & Fuse2 & 0.278 & 8185 & 20418 \\
\hline
\end{tabular}

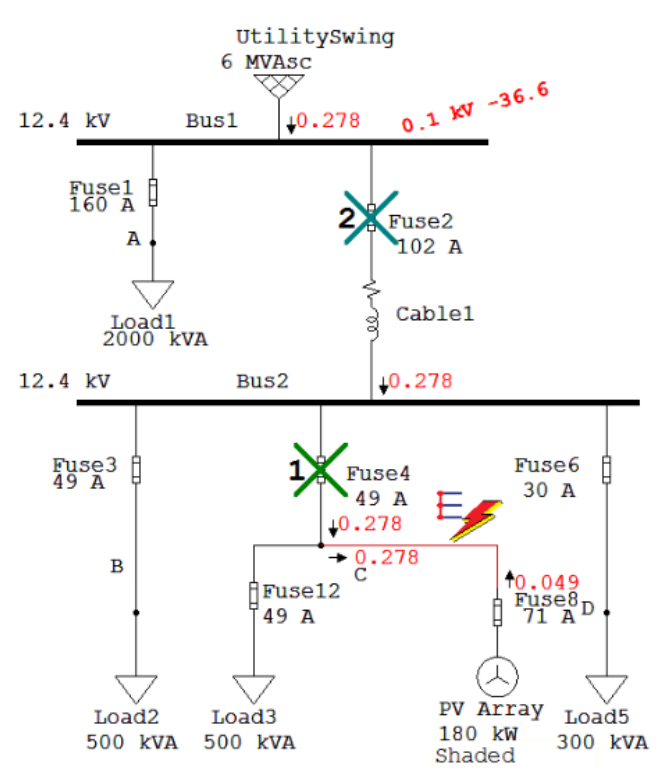

[b]

\begin{tabular}{|lllll|}
\hline Time $(\mathrm{ms})$ & ID & If $(\mathrm{kA})$ & T1 (ms) & T2 (ms) \\
\hline 1542 & Fuse4 & 0.278 & 592 & 1542 \\
20418 & Fuse2 & 0.278 & 8185 & 20418 \\
\hline
\end{tabular}

Figure IV.6: Fuse Protection Problems for a Fault at Node C. [a] - Unshaded PV fault operating conditions, represented by a $360 \mathrm{~kW}$ generator, [b] - Shaded PV fault operating conditions, represented by a $180 \mathrm{~kW}$ generator.

Case 3, represented by Figure IV.6, illustrates another example where fuse protection fails to remove the PV array's fault contribution from the system. For both the shaded and unshaded conditions, Fuse 4 blows due to the 278A flowing from the utility to the fault. According to the fuse tripping tables, listed below each diagram in Figure IV.6, Fuse 4 clears before Fuse 2's MM time (T1) is ever reached. Therefore, a fault at Load 3 does not cause any damage to Fuse 2. Yet, while Fuse 4 removes the utility's contribution to the fault, Fuse 8 fails to remove the PV array's fault contribution for both the shaded and unshaded conditions.

Therefore, if the inverter's anti-islanding protection was to fail, the PV system would continue to energize the fault at Node C. Such a scenario is unsafe because repairing an energized faulted location could lead to electrocution and possibly death. Situations that put others in harmful situations should be avoided at all costs. While Fuse 8's rating can be reduced so as to trip for 
fault currents of 98A, caused by unshaded, full-sun conditions, such ratings cannot be reduced low enough to trip for both shaded and unshaded PV fault currents.

Furthermore, the next available fuse rating below 71A is $49 \mathrm{~A}$, which is rather close to the normal operating PV current of 47A. While such a fuse would trip for a fault at Node C under unshaded, full-sun conditions, the shaded PV array would not contribute enough fault current to blow the 49A fuse. Additionally, if a 49A fuse replaced Fuse 8 for a fault at Bus 2, both Fuses 4 and 8 would trip because their MM and TC times are identical. Similarly, for a fault at Load 1, as investigated in Case 2, both Fuses 4 and 8 would endure damage. Thus, reducing the rating of Fuse 8 to 49A would increase the number of fuses that must be replaced for several other faulted locations. Therefore, although Fuse 8, rated at 71A, does not trip for both shaded and unshaded PV fault contributions, the addition of a backup undervoltage relay at the AC output terminals of the PV system's inverter would guarantee that even if the anti-islanding protection were to fail, the PV array's fault contribution would still be stopped.

The examples used in the above three examples are simplistic so as to illustrate potential fuse protection problems incorporated with the introduction of PV generation to a radial distribution system. Real utility distribution systems are larger and more complicated, making these problems much more complex to solve or even recognize. Such distribution systems employ much more comprehensive, multifaceted protection schemes in which coordination and reliable operation would also be affected by the introduction of photovoltaic generation.

\section{ii. PV Effects on Circuit Breakers and Overcurrent Relay Protection}

Another type of protection often utilized by utility companies is circuit breakers. Circuit breakers are devices controlled by relays which open a section of the power system to clear a fault when a fault is detected by a relay. Relays employ voltage transformers (VTs) and current 
transformers (CTs) to detect faults within a system. When a fault is detected by a relay, the relay will open the circuit breakers within the area so as to disconnect the faulted portion of the grid from the rest of the power system. As previously mentioned, grid-connected PV-arrays contribute fault currents when connected to a power system. Additionally, the amount of power that a PV array can output also affects the amount of fault current that the PV array can contribute to a fault. Therefore, grid-connected PV arrays alter the fault currents that relays observe which in turn could affect whether the relay system can properly detect and remove a fault. The following radial distribution system, shown in Figure IV.7, will be used to illustrate how variations in PV-generated power affect the overall performance of an overcurrent relay protection scheme.

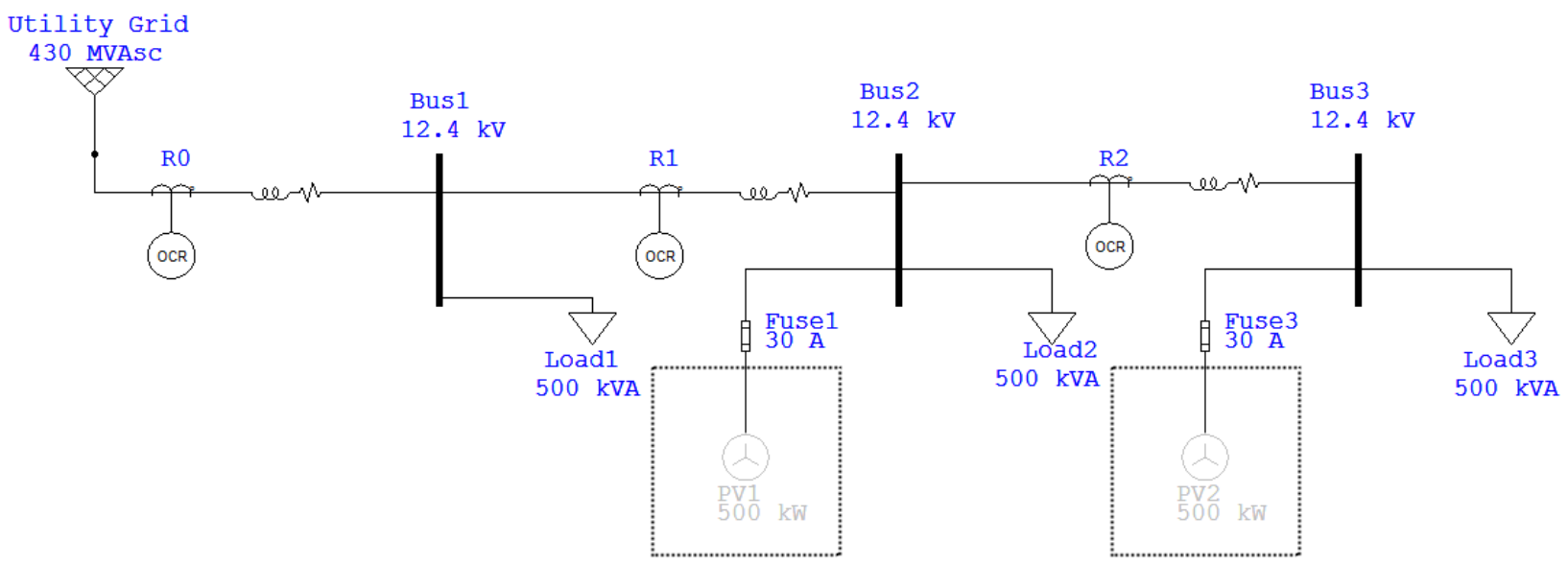

Figure IV.7: Radial Distribution System with Overcurrent Relay Protection

With no PV arrays connected to the above radial distribution system, the overcurrent relay protection system would be designed so as to remove a fault while removing the least amount of loads from the system. For a fault at Bus 3, for example, Relay R2 should trip, but R1 and R0 should not. When Bus 3 is faulted, R0, R1, and R2 will all see the same fault current. Thus, the relays must be coordinated so that $\mathrm{R} 2$ trips before $\mathrm{R} 0$ and $\mathrm{R} 1$. 
Overcurrent relay coordination is accomplished by setting relays' current transformer ratios (CTR), current tap settings (CTS) and time dial settings (TDS). As mentioned before, relays utilize current transformers which have a current transformer ratio (CTR) that steps the large current flowing through a phase conductor down to a smaller secondary current. Overcurrent relays observe this secondary current to determine if a current flowing through a phase conductor is large enough that it could damage power system equipment. If the phase current is too large, it should be removed from the power system by opening the phase conductor circuit breaker.

Overcurrent relays, therefore, compare the secondary current from the CT with their current tap setting (CTS), also known as pick-up current, to determine if a circuit breaker should be tripped. In addition to the CTR and CTS settings, relay coordination is also determined by a relay's TDS setting. Most overcurrent relays follow tripping curves that control the amount of time a relay trips based on the amount of current flowing through the phase conductor CT. TDS settings produce various tripping curves. The smaller the TDS setting, the quicker an overcurrent relay will trip for a given amount of current.

For a fault at Bus 3, the TDS of relay R2 (TDS 2 ) will be smaller than the TDS of R1 (TDS 1 ), which will be smaller than the TDS of R0 (TDS $)_{0}$. This will ensure that $\mathrm{R} 2$ will trip first for a fault at Bus 3, and if R2 fails to trip, then R1 provides backup protection because it is set to trip shortly after R2 trips. Similarly, R0 backs up R1 just in the case that it also fails. The short delay between $\mathrm{R} 2$ tripping and $\mathrm{R} 1$ tripping, or the short delay between $\mathrm{R} 1$ tripping and $\mathrm{R} 0$ tripping is known as the coordination time interval (CTI). Figure IV.8 shows the tripping curves and relay coordination setup for Relays R0, R1, and R2. 


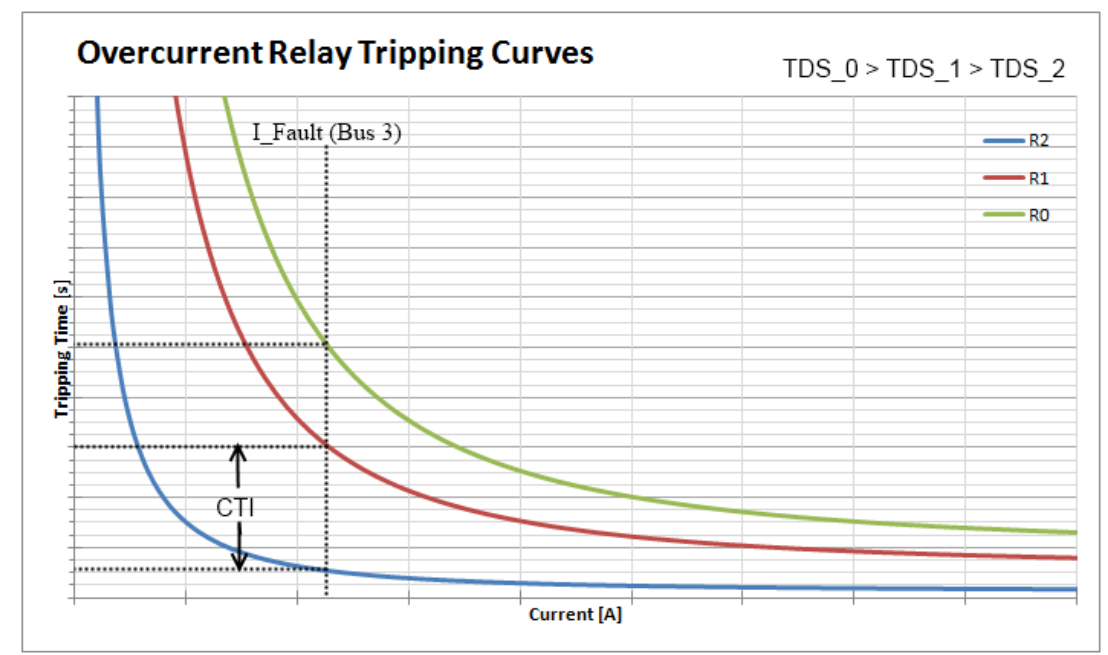

Figure IV.8: Relay Coordination for Radial Distribution System of Figure IV.7 A power flow diagram for the radial distribution system of Figure IV.7 is shown in Figure IV.9 below. This diagram shows currents rather than power flow values.

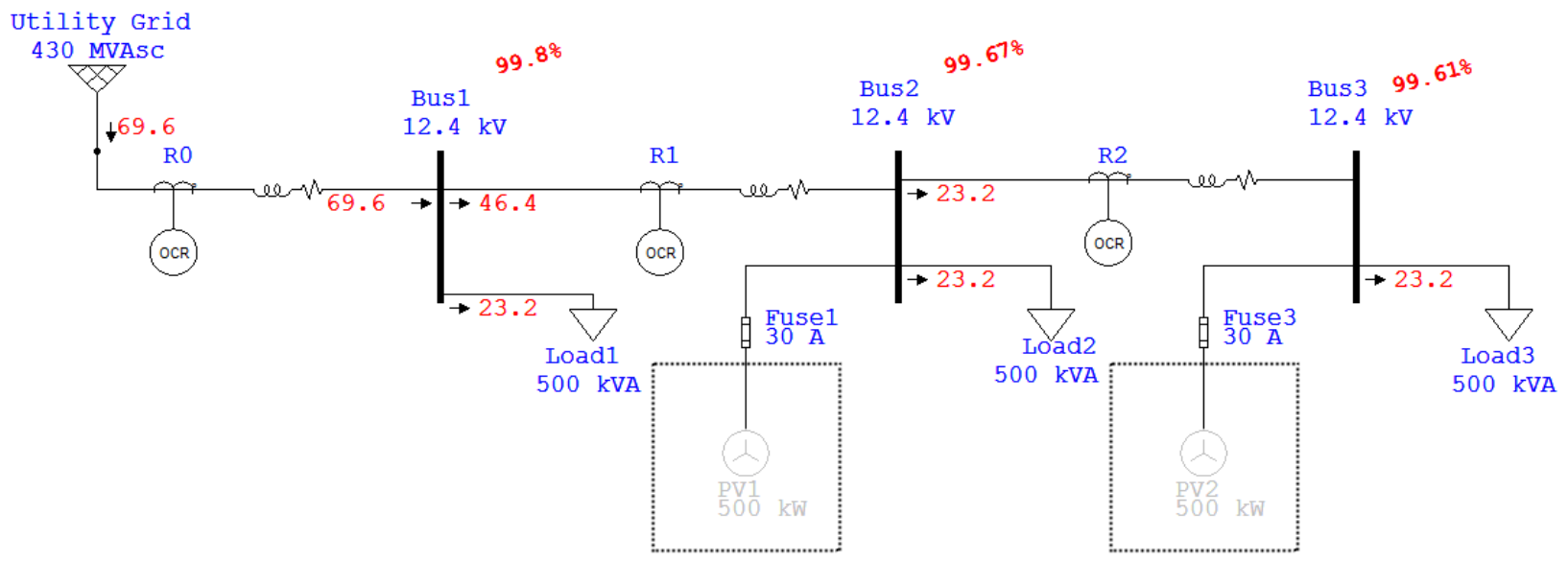

Figure IV.9: Radial Distribution System Current Flow Diagram with No PV Connected

Figure IV.9 shows the currents that flow through the radial distributions system. The currents traveling through each overcurrent relay will be used to calculate the relay coordination of the system.

The primary currents flowing through the relays' CTs are:

$I_{R 2}=23.2 A ; I_{R 1}=46.4 A ; I_{R 0}=69.6 A$

From these currents the CTR ratios are determined: 
$C T R_{2}=50: 5=10$

$C T R_{1}=50: 5=10$

$C T R_{0}=100: 5=20$

The secondary currents seen by the overcurrent relays are calculated as follows:

$I_{R^{n}}=I_{R} / C T R$

$I_{R 2}=23.2 / 10=2.32 \mathrm{~A}$

$I_{R 1^{\prime \prime}}=46.4 / 10=4.64 \mathrm{~A}$

$I_{R 0^{0}}=69.6 / 20=3.48 \mathrm{~A}$

CTS Settings were chosen for R0, R1, and R2 based on the secondary currents. They are as follows:

$\mathrm{CTS}_{2}=2.5 \mathrm{~A}$

$C T S_{1}=5 A$

$C T S_{0}=3.5 A$

Figure IV.10 shows the fault currents flowing through the radial distribution system for a fault at Bus 3. Note that all currents listed in Figure IV.10 are shown in kA.

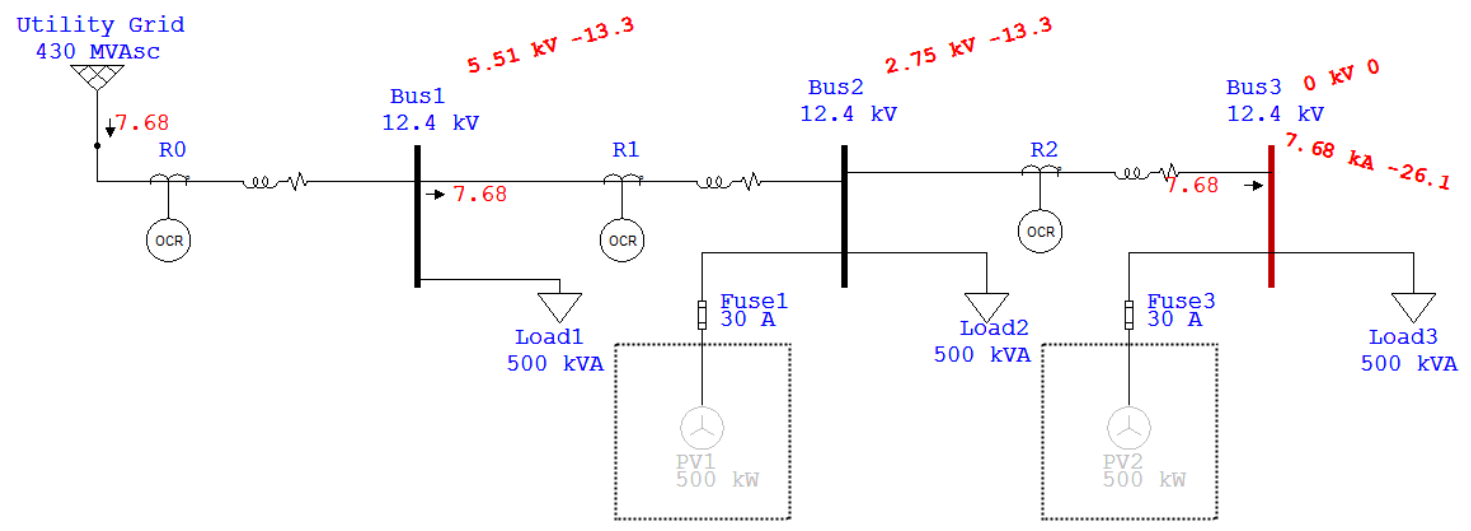

Figure IV.10: Fault Currents Flowing for Fault at Bus 3 with No PV Connected 
For a fault at Bus 3, the secondary current, in multiples of the CTS ratings, as seen by each relay are calculated below:

$$
\begin{aligned}
& M=\frac{I_{F @ 3}}{(C T R)(C T S)} \\
& M_{2}=\frac{7.68 \times 10^{3}}{(10)(2.5)}=307.2
\end{aligned}
$$

For a fault at Bus 3, Relay R2 should trip before Relays R1 and R0. Therefore, R2 will have a $\mathrm{TDS}_{2}=0.5$, which is the smallest TDS value. Thus, for a given fault current seen by all 3 relays, R2 will trip in the shortest amount of time.

All 3 Relays have trip curves equated by the following equation. For the sake of this paper, the CO-8 Relay trip curves will be used to coordinate all 3 relays. The equation for calculating the tripping time (in seconds) for a given current multiple of the CTS setting (M) is:

$T_{T}=\frac{8.9341(T D S)}{M^{2.0938}-1}+0.17966(T D S)+0.028 \quad[23]$

Using the $\mathrm{M}$ equation above, the tripping time equation can also be written as:

$$
T_{T}=\frac{8.9341(T D S)}{\left[\frac{I}{(C T R)(C T S)}\right]^{2.0938}-1}+0.17966(T D S)+0.028
$$

NOTE: I equals the primary current seen by a relay's CT.

Therefore, for $\mathrm{M}_{2}=307.2, \mathrm{~T}_{\mathrm{T} 2}=0.117 \mathrm{~s}$. In order to remove any time delay errors, in addition to the relay time $\mathrm{T}_{\text {Breaker }}=0.083$ seconds is included to the operating time of each relay.

Thus, the operation time for $\mathrm{R} 2$ is:

$\mathrm{T}_{\mathrm{op} 2}=\mathrm{T}_{\mathrm{T} 2}+\mathrm{T}_{\mathrm{Breaker}}=0.117 \mathrm{~s}+0.083 \mathrm{~s}=0.2 \mathrm{~s}$ 
Additionally, a coordination time of $\mathrm{T}_{\text {Coord }}=0.3$ seconds is added between each relay operation time so as to remove any cross-operation overlap timing between relays. Thus to calculate the operating time of Relay 1:

$\mathrm{T}_{\mathrm{op} 1}=\mathrm{T}_{\mathrm{op} 2}+\mathrm{T}_{\text {Coord }}=0.2 \mathrm{~s}+0.3 \mathrm{~s}=0.5 \mathrm{~s}$.

With $\mathrm{M}$ equation listed previously, $\mathrm{M}_{1}$ and $\mathrm{M}_{0}$ can calculated to be:

$\mathrm{M}_{1}=153.6$

$\mathrm{M}_{0}=109.7$

Knowing $\mathrm{T}_{\mathrm{op} 1}$ and $\mathrm{M}_{1}$, the TDS curve where both values intersect gives us $\operatorname{TDS}_{1}=3$.

$\mathrm{T}_{\mathrm{op} 0}=\mathrm{T}_{\mathrm{op} 1}+\mathrm{T}_{\text {Breaker }}+\mathrm{T}_{\text {Coord }}=0.5 \mathrm{~s}+0.083 \mathrm{~s}+0.3 \mathrm{~s}=0.883 \mathrm{~s}$

Knowing $\mathrm{T}_{\mathrm{op} 0}$ and $\mathrm{M}_{0}$, the TDS curve where both values intersect gives us $\operatorname{TDS}_{0}=5$.

Therefore, the 3 equations for calculating tripping times are listed below using the equation:

$T_{T 2}=\frac{4.46705}{\left(\frac{I}{25}\right)^{2.0938}-1}+0.11783$

$T_{T 1}=\frac{26.8023}{\left(\frac{I}{50}\right)^{2.0938}-1}+0.56698$

$T_{T 0}=\frac{44.6705}{\left(\frac{I}{70}\right)^{2.0938}-1}+0.9263$

These three equations can be used to calculate the breaker tripping times for any primary current flowing through any relay's CT. For example, for a fault at Bus 3, the tripping times for the 3 relays are listed in Table IV.1 below:

Table IV.1: Summary of Relay Tripping Times for Fault at Bus 3

\begin{tabular}{|c|c|c|c|}
\hline & Ro & R1 & R2 \\
\hline Tripping Time [s] & 0.93 & 0.568 & 0.118 \\
\hline
\end{tabular}


For a fault at Bus 3, R2 trips first, followed by R1 and then R0, which is exactly what should occur. Now that the overcurrent relays have been coordinated for the radial distribution system shown in Figure IV.7; several problems arise with the connection of PV to the radial distribution system.

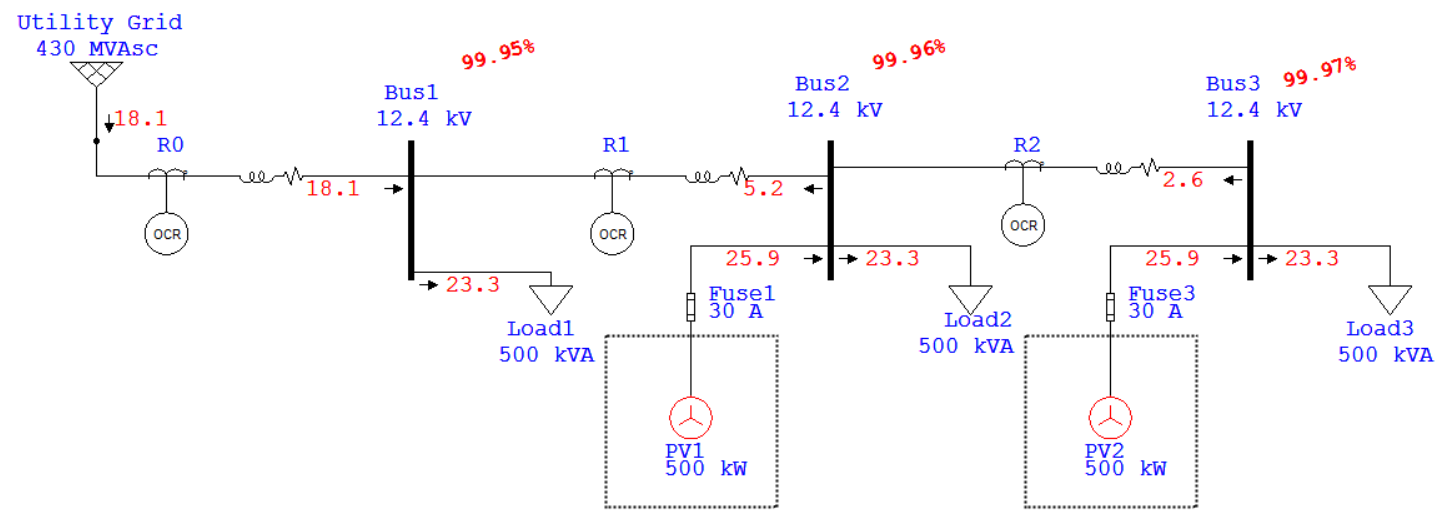

\section{Figure IV.11: Current Flow of the Radial Distribution System with PV Generation}

Figure IV.11 shows the power flow of the radial distribution system of Figure IV.7 with PV Generation connected. Moreover, Figure IV.11 shows the currents flowing rather than power flow. Notice that a 500kW array supplies 25.9A to the power system. Recall that inverters only contribute up to twice their rated current to a fault. Therefore, for a fault condition, the maximum amount of current that each PV array can contribute to the fault is around 52A. For fault analysis, the PV arrays, represented by generators, must be resized so that their fault contributions are close to 52A. A $200 \mathrm{~kW}$ generator, which supplies a maximum of 54A of fault current, will represent the $500 \mathrm{~kW}$ unshaded PV array for fault conditions.

Recall also that the amount of solar irradiance that a PV array is exposed to limits the amount of power that the PV array can generate. Therefore, solar irradiance also limits the amount of fault current that a PV array's inverter can contribute to a fault. Say that a cloud shades a PV array and limits the PV array's power output to $50 \%$ of nominal power. Therefore, the fault current that a shaded PV array can contribute will be reduced by $50 \%$ as well. A shaded 
PV array can, therefore, only contribute around 22A of fault current to the power system, and a $80 \mathrm{~kW}$ generator, which supplies a maximum fault current of $22 \mathrm{~A}$, will represent a shaded PV array under fault conditions.

Additionally, Fuse 1 and Fuse 3 are rated at 30A while the maximum operating current under non-shaded conditions of the PV array is around 26A. Such a decision was made because the next available fuse rating of 49A does not blow for a fault current of 54A, while a 30A fuse blows in around 500 seconds for a fault current of 54A. Thus, although $30 \mathrm{~A}$ is $118 \%$ of the normal, unshaded operating current supplied by the 500kW PV array, 30A fuses were used to discontinue PV1 and PV2 from contributing fault current to the system under certain fault conditions.

\section{Case 1 - Fault at Bus 1}

Ideally, for a fault on Bus 1, relays R0 and R1 should trip and R2 should not trip. However, for a fault on Bus 1 with both PV1 and PV2 connected to the radial system, the relays do not follow that result. Figure IV.12 shows the radial distribution system and fault current contributions for a fault at Bus 1 .

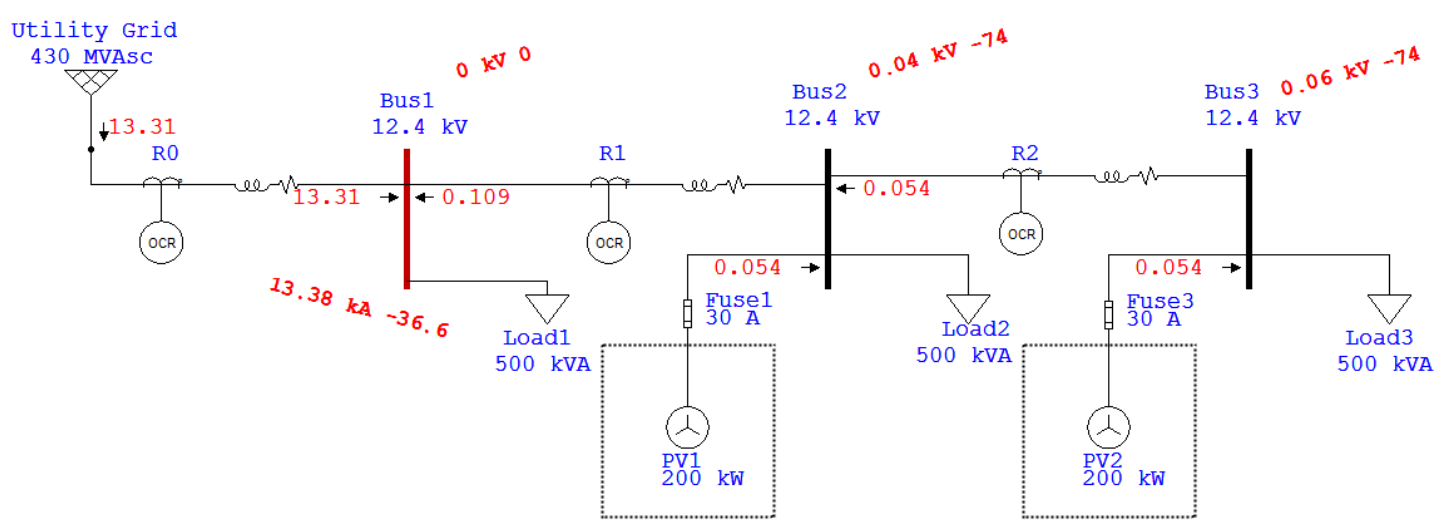

Figure IV.12: Fault Current Contributions for a Fault at Bus 1 
The primary fault currents flowing through the overcurrent relays are used to calculate the tripping times for the three relays, and the tripping times are shown in Table IV.2 below:

Table IV.2: Relay and Fuse Primary Currents and Tripping Times for Fault at Bus 1

\begin{tabular}{|l|r|r|r|r|r|}
\cline { 2 - 6 } \multicolumn{1}{c|}{} & \multicolumn{1}{l|}{ R0 } & R1 & R2 & Fuse 1 & Fuse 3 \\
\hline Primary Current [kA] & 13.31 & 0.109 & 0.054 & 0.054 & 0.054 \\
\hline Tripping Time [s] & 0.927 & 7.083 & 1.23 & 500 & 500 \\
\hline
\end{tabular}

Table IV.2 shows that for a fault at Bus 1, R0 trips first, then R2, and lastly R1. Notice that R2 trips before R1 trips. This can be attributed to the fact that inverters do not contribute much fault current, and there is not much difference between the fault current traveling through R1 and R2 when compared to R0. Therefore, because R1 and R2 have different TDS settings and the fault current contributions are small, for rather similar fault currents, R1 has a much larger trip time than R2. Ideally, R1 would trip before R2 so as to clear the fault from the system while maintaining continuity among the loads on the right end of the distribution system.

Additionally, because the fault contribution of inverter-connected generation sources is rather limited, the trip times for Fuses 1 and 3 are much larger than the overcurrent trip times. While, the purpose of this subsection is to focus on the effects that PV generation has on overcurrent relay coordination and reliable operation, fuse protection was added so as to discontinue PV fault contribution when overcurrent relays fail to do so.

\section{Case 2 - Fault at Bus 2 and Cloud shades PV2}

The next case deals with the effects that cloud shading has on overcurrent coordination. If the fault contribution current of a source does not exceed a relay's CTS settings, the relay will not trip even though such a source is feeding a fault. This condition is known as underreaching, and if a relay does not trip, the source contributing to a fault will continue to feed the fault until the fault is removed. The following two figures (Figure IV.13 and IV.14) show how when PV2 is 
shaded, its fault current contribution causes relay R2 to underreach and not trip for a fault at Bus 2.

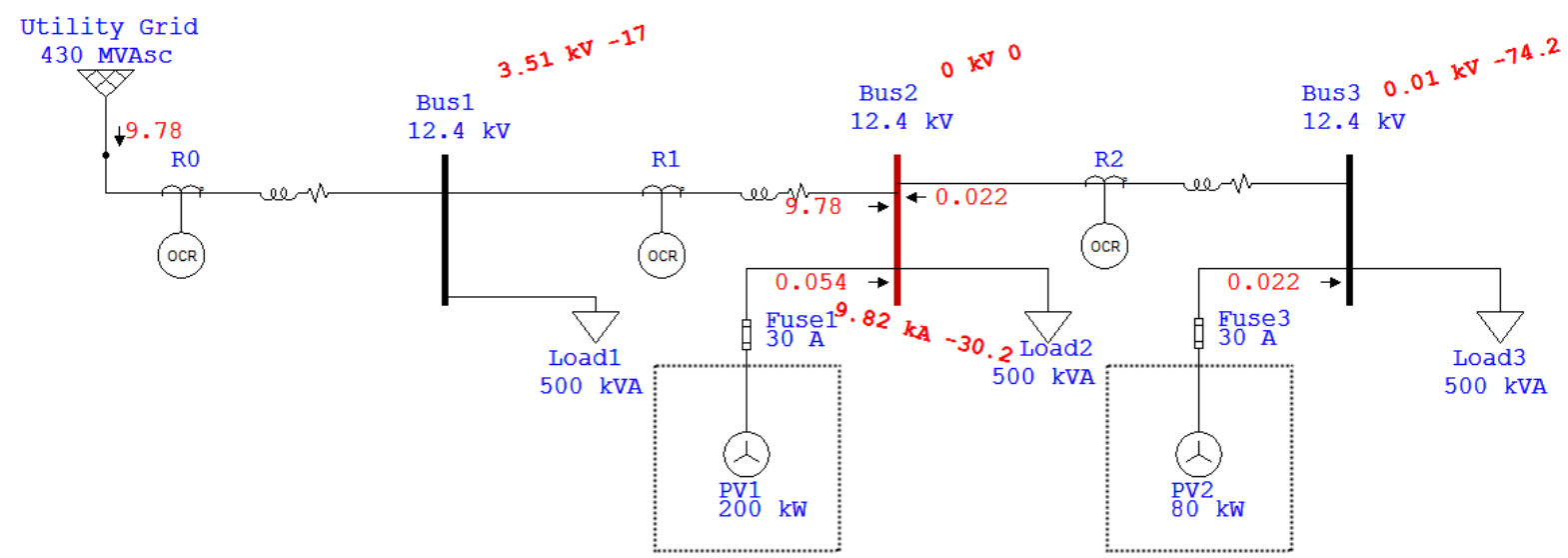

Figure IV.13: Single Line-Ground Fault at Bus 2 with PV2 Shaded and PV1 Unshaded

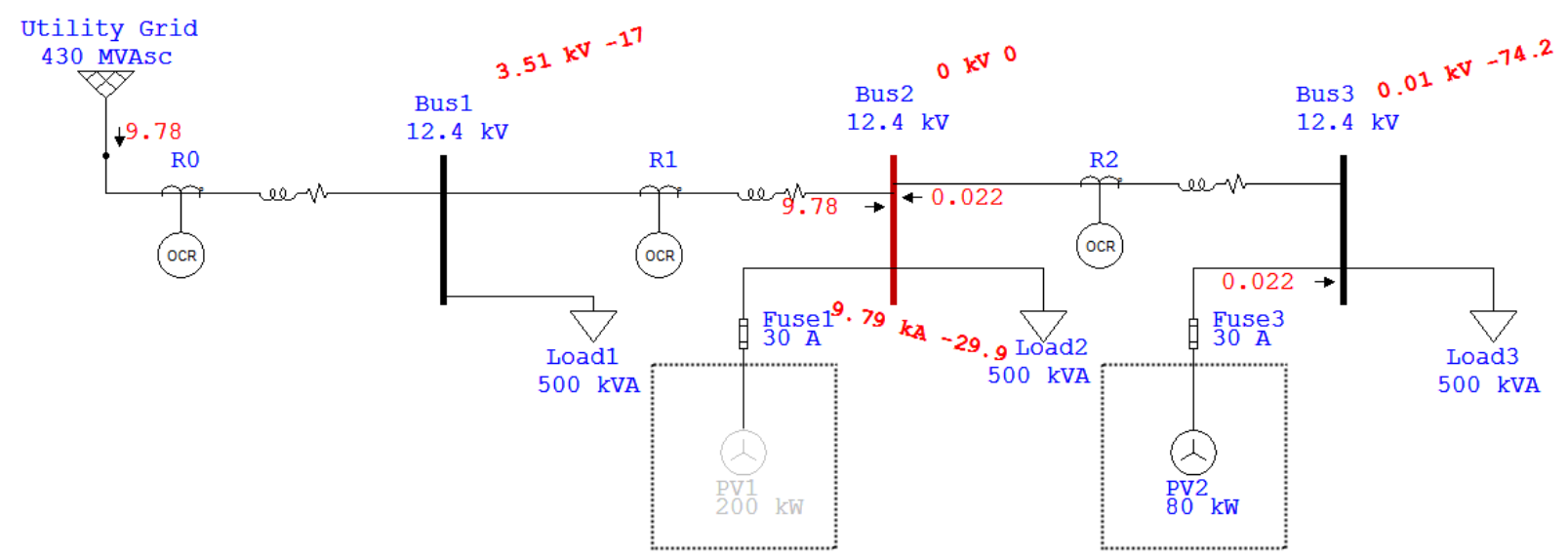

Figure IV.14: Fault at Bus 2 with PV2 Shaded and No PV1 Connected

Figures IV.13 and IV.14 show 2 different scenarios where a shaded PV2 array leads R2 to underreach and not trip for a fault at Bus 2. The first scenario has both PV1 and PV2 contributing fault current, while the second scenario has only PV2 connected to the radial distribution system. Table IV.3 below shows the tripping times for relays R0, R1, and R2 as well as fuses 1 and 3 . 
Table IV.3: Tripping Times for PV2 Shaded

\begin{tabular}{|l|l|r|r|r|r|r|}
\cline { 2 - 7 } \multicolumn{1}{c|}{} & R0 & R1 & R2 & Fuse 1 & Fuse 3 \\
\hline \multirow{2}{*}{ PV1, PV2 } & Primary Current [kA] & 9.78 & 9.78 & 0.022 & 0.054 & 0.022 \\
\cline { 2 - 7 } & Tripping Time [s] & 0.928 & 0.567 & N/A & 500 & N/A \\
\hline \multirow{2}{*}{ PV2 Only } & Primary Current [kA] & 9.78 & 9.78 & 0.022 & N/A & 0.022 \\
\cline { 2 - 7 } & Tripping Time [s] & 0.928 & 0.567 & N/A & N/A & N/A \\
\hline
\end{tabular}

Notice for both scenarios that R2 does not even trip. Ideally, for a fault at Bus 2, Relays 1 and 2 would trip so as to remove the sources from both sides of Bus 2 from contributing fault current to the fault. However, when PV2's power is limited to 50\%, due to a cloud covering the sun, PV2's fault current contribution of 22A is less current than what load 3 would normally pull during normal, non-faulted operating conditions. R2 and Fuse 3 were designed to trip for a current larger than the $23.3 \mathrm{~A}$ which Load 3 pulls during normal conditions. Therefore, $22 \mathrm{~A}$ contributed by the shaded PV array PV2 will not trip R2 nor Fuse 3. Moreover, R2's pick-up current setting cannot be reduced to make R2 trip for $22 \mathrm{~A}$ fault current contribution, because such a setting would trip R2 during non-faulted normal operating conditions when Load 3 pulls its 23.3A. Therefore, a drop in solar irradiance can cause not only a drop in PV generation but also can affect the overcurrent relay coordination within a radial distribution network.

Equally important, recall that Fuses 1 and 3 were introduced into the radial distribution network to discontinue PV1 and PV2 from contributing fault current during fault conditions. Fuses rating were based on PV normal operating currents and, therefore, if a PV array is shaded and its fault contribution current is below the $30 \mathrm{~A}$ rating of the fuse, the $30 \mathrm{~A}$ fuse protection will not discontinue the flow of such fault current. When shaded, PV2 only contributes $22 \mathrm{~A}$ which is less current than the 30A rating of Fuse 3. Therefore, both overcurrent relay R2 and Fuse 3 will fail to operate for this shaded PV2 fault condition. If the anti-islanding protection of PV2 were to also fail, PV2 would continue to contribute fault current to the fault at Bus 2. Such conditions are 
dangerous and therefore, PV2 should also have back-up undervoltage relay protection so as to make sure PV2 is removed from the system under such fault conditions.

All in all, these two cases previously addressed demonstrate some of the various ways that relay protection reliability and coordination can be compromised with the introduction of PV arrays. The system investigated in this paper is very simplistic compared to the complexity of most distribution systems. Every distribution system is different and therefore requires its own uniquely designed protection. To implement a reliable protection system, the issues addressed here must be further scrutinized so as to design a protection scheme that works with the newly introduced PV systems. Possibly a more expensive dynamic protection system that adapts its coordination settings based on the power output of the PV arrays must be implemented so as to reliably protect a distribution system with PV generation. Such a system would be very complex and costly because coordination times would have to be changed in accordance to real-time PV output power measurements. While the introduction of PV generation requires its own specific protection, the effect that PV's varying generation has on relay coordination poses yet another hurdle that protection engineers must overcome as PV generation becomes more and more prevalent within our power system.

\section{Effects of Large-Scale PV Solar Irradiation-induced Power Transients}

In addition to studying the effects that small and medium sized PV plants have on distribution protection schemes, the effects of large-scale PV plants on a larger power system must also be investigated. With all of the government regulations on utilities that require utilities to employ a certain percentage of alternative-energy power production, new propositions for PV plants have sprung up not only for small- and medium-sized PV plants (small being $\leq 1 \mathrm{MW}$, and medium being in the 10's of MW), but also larger PV plants as well (large being 100's of MW). 
The Carrizo Plain in Southern San Luis Obispo County has been a hotspot for possible future large-scale PV plant implementations. SunPower, for instance, has proposed a possible $250 \mathrm{MW}$ PV plant, and First Solar and Optisolar have also proposed a $550 \mathrm{MW} \mathrm{PV} \mathrm{plant} \mathrm{for} \mathrm{the} \mathrm{Carrizo}$ Plains area. Both propositions are in the process of pursuing building permits while environmentalists study the impacts that building of these large-scale PV arrays would have on the surrounding environment. Figure IV.15 shows a generic 14-Bus power system with a $60 \mathrm{MW}$ PV generation plant connected to Bus 17. Transient Analysis will be conducted on the power system of Figure IV.15 for a 10 second PV power ramp from $100 \%$ power (60MW) to $60 \%$ power (36MW) caused by a cloud's shadow traveling over the 60 MW PV array.

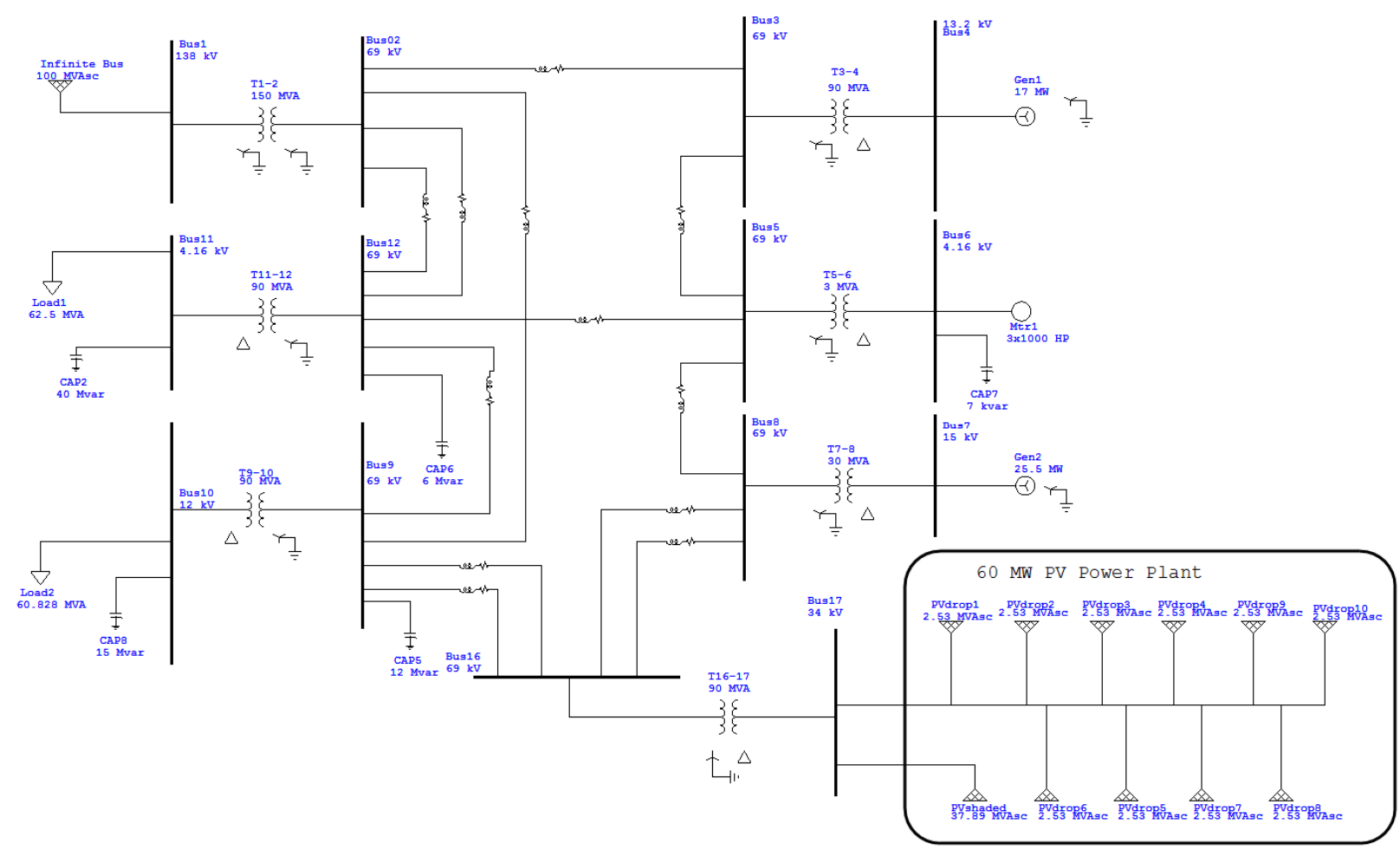

Figure IV.15: Power System with a 60 MW PV Power Plant

Figure IV.15 shows a power system with a 60 MW PV Generation Plant. ETAP does not have a PV array module implemented in their current software version; so a PV simulation model must be improvised. In order to simulate a PV array and its cloud-shading induced power 
ramps, a collection of voltage-controlled utility modules are utilized. Two different types of PV voltage-controlled utility modules are used for transient analysis: one that represents a PV power drop when removed from the power system, and one that represents the final power output of the PV array once the power ramp has completed (PVshaded). To simulate a 10 second PV power ramp from $100 \%$ power to $60 \%$ power, PVdrop1 through PVdrop10 are deleted one at a time from the power system every second until all PVdrop voltage-controlled utility modules have been deleted. This leaves the last voltage-controlled utility module, PVshaded, to represent the PV array's output after the power ramp has completed. See Figure IV.16 for a graphical illustration of the $\mathrm{PV}$ power ramp.

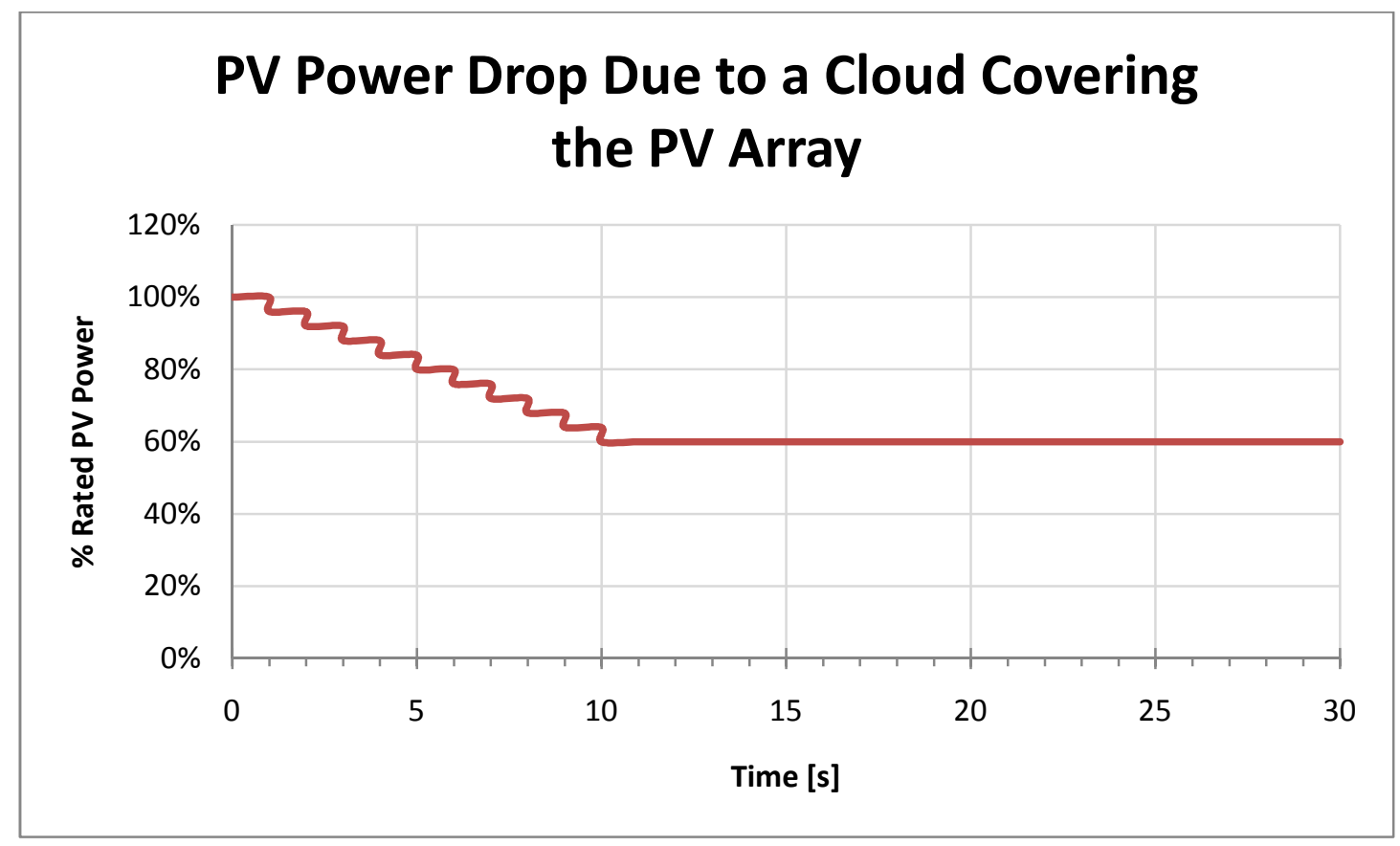

Figure IV.16: Simulation of a PV Power Drop Caused by a Cloud's Shade Passing Over the 60 MW PV Array

Limited by the functionality of ETAP's transient analysis abilities, voltage-controlled utility modules cannot be reconnected to the power system after they have been deleted. Therefore, only a cloud-cover induced PV power drop can be simulated for this paper. In the future, ETAP might eventually provide power transient options that would allow one to simulate an increase in 
$\mathrm{PV}$ power. An investigation as to the effects of an increasing PV power ramp on a power system would prove very useful and should be investigated in future studies.

The power ramp in Figure IV.16 is not a smooth, decreasing power drop, but instead is comprised of ten 1-second 2.4 MW power drops. Although a PV power drop might ideally appear smooth and less jagged, a down stepping, linear power drop was assumed sufficient to test the effects that a 10 second power drop has on a power system and its protection. The resolution of this study could be improved by increasing the number of voltage-controlled utility buses that are deleted over the 10 second period. However, although still jagged, ten consecutive drops in PV power over the ten second period effectively simulated the general effect that a drop in large scale PV power had on the power system.

\section{i. Effect on Frequency}

The following figure, Figure IV.17 shows the frequency oscillations caused by a 10s PV power ramp from $100 \%$ to $60 \%$ induced by a cloud's shadow passing over the $60 \mathrm{MW}$ array. Figure IV.18 shows a more zoomed-in version of Figure IV.17.

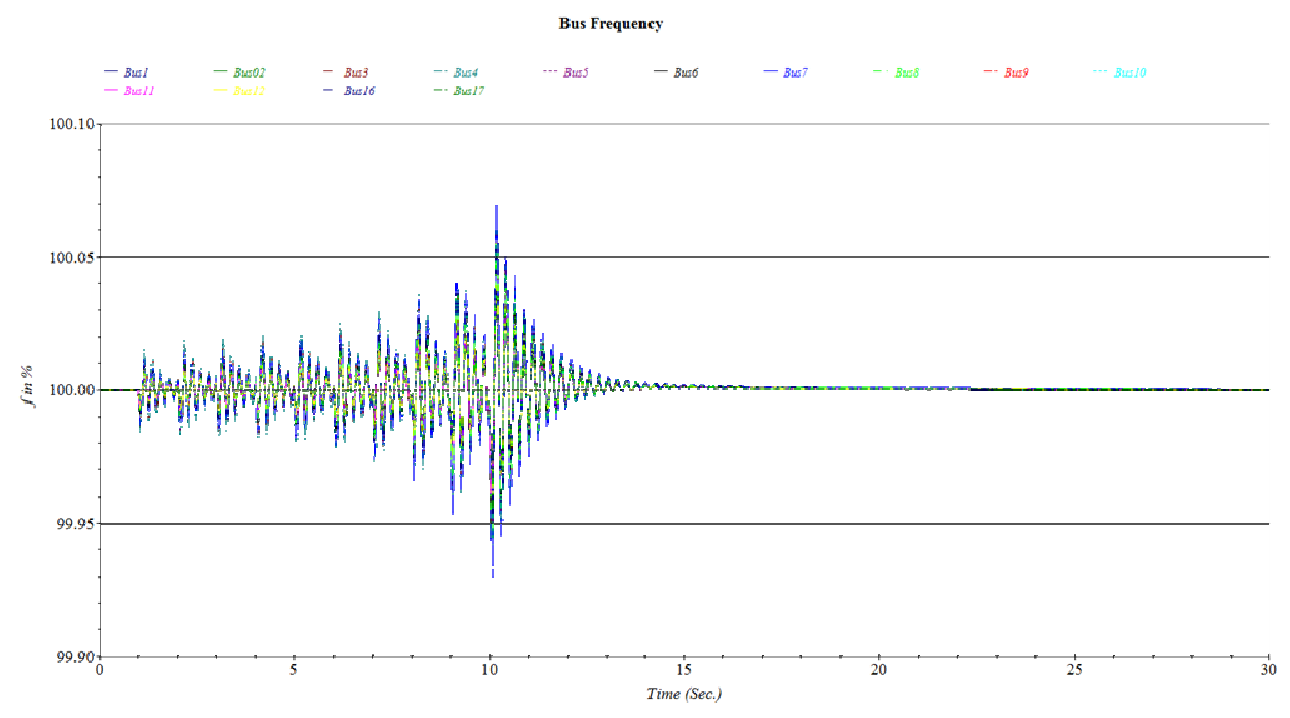

Figure IV.17: Frequency Oscillations caused by 10s PV Power Ramp 


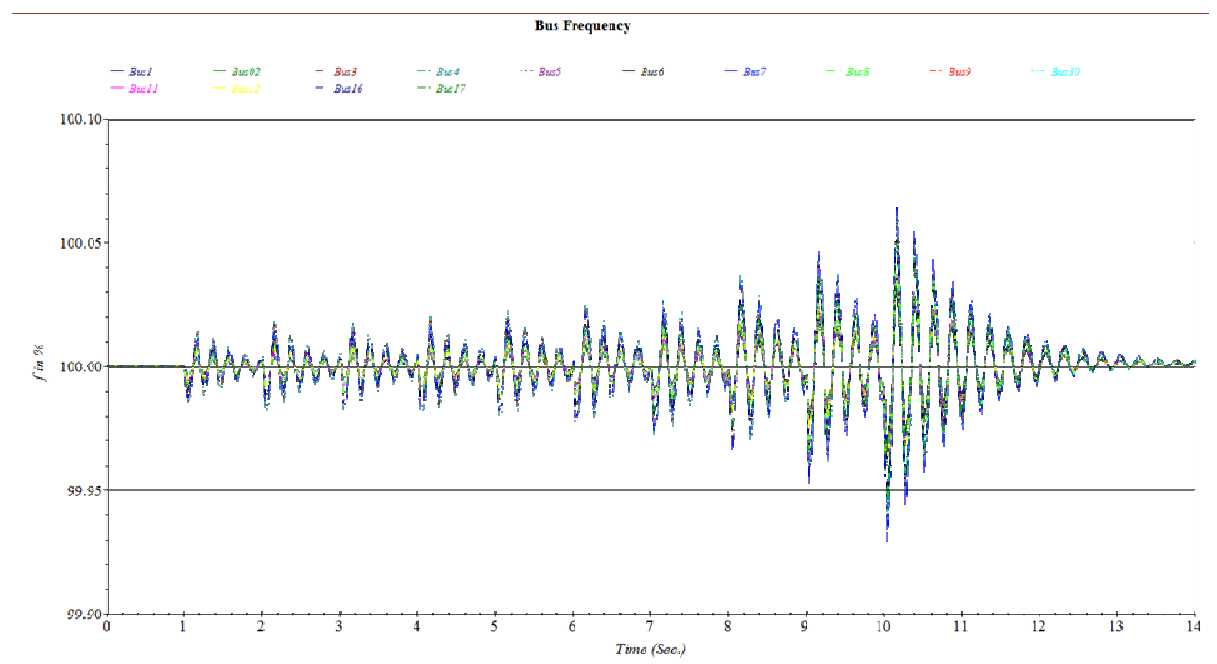

Figure IV.18: Zoomed in Version of Figure IV.17 - Frequency Oscillations

Figures IV.17 and IV.18 show the frequency variations caused by the 10 drops in PV power over the 10 second power drop duration. As time goes on, the frequency variations slowly increase as the PV array's power becomes smaller and smaller. Yet, the frequency oscillations quickly dampen out and eventually return to $100 \%$ frequency. Therefore, a cloud cover induced power ramp of 10s does not produce a steady state frequency outside the acceptable frequency range. The stepped frequency oscillations in Figures IV.17 and IV.18 are due to the quick immediate deletion of the voltage-controlled utility modules. While such stepped oscillations could be made smoother by increasing the number of deleted voltage-controlled utility buses over the 10 second period, Figures IV.17 and IV.18 still show a general trend of how the power system's frequency will respond to a PV power drop. Table IV.4 below provides the IEEE1547 acceptable frequency ranges. 
Table IV.4: IEEE 1547 Frequency Relay Recommended Trip Times [18]

Table 8 -Interconnection system response to abnormal frequencies

\begin{tabular}{|c|c|c|}
\hline DR size & Frequency range $\mathbf{( H z )}$ & Clearing time $^{\text {a }}$ (s) \\
\hline \multirow{2}{*}{$\leq 30 \mathrm{~kW}$} & $>60.5$ & 0.16 \\
\hline \multirow{3}{*}{$>30 \mathrm{~kW}$} & $<59.3$ & 0.16 \\
\cline { 2 - 3 } & $>60.5$ & 0.16. \\
\cline { 2 - 3 } & $\begin{array}{c}<\{59.8 \text { to } 57.0\} \\
\text { (adjustable set point) }\end{array}$ & Adjustable 0.16 to 300 \\
\cline { 2 - 3 } & $<57.0$ & 0.16 \\
\hline
\end{tabular}

${ }^{\mathrm{a}} \mathrm{DR} \leq 30 \mathrm{~kW}$, maximum clearing times; DR $>30 \mathrm{~kW}$, default clearing times.

The maximum frequency swing from Figures IV.17 and IV.18 for the PV power ramp was between $99.93 \%$ and $100.07 \%$ and lasted no more than 0.2 seconds. Note that $\mathrm{f}>60.5 \mathrm{~Hz}$ corresponds to $\mathrm{f}>100.83 \%, \mathrm{f}<\{59.8$ to $57 \mathrm{~Hz}\}$ corresponds to $\mathrm{f}<\{99.67 \%$ to $95 \%\}$, and $\mathrm{f}<57$ $\mathrm{Hz}$ corresponds to $\mathrm{f}<95 \%$. The frequency oscillations also dampened rather quickly. Therefore, the frequency oscillations caused by the 10 s power ramp from $100 \%$ to $60 \%$ power did not exceed any frequency limitations, and nuisance frequency relay trips should not be caused by a cloud-shading-induced PV power drop.

\section{ii. Effect on Bus Voltage}

While the frequency relays within the power system will not nuisance trip due to a $10 \mathrm{~s}$ 40\% drop in PV power, undervoltage relays within the power system will definitely trip. Table IV.5 provides the IEEE 1547 standard for abnormal voltage tripping times. According to IEEE 1547, when a distributed resource's point of common coupling's (PCC) voltage or interconnection bus's voltage lies within one of the voltage ranges listed in Table IV.5, the alternative energy source must cease to energize the power system within the associated clearing time [14]. While low voltage tripping is prohibited for large-scale wind generation according to FERC Rule 661a, application of low voltage ride through (LVRT) technology will also be needed for PV design [2]. However, no US standards for PV LVRT technology are in place at 
this time. Thus, PV arrays without such LVRT technology, both large and small, must disconnect from the power system if their interconnection voltage is too low.

Table IV.5: Alternative Energy Source Clearing Times for Abnormal Voltage Conditions [18]

\section{Table 7-Interconnection system response to abnormal voltages}

\begin{tabular}{|l|c|}
\hline $\begin{array}{c}\text { Voltage range } \\
\left(\% \text { of the base voltage }{ }^{\mathbf{a}}\right)\end{array}$ & $\begin{array}{c}\text { Clearing time } \\
\text { (s) }\end{array}$ \\
\hline $\mathrm{V}<50$ & 0.16 \\
\hline $50 \leq \mathrm{V}<88$ & 2.00 \\
\hline $110<\mathrm{V}<120$ & 1.00 \\
\hline $\mathrm{V} \geq 120$ & 0.16 \\
\hline
\end{tabular}

${ }^{\text {a }}$ Base voltages are the nominal system voltages stated in ANSI C84.1 Table 1.

${ }^{\mathrm{b}} \mathrm{DR} \leq 30 \mathrm{~kW}$, maximum clearing times; $\mathrm{DR}>\mathbf{3 0} \mathrm{kW}$, default clearing times.

Table IV.5 lists the clearing times that alternative energies must disconnect from the power system if their Bus's voltages are within any of the listed voltage ranges. That being said, the Bus voltages within the power system over a 30 second time period are portrayed in Figure IV.19.

Note: in Figure IV.19, Bus 6, with the induction motor connected, begins to slowly increase in voltage after the PV power drop has completed at 10 seconds. The reason for this phenomenon is that an automatic tap changer was implemented on Transformer T5-6 which strives to maintain a voltage of $100 \%$ on Bus 6 . Therefore, the automatic tap changer adjusts the tap settings of T5-6 over time so as to attempt to regulate the voltage on Bus 6 . 


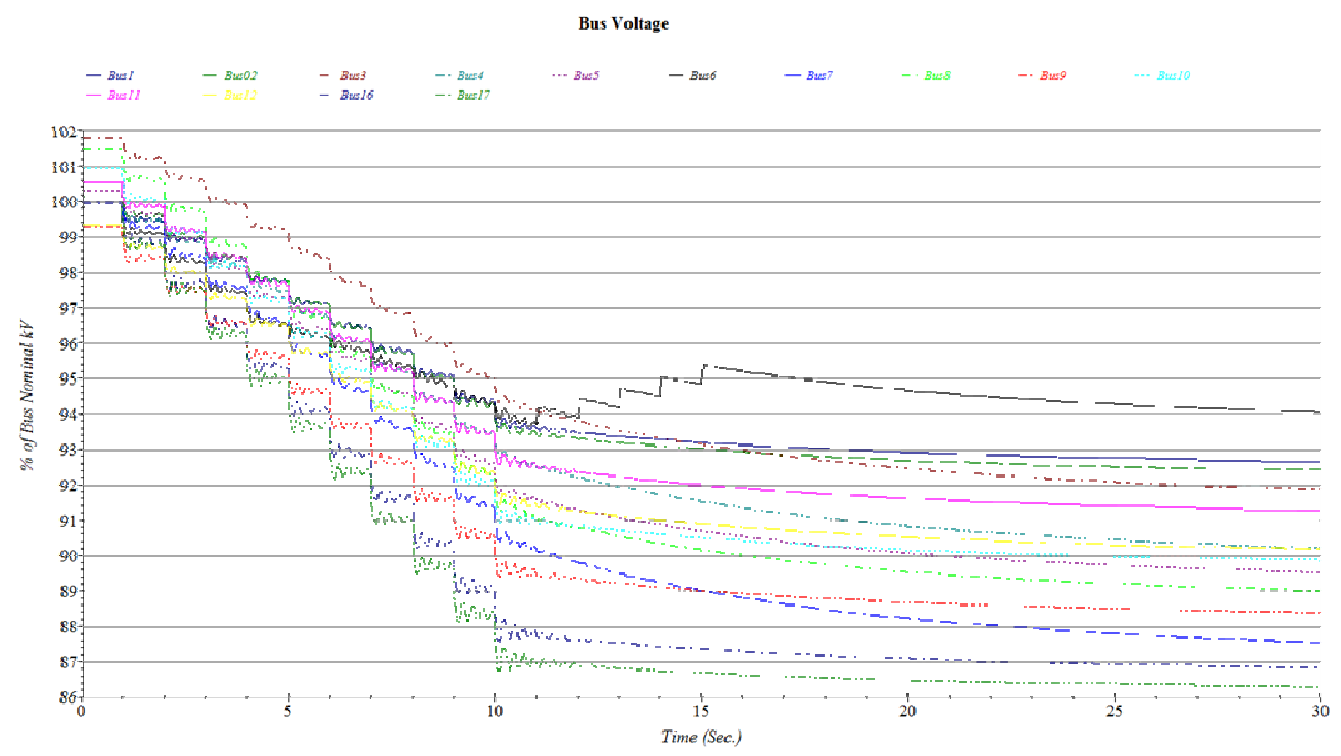

Figure IV.19: Power System Bus Voltages for a 10 second $40 \%$ PV Power Drop

In Figure IV.19, the stepped reduction in bus voltage is due to the quick immediate deletion of the voltage-controlled utility modules. While such stepped voltage drops could be made smoother by increasing the number of deleted voltage-controlled utility buses over the 10 second period, Figure IV.19 shows a general trend of how the power system's bus voltages respond to a PV power drop.

When analyzing Figure IV.19, recall that the 60 MW PV array is connected to Bus 17. After the 10 second PV ramp has completed, Bus 17 lies at around $87 \%$ and continues to slowly drop to its steady-state value of $86.4 \%$. According to Table IV.5, with a Bus voltage around $87 \%$, the PV array must be completely disconnected from the power system within 2 seconds.

However, IEEE Standard 1547 states that for alternative energy sources greater than $30 \mathrm{~kW}$, the voltage set points of Table IV.5 shall be field adjustable. Nevertheless, even if the 50 $\leq \mathrm{V}<88$ voltage range were adjusted by dropping the $88 \mathrm{~V}$ limit to reduce nuisance tripping, if the PV array's power were to continue to drop, Bus 17's voltage would also continue to drop. Thus, the PV array's inverters would eventually disconnect from the power system. If the PV 
array's inverters were to trip due to undervoltage conditions, the severity and magnitude of inverter trips would exceed the severity and magnitude of cloud-induced PV power ramps [2]. Therefore, lowering the Bus voltage limit does not solve the nuisance trip problem if a PV's power continues to drop.

In addition to affecting the PV array inverter's protection, such a PV power drop leads to diminishing bus voltages around the whole power system. The PV ramp's effects are substantial enough that they could trip undervoltage relay protection around the system. Undervoltage relays may either alarm or trip voltage sensitive loads such as induction motors whenever the line voltage drops below the designed setting [24]. Figure IV.20 shows typical time-voltage characteristics of undervoltage relays (Relay 27). Depending on the time dial setting selected for a specific undervoltage relay and the bus voltage that the relay is connected to, the

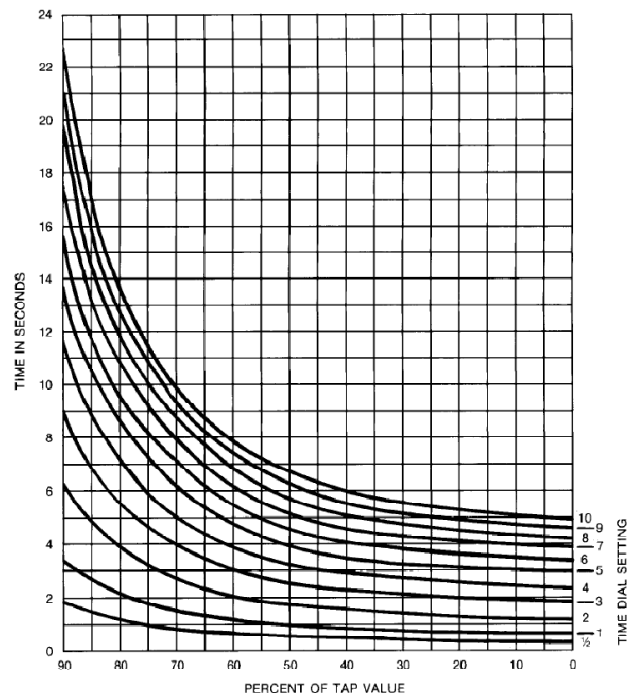

Figure IV.20: Undervoltage Relay Time-Voltage Characteristics [23] undervoltage relay will trip within a specific time determined by the relay's time-voltage characteristic curve. Because each protection system implements its own unique undervoltage protection scheme, and undervoltage relays are often used as backup protection to other protection schemes within a power system, their trip/alarm settings must be coordinated so as to delay tripping until other protection means should have tripped. Each system will employ its own unique undervoltage protection settings and thus trip/alarm times will vary from system to system. 
Table IV.6 shows a summary of the power system's Bus's voltages and their associated tripping time ranges.

Table IV.6: Summary of Undervoltage Relay Trip Times

\begin{tabular}{|c|c|c|c|c|c|}
\hline Bus & Bus Description & Steady State Voltage [\%] & Time when Vbus $\leq 90 \%[\mathrm{~s}]$ & Tripping Time [s] & Trip/Alarm \\
\hline 1 & Infinite Bus & $92.7 \%$ & $\mathrm{~N} / \mathrm{A}$ & $\mathrm{N} / \mathrm{A}$ & $\mathrm{N} / \mathrm{A}$ \\
\hline 2 & 69kV Transmission Bus & $92.5 \%$ & $\mathrm{~N} / \mathrm{A}$ & $\mathrm{N} / \mathrm{A}$ & N/A \\
\hline 3 & $69 \mathrm{kV}$ Transmission Bus & $92.0 \%$ & N/A & $\mathrm{N} / \mathrm{A}$ & $\mathrm{N} / \mathrm{A}$ \\
\hline 4 & 17 MW Generator & $90.0 \%$ & 30 & $9.0 \leq x \leq 10.0$ & Alarm \\
\hline 5 & 69kV Transmission Bus & $89.6 \%$ & 20.5 & $1.85 \leq x \leq 22.0$ & Alarm/Trip \\
\hline 6 & $3 \times 1000 \mathrm{Hp}$ Motor & $94.1 \%$ & $\mathrm{~N} / \mathrm{A}$ & $\mathrm{N} / \mathrm{A}$ & $\mathrm{N} / \mathrm{A}$ \\
\hline 7 & 25 MW Generator & $87.6 \%$ & 11.5 & $9.0 \leq x \leq 10.0$ & Alarm \\
\hline 8 & 69kV Transmission Bus & $89.0 \%$ & 16.4 & $1.8 \leq x \leq 21.2$ & Alarm/Trip \\
\hline 9 & 69kV Transmission Bus & $88.4 \%$ & 10.0 & $1.75 \leq x \leq 20.0$ & Alarm/Trip \\
\hline 10 & 60 MVA Load & $89.9 \%$ & 20.5 & $1.9 \leq x \leq 22.6$ & Alarm/Trip \\
\hline 11 & 62.5 MVA Load & $91.3 \%$ & $\mathrm{~N} / \mathrm{A}$ & $\mathrm{N} / \mathrm{A}$ & $\mathrm{N} / \mathrm{A}$ \\
\hline 12 & 69kV Transmission Bus & $90.2 \%$ & $\mathrm{~N} / \mathrm{A}$ & $\mathrm{N} / \mathrm{A}$ & $\mathrm{N} / \mathrm{A}$ \\
\hline 16 & 69kV Transmission Bus & $86.8 \%$ & 9.0 & $1.75 \leq x \leq 18.2$ & Alarm/Trip \\
\hline 17 & 60 MW PV Array & $86.3 \%$ & 8.0 & 2.0 & Trip \\
\hline
\end{tabular}

Tripping time ranges are specified in Table IV.6 rather than discrete, fixed times because undervoltage relay time dial settings are unique for each power system. Therefore, the time ranges provide tripping times for all available time dial settings shown in Figure IV.20. Notice, however, that Bus 17 will trip after 2 seconds. This trip time was taken from Table IV.5 based on IEEE 1547 standards for alternative energy sources. Buses 4 and 7, which have generators connected to them, do not trip, but only alarm after 9.0 to 10.0 seconds. This setting will be further discussed in the "Effects on Generators" subsection.

Equally important, Buses 5,7, 8, 9, 10, 16, and 17 will all trip if their Bus voltages remain at their steady state voltages for several more seconds. Additionally, Buses 11 and 12 are on the verge of tripping undervoltage relays, and a further drop in PV power would definitely lead to nuisance undervoltage tripping. Manually switched or automatic capacitor banks can be applied to all buses within the power system so as to boost the bus voltages to within acceptable ranges. Nonetheless, the amount of capacitance connected to the system must be limited so that it does not force local generators within the power system to absorb capacitive reactive power, rather 
than supply inductive reactive power. Such conditions are unhealthy operating conditions for generators.

\section{iii. Effect of Generators}

Similar to operating a generator where it absorbs reactive power, supplying too much field current to a generator can also be unhealthy for generators. In Table IV.6, the generator connected buses (buses 4 and 7) both operate within undervoltage relay operating ranges. While other undervoltage relays may alarm and/or trip, generator undervoltage relays often only alarm when their bus voltages are too low. Generator undervoltage relays only alarm because operators can remedy the situation by increasing the generator's field current to elevate generator terminal voltage.

Equally important, operating generators lower than $95 \%$ of their rated voltages can results in various undesirable effects: reduction in generator stability limits, import of excessive Q, malfunction of excessive voltage-sensitive devices [25]. Therefore, although operating a generator at low terminal voltages may have harmful side effects, generators can operate under such conditions for a brief period of time. Therefore, rather than shutting the generator down and removing a power-generating source from the power system, operators can adjust the field of a generator while it is still running to increase the generator's bus voltage within acceptable, healthy ranges. Nonetheless, generator field currents during and after the PV power ramp must be evaluated so as to determine whether operators can safely increase the generators' field currents without causing generator damage or tripping generator protection. Figure IV.21 illustrates generators 1 and 2's field currents over the duration of the cloud-induced PV power ramp. 


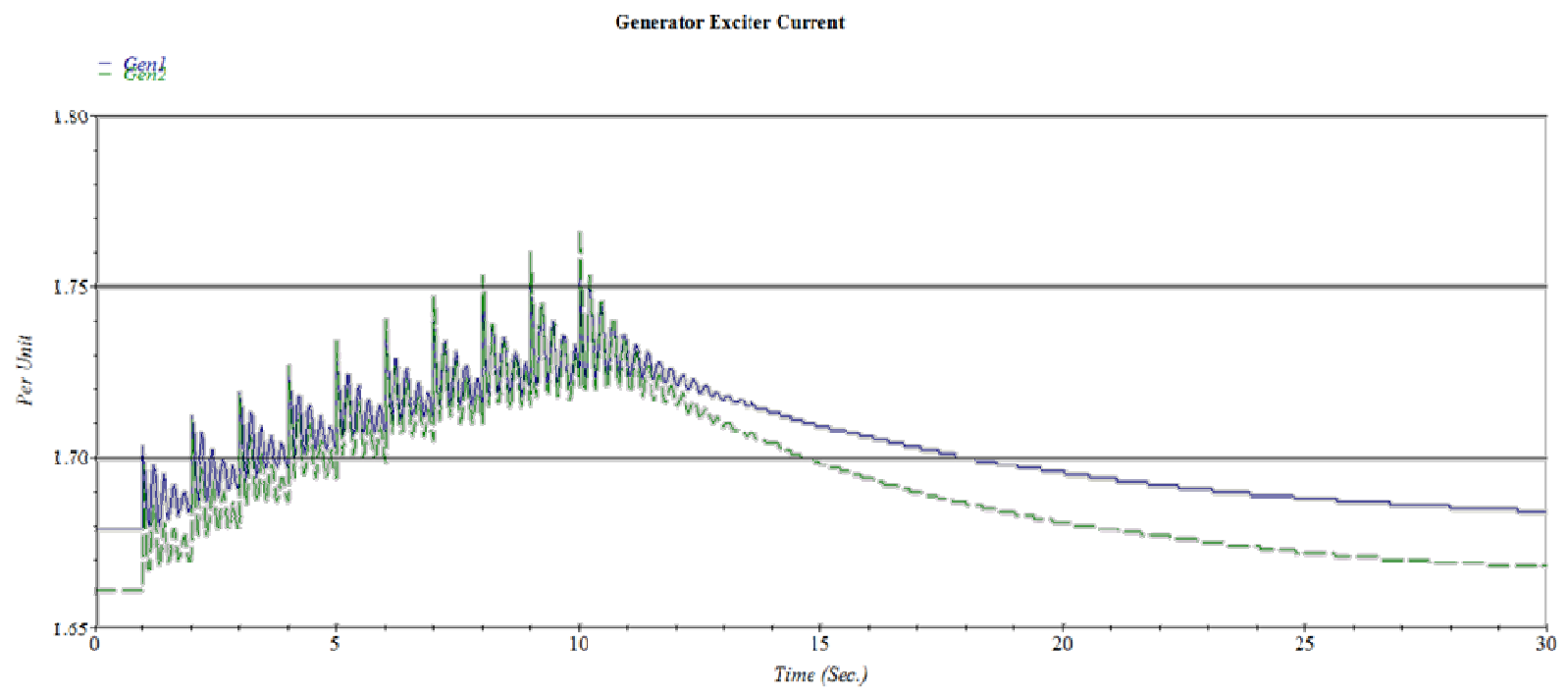

Figure IV.21: Generators' Field Currents during a 10s PV Power Ramp

Figure IV.21 shows Generator 1 and 2's field or excitation currents. As the PV power drops from time $t=1.0 \mathrm{~s}$ to $\mathrm{t}=10 \mathrm{~s}$, the field currents for both generators increase as their automatic voltage regulator or (AVR) control system struggles to maintain control. Figure IV.22 below shows IEEE C37.102 generator short-time thermal capabilities.

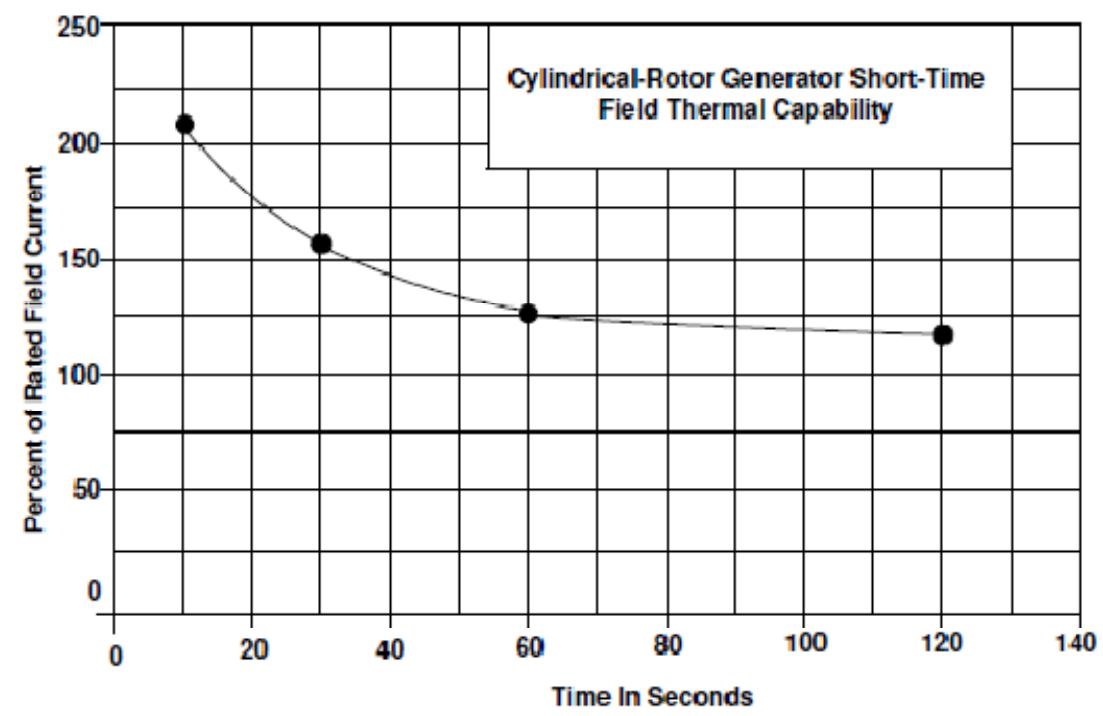

Figure IV.22: Generator Field Short-time Thermal Capability 
For a given percentage of rated field current supplied to a generator, the generator can withstand a short period of time before experiencing thermal stress. Exceeding a generator's thermal capabilities reduces the lifespan of a generator. Generator 1 and 2 remain above $168 \%$ and $166 \%$ respectively for the entire 30 second duration. An increase in field current occurs during the 10 second duration of cloud-induced $40 \%$ reduction in PV power generation. According to Figure IV.22, generators operating between $166 \%$ and $168 \%$ can endure the thermal conditions for 25 to 26 seconds. Therefore, the $40 \%$ descent in PV power generation could lead to generator field protection trip which in turn would eventually bring down the entire power system.

Most generators employ some sort of overexcitation protection. There are different forms of protection schemes utilized. Some employ excitation control systems, others employ protective relays, and others utilize both [25]. Nevertheless, most field protection systems respond to overexcitation conditions in the following way:

1. Sound an alarm

2. Adjust the field excitation to a specified full-load value.

3. After a time delay, trip the generator or transfer to an alternate control channel

4. If overexcitation is not reduced after another short time interval, trip the generator. Notice that even though the control system of both generators adjusted their settings, in response to the PV power drop, they were unable to remove the overexcitation conditions. Therefore, such an event was sufficient enough to trip both generators. Costly solutions to this problem may be either adjusting the short-time overexcitation tripping times and risk the chance of damaging the generators, or to invest in larger, heftier generators so that the power output of each generator requires less excitation current to maintain stability. 
All in all, the size of the PV array and the power system that the PV array is connected to may lead to a variety of unique outcomes. Therefore, it is very important that the system and its components be extensively studied so as to investigate whether PV power variations may cause harm to power system components and/or affect the reliability of power system protection. 


\section{Conclusions}

All things considered, with the introduction of photovoltaic systems, both large and small, comes an abundance of uncertainties and variations. This report endeavors to better characterize the dynamic properties of solar irradiance-dependent PV power variations. Large, quick fluctuations in solar irradiance lead to condensed, protracted variations in PV output power. Comparison of solar insolation variations to PV plant power ramps reveals a reduction in variation between single-point measurements and actual PV plant output. The behaviors of the intrinsic electrical components of a PV array and its grid-connected inverter, as well the wide, extensive, spread-out surface area of a PV array smooth the PV output-response for a given, rapid ramp in solar irradiance. Nevertheless, a cloud-induced change in solar irradiance can alter the operating conditions of a PV system. Conditions altered by solar irradiance changes include the PV array's operating DC voltage, and the PV plant's power generation capabilities. Hence, this report also investigated the effects that variation in DC input voltage and supplied DC power have on an inverter's harmonic generation and total harmonic distortion. Although variations in input DC voltage and power did not cause the inverter to exceed IEEE 519 total harmonic distortion limits, such variations produced individual harmonic components that exceeded IEEE 519 standards. Because electrical standards are only suggestive measures, inverters that exceed IEEE 519 harmonic standards are still allowed to connect to the power grid. However, with the rising introduction of PV systems on the electric grid, future harmonic regulations or harmonic power filtering might need to be implemented so as to maintain reliable power quality through the power system.

Additionally, this report investigated the effects that the variation in PV output power had on the operational reliability of power systems and their protective schemes. Even though the fault 
contribution of PV systems is limited to $200 \%$ of nominal rated current, the introduction of PV systems to a power system caused a variety of failures in the operation of power system protection. Such failures include blown fuses, underreaching and ill-coordinated overcurrent relay operations, etc... Each power system and its implemented protection scheme are unique. Therefore, it is extremely important that extensive investigation be conducted and the issues addressed in this paper be considered before implementing future PV systems to the power grid. Development of new electrical standards is quite necessary to deal with the variability and uncertainty associated with PV integration. Such standards provide reliable operating limits, but do not, however, explain how to adhere to such standards. Therefore, further research must be conducted so as to better characterize the effects of PV variability on the power system. It is very likely that future power grids may embrace a much larger implementation of PV generation. Nevertheless, the present power grid system must be re-engineered so as to alleviate the adverse effects of PV variability and allow for the many benefits of PV generation to be fully appreciated.

\section{i. Future Studies}

Each section within this paper could be investigated more deeply and therefore could produce several individual thesis topics. Yet, the intent of this report was to skim the surface and provide a wide-ranged study of the issues involved with photovoltaic variability. This paper was focused on characterizing PV variations and uncertainties so as to more accurately simulate the extensive effects that such fluctuations have on the power system and its protection. Further studies that could be investigated include, but are not limited to:

- A more in-depth investigation of grid-connected PV output response for a given variation in solar irradiance. 
- Investigating the effects that large step-changes in PV plant power, due to inverter tripping, have on power systems and their protection. Such a study could also investigate whether a nearby fault would trip an inverter's ant-islanding protection when it should not.

- A cost analysis investigation on the implementation of PV systems to the power grid, including the costs involved in upgrading existing protection so as to solve issues with PV power variability.

- Research focused on predicting whether or not a cloud is heading in the direction of a PV plant and the extent that such cloud-cover will affect the solar irradiance levels and power output of a PV plant.

- Engineering solutions for the handful of adverse effects that a large drop in PV generated power has on the electric grid. 


\section{Bibliography}

[1] Institute of Electrical and Electronic Engineers. (April 1993). IEEE Recommended Practices and Requirements for Harmonic Control in Electrical Power Systems. IEEE Std 519-1992, 24, 37-84.

[2] Mills, A. , Ahlstrom, M. , Brower, M. , Ellis, A. , George, R. , Hoff, T. , Kroposki, B. , Lenox, C. , Miller, N. , Stein, J. , Wan, Y. "Understanding Variability and Uncertainty of Photovoltaics for Integration with the Electric Power System.” Ernst Orlando Lawrence Berkley National Laboratory: Environmental Energy Technologies Division, December 2009.

[3] Stein, J. "Photovoltaic (PV) Power Variability Modeling and Analysis Approaches." Sandia National Laboratories: Photovoltaic and Grid Integration Department, April 2010.

[4] De Soto W, Klein SA, Beckman WA. "Improvement and validation of a model for photovoltaic array performance", Solar Energy 2006; 80(1):78-88.

[5] King, L. , Boyson, W. , Kratochvill, J. "Photovoltaic Array Performance Model", Sandia Report, Albuquerque, New Mexico, 2003; (10)

[6] AltE University. "Electrical Characteristics of Solar Panels." (2008) http://www.altestore.com/howto/images/article/IV_curve.jpg (Nov 10, 2010).

[7] Agbo, S. "Lecture Notes \#4: PV Cells, Modules and Arrays," Lecture Notes from EE520: Solar Photovoltaic System Design, Cal Poly, Spring 2010, (5,6).

[8] National Renewable Research Laboratory. "MIDC Research Stations." Atmospheric Radiation Measurement Program. (2009) http://www.nrel.gov/midc/research/ (July 7, 2009).

[9] Seul-Ki, K. , Jeon, J., Cho, C. , Kim, E. , Ahn, J. (October 2008). "Modeling and simulation of grid-connected PV generation system for electromagnetic transient analysis.” Korea Electro-Technology Research Institute, Seongju-dong 28-1, Changwon, Republic of Korea.

[10] Femia, N. , Petrone, G. , Spangnuolo, G. , Vitelli, M. (July 2005). "Optimization of Perturb and Observe Maximum Power Point Tracking Method." IEEE Transactions on Power Electronics, Vol. 20, No. 4.

[11] Kern, E. , Gulachenski, E. , Kern, G. (June 1989). "Cloud Effects on Distributed Photovoltaic Generation: Slow Transients at the Gardner, Massachusetts Photovoltaic Experiment.” IEEE Transactions on Energy Conversion, Vol. 4, No. 2.

[12] Taufik. Advanced Power Electronics. September 2010. (212-215).

[13] Wagner, V. E. (April 1993). Effects of Harmonics on Equipment. IEEE Transactions on Power Delivery, Vol. 8, No. 2 , (672-680).

[14] Farret, F. , Simões, M. (2006). Integration of Alternative Sources of Energy Hoboken: John Wiley \& Sons.

[15] Calias, M. , Myrzik, J. , Spooner, T. , Angelidis, V. "Inverters for Single-Phase GridConnected Photovoltaic Systems - An Overview" Power Electronics Specialist Conference, 2002. IEEE $33^{\text {rd }}$ Annual 2002, (1997).

[16] Sangpanich, U. , Thongpron, J. , Kirtikara, K. , Jivacate, C. (2004). Study of Moving Cloud effects on the Power Quality of Grid-Connected Photovoltaic System 
Compared with Simulation of PV Power Using a DC Generator. Technical Digest of the International PVSEC-14.

[17] Chen, H. , Sun, Y. , \& Chen, W. (2009). "Harmonic suppression of grid-connected distributed generation based on novel hybrid power filter". 2009 4th IEEE Conference on Industrial Electronics and Applications, ICIEA 2009

[18] Institute of Electrical and Electronic Engineers. (April 2009). IEEE Application Guide for IEEE Std $1547^{\mathrm{TM}}$, IEEE standard for Interconnecting Distributed Resources with Electric Power Systems. IEEE Std 1547.2-2008, (46, 59, 67, 76, 77, 98, 107, 108).

[19] Turcotte, D. , Katiraei, F. (October 2009) "Fault Contribution of Grid-Connected Inverters." IEEE Electrical Power Conference, Montreal, Quiebec, Canada. 1-3.

[20] Plet, C. , Graovac, M. , Green, T. , Iravani, R. , "Fault Response of Grid-Connected Inverter Dominated Networks," in Power \& Energy Society General Meeting. IEEE, July 2010.

[21] Phuttapatimok, S. , Sangswang, A. , Seapan, M. , Chenvidhya, D. , Kirtikara, K. , "Evaluation of Fault Contribution in the Presence of PV Grid-Connected Systems." In Photovoltaic Specialists Conference, 2008. PVSC'08 33' IEEE, May 2008.

[22] Stevens, J. , Bonn, R. , Ginn, J. , Gonzalez, S. , Kern, G. "Development and Testing of an Approach to Anti-Islanding in Utility-Interconnected Photovoltaic Systems," in Sandia Report SAND2000-1939. August 2000.

[23] Basler Electric. "Instruction Manual for Overcurrent Relays." December 2000.

[24] American National Standards Board. (February 1986). IEEE Recommended Practive for Protection and Coordination of Industrial and Commercial Power Systems. IEEE Std 242-1986, (97)

[25] IEEE Power Engineering Society. (February 2007). IEEE Guide for AC Generator Protection. IEEE Std C37.102-2006, (71, 72, 131, 152).

[26] Therien, Scott. (2010) "Distributed Generation: Issues Concerning a Changing Power Grid Paradigm.” Master's Thesis. California Polytechnic State University. 


\section{Appendix A - Nominclature}

\begin{tabular}{|c|c|c|}
\hline$\underline{\text { Symbol }}$ & $\underline{\text { Description }}$ & $\underline{\text { Units }}$ \\
\hline $\mathrm{a}_{\mathrm{o}}$ & Ideality factor at STD conditions & \\
\hline$a_{c}$ & Ideality factor based on Temperature Conditions & \\
\hline $\mathrm{k}$ & Boltzmann's Constant $=1.38066 \times 10^{-23}$ & $\mathrm{~J} / \stackrel{\circ}{\mathrm{o}} \mathrm{K}$ \\
\hline q & Charge of an electron $=1.60218 \times 10^{-19}$ & Coulombs \\
\hline $\mathrm{I}_{\mathrm{L}}$ & Light Current & A \\
\hline $\mathrm{I}_{0}$ & Diode Reverse Saturation Current & A \\
\hline $\mathrm{R}_{\mathrm{S}}$ & Series Resistance & $\Omega$ \\
\hline $\mathrm{R}_{\mathrm{SH}}$ & Shunt Resistance & $\Omega$ \\
\hline \multicolumn{3}{|c|}{ KING'S MODEL PARAMETERS } \\
\hline Area & Solar cell area & $\mathrm{m}^{2}$ \\
\hline $\mathrm{N}_{\mathrm{s}}$ & Number Solar Cells in a series string & \\
\hline $\mathrm{N}_{\mathrm{p}}$ & Number of parallel series strings & \\
\hline $\mathrm{M}_{\mathrm{s}}$ & Number of Series PV Modules in a String & \\
\hline $\mathrm{E}_{\mathrm{e}}$ & Effective Irradiance $($ Percentage $)=$ Irradiance $/\left\{1000 \mathrm{~W} / \mathrm{m}^{2}\right\}$ & \\
\hline $\mathrm{T}_{\mathrm{o}}$ & Standard Temperature $=25^{\circ}$ Celsius $=298^{\circ}$ Kelvin & \\
\hline $\mathrm{T}_{\mathrm{c}}$ & Cell Operating Temperature & ${ }^{\circ} \mathrm{C}$ \\
\hline $\mathrm{E}_{\mathrm{o}}$ & Reference Solar Irradiance $=1000 \mathrm{~W} / \mathrm{m}^{2}$ & $\mathrm{~W} / \mathrm{m}^{2}$ \\
\hline SRC & Standard Reference Conditions $\left(\mathrm{T}_{\mathrm{c}}=25^{\circ} \mathrm{C}, \mathrm{Ee}=1\right)$ & \\
\hline $\mathrm{I}_{\mathrm{sc}}$ & Short Circuit Current & A \\
\hline $\mathrm{I}_{\mathrm{sco}}$ & Short Circuit Current at SRC & A \\
\hline $\mathrm{V}_{\mathrm{oc}}$ & Open Circuit Voltage & $\mathrm{V}$ \\
\hline $\mathrm{V}_{\text {oco }}$ & Open Circuit Voltage at SRC & $\mathrm{V}$ \\
\hline $\mathrm{V}_{\mathrm{x}}$ & $\mathrm{V}_{\mathrm{x}}=0.5 \mathrm{~V}_{\mathrm{oc}}$ & $\mathrm{V}$ \\
\hline $\mathrm{V}_{\mathrm{xo}}$ & $\mathrm{V}_{\mathrm{x}}$ at $\mathrm{SRC}$ & $\mathrm{V}$ \\
\hline $\mathrm{I}_{\mathrm{x}}$ & The current at voltage $\mathrm{V}=\mathrm{V}_{\mathrm{x}}$ & A \\
\hline $\mathrm{I}_{\mathrm{xo}}$ & $\mathrm{I}_{\mathrm{x}}$ at $\mathrm{SRC}$ & A \\
\hline $\mathrm{V}_{\mathrm{mp}}$ & Voltage at maximum-power-point & $\mathrm{V}$ \\
\hline $\mathrm{V}_{\mathrm{mpo}}$ & $\mathrm{V}_{\mathrm{mp}}$ at $\mathrm{SRC}$ & $\mathrm{V}$ \\
\hline $\mathrm{I}_{\mathrm{mp}}$ & Current at maximum-power-point & A \\
\hline $\mathrm{I}_{\mathrm{mpo}}$ & $\mathrm{I}_{\mathrm{mp}}$ at $\mathrm{SRC}$ & A \\
\hline $\mathrm{V}_{\mathrm{xx}}$ & $\mathrm{V}_{\mathrm{xx}}=0.5\left(\mathrm{~V}_{\mathrm{oc}}+\mathrm{V}_{\mathrm{mp}}\right)$ & $\mathrm{V}$ \\
\hline $\mathrm{V}_{\mathrm{xxo}}$ & $\mathrm{V}_{\mathrm{xx}}$ at $\mathrm{SRC}$ & $\mathrm{V}$ \\
\hline $\mathrm{I}_{\mathrm{xx}}$ & The current at voltage $\mathrm{V}=\mathrm{V}_{\mathrm{xx}}$ & A \\
\hline $\mathrm{I}_{\mathrm{xxo}}$ & $\mathrm{I}_{\mathrm{xx}}$ at $\mathrm{SRC}$ & A \\
\hline $\mathrm{a}_{0}, \mathrm{a}_{1}, \mathrm{a}_{2}, \mathrm{a}_{3}, \mathrm{a}_{4}$ & Coefficients for air mass modifier calculation & \\
\hline AOI $(\theta)$ & Solar angle of incidence & Degrees \\
\hline $\mathrm{b}_{0}, \mathrm{~b}_{1}, \mathrm{~b}_{2}, \mathrm{~b}_{3}, \mathrm{~b}_{4}, \mathrm{~b}_{5}$ & Coefficients for incidence angle modifier calculation & \\
\hline $\mathrm{C}_{0}, \mathrm{C}_{1}$ & Coefficients used for calculating $\mathrm{I}_{\mathrm{mp}}$ for a given irradiance & $\left(\mathrm{C}_{0}+\mathrm{C}_{1}=1\right)$ \\
\hline $\mathrm{C}_{2}, \mathrm{C}_{3}$ & Coefficients used for calculating $\mathrm{V}_{\mathrm{mp}}$ for a given irradiance & \\
\hline $\mathrm{C}_{4}, \mathrm{C}_{5}$ & Coefficients used for calculating $\mathrm{I}_{\mathrm{x}}$ for a given irradiance & $\left(\mathrm{C}_{4}+\mathrm{C}_{5}=1\right)$ \\
\hline
\end{tabular}


$\underline{\text { Symbol }}$

$\mathrm{C}_{6}, \mathrm{C}_{7}$

$\alpha \mathrm{I}_{\mathrm{mp}}$

$\alpha I_{s c}$

$\beta \mathrm{V}_{\mathrm{mp}}$

$\beta \mathrm{V}_{\mathrm{oc}}$

$\delta\left(\mathrm{T}_{\mathrm{c}}\right)$
Description

Coefficients used for calculating

Temperature Coefficient for the maximum-power current

Temperature Coefficient for Short Circuit Current

Temperature Coefficient for the maximum-power voltage

Temperature Coefficient for open-circuit voltage

"Thermal Voltage" per cell at operating temperature $T_{c}$
Units

$\left(\mathrm{C}_{6}+\mathrm{C}_{7}=1\right)$

$1 /{ }^{\circ} \mathrm{C}$

$1 /{ }^{\circ} \mathrm{C}$

$\mathrm{V} /{ }^{\circ} \mathrm{C}$

$\mathrm{V} /{ }^{\circ} \mathrm{C}$ 


\section{Appendix B}

The following information is specification data for a Kyocera KC50T PV Module:

\section{THE NeW VALUE FrontieR}

KC50T

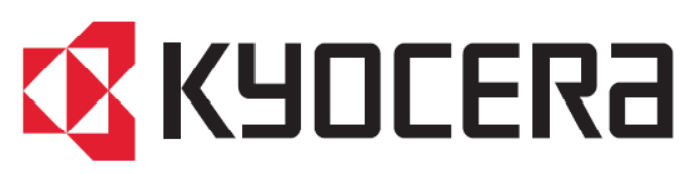

HIGH EFFICIENCY MULTICRYSTAL PHOTOVOLTAIC MODULE

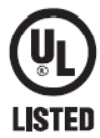

HIGHLIGHTS OF

KYOCERA PHOTOVOLTAIC MODULES

Kyocera's advanced cell processing technology and automated production facilities produce a highly efficient multicrystal photovoltaic modules.

The conversion efficiency of the Kyocera solar cell is over $16 \%$.

These cells are encapsulated between a tempered glass cover

and a pottant with back sheet to provide efficient protection from the severest environmental conditions.

The entire laminate is installed in an anodized aluminum frame to provide structural strength and ease of installation.

\section{ELECTRICAL CHARACTERISTICS}

Current-Voltage characteristics of Photovoltaic Module KC50T at various cell temperatures

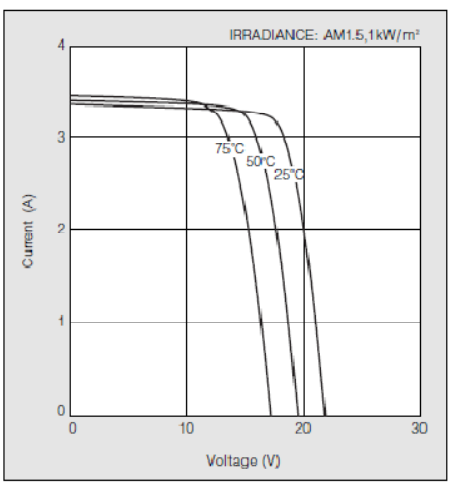

Current-Voltage characteristics of Photovoltaic Module KC50T at various irradiance levels

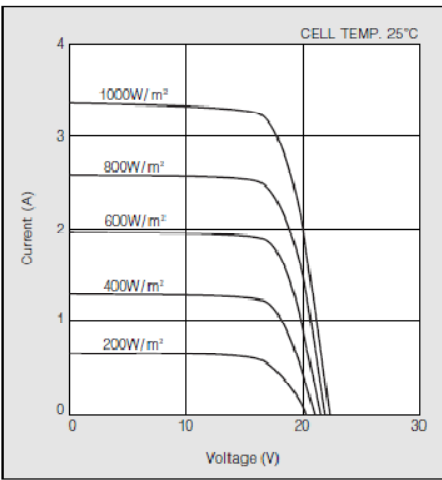


Specifications

Electrical Performance under Standard Test Conditions ( ${ }^{*} \mathrm{STC}$ )

Maximum Power (Pmax)

Maximum Power Voltage (Vmpp)

$54 \mathrm{~W}(+10 \% /-5 \%$

Open Circuit Voltage (Voc) $21.7 \mathrm{~V}$

Short Circuit Current (Isc) 3.31A

Max System Voltage 600

Temperature Coefficient of Voc $\quad-8.21 \times 10^{-2} \mathrm{~V} /{ }^{\circ} \mathrm{C}$

Temperature Coefficient of Isc

$1.33 \times 10^{-3} \mathrm{~A} /{ }^{\circ} \mathrm{C}$

"STC: Irradiance 1000W: ${ }^{2}$, AM1.C spectrum, module temperture 25"

Electrical Performance at $800 \mathrm{~W} / \mathrm{m}^{2}, \mathrm{NOCT}, \mathrm{AM} 1.5$

Maximum Power (Pmax)

Maximum Power Voltage (Vmpp)

Maximum Power Current (Impp)

Open Circuit Voltage (Voc)

$38 \mathrm{~W}$

$1.33 \times 10^{-3} \mathrm{~A} /{ }^{\circ} \mathrm{C}$

Short Circuit Current (Isc)

NOCT (Noninal Cprating Cell Temperature) : $47^{\circ} \mathrm{C}$
Cells

Number per Module

36

Module Characteristics

Length $\times$ Width $\times$ Depth

Weight

$639 \mathrm{~mm}(25.2 \mathrm{in}) \times 652 \mathrm{~mm}(2.7 \mathrm{Tin}) \times 54 \mathrm{~mm}[2.1 \mathrm{in})$

$5.0 \mathrm{~kg}(11.0 \mathrm{lbs}$.)

Junction Box Characteristics

Length $\times$ Width $\times$ Depth

IP Code

1201mn(4.7in $) \times 180 m \pi(7.1 \mathrm{in}) \times 46 \mathrm{mn}(1.8 \mathrm{in})$

IP65

Reduction of Efficiency under Low Irradiance

Reduction

$6.2 \%$

Reduction of efficiency trom an irrandiance of $1000 \mathrm{~W} / \mathrm{m}^{2}$ to $200 \mathrm{~W} / \mathrm{m}^{2}$ (module temperature $25^{\circ} \mathrm{C}$ ) 


\section{Appendix C}

Table C.0.1: Experimental PV Power Drop Data for 4-Shade-Layers

\begin{tabular}{|c|c|c|c|c|c|c|c|c|c|c|c|c|c|}
\hline \multirow[b]{3}{*}{$\mathrm{R}[\Omega]$} & \multicolumn{13}{|c|}{ EXPERIMENTAL RESULTS } \\
\hline & \multicolumn{3}{|c|}{ No Shade } & \multicolumn{2}{|r|}{ Shade } & \multicolumn{2}{|c|}{ No Shade } & \multicolumn{2}{|c|}{ Shade } & \multicolumn{2}{|c|}{ Delta S } & \multicolumn{2}{|c|}{ Delta P } \\
\hline & $\mathrm{S}\left[\mathrm{W} / \mathrm{m}^{\wedge} 2\right]$ & $\mathrm{T}[\mathrm{C}]$ & Vsun $[\mathrm{V}]$ & $\mathrm{S}\left[\mathrm{W} / \mathrm{m}^{\wedge} 2\right]$ & Vshade [V] & Isun $[A]$ & Psun [W] & Ishade $[\mathrm{A}]$ & Pshade [W] & $\Delta \mathrm{S}[\mathrm{W}]$ & $\Delta \mathrm{S}[\%]$ & $\Delta \mathrm{P}[\mathrm{W}]$ & $\Delta \mathrm{P}[\%]$ \\
\hline 1 & 760 & $\begin{array}{ll}6.3 \\
\end{array}$ & 2.126 & 50 & 0.098 & 2.126 & 4.519876 & 0.098 & 0.009604 & 710 & $93 \%$ & -4.510272 & $100 \%$ \\
\hline 1 & 737 & 48.7 & 2.64 & 48.7 & 0.245 & 2.64 & 6.9696 & 0.245 & 0.060025 & 688.3 & $93 \%$ & -6.909575 & $99 \%$ \\
\hline 1 & 725 & 48.7 & 2.64 & 50.3 & 0.241 & 2.64 & 6.9696 & 0.241 & 0.058081 & 674.7 & $93 \%$ & -6.911519 & $99 \%$ \\
\hline 2 & 735 & 48 & 5.2 & 75.9 & 0.427 & 2.6 & 13.52 & 0.2135 & 0.0911645 & 659.1 & $90 \%$ & -13.428836 & $99 \%$ \\
\hline 2 & 732 & 48.1 & 5.2 & 72.3 & 0.406 & 2.6 & 13.52 & 0.203 & 0.082418 & 659.7 & $90 \%$ & -13.437582 & $99 \%$ \\
\hline 2 & 743 & 48.9 & 5.19 & 66 & 0.416 & 2.595 & 13.46805 & 0.208 & 0.086528 & 677 & $91 \%$ & -13.381522 & $99 \%$ \\
\hline 5 & 739 & 50.6 & 12.57 & 66 & 1.16 & 2.514 & 31.60098 & 0.232 & 0.26912 & 673 & $91 \%$ & -31.33186 & $99 \%$ \\
\hline 5 & 734 & 49.2 & 12.63 & 43.3 & 1.1 & 2.526 & 31.90338 & 0.22 & 0.242 & 690.7 & $94 \%$ & -31.66138 & $99 \%$ \\
\hline 5 & 736 & 49.3 & 12.64 & 45 & 0.997 & 2.528 & 31.95392 & 0.1994 & 0.1988018 & 691 & $94 \%$ & -31.755118 & $99 \%$ \\
\hline $10=$ & 739 & 49.8 & 17.89 & 69.4 & 2.24 & 1.789 & 32.00521 & 0.224 & 0.50176 & 669.6 & $91 \%$ & -31.50345 & $98 \%$ \\
\hline 10 & 741 & 49.9 & 17.79 & 58 & 2.25 & 1.779 & 31.64841 & 0.225 & 0.50625 & 683 & $92 \%$ & -31.14216 & $98 \%$ \\
\hline 10 & 735 & 49.1 & 17.92 & 67 & 2.23 & 1.792 & 32.11264 & 0.223 & 0.49729 & 668 & $91 \%$ & -31.61535 & $98 \%$ \\
\hline 20 & 724 & 50.1 & 18.89 & 65 & 4.45 & 0.9445 & 17.84161 & 0.2225 & 0.990125 & 659 & $91 \%$ & -16.85148 & $94 \%$ \\
\hline 20 & 730 & 50.1 & 18.88 & 57 & 4.37 & 0.944 & 17.82272 & 0.2185 & 0.954845 & 673 & $92 \%$ & -16.867875 & $95 \%$ \\
\hline 20 & 710 & 50 & 18.84 & 60 & 4.26 & 0.942 & 17.74728 & 0.213 & 0.90738 & 650 & $92 \%$ & -16.8399 & $95 \%$ \\
\hline 50 & 740 & 52.2 & 19.27 & 46 & 9.94 & 0.3854 & 7.426658 & 0.1988 & 1.976072 & 694 & $94 \%$ & -5.450586 & $73 \%$ \\
\hline 50 & 820 & 52.3 & 19.27 & 84 & 10.11 & 0.3854 & 7.426658 & 0.2022 & 2.044242 & 736 & $90 \%$ & -5.382416 & $72 \%$ \\
\hline 50 & 808 & 51.4 & 19.47 & 67 & 10.83 & 0.3894 & 7.581618 & 0.2166 & 2.345778 & 741 & $92 \%$ & -5.23584 & $69 \%$ \\
\hline $100=$ & 723 & 55.1 & 19.27 & 80 & 14.59 & 0.1927 & 3.713329 & 0.1459 & 2.128681 & 643 & $89 \%$ & -1.584648 & $43 \%$ \\
\hline $100=$ & 720 & 52.2 & 19.26 & 59 & 12.78 & 0.1926 & 3.709476 & 0.1278 & 1.633284 & 661 & $92 \%$ & -2.076192 & $56 \%$ \\
\hline 100 & 730 & 57.7 & 19.15 & 50 & 14.46 & 0.1915 & 3.667225 & 0.1446 & 2.090916 & 680 & $93 \%$ & -1.576309 & $43 \%$ \\
\hline 200 & 729 & 49.2 & 19.75 & 46.7 & 16.18 & 0.09875 & 1.950313 & 0.0809 & 1.308962 & 682.3 & $94 \%$ & -0.6413505 & $33 \%$ \\
\hline 200 & 728 & 49 & 19.79 & 60.6 & 16.24 & 0.09895 & 1.958221 & 0.0812 & 1.318688 & 667.4 & $92 \%$ & -0.6395325 & $33 \%$ \\
\hline $200=$ & 753 & 46.8 & 19.95 & 66 & 16.47 & 0.09975 & 1.990013 & 0.08235 & 1.3563045 & 687 & $91 \%$ & $\begin{array}{r}-0.633708 \\
\end{array}$ & $32 \%$ \\
\hline 500 & 750 & 47.9 & 19.97 & 67.7 & 16.77 & 0.03994 & 0.797602 & 0.03354 & 0.5624658 & 682.3 & $91 \%$ & -0.235136 & $29 \%$ \\
\hline 500 & 730 & 47.4 & 20.02 & 70.7 & $\begin{array}{ll}16.8 \\
\end{array}$ & 0.04004 & 0.801601 & 0.0336 & 0.56448 & 659.3 & $90 \%$ & -0.2371208 & $30 \%$ \\
\hline 500 & 754 & 48.5 & 19.91 & 48.5 & 16.7 & 0.03982 & 0.792816 & 0.0334 & 0.55778 & 705.5 & $94 \%$ & -0.2350362 & $30 \%$ \\
\hline 1000 & 760 & 46.5 & 20.08 & 67.6 & 17.09 & 0.02008 & 0.403206 & 0.01709 & 0.2920681 & 692.4 & $91 \%$ & -0.1111383 & $28 \%$ \\
\hline 1000 & 745 & 47.3 & 20.01 & 64 & 16.93 & 0.02001 & 0.4004 & 0.01693 & 0.2866249 & 681 & $91 \%$ & -0.1137752 & $28 \%$ \\
\hline 1000 & 766 & 47.5 & 20.01 & 74.5 & 16.87 & 0.02001 & 0.4004 & 0.01687 & 0.2845969 & 691.5 & $90 \%$ & -0.1158032 & $29 \%$ \\
\hline
\end{tabular}


Table C.0.2: Experimental PV Power Drop Data for 3-Shade-Layers

\begin{tabular}{|c|c|c|c|c|c|c|c|c|c|c|c|c|c|c|}
\hline \multirow[b]{3}{*}{$\mathrm{R}[\Omega]$} & \multicolumn{13}{|c|}{ EXPERIMENTAL RESULTS } & \\
\hline & \multicolumn{3}{|c|}{ No Shade } & \multicolumn{2}{|c|}{ Shade } & \multicolumn{2}{|c|}{ No Shade } & \multicolumn{2}{|c|}{ Shade } & \multicolumn{2}{|c|}{ Delta S } & \multicolumn{2}{|c|}{ Delta P } & \\
\hline & $\mathrm{S}\left[\mathrm{W} / \mathrm{m}^{\wedge} 2\right]$ & $\mathrm{T}[\mathrm{C}]$ & Vsun [V] & $\mathrm{S}\left[\mathrm{W} / \mathrm{m}^{\wedge} 2\right]$ & Vshade [V] & $\operatorname{ssun}[\mathrm{A}]$ & Psun [W] & Ishade $[\mathrm{A}]$ & Pshade [W] & $\Delta \mathrm{S}[\mathrm{W}]$ & $\Delta \mathrm{S}[\%]$ & $\Delta \mathrm{P}[\mathrm{W}]$ & $\Delta \mathrm{P}[\%]$ & \\
\hline 1 & \begin{tabular}{|l|}
724 \\
\end{tabular} & 50.3 & 2.5243 & 148.4 & 0.351 & 2.5243 & 6.37209049 & 0.351 & 0.123201 & \begin{tabular}{|r|}
575.6 \\
\end{tabular} & $80 \%$ & -6.249 & $98 \%$ & \\
\hline 1 & 662 & 49.4 & 2.281 & 160.4 & 0.357 & 2.281 & 5.202961 & 0.357 & 0.127449 & 501.6 & $76 \%$ & -5.076 & $98 \%$ & \\
\hline 1 & 640.5 & 49.1 & 2.347 & 79.7 & 0.1324 & 2.347 & 5.508409 & 0.1324 & 0.01752976 & 560.8 & $88 \%$ & -5.491 & $100 \%$ & \\
\hline 2 & 687 & 48.3 & 4.827 & 127 & 0.714 & 2.4135 & 11.6499645 & 0.357 & 0.254898 & 560.0 & $82 \%$ & -11.4 & $98 \%$ & \\
\hline 2 & 684 & 48.2 & 4.85 & 145 & 0.71 & 2.425 & \begin{tabular}{|l|}
11.76125 \\
\end{tabular} & 0.355 & 0.25205 & 539.0 & $79 \%$ & -11.51 & $98 \%$ & \\
\hline 2 & 706 & 47.47 & 4.813 & 138.3 & 0.714 & 2.4065 & 11.5824845 & 0.357 & 0.254898 & 567.7 & $80 \%$ & -11.33 & $98 \%$ & \\
\hline 5 & 722 & 49.2 & 12.23 & 112 & 1.87 & 2.446 & \begin{tabular}{|r|}
29.91458 \\
\end{tabular} & 0.374 & 0.69938 & 610.0 & $84 \%$ & -29.22 & $98 \%$ & \\
\hline 5 & 715 & 48.3 & 12.24 & 135 & 1.865 & 2.448 & 29.96352 & 0.373 & 0.695645 & 580.0 & $81 \%$ & -29.27 & $98 \%$ & \\
\hline 5 & 724 & 48.2 & 12.29 & 128 & 0.993 & 2.458 & 30.20882 & 0.1986 & 0.1972098 & 596.0 & $82 \%$ & -30.01 & $99 \%$ & \\
\hline 10 & 732 & 47.4 & 17.94 & 125 & 3.78 & 1.794 & 32.18436 & 0.378 & 1.42884 & 607.0 & $83 \%$ & -30.76 & $96 \%$ & \\
\hline 10 & 721 & 47.3 & 17.95 & 142 & 3.886 & 1.795 & 32.22025 & 0.3886 & 1.5100996 & 579.0 & $80 \%$ & -30.71 & $95 \%$ & \\
\hline 10 & 749 & 47.3 & 17.93 & 110 & 3.953 & 1.793 & 32.14849 & 0.3953 & 1.5626209 & 639.0 & $85 \%$ & -30.59 & $95 \%$ & \\
\hline 20 & 730 & 47.4 & 19.11 & 118 & 7.51 & 0.9555 & 18.259605 & 0.3755 & 2.820005 & 612.0 & $84 \%$ & -15.44 & $85 \%$ & \\
\hline 20 & 735 & 47.2 & 19.1 & 112 & 7.52 & 0.955 & 18.2405 & 0.376 & 2.82752 & 623.0 & $85 \%$ & -15.41 & $84 \%$ & \\
\hline 20 & 731.2 & 47.4 & 19.1 & 110.3 & 7.51 & 0.955 & 18.2405 & 0.3755 & 2.820005 & 620.9 & $85 \%$ & -15.42 & $85 \%$ & \\
\hline 50 & 752 & 47.1 & 19.7 & 153 & 15.45 & 0.394 & 7.7618 & 0.309 & 4.77405 & 599.0 & $80 \%$ & -2.988 & $38 \%$ & \\
\hline 50 & 720 & 47.9 & 19.68 & 122 & 15.59 & 0.3936 & 7.746048 & 0.3118 & 4.860962 & 598.0 & $83 \%$ & -2.885 & $37 \%$ & \\
\hline 50 & 735 & 48.4 & 19.66 & 140 & 15.41 & 0.3932 & 7.730312 & 0.3082 & 4.749362 & 595.0 & $81 \%$ & -2.981 & $39 \%$ & \\
\hline 100 & 731 & 48.3 & 19.77 & 159 & 17.05 & 0.1977 & 3.908529 & 0.1705 & 2.907025 & 572.0 & $78 \%$ & -1.002 & $26 \%$ & \\
\hline 100 & 755 & 48.5 & 19.81 & 129 & 16.96 & 0.1981 & 3.924361 & 0.1696 & 2.876416 & 626.0 & $83 \%$ & -1.048 & $27 \%$ & \\
\hline 100 & 754 & 49.3 & 19.75 & 145 & 16.9 & 0.1975 & 3.900625 & 0.169 & 2.8561 & 609.0 & $81 \%$ & -1.045 & $27 \%$ & \\
\hline 200 & 772 & 49.7 & 19.84 & 154 & 17.34 & 0.0992 & 1.968128 & 0.0867 & 1.503378 & 618.0 & $80 \%$ & -0.465 & $24 \%$ & \\
\hline 200 & 757 & 50.1 & 19.83 & 133 & 17.39 & 0.09915 & 1.9661445 & 0.08695 & 1.5120605 & 624.0 & $82 \%$ & -0.454 & $23 \%$ & \\
\hline 200 & 763 & 50.5 & 19.76 & 145 & 17.37 & 0.0988 & 1.952288 & 0.08685 & 1.5085845 & 618.0 & $81 \%$ & -0.444 & $23 \%$ & \\
\hline 500 & 755 & 48.7 & 19.91 & 163 & 17.64 & 0.03982 & 0.7928162 & 0.03528 & 0.6223392 & 592.0 & $78 \%$ & -0.17 & $22 \%$ & \\
\hline 500 & 773 & 50.7 & 19.8 & 161 & 17.54 & 0.0396 & 0.78408 & 0.03508 & 0.6153032 & 612.0 & $79 \%$ & -0.169 & $22 \%$ & \\
\hline 500 & 777 & 50.7 & 19.8 & 163 & 17.6 & 0.0396 & 0.78408 & 0.0352 & 0.61952 & 614.0 & $79 \%$ & -0.165 & $21 \%$ & \\
\hline 1000 & 769 & 50.4 & 19.81 & 151 & 17.6 & 0.01981 & 0.3924361 & 0.0176 & 0.30976 & 618.0 & $80 \%$ & -0.083 & $21 \%$ & \\
\hline 1000 & 776 & 50.4 & 19.85 & 152 & 17.61 & 0.01985 & 0.3940225 & 0.01761 & 0.3101121 & 624.0 & $80 \%$ & -0.084 & $21 \%$ & \\
\hline 1000 & 767 & 50.9 & 19.81 & 153 & 17.5 & 0.01981 & 0.3924361 & 0.0175 & 0.30625 & 614.0 & $80 \%$ & -0.086 & $22 \%$ & \\
\hline
\end{tabular}

Table C.0.3: Experimental PV Power Drop Data for 2-Shade-Layers

\begin{tabular}{|c|c|c|c|c|c|c|c|c|c|c|c|c|c|c|}
\hline \multirow[b]{3}{*}{$\mathrm{R}[\Omega]$} & \multicolumn{13}{|c|}{ EXPERIMENTAL RESULTS } & \\
\hline & \multicolumn{3}{|c|}{ No Shade } & \multicolumn{2}{|c|}{ Shade } & \multicolumn{2}{|c|}{ No Shade } & \multicolumn{2}{|c|}{ Shade } & \multicolumn{2}{|c|}{ Delta S } & \multicolumn{2}{|c|}{ Delta P } & \\
\hline & $\mathrm{S}\left[\mathrm{W} / \mathrm{m}^{\wedge} 2\right]$ & $\mathrm{T}[\mathrm{C}]$ & Vsun [V] & $\mathrm{S}\left[\mathrm{W} / \mathrm{m}^{\wedge} 2\right]$ & Vshade [V] & Isun $[A]$ & Psun [W] & Ishade $[\mathrm{A}]$ & Pshade [W] & $\Delta \mathrm{S}[\mathrm{W}]$ & $\Delta \mathrm{S}[\%]$ & $\Delta \mathrm{P}[\mathrm{W}]$ & $\Delta \mathrm{P}[\%]$ & \\
\hline 1 & 757 & 52 & \begin{tabular}{|l|}
2.785 \\
\end{tabular} & 387 & 0.847 & 2.785 & 7.756225 & 0.847 & 0.717409 & 370.0 & $49 \%$ & \begin{tabular}{|l|}
-7.039 \\
\end{tabular} & $91 \%$ & \\
\hline 1 & 754 & 49 & 2.781 & 322 & 0.838 & 2.781 & 7.733961 & 0.838 & 0.702244 & 432.0 & $57 \%$ & -7.032 & $91 \%$ & \\
\hline 2 & 752 & 46.8 & 5.34 & 350 & 1.69 & 2.67 & 14.2578 & 0.845 & 1.42805 & 402.0 & $53 \%$ & -12.83 & $90 \%$ & \\
\hline 2 & 749 & 47.4 & 5.35 & 257 & 1.572 & 2.675 & 14.31125 & 0.786 & 1.235592 & 492.0 & $66 \%$ & -13.08 & $91 \%$ & \\
\hline 5 & 752 & 47.3 & 12.71 & 357 & 3.74 & 2.542 & 32.30882 & 0.748 & 2.79752 & 395.0 & $53 \%$ & -29.51 & $91 \%$ & \\
\hline 5 & 756 & 49 & 12.72 & 300 & 3.71 & 2.544 & 32.35968 & 0.742 & 2.75282 & 456.0 & $60 \%$ & -29.61 & $91 \%$ & \\
\hline 10 & 753 & 47.9 & 18.15 & 254 & 7.58 & 1.815 & 32.94225 & 0.758 & 5.74564 & 499.0 & $66 \%$ & -27.2 & $83 \%$ & \\
\hline 10 & 753 & 47.8 & 18.06 & 320 & 7.5 & 1.806 & 32.61636 & 0.75 & 5.625 & 433.0 & $58 \%$ & -26.99 & $83 \%$ & \\
\hline 20 & 755 & 46.6 & 19.22 & 320 & 14.33 & 0.961 & 18.47042 & 0.7165 & 10.267445 & 435.0 & $58 \%$ & -8.203 & $44 \%$ & \\
\hline 20 & 756 & 46.7 & 19.19 & 254 & 14.29 & 0.9595 & 18.412805 & 0.7145 & 10.210205 & 502.0 & $66 \%$ & -8.203 & $45 \%$ & \\
\hline 50 & 754 & 46.2 & 19.82 & 273 & 17.82 & 0.3964 & 7.856648 & 0.3564 & 6.351048 & 481.0 & $64 \%$ & -1.506 & $19 \%$ & \\
\hline 50 & 760 & 46.2 & 19.72 & 252 & 17.75 & 0.3944 & 7.777568 & 0.355 & 6.30125 & 508.0 & $67 \%$ & -1.476 & $19 \%$ & \\
\hline 100 & 755 & 48 & 19.82 & 250 & 18.33 & 0.1982 & 3.928324 & 0.1833 & 3.359889 & 505.0 & $67 \%$ & -0.568 & $14 \%$ & \\
\hline 100 & 756 & 47.3 & 19.78 & 253 & 18.23 & 0.1978 & 3.912484 & 0.1823 & 3.323329 & 503.0 & $67 \%$ & -0.589 & $15 \%$ & \\
\hline 200 & 750 & 46.6 & 20 & 253 & 18.5 & 0.1 & 2 & 0.0925 & 1.71125 & 497.0 & $66 \%$ & -0.289 & $14 \%$ & \\
\hline 200 & 752 & 46.9 & 19.94 & 252 & 18.48 & 0.0997 & 1.988018 & 0.0924 & 1.707552 & 500.0 & $66 \%$ & -0.28 & $14 \%$ & \\
\hline 500 & 754 & 46.5 & 20.06 & 250 & 18.61 & 0.04012 & 0.8048072 & 0.03722 & 0.6926642 & 504.0 & $67 \%$ & -0.112 & $14 \%$ & \\
\hline 500 & 756 & 46.9 & 20.01 & 246 & 18.62 & 0.04002 & 0.8008002 & 0.03724 & 0.6934088 & 510.0 & $67 \%$ & -0.107 & $13 \%$ & \\
\hline 1000 & 754 & 46.7 & 20.06 & 244 & 18.68 & 0.02006 & 0.4024036 & 0.01868 & 0.3489424 & 510.0 & $68 \%$ & -0.053 & $13 \%$ & \\
\hline 1000 & 755 & 47.4 & 19.98 & 240 & 18.63 & 0.01998 & 0.3992004 & 0.01863 & 0.3470769 & 515.0 & $68 \%$ & -0.052 & $13 \%$ & \\
\hline
\end{tabular}


Table C.0.4: Experimental PV Power Drop Data for 1-Shade-Layer

\begin{tabular}{|c|c|c|c|c|c|c|c|c|c|c|c|c|c|c|}
\hline \multirow[b]{3}{*}{$\mathrm{R}[\Omega]$} & \multicolumn{13}{|c|}{ EXPERIMENTAL RESULTS } & \\
\hline & \multicolumn{3}{|c|}{ No Shade } & \multicolumn{2}{|c|}{ Shade } & \multicolumn{2}{|c|}{ No Shade } & \multicolumn{2}{|c|}{ Shade } & \multicolumn{2}{|c|}{ Delta S } & \multicolumn{2}{|c|}{ Delta P } & \\
\hline & $\mathrm{S}\left[\mathrm{W} / \mathrm{m}^{\wedge} 2\right]$ & $\mathrm{T}[\mathrm{C}]$ & Vsun [V] & $\mathrm{S}\left[\mathrm{W} / \mathrm{m}^{\wedge} 2\right]$ & Vshade [V] & Isun $[\mathrm{A}]$ & Psun [W] & Ishade $[A]$ & Pshade [W] & $\Delta \mathrm{S}[\mathrm{W}]$ & $\Delta \mathrm{S}[\%]$ & $\Delta \mathrm{P}[\mathrm{W}]$ & $\Delta \mathrm{P}[\%]$ & \\
\hline 1. & 866 & 51.7 & 3.05 & 540 & 1.485 & 3.05 & 9.3025 & 1.485 & 2.205225 & 326.0 & $38 \%$ & -7.097 & $76 \%$ & \\
\hline 1 & 866 & 50 & 3.03 & 530 & 1.486 & 3.03 & 9.1809 & 1.486 & 2.208196 & 336.0 & $39 \%$ & -6.973 & $76 \%$ & \\
\hline 2 & 868 & 49.2 & 5.83 & 540 & 2.932 & 2.915 & 16.99445 & 1.466 & 4.298312 & 328.0 & $38 \%$ & -12.7 & $75 \%$ & \\
\hline 2 & 856 & 48.7 & 5.88 & 520 & 2.95 & 2.94 & 17.2872 & 1.475 & 4.35125 & 336.0 & $39 \%$ & -12.94 & $75 \%$ & \\
\hline 5 & 854 & 48.1 & 13.85 & 539 & 6.83 & 2.77 & 38.3645 & 1.366 & 9.32978 & 315.0 & $37 \%$ & -29.03 & $76 \%$ & \\
\hline 5 & 858 & 48.9 & 13.89 & 538 & 6.85 & 2.778 & 38.58642 & 1.37 & 9.3845 & 320.0 & $37 \%$ & -29.2 & $76 \%$ & \\
\hline 10 & 861 & 45.7 & 18.22 & 536 & 12.93 & 1.822 & 33.19684 & 1.293 & 16.71849 & 325.0 & $38 \%$ & -16.48 & $50 \%$ & \\
\hline 10 & 860 & 48.4 & 18.26 & 533 & 12.86 & 1.826 & 33.34276 & 1.286 & 16.53796 & 327.0 & $38 \%$ & -16.8 & $50 \%$ & \\
\hline 20 & 860 & 47.9 & 19.21 & 520 & 17.99 & 0.9605 & 18.451205 & 0.8995 & 16.182005 & 340.0 & $40 \%$ & -2.269 & $12 \%$ & \\
\hline 20 & 864 & 48.9 & 19.23 & 535 & 18.01 & 0.9615 & 18.489645 & 0.9005 & 16.218005 & 329.0 & $38 \%$ & -2.272 & $12 \%$ & \\
\hline 50 & 867 & 48.8 & 19.67 & 530 & 18.88 & 0.3934 & 7.738178 & 0.3776 & 7.129088 & 337.0 & $39 \%$ & -0.609 & $8 \%$ & \\
\hline 50 & 870 & 48.4 & 19.69 & 529 & 18.9 & 0.3938 & 7.753922 & 0.378 & 7.1442 & 341.0 & $39 \%$ & -0.61 & $8 \%$ & \\
\hline 100 & 860 & 48 & 19.84 & 535 & 19.13 & 0.1984 & 3.936256 & 0.1913 & 3.659569 & 325.0 & $38 \%$ & -0.277 & $7 \%$ & \\
\hline 100 & 864 & 47.8 & 19.89 & 526 & 19.17 & 0.1989 & 3.956121 & 0.1917 & 3.674889 & 338.0 & $39 \%$ & -0.281 & $7 \%$ & \\
\hline 200 & 863 & 47.8 & 19.96 & 537 & 19.3 & 0.0998 & 1.992008 & 0.0965 & 1.86245 & 326.0 & $38 \%$ & -0.13 & $7 \%$ & \\
\hline 200 & 866 & 47.6 & 20 & 539 & 19.34 & 0.1 & 2 & 0.0967 & 1.870178 & 327.0 & $38 \%$ & -0.13 & $6 \%$ & \\
\hline 500 & 861 & 48.1 & 20.01 & 532 & 19.37 & 0.04002 & 0.8008002 & 0.03874 & 0.7503938 & 329.0 & $38 \%$ & -0.05 & $6 \%$ & \\
\hline 500 & 850 & 47.7 & 20.01 & 540 & 19.39 & 0.04002 & 0.8008002 & 0.03878 & 0.7519442 & 310.0 & $36 \%$ & -0.049 & $6 \%$ & \\
\hline 1000 & 865 & 47.8 & 20.04 & 534 & 19.42 & 0.02004 & 0.4016016 & 0.01942 & 0.3771364 & 331.0 & $38 \%$ & -0.024 & $6 \%$ & \\
\hline 1000 & 860 & 47.4 & 20.05 & 545 & 19.43 & 0.02005 & 0.4020025 & 0.01943 & 0.3775249 & 315.0 & $37 \%$ & -0.024 & $6 \%$ & \\
\hline
\end{tabular}

Table C.0.5: Experimental Summary of Solar Irradiance Changes for Various ShadeLayers Over a Range of Load Resistances

\begin{tabular}{|r|r|r|r|r|r|r|r|r|r|r|r|r|r|r|}
\hline & \multicolumn{4}{|c|}{ 4-shades } & \multicolumn{4}{|c|}{ 3-Shades } & \multicolumn{4}{|c|}{ 2-Shades } & \multicolumn{3}{|c|}{ 1-Shade } \\
\hline
\end{tabular}

Table C.0.6: Experimental Summary of PV Power Changes for Various Shade-Layers Over a Range of Load Resistances

\begin{tabular}{|r|r|r|r|r|r|r|r|r|r|r|r|r|r|r|}
\hline & \multicolumn{4}{|c|}{ 4-shades } & \multicolumn{4}{|c|}{ 3-Shades } & \multicolumn{3}{|c|}{ 2-Shades } & \multicolumn{2}{|c|}{ 1-Shade } \\
\hline & A & B & C & AVG & A & B & C & AVG & A & B & AVG & A & B & AVG \\
\hline 1 & $99.79 \%$ & $99.14 \%$ & $99.17 \%$ & $99.36 \%$ & $98.07 \%$ & $97.55 \%$ & $99.68 \%$ & $98.43 \%$ & $90.75 \%$ & $90.92 \%$ & $90.84 \%$ & $76.29 \%$ & $75.95 \%$ & $76.12 \%$ \\
\hline 2 & $99.33 \%$ & $99.39 \%$ & $99.36 \%$ & $99.36 \%$ & $97.81 \%$ & $97.86 \%$ & $97.80 \%$ & $97.82 \%$ & $89.98 \%$ & $91.37 \%$ & $90.68 \%$ & $74.71 \%$ & $74.83 \%$ & $74.77 \%$ \\
\hline 5 & $99.15 \%$ & $99.24 \%$ & $99.38 \%$ & $99.26 \%$ & $97.66 \%$ & $97.68 \%$ & $99.35 \%$ & $98.23 \%$ & $91.34 \%$ & $91.49 \%$ & $91.42 \%$ & $75.68 \%$ & $75.68 \%$ & $75.68 \%$ \\
\hline 10 & $98.43 \%$ & $98.40 \%$ & $98.45 \%$ & $98.43 \%$ & $95.56 \%$ & $95.31 \%$ & $95.14 \%$ & $95.34 \%$ & $82.56 \%$ & $82.75 \%$ & $82.66 \%$ & $49.64 \%$ & $50.40 \%$ & $50.02 \%$ \\
\hline 20 & $94.45 \%$ & $94.64 \%$ & $94.89 \%$ & $94.66 \%$ & $84.56 \%$ & $84.50 \%$ & $84.54 \%$ & $84.53 \%$ & $44.41 \%$ & $44.55 \%$ & $44.48 \%$ & $12.30 \%$ & $12.29 \%$ & $12.29 \%$ \\
\hline 50 & $73.39 \%$ & $72.47 \%$ & $69.06 \%$ & $71.64 \%$ & $38.49 \%$ & $37.25 \%$ & $38.56 \%$ & $38.10 \%$ & $19.16 \%$ & $18.98 \%$ & $19.07 \%$ & $7.87 \%$ & $7.86 \%$ & $7.87 \%$ \\
\hline 100 & $42.67 \%$ & $46.90 \%$ & $42.98 \%$ & $44.19 \%$ & $25.62 \%$ & $26.70 \%$ & $26.78 \%$ & $26.37 \%$ & $14.47 \%$ & $15.06 \%$ & $14.76 \%$ & $7.03 \%$ & $7.11 \%$ & $7.07 \%$ \\
\hline 200 & $32.88 \%$ & $32.66 \%$ & $31.84 \%$ & $32.46 \%$ & $23.61 \%$ & $23.10 \%$ & $22.73 \%$ & $23.15 \%$ & $14.44 \%$ & $14.11 \%$ & $14.27 \%$ & $6.50 \%$ & $6.49 \%$ & $6.50 \%$ \\
\hline 500 & $29.48 \%$ & $29.58 \%$ & $29.65 \%$ & $29.57 \%$ & $21.50 \%$ & $21.53 \%$ & $20.99 \%$ & $21.34 \%$ & $13.93 \%$ & $13.41 \%$ & $13.67 \%$ & $6.29 \%$ & $6.10 \%$ & $6.20 \%$ \\
\hline 100 & $27.56 \%$ & $28.42 \%$ & $28.92 \%$ & $28.30 \%$ & $21.07 \%$ & $21.30 \%$ & $21.96 \%$ & $21.44 \%$ & $13.29 \%$ & $13.06 \%$ & $13.17 \%$ & $6.09 \%$ & $6.09 \%$ & $6.09 \%$ \\
\hline
\end{tabular}

